Florida International University FIU Digital Commons

4-10-2018

\title{
Synthesis \& Fundamental Formation Mechanism Study of High Temperature \& Ultrahigh Temperature Ceramics
}

Paniz Foroughi

pforo002@fiu.edu

DOI: $10.25148 /$ etd.FIDC006906

Follow this and additional works at: https://digitalcommons.fiu.edu/etd

Part of the Ceramic Materials Commons

\section{Recommended Citation}

Foroughi, Paniz, "Synthesis \& Fundamental Formation Mechanism Study of High Temperature \& Ultrahigh Temperature Ceramics" (2018). FIU Electronic Theses and Dissertations. 3730.

https://digitalcommons.fiu.edu/etd/3730 


\section{FLORIDA INTERNATIONAL UNIVERSITY}

Miami, Florida

SYNTHESIS \& FUNDAMENTAL FORMATION MECHANISM STUDY OF HIGH

TEMPERATURE \& ULTRAHIGH TEMPERATURE CERAMICS

A dissertation submitted in partial fulfillment of

the requirements for the degree of

DOCTOR OF PHILOSOPHY

in

MATERIALS SCIENCE AND ENGINEERING

by

Paniz Foroughi

2018 
To: Dean John L. Volakis

College of Engineering and Computing

This dissertation, written by Paniz Foroughi and, entitled Synthesis \& Fundamental Formation Mechanism Study of High Temperature \& Ultrahigh Temperature Ceramics, having been approved in respect to style and intellectual content, is referred to you for judgment.

We have read this thesis and recommend that it be approved.

Arvind Agarwal

Surendra K. Saxena

Yu Zhong

Wenzhi Li

Zhe Cheng, Major Professor

Date of Defense: April 10, 2018

The dissertation of Paniz Foroughi is approved.

Dean John L. Volakis College of Engineering and Computing

Andrés G. Gil

Vice President for Research and Economic Development and Dean of the University Graduate School

Florida International University, 2018 


\section{DEDICATION}

I dedicate this thesis to my parents Negar Safizadeh Shabestari and Ata Foroughi.

Without their patience, understanding, support, and most of all love, the completion of this work would not have been possible. 


\section{ACKNOWLEDGMENTS}

I would like to express my deepest gratitude to my adviser Dr. Zhe Cheng for his continuous support, guidance and encouragement during the project. Working with him has been a constant learning experience for me. Also, I would like to extend my appreciation to Dr. Arvind Agarwal, Dr. Surendra Saxena, Dr. Yu Zhong and Dr. Wenzhi Li for serving as my committee members and providing insightful suggestions and guidance throughout the course of this research.

I like to take this opportunity and thank the support of Advanced Materials Engineering Research (AMERI) and Center for Study of Matter at Extreme Conditions (CeSMEC) at FIU for providing facilities. I would also like to thank Dr. Andriy Durygin and Dr. Alex Franco for their tremendous help and support.

I am thankful to University Graduate School, FIU for supporting me through Dissertation Evidence Acquisition (DEA) and Dissertation Year Fellowship (DYF) awards.

Last but not the least; I would like to thank my parents and my brothers (Alireza and Babak) for having faith in me and motivating me in pursuing my goal. 


\section{ABSTRACT OF THE DISSERTATION \\ SYNTHESIS \& FUNDAMENTAL FORMATION MECHANISM STUDY OF HIGH \\ TEMPERATURE \& ULTRAHIGH TEMPERATURE CERAMICS}

by

\section{Paniz Foroughi}

Florida International University, 2018

Miami, Florida

\section{Professor Zhe Cheng, Major Professor}

Borides and carbides of tantalum and hafnium are of great interest due to their ultrahigh temperature applications. Properties of these ceramics including oxidation resistance and mechanical properties might be further improved through solid solution/composite formation.

Synthesis of single-phase $\mathrm{Ta}_{\mathrm{x}} \mathrm{Hf}_{1-\mathrm{x}} \mathrm{C}$ and $\mathrm{Ta}_{\mathrm{x}} \mathrm{Hf}_{1-\mathrm{x}} \mathrm{B}_{2}$ solid solution powders including nanopowders via carbothermal reduction (CTR) is complicated due to noticeable difference in reactivity of parent oxides with carbon, and also the low solubility of those oxides in each other. Moreover, for TaC-HfC system the solid solution may go through phase separation due to the presence of a miscibility gap at temperatures below $887^{\circ} \mathrm{C}$.

In this study, a method of low-cost aqueous solution processing followed by CTR was used to synthesize $\mathrm{Ta}_{\mathrm{x}} \mathrm{Hf}_{1-\mathrm{x}} \mathrm{C}$ and $\mathrm{Ta}_{\mathrm{x}} \mathrm{Hf}_{1-\mathrm{x}} \mathrm{B}_{2}$ solid solution powders. In fact, method was first used to synthesize boron carbide $\left(\mathrm{B}_{4} \mathrm{C}\right)$ powders as it paves the way for a 
detailed study on the synthesis of $\mathrm{Ta}_{\mathrm{x}} \mathrm{Hf}_{1-\mathrm{x}} \mathrm{C}$ and $\mathrm{Ta}_{\mathrm{x}} \mathrm{Hf}_{1-\mathrm{x}} \mathrm{B}_{2}$ solid solutions powders considering the fact that $\mathrm{B}_{4} \mathrm{C}$ contains both carbon and boron in its structure.

Particular emphasis was given to investigate the influences of starting compositions and processing conditions on phase separation during the formation of both carbide and boride phase(s). It was found that individual $\mathrm{TaC}-\mathrm{HfC}$ and $\mathrm{TaB}_{2}-\mathrm{HfB}_{2}$ phases always form quickly but separately during the CTR process (e.g., at $1600{ }^{\circ} \mathrm{C}$ within a few minutes). Those carbides and borides remain phase-separated unless heated to much higher temperatures for long time due to the slow inter-diffusion between them.

It was also found that for $\mathrm{Ta}_{\mathrm{x}} \mathrm{Hf}_{1-\mathrm{x}} \mathrm{C}$ applying a $\mathrm{DC}$ electric field through the use of spark plasma sintering (SPS) system significantly accelerates the inter-diffusion of Ta and $\mathrm{Hf}$ leading to formation of a single-phase $\mathrm{Ta}_{\mathrm{x}} \mathrm{Hf}_{1-\mathrm{x}} \mathrm{C}$ solid solution at $1600{ }^{\circ} \mathrm{C}$ for 15 minutes. On the other hand, for borides alkali metal reduction reaction (AMR) method appears to be an excellent alternative to CTR-based method for formation of a singlephase $\mathrm{Ta}_{\mathrm{x}} \mathrm{Hf}_{1-\mathrm{x}} \mathrm{B}_{2}$ solid solution. In this method, chlorides of tantalum and hafnium are directly reduced using sodium borohydride $\left(\mathrm{NaBH}_{4}\right)$ giving rise to formation of a singlephase $\mathrm{Ta}_{0.5} \mathrm{Hf}_{0.5} \mathrm{~B}_{2}$ solid solution nanopowders in one step at much lower temperatures (e.g., $700{ }^{\circ} \mathrm{C}$ ) by avoiding the oxides formation and the associated phase separation of individual borides as observed in the CTR-based process. 


\section{TABLE OF CONTENTS}

CHAPTER

PAGE

Chapter I: Introduction.......................................................................................... 1

Chapter II: Literature Review …………………………...................................... 5

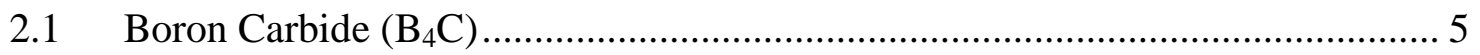

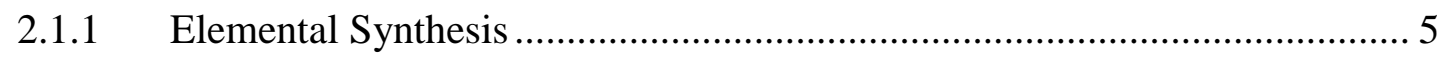

2.1.2 Magnesiothermic Reduction Reaction ...................................................... 5

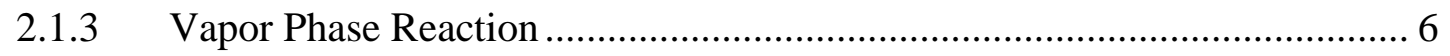

2.1.4 Carbothermal Reduction Reaction ............................................................ 7

2.2 UHTC Carbides and Borides Synthesis .................................................... 9

2.2.1 Direct Reaction Using Elemental Metals ............................................... 9

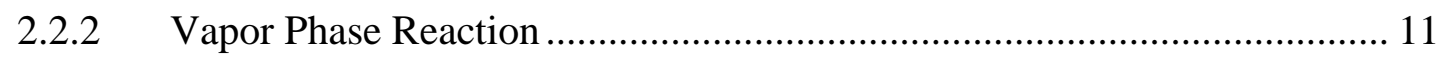

2.2.3 Carbothermal and Borothermal Reduction Reactions ............................. 11

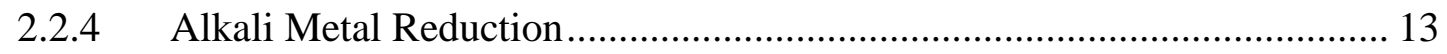

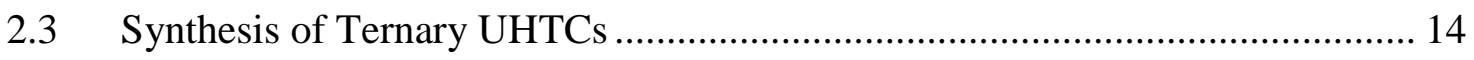

2.3.1 Previous Study on Synthesis of Ternary UHTC Carbides and Borides...... 16

2.3.2 Challenges with Synthesis of $\mathrm{Ta}_{\mathrm{x}} \mathrm{Hf}_{1-\mathrm{x}} \mathrm{C}$ and $\mathrm{Ta}_{\mathrm{x}} \mathrm{Hf}_{1-\mathrm{xB}} \mathrm{B}_{2}$ Solid Solution

Powders via Aqueous Solution Processing/CTR Method ....................................... 18

Chapter III: Morphological Variation in the Formation of $\mathrm{B}_{4} \mathrm{C}$ via CTR ...................... 26

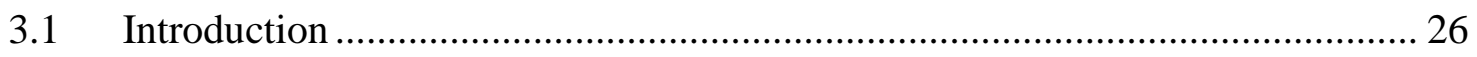

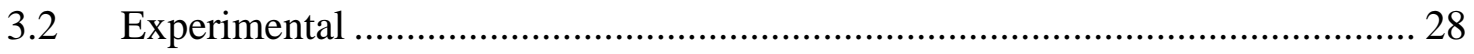

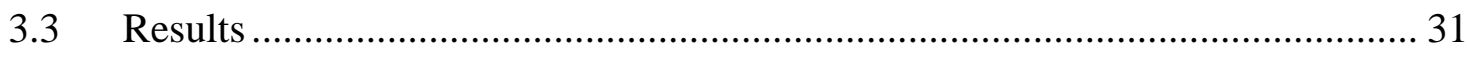

3.3.1 Impacts of CTR Temperature and Time .............................................. 31

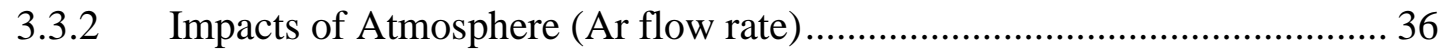

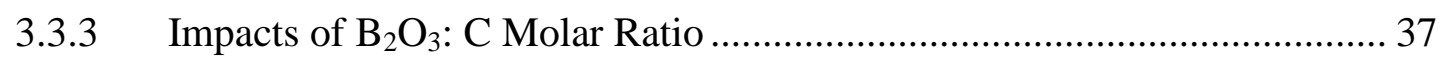

3.3.4 Impacts of Carbon Precursor Type ......................................................... 38

3.3.5 Impacts of Aging after CTR (For Partially Reacted Sample that Still

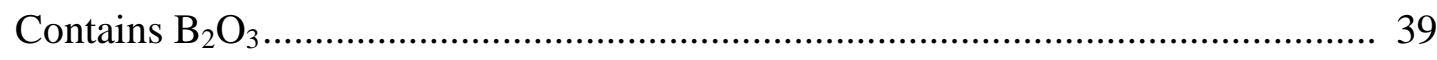




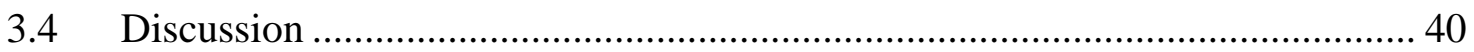

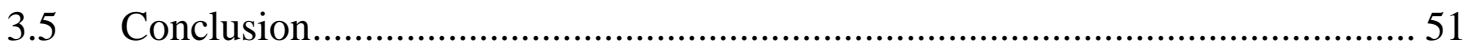

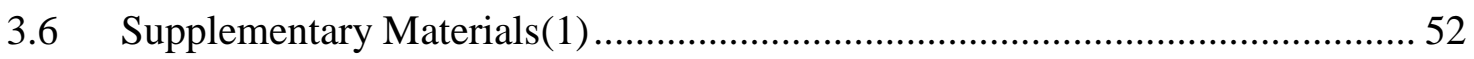

3.6.1 Example Showing Definition of the (carbon) Fractional Conversion ( $\alpha$ ) .. 52

3.6.2 Critical Nucleus Size and Free Energy Change for the Formation of $\mathrm{B}_{4} \mathrm{C}$

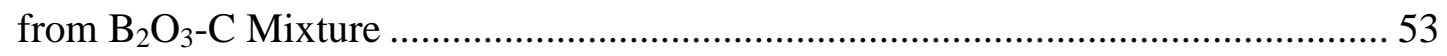

3.6.3 Change of Free Energy of Formation for the CTR Reaction Eq. 3.1 ......... 57

Chapter IV: Controlling Phase Separation of $\mathrm{Ta}_{\mathrm{x}} \mathrm{Hf}_{1-\mathrm{x}} \mathrm{C}$ Solid Solution Nano-powders

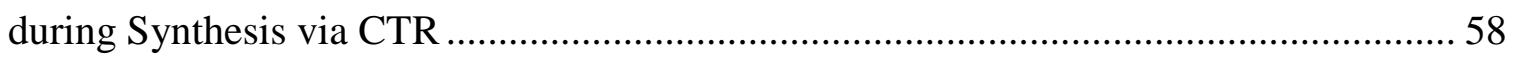

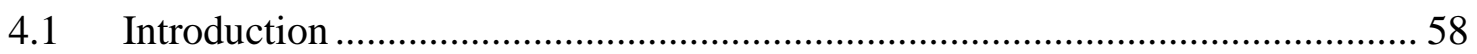

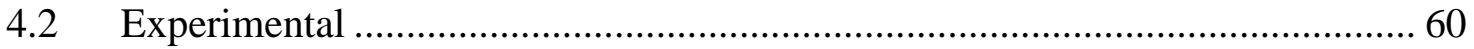

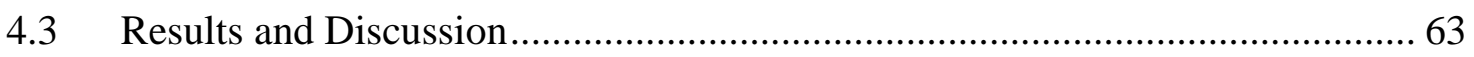

4.3.1 Characterization of Pyrolyzed Material ........................................................ 63

4.3.2 Observation of Phase Separation ............................................................. 66

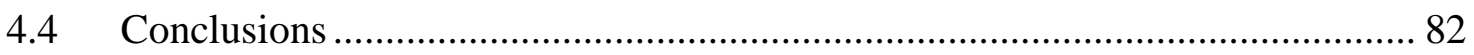

4.5 Supplementary Materials (2) ................................................................... 83

4.5.1 Schematic(s) of the Set-up(s) used in this Study for Powder Synthesis via Rapid Heating/Cooling Rate CTR and SPS ......................................................... 83

4.5.2 Effect of Pre-Pyrolysis and CTR Heating Rate on Phase Separation ......... 83

4.5.3 Estimation of $\mathrm{Ta}^{+4} / \mathrm{Hf}^{+4}$ Migration Length due to the DC Electrical Field 85

4.5.4 Summary of Experimental Observation and Their Implications ................ 88

Chapter V: Phase Control during Synthesis of Nanocrystalline Ultrahigh Temperature Tantalum-Hafnium Diboride Powders........................................................................... 90

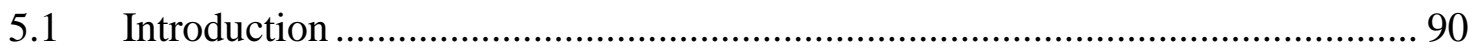

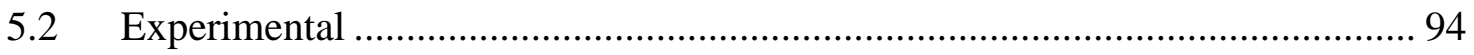

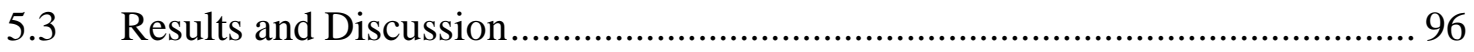

5.3.1 Phase Separation in $\mathrm{Ta}_{0.5} \mathrm{Hf}_{0.5} \mathrm{~B}_{2}$ Powders for CTR-based Method and its Mitigation .................................................................................................. 96

5.3.2 Preparation of Nanocrystalline $\mathrm{Ta}_{0.5} \mathrm{Hf}_{0.5} \mathrm{~B}_{2}$ Solid Solution Powders via AMR Method 106 


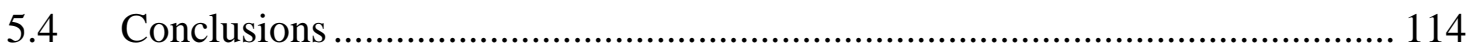

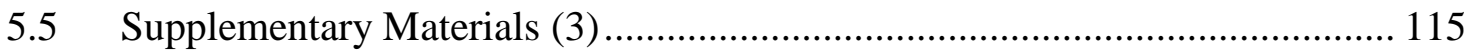

5.5.1 XRD Pattern for the Synthesized Sample from Recipe R8 at $1600{ }^{\circ} \mathrm{C}$

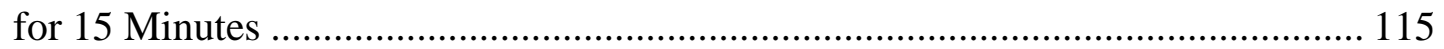

5.5.2 Annealing of $\mathrm{Ta}_{2} \mathrm{O}_{5}-\mathrm{HfO}_{2}$ Mixture for 6 hours at $1500{ }^{\circ} \mathrm{C}$..................... 116

5.5.3 BET Analysis of $\mathrm{Ta}_{0.5} \mathrm{Hf}_{0.5} \mathrm{~B}_{2}$ Solid Solution Powders Synthesized

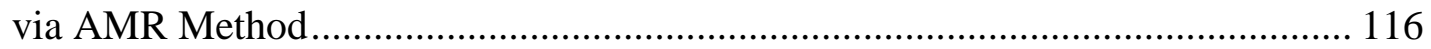

5.5.4 TGA Analysis of Boride Powders Synthesized via AMR Method............ 118

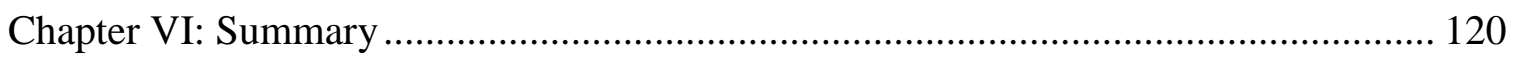

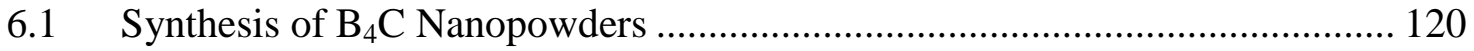

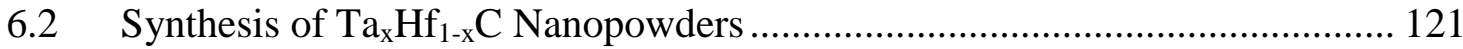

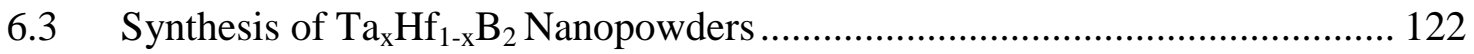

6.4 Recommendation for Future Work ……………....................................... 123

6.4.1 Synthesis of Nanocrystalline High Entropy UHTC Powders ................... 123

6.4.2 Flash Sintering of the Synthesized Nanocrystalline $\mathrm{Ta}_{\mathrm{x}} \mathrm{Hf}_{1-\mathrm{X}} \mathrm{C}$ and $\mathrm{Ta}_{\mathrm{x}} \mathrm{Hf}_{1-\mathrm{x}} \mathrm{B}_{2}$ Solid Solution Powders ................................................................... 124

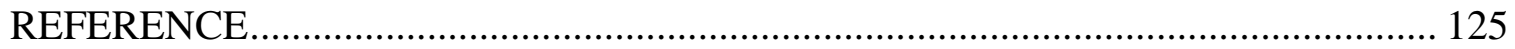

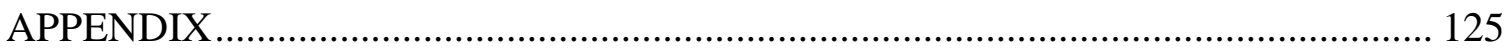

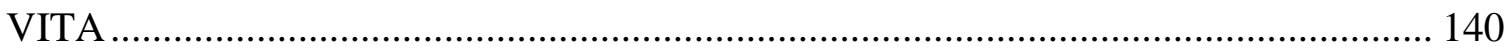




\section{LIST OF FIGUERS}

FIGURE

PAGE

Figure 2.1: SEM image of the $\mathrm{B}_{4} \mathrm{C}$ powders synthesized by Alizadeh et al.[28] .............. 8

Figure 2.2: SEM image of synthesized $\mathrm{ZrB}_{2}+\mathrm{SiC}$ composite via SHS method [50]...... 10

Figure 2.3: Hardness of single-phase $\mathrm{TaZrB}_{2}$ solid solution with different

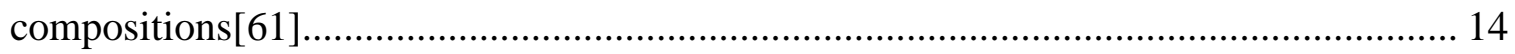

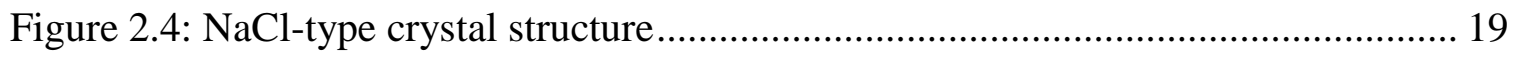

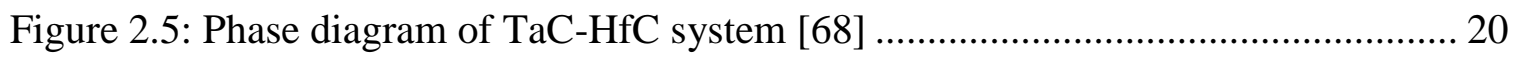

Figure 2.6: Equilbrium temperatures of $\mathrm{TaC}$ and $\mathrm{HfC}$ formation via $\mathrm{CTR}$ under

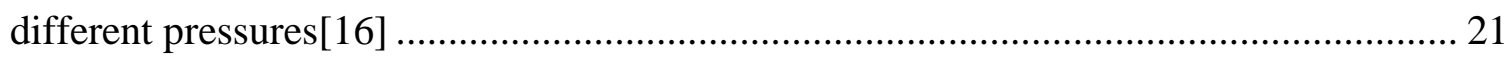

Figure 2.7: $\mathrm{AlB}_{2}$ crystal structure showing P6/mmm symmetry.[24] .......................... 23

Figure 3.1: Schematic (a) and exploded view (b) of the set-up (micro-reactor) for rapid

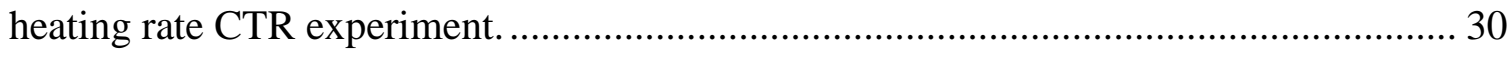

Figure 3.2: SEM micrographs of synthesized $\mathrm{B}_{4} \mathrm{C}$ powders via $\mathrm{CTR}$ at $1450^{\circ} \mathrm{C}$ for 2 hours from recipe $\mathrm{R} 4$ (boric acid : sucrose weight ratio $1: 0.81$ ) showing significant non-uniformity in morphology such as micron sized elongated platelets (a and b), sized particles (c), and nanoparticles (d).

Figure 3.3: XRD patterns of synthesized $\mathrm{B}_{4} \mathrm{C}$ powders via $\mathrm{CTR}$ at $1450^{\circ} \mathrm{C}$ and $1750^{\circ} \mathrm{C}$ for holding time of 2 hours and 3 minutes respectively from recipe $\mathrm{R} 4$ (starting boric acid : sucrose molar ratio $=1: 0.81$ ).

Figure 3.4: SEM micrographs of synthesized $\mathrm{B}_{4} \mathrm{C}$ powders via $\mathrm{CTR}$ at $1450^{\circ} \mathrm{C}$ for 20 minutes from recipe $\mathrm{R} 4$ (boric acid : sucrose weight ratio $1: 0.81$ ) showing significant non-uniformity in morphology including micron sized elongated platelets (a), micron and nano-sized polyhedral particles (b), and nanoparticles (c). 
Figure 3.5: SEM micrographs of CTR product at $1250^{\circ} \mathrm{C}$ for 2 hours from recipe R4 (boric acid : sucrose weight ratio $1: 0.81$ ) showing heterogeneous nucleation of $\mathrm{B}_{4} \mathrm{C}$ particles on the surface of a pyrolyzed particle (a), and nucleated micron-sized $\mathrm{B}_{4} \mathrm{C}$

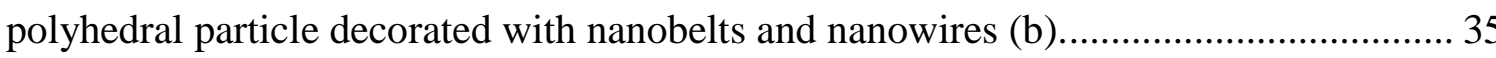

Figure 3.6: SEM micrographs of synthesized $\mathrm{B}_{4} \mathrm{C}$ via rapid heating rate $\mathrm{CTR}$ at $1750^{\circ} \mathrm{C}$ for 3 minutes from recipe $\mathrm{R} 4$ (boric acid : sucrose weight ratio $1: 0.81$ ). 36

Figure 3.7: SEM micrographs of synthesized $\mathrm{B}_{4} \mathrm{C}$ powders via $\mathrm{CTR}$ at $1450^{\circ} \mathrm{C}$ for 2 hours from recipe $\mathrm{R} 4$ (boric acid: sucrose weight ratio $1: 0.81$ ) under argon flow rate of $80 \mathrm{cc} / \mathrm{min}(\mathrm{a})$, and $800 \mathrm{cc} / \mathrm{min}(\mathrm{b})$.

Figure 3.8: SEM micrographs of synthesized $\mathrm{B}_{4} \mathrm{C}$ via CTR at $1450^{\circ} \mathrm{C}$ for 2 hours from recipe R4 (boric acid : sucrose weight ratio 1 : 0.81) (a), and recipe R16 (boric acid : sucrose weight ratio $1: 1.2)(\mathrm{b})$.

Figure 3.9: SEM micrographs of CTR product at $1300^{\circ} \mathrm{C}$ for 5 hours from recipe RP1 using PVA as carbon precursor (boric acid : PVA weight ratio $1: 3.1$ )........................ 39

Figure 3.10: SEM micrographs of synthesized $\mathrm{B}_{4} \mathrm{C}$ after $\mathrm{CTR}$ at $1350^{\circ} \mathrm{C}$ for 20 minutes from recipe $\mathrm{R} 4$ (boric acid : sucrose weight ratio 1 : 0.81) before aging (a), and after aging for 6 months (b)....

Figure 3.11: Raman spectra of the formed crystal in post CTR sample at $1350^{\circ} \mathrm{C}$ for 20 minutes from recipe $\mathrm{R} 4$ ((boric acid : sucrose weight ratio $1: 0.81$ ).

Figure 3.12: Plot of natural $\log$ of fitted reaction rate constant $\mathrm{k}$ (in unit of sec-1), $\ln (\mathrm{k})$ , versus inverse temperature for formation of $\mathrm{B}_{4} \mathrm{C}$ via CTR for different data in the literature (i.e., Weimer (1992) [41], Alizade et al. (2004) [28], Bigdeloo et al. (2009) [30] ), and the current study 
Figure 3.13: Schematic of nucleation and growth process via CTR at low CTR temperature (e.g., $1150^{\circ} \mathrm{C}$, which favors growth due to very slow nucleation and results in formation of huge micron-sized $\mathrm{B}_{4} \mathrm{C}$ particles) (a), intermediate CTR temperature (e.g., $1450^{\circ} \mathrm{C}$ when nucleation and growth rates are comparable, resulting in formation of huge $\mathrm{B}_{4} \mathrm{C}$ micron-sized particles accompanied with nanoparticles) (b), very high CTR temperature (e.g., $>1800^{\circ} \mathrm{C}$ which favors nucleation and results in formation of uniformsized fine B4C particles (c), and SEM micrograph of the CTR product at $1150^{\circ} \mathrm{C}$ for 24 hours from recipe $\mathrm{R} 4$ (boric acid : sucrose weight ratio $1: 0.81$ ) showing micron-sized heterogeneously distributed $\mathrm{B}_{4} \mathrm{C}$ particles emerging from the surrounding pyrolyzed materials (d)

Figure 3.14: FIB micrograph of the junction between pyrolyzed materials and synthesized micron-sized $\mathrm{B}_{4} \mathrm{C}$ polyhedral particle at $1150^{\circ} \mathrm{C}$ for 24 hours. 46

Figure 3.15: SEM micrographs of CTR product at $1250^{\circ} \mathrm{C}$ for 5 hours from recipe R16 (boric acid : sucrose weight ratio $1: 1.2$ ) showing heterogeneous nucleation of submicron and micron $\mathrm{B}_{4} \mathrm{C}$ particles on the surface of pyrolyzed material (a), and uniform submicron $\mathrm{B}_{4} \mathrm{C}$ particles (b). 48

Figure 3.16: Weight gain of pyrolyzed recipe R4 versus time after exposure to the air for 15 days.

Figure 3.17: Figure.17. XRD pattern of pyrolyzed powders from recipe R4 (starting boric acid : sucrose molar ratio $=1: 0.81$ ) before and after 15 days of aging. 50

Figure 3.18: SEM micrographs of pyrolyzed recipe R4 (boric acid : sucrose weight ratio $1: 0.81$ ) before aging (a), and after aging (b).

Figure 4.1:XRD patterns of synthesized powders for all recipes with different CTR conditions in a tube furnace.

Figure 4.2: SEM micrographs of (a) pyrolyzed powders at $700{ }^{\circ} \mathrm{C}$ for one hour from recipe $\mathrm{R} 6(\mathrm{Ta}: \mathrm{Hf}=$ of $4: 1$ ) showing formation of 50-100 $\mu \mathrm{m}$-sized particles with low porosity (b) synthesized powders via CTR at $1600^{\circ} \mathrm{C}$ for 1.5 hour from recipe $\mathrm{R} 7$ (Ta : $\mathrm{Hf}=1: 1)$ showing the formation of uniform nano-sized powders $(\sim<100 \mathrm{~nm})$. It is noted that this sample is actually phase separated into $\mathrm{TaC}$ and $\mathrm{HfC}$, as indicated by XRD (see Figure 4.1(c)). 
Figure 4.3: (a) XRD pattern for the sample from recipe $\mathrm{R} 6$ ( $\mathrm{Ta}: \mathrm{Hf}=4: 1$ ) synthesized via CTR at $1500{ }^{\circ} \mathrm{C}$, annealed for 10 hours at $1600{ }^{\circ} \mathrm{C}$ (b) SEM image of this sample before annealing showing the formation of uniform nano-sized powders (c) after annealing at $1600{ }^{\circ} \mathrm{C}$ for 10 hours indicating a noticeable grain growth.

Figure 4.4: TEM images of TaC-HfC nanocomposite powders synthesized via CTR at $1600{ }^{\circ} \mathrm{C}$ for 1.5 hours from recipe $\mathrm{R} 7$ ( $\mathrm{Ta}: \mathrm{Hf}=1: 1$ ) showing the formation of nanosized particles $(\sim<50 \mathrm{~nm})$ often covered by a low-atomic mass shell that is assumed to be amorphous carbon.

Figure 4.5: TGA analysis in air of synthesized powders at $1600{ }^{\circ} \mathrm{C}$ via $\mathrm{CTR}$ in the tube furnace from aqueous recipes of (a) R7 (Ta : Hf : $\mathrm{C}=1: 1: 6.5$ before CTR) and (b) R11 (Ta : Hf : C = $1: 1: 4.87$ before CTR).

Figure 4.6: XRD patterns of synthesized powders from aqueous recipe R7 (Ta : Hf = 1 : 1) via CTR in the SPS instrument at $1600{ }^{\circ} \mathrm{C}$ for 15 minutes: (a) under pressure of 5 $\mathrm{MPa}$ with current passing through the sample, (b) under pressure of $10 \mathrm{MPa}$ while the electric current passing through the sample was suppressed using BN disks as insulator.

Figure 4.7: SEM micrographs of synthesized powders from recipe R7 (Ta: Hf = 1:1) via CTR in the SPS instrument at $1600{ }^{\circ} \mathrm{C}$ for 15 minutes: (a) under pressure of $5 \mathrm{MPa}$ with electric current passing through the sample, (b) under pressure of $10 \mathrm{MPa}$ while electric current passing through the sample was suppressed using $\mathrm{BN}$ disks as insulator. Note that both samples consist of uniform fine powders. However, coarsening due to the electric current passing through the sample is noticeable for (a).

Figure 5.1: XRD patterns of all samples synthesized via CTR method from different recipes at various temperature and time.

Figure 5.2: SEM micrographs of synthesized powders from recipe R8 via the CTR-based method at (a) $1500{ }^{\circ} \mathrm{C}$ for 3 hours and (b) $1650{ }^{\circ} \mathrm{C}$ for 1.5 hours. Both samples shows relatively uniform submicron-sized particles with coarsening due to the higher CTR temperature more noticeable for the $1650{ }^{\circ} \mathrm{C} / 1.5$ hours sample.

Figure 5.3: Calculated standard Gibbs free energy change as a function of temperature at $p \mathrm{CO}=1 \mathrm{~atm}$ for the formation of $\mathrm{TaB}_{2}$ and $\mathrm{HfB}_{2}$ from carbothermal reduction (CTR) reaction. 
Figure 5.4: SEM micrographs of synthesized powders after CTR at $1650{ }^{\circ} \mathrm{C}$ for 1.5 hours from (a) recipe $\mathrm{R} 9$, which contains copper metal $(\mathrm{Cu})$ as a "catalyst" or, more precisely, a diffusion promoter and (b) recipe $\mathrm{R} 8$, which does not contain $\mathrm{Cu}$, respectively. Particle coarsening due to the presence of the liquid $\mathrm{Cu}$ as a diffusion promoter during the CTR process is noticeable for the sample from recipe $\mathrm{R} 9$ with $\mathrm{Cu}(\mathrm{a})$.

Figure 5.5: XRD patterns of three samples synthesized via the alkaline metal reduction (AMR) method from different recipes after the AMR reaction at $700{ }^{\circ} \mathrm{C}$ for 24 in close graphite boat in a tube furnace with flow argon atmosphere: (a) from recipe $\mathrm{R} 17$ targeting pure $\mathrm{HfB}_{2}$, (b) from recipe $\mathrm{R} 14$ targeting $\mathrm{Ta}_{0.5} \mathrm{Hf}_{0.5} \mathrm{~B}_{2}$, and (c) from recipe $\mathrm{R} 18$ targeting pure $\mathrm{TaB}_{2}$ 108

Figure 5.6: SEM (a) and TEM (b and c) micrographs of the synthesized powder via AMR reaction at $700{ }^{\circ} \mathrm{C}$ for 24 hours from recipe $\mathrm{R} 14$ showing the formation of uniform nanocrystalline $\mathrm{Ta}_{0.5} \mathrm{Hf}_{0.5} \mathrm{~B}_{2}$ solid solution powders with grain size much smaller than $\sim 50 \mathrm{~nm}$. The measured d-spacing of $\sim 0.34 \mathrm{~nm}$ from TEM is very close to the expected value for the (0001) plane of the $\mathrm{Ta}_{0.5} \mathrm{Hf}_{0.5} \mathrm{~B}_{2}$ solid solution.

Figure 5.7: XRD patterns of two samples synthesized via the alkaline metal reduction (AMR) method at $700{ }^{\circ} \mathrm{C}$ for 24 hours and then annealed at $1500{ }^{\circ} \mathrm{C}$ for 3 hours in flow argon: (a) from recipe $\mathrm{R} 17$ targeting pure $\mathrm{HfB}_{2}$, (b) from recipe $\mathrm{R} 14$ targeting $\mathrm{Ta}_{0.5} \mathrm{Hf}_{0.5} \mathrm{~B}$. solid solution.

Figure 5.8: SEM micrographs of the $\mathrm{HfB}_{2}(\mathrm{a}, \mathrm{b})$ and $\mathrm{Ta}_{0.5} \mathrm{Hf}_{0.5} \mathrm{~B}_{2}$ solid solution $(\mathrm{c}, \mathrm{d})$ powders synthesized via the AMR method (at $700{ }^{\circ} \mathrm{C}$ for 24 hours) before (a, c) and after $(b, d)$ the separate annealing at $1500{ }^{\circ} \mathrm{C}$ for 3 hours. The grains grow significantly after the $1500{ }^{\circ} \mathrm{C} / 3 \mathrm{~h}$ annealing for both $\mathrm{HfB}_{2}$ (from R17, compare (b) versus (a)) and $\mathrm{Ta}_{0.5} \mathrm{Hf}_{0.5} \mathrm{~B}_{2}$ solid solution (from R14, compare (d) versus (c)) samples. 
Chapter I: Introduction

Ultrahigh temperature ceramics (UHTCs) are a group of ceramics, which possess very high melting points (above $3000{ }^{\circ} \mathrm{C}$ ). Transition metal carbides and borides of groups IV and V are both considered as UHTCs [1-4]. These ceramics have a unique combination of properties such as high hardness, high melting point, high electrical and thermal conductivity, which makes them promising materials for cutting tools and ultrahigh temperature applications such as critical parts for engines and hypersonic vehicles that may need to tolerate temperatures even above $2000{ }^{\circ} \mathrm{C}$ [5-10]. However, it has been noticed that conventional binary UHTCs are not sufficient for the oxidizing and rapid heating environments $[9,10]$. Previous studies show that, by controlling the composition via using alloying elements, ternary UHTC solid solutions/composites could provide better properties compared to binary systems such as higher oxidation resistance, higher melting point and enhanced mechanical properties [11,12]. In addition to composition, refining microstructure plays a significant role in improving the UHTCs properties such as hardness and toughness. Obtaining UHTC powders with reduced particle size will help achieving finer microstructure of the fabricated parts, and it also helps simplify the post synthesis processing such as milling/grinding and improves the sintering activity. All of these motivate the research on synthesis and processing of nanoscale ternary UHTC powders $[13,14]$.

Among transition metal carbide UHTCs, hafnium carbide $\left(\mathrm{HfC}, \mathrm{T}_{\mathrm{m}}=3900^{\circ} \mathrm{C}\right)$ and tantalum carbide $\left(\mathrm{TaC}, \mathrm{T}_{\mathrm{m}}=3985^{\circ} \mathrm{C}\right)$ are of particular interest due to their very high melting points, high hardness (TaC: 19GPa and HfC: 20GPa), high electrical and 
thermal conductivity [1,2,5-10]. However, these properties could improve further through forming solid solutions and/or composites. It has been observed that compared to binary HfC and TaC, (Ta,Hf)C solid solutions provide better properties such as higher melting point (above $4000{ }^{\circ} \mathrm{C}$ ), higher electrical resistivity and microhardness [15-17]. $\mathrm{TaC}$ and $\mathrm{HfC}$ can form continuous solid solutions in a broad composition range thanks to their similar crystal structure and also physical-chemical properties. Nevertheless, the solid solution may go through phase separation because of the presence of a miscibility gap at temperatures below $887{ }^{\circ} \mathrm{C}$. Therefore, it is critical to understand how to control the synthesis process to avoid phase separation, which is an energetically favorable process under certain condition. There are a few studies on synthesis of $\mathrm{Ta}_{\mathrm{x}} \mathrm{Hf}_{1-\mathrm{x}} \mathrm{C}$ solid solution powders using different approaches[18][16][19]. However, all these approaches suffer from certain drawbacks such as high cost of the starting materials (e.g., organometallic precursors, organic solvents), applying vacuum, long processing time, or introducing impurities. Moreover, the suggested methods are only used to synthesize a single composition of $\mathrm{Ta}_{0.8} \mathrm{Hf}_{0.2} \mathrm{C}$ solid solution and there is no study on the synthesis of other compositions, which show even greater properties such as higher oxidation resistance and better mechanical properties [20]. Therefore all these bring the question of how to control the phase separation of TaC-HfC during the synthesis process using lowcost methods without any composition constraints.

Among refractory UHTC diborides hafnium diboride $\left(\mathrm{HfB}_{2}, \mathrm{~T}_{\mathrm{m}}=3250^{\circ} \mathrm{C}\right)$ and zirconium diboride $\left(\mathrm{ZrB}_{2} \mathrm{~T}_{\mathrm{m}}=3000^{\circ} \mathrm{C}\right)$ are top candidates for thermal protection materials in both reentry and hypersonic vehicles due to their high melting point and superior oxidation resistance and thermal-mechanical properties $[3,4]$. Similar to UHTC carbides, 
different properties of diborides such as oxidation resistance, toughness, mechanical and electrical properties could be improved using alloying elements [21-24]. For example, it has been observed that adding $\mathrm{TaB}_{2}$ improves the oxidation resistance of $\mathrm{HfB}_{2}$ noticeably. This is mainly because of the formation of tantalum pentoxide $\left(\mathrm{Ta}_{2} \mathrm{O}_{5}, \mathrm{~T}_{\mathrm{m}}=1880^{\circ} \mathrm{C}\right)$, which has lower melting point than hafnium oxide $\left(\mathrm{HfO}_{2}, \mathrm{~T}_{\mathrm{m}}=2758^{\circ} \mathrm{C}\right)$. Hence, during the oxidation process $\mathrm{Ta}_{2} \mathrm{O}_{5}$ melts before $\mathrm{HfO}_{2}$ and form a more dense oxide layer leading to less oxygen transport [25]. Up to now there is only one study by Xie et al. [26][27]on the synthesis of $\mathrm{TaB}_{2}-\mathrm{ZrB}_{2}$ composite powders. However, in addition to not being able to synthesize single phase $\operatorname{Ta}_{x} Z_{1-x} B_{2}$ solid solution, their method suffers from several drawbacks such as high cost of the starting materials and issues with waste disposal. On the other hand, there is no study on the synthesis of $\mathrm{Ta}_{\mathrm{x}} \mathrm{Hf}_{1-\mathrm{x}} \mathrm{B}_{2}$ solid solution/composite powders, which could have even higher melting point than $\operatorname{Ta}_{x} Z_{1-x} B_{2}$ composite/solid solution thanks to the higher melting point of $\mathrm{HfB}_{2}$ when compared with $\mathrm{ZrB}_{2}$. Additionally, there are several studies reporting rapid coarsening and abnormal grain growth during the synthesis of boron containing ceramics even at moderate temperatures [28][29][30][31]. All these bring the fundamental question of how to precisely control the phase and microstructure of $\mathrm{Ta}_{x} \mathrm{Hf}_{1-\mathrm{x}} \mathrm{B}_{2}$ solid solution powders using low cost methods.

On the other hand, synthesis of high temperature ceramics (HTC) of boron carbide $\left(\mathrm{B}_{4} \mathrm{C}, \mathrm{T}_{\mathrm{m}}=2763^{\circ} \mathrm{C}\right)$ powders was also of interest since it is closely related to the synthesis of both $\mathrm{Ta}_{\mathrm{x}} \mathrm{Hf}_{1-\mathrm{x}} \mathrm{C}$ and $\mathrm{Ta}_{\mathrm{x}} \mathrm{Hf}_{1-\mathrm{x}} \mathrm{B}_{2}$ solid solutions considering the fact that $\mathrm{B}_{4} \mathrm{C}$ contains both carbon and boron in its structure. Therefore, studying the synthesis of nano/submicron-sized $\mathrm{B}_{4} \mathrm{C}$ with the emphasis on understanding the compositionprocessing-microstructure relationship is also very important as it will provide guidance 
to low cost synthesis of other carbides and borides with controlled microstructure and properties.

Thus, the main objective of this work is to study the synthesis and formation mechanisms of nanocrystalline ternary $\mathrm{Ta}_{\mathrm{x}} \mathrm{Hf}_{1-\mathrm{x}} \mathrm{C}$ and $\mathrm{Ta}_{\mathrm{x}} \mathrm{Hf}_{1-\mathrm{x}} \mathrm{B}_{2}$ solid solution powders with a focus on the interrelationships between composition, processing and microstructure. This is critical as it will provide better understanding about how to precisely control stoichiometry, phase, morphology and properties of the synthesized ternary UHTC materials. The secondary objective of this research is to synthesize nano/submicron-sized high temperature $\mathrm{B}_{4} \mathrm{C}$ ceramic powders using a low-cost method, study the interrelationships between composition-processing-microstructure and develop understanding about the reaction kinetics and mechanisms of formation for such a highly applicable ceramic, which would help guide the synthesis of ternary UHTC carbides and borides.

This thesis will be organized into 6 chapters. Chapter 1 provides an introduction for $\mathrm{B}_{4} \mathrm{C}$ and ternary carbide and boride UHTCs. Chapter 2 details the historic researches on the synthesis of nano $\mathrm{B}_{4} \mathrm{C}$ and ternary UHTCs and their challenges with particularly focuses on the $\mathrm{Ta}_{\mathrm{x}} \mathrm{Hf}_{1-\mathrm{x}} \mathrm{C}$ and $\mathrm{Ta}_{\mathrm{x}} \mathrm{Hf}_{1-\mathrm{x}} \mathrm{B}_{2}$ solid solutions/composites. Chapter 3 contains the materials, methods used for the synthesis of fine $\mathrm{B}_{4} \mathrm{C}$ powders as well as the obtained results and detailed analysis of them. Materials, methods, results and detailed discussion for synthesis of $\mathrm{Ta}_{\mathrm{x}} \mathrm{Hf}_{1-\mathrm{x}} \mathrm{C}$ andTa $\mathrm{Ta}_{\mathrm{x}} \mathrm{Hf}_{1-\mathrm{x}} \mathrm{B}_{2}$ solid solutions could be found in chapter 4 and 5 , respectively. Summary of the major findings in this work and recommendations for future work are provided in Chapter 6. 


\section{Chapter II: Literature Review}

\subsection{Boron Carbide $\left(\mathrm{B}_{4} \mathrm{C}\right)$}

Synthesis methods used to produce $\mathrm{B}_{4} \mathrm{C}$ powders are reviewed below. Advantages and also disadvantages of each method are explained in details in order to provide a rationale for the synthesis approach used in this work. These methods are: elemental synthesis, magnesiothermic reduction reaction, vapor phase reaction (e.g., chemical vapor deposition) and carbothermal reduction reaction. Most of these approaches are not practical for synthesis of nano-scale boron carbide on a large industrial scale.

\subsubsection{Elemental Synthesis}

There are some studies on the synthesis of $\mathrm{B}_{4} \mathrm{C}$ powders via elemental synthesis method. For example, Chang et al. [32] synthesized submicron-sized $\mathrm{B}_{4} \mathrm{C}$ powders $(\sim 350 \mathrm{~nm})$ through heat treating a mixture of amorphous boron and carbon powders at $1550{ }^{\circ} \mathrm{C}$ for 4 hours under argon flow. Wei et al. [33] synthesized $\mathrm{B}_{4} \mathrm{C}$ nanorods through mixing the carbon nanotubes (CNT) with amorphous boron (B) powders followed by heat treating at $1150{ }^{\circ} \mathrm{C}$ for 2 hours under flowing of argon gas. However, synthesis of $\mathrm{B}_{4} \mathrm{C}$ powders using elemental synthesis method is not economically preferred for industrial production due to the high cost of the elemental boron.

\subsubsection{Magnesiothermic Reduction Reaction}

$\mathrm{B}_{4} \mathrm{C}$ powders can also be synthesized via magnesiothermic reduction reaction. Equation below shows the formation of $\mathrm{B}_{4} \mathrm{C}$ using magnesium as the reducing agent:[34]

$$
2 \mathrm{~B}_{2} \mathrm{O}_{3}+6 \mathrm{Mg}+\mathrm{C} \rightarrow \mathrm{B}_{4} \mathrm{C}+6 \mathrm{MgO}
$$


However, the above reaction does not occur in a single step but they rather in two subsequent steps see equations below:

$$
\begin{aligned}
& 2 \mathrm{~B}_{2} \mathrm{O}_{3}+6 \mathrm{Mg} \rightarrow 4 \mathrm{~B}+6 \mathrm{MgO} \\
& 4 \mathrm{~B}+\mathrm{C} \rightarrow \mathrm{B}_{4} \mathrm{C}
\end{aligned}
$$

Nevertheless, the $\mathrm{B}_{4} \mathrm{C}$ powders synthesized by this method always contain residual magnesium compounds. Although hot acids could be applied to purify the synthesized powders, those impurity compounds would not be removed completely. Moreover, the high cost of magnesium and the need for treating the waste acid make this method less favorable to be implemented for industrial scale synthesis of $\mathrm{B}_{4} \mathrm{C}$. There has been a report by Singh et al. [35], which describes the synthesis of uniform $\mathrm{B}_{4} \mathrm{C}$ nanoparticles by one step reduction of boric acid using activated magnesium at very low temperatures $\left(800^{\circ} \mathrm{C}\right)$ for 20 hours. However, that method utilized a specially designed high pressure autoclave, which is expensive and has safety and productivity concerns.

\subsubsection{Vapor Phase Reaction}

Vapor phase reaction method has been widely used to synthesize $\mathrm{B}_{4} \mathrm{C}$ powders, thin film coatings, and whiskers[36][37][38][39]. In this method, the boron containing gaseous species such as boron trichloride $\left(\mathrm{BCl}_{3}\right)$ and boron triiodide $\left(\mathrm{BI}_{3}\right)$ will be reduced by carbon containing gaseous species such as carbon tetrachloride $\left(\mathrm{CCl}_{4}\right)$ and hydrocarbon gases (e.g., $\mathrm{CH}_{4}$ ) to form $\mathrm{B}_{4} \mathrm{C}[34,40]$.The equation below refers to the formation of $\mathrm{B}_{4} \mathrm{C}$ through the reduction of gaseous $\mathrm{BCl}_{3}$ with $\mathrm{CH}_{4}$ :

$$
4 \mathrm{BCl}_{3}+\mathrm{CH}_{4}+4 \mathrm{H}_{2} \rightarrow \mathrm{B}_{4} \mathrm{C}+12 \mathrm{HCl}
$$


It should be noted that in this method, hydrogen $\left(\mathrm{H}_{2}\right)$ gas must be added to $\mathrm{CH}_{4}$ during the whole process in order to covert the chlorine to hydrogen chloride $(\mathrm{HCl})$. Although this method leads to formation of $\mathrm{B}_{4} \mathrm{C}$ products with high purity, it is not ideal for synthesis of $\mathrm{B}_{4} \mathrm{C}$ nano powders on large scale due to the high cost of gaseous materials and equipment. As a result, it is not appropriate for large industrial $\mathrm{B}_{4} \mathrm{C}$ powders production.

\subsubsection{Carbothermal Reduction Reaction}

Among all the methods mentioned earlier, carbothermal reduction reaction (CTR) is most commonly carried out since it is an inexpensive method that uses low cost starting materials such as boron trioxide $\left(\mathrm{B}_{2} \mathrm{O}_{3}\right)$ and carbon and relative simple equipment. In fact, it is used for industrial production of $\mathrm{B}_{4} \mathrm{C}$ (e.g., via the Acheson process). Eq. 2.5 shows the overall reaction for boron carbide synthesis through CTR [40]:

$$
2 \mathrm{~B}_{2} \mathrm{O}_{3}(\mathrm{l}, \mathrm{g})+7 \mathrm{C}(\mathrm{s}) \rightarrow \mathrm{B}_{4} \mathrm{C}(\mathrm{s})+6 \mathrm{CO}(\mathrm{g})
$$

Researchers have made numerous reports on the synthesis of $\mathrm{B}_{4} \mathrm{C}$ powders based on CTR process. For example, Weimer et al. [40,41] has synthesized uniform and fine $\mathrm{B}_{4} \mathrm{C}$ particles $(\sim 100 \mathrm{~nm})$ at $2000{ }^{\circ} \mathrm{C}$ for a few seconds in a graphite transport reactor using rapid CTR reaction of $\mathrm{B}_{2} \mathrm{O}_{3}$ and carbon from cornstarch. Miler et al. [42] also has synthesized submicron $\mathrm{B}_{4} \mathrm{C}$ particles $(\sim 0.4 \mu \mathrm{m})$ through rapid CTR reaction of $\mathrm{B}_{2} \mathrm{O}_{3}$ and carbon lamp black at $1750{ }^{\circ} \mathrm{C}$ in a specially designed graphite furnace. Gao et al. $[43,44]$ has also synthesized submicron $\mathrm{B}_{4} \mathrm{C}$ particles $(\sim 0.35 \mu \mathrm{m})$ using an aqueous solution of boric acid and carbon as precursors followed by pyrolysis (to remove the low molecule 
species such as excess water) and rapid CTR at $1850^{\circ} \mathrm{C}$. Kakiage et al. [45] synthesized micron-sized $\mathrm{B}_{4} \mathrm{C}$ particles $(\sim 5 \mu \mathrm{m})$ using PVA and boric acid through conventional CTR at a low temperature of $1100^{\circ} \mathrm{C}$. Najafi et al. [46,47] synthesized a mixture of nano $\mathrm{B}_{4} \mathrm{C}$ particles and whiskers using sol-gel process of phenolic resin and boron alkoxide followed by pyrolysis and conventional CTR reaction at $1270{ }^{\circ} \mathrm{C}$. However, despite the successful synthesis of $\mathrm{B}_{4} \mathrm{C}$ powders via CTR method there are still some issues that need to be addressed, especially in terms of product microstructure.

In spite of CTR advantages over other $\mathrm{B}_{4} \mathrm{C}$ synthesis methods, there are not enough studies on a detailed examination of interrelationships between compositionprocessing-microstructure and there is still a significant lack of a systematic study on the effect of different parameters (e.g., CTR processing conditions and precursors) on final morphology and as a result properties of $\mathrm{B}_{4} \mathrm{C}$. For example, Alizadeh et al.[28]reported the formation of highly non-uniform $\mathrm{B}_{4} \mathrm{C}$ powders via $\mathrm{CTR}$ reaction between boric acid and carbon (see Figure 2.1).

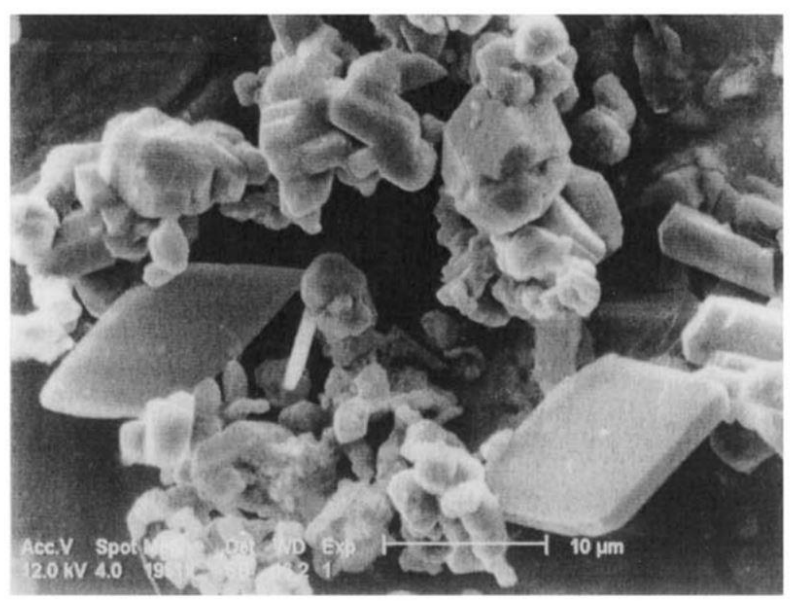

Figure 2.1: SEM image of the $\mathrm{B}_{4} \mathrm{C}$ powders synthesized by Alizadeh et al.[28] 
Ma et al. [48] reported formation of $\mathrm{B}_{4} \mathrm{C}$ nanowires through CTR of $\mathrm{B}_{2} \mathrm{O}_{3} / \mathrm{B} / \mathrm{C}$ mixture without adding any catalyst. On the other hand, Weimer et al. [40][41] reports the synthesis of highly uniform $\mathrm{B}_{4} \mathrm{C}$ powders via CTR method using essentially the same kinds of starting materials. All these bring questions of:

1- What causes such large variations in $\mathrm{B}_{4} \mathrm{C}$ powder microstructure?

2-How to better control the $\mathrm{B}_{4} \mathrm{C}$ product morphology?

Study aimed at revealing the interrelationships between composition-processingmicrostructure for synthesis of nano/submicron-sized $\mathrm{B}_{4} \mathrm{C}$ powders via CTR method will help answer those questions and also influence the scaling up of the synthesis process to industrial production for fine $\mathrm{B}_{4} \mathrm{C}$ powders.

\subsection{UHTC Carbides and Borides Synthesis}

All the methods used to synthesize UHTC carbides and borides along with their advantages and disadvantages are discussed in the following section.

\subsubsection{Direct Reaction Using Elemental Metals}

In this method, the elemental transition metal powders react with boron or carbon powders in order to form UHTC borides and carbides, respectively. There are several studies on the synthesis of UHTC borides and carbides using this method [49-51]. For example, Matsudaira et al. [49] synthesized a mixture of niobium diboride $\left(\mathrm{NbB}_{2}\right)$ and niobium boride $(\mathrm{NbB})$ with particle size of $\sim 5-10 \mu \mathrm{m}$ at $1000{ }^{\circ} \mathrm{C}$ for 1 hour using elemental niobium metal and amorphous boron powder. However, as earlier explained in section 2.1.1, elemental synthesis suffers from several drawbacks including high cost of the elemental precursors. On the other hand, the use of coarse starting materials (in 
particular transition metal powders) along with the relatively high reaction temperatures leads to a noticeable grain growth.

Moreover, there are also several studies on the synthesis of UHTC borides and carbides from the elements using self-propagating-high-temperature synthesis (SHS) method [50,51][52]. However, the obtained products from the SHS process may have non-uniform morphology due to the temperature non-uniformities during the synthesis procedure (see Figure 2.2). In other words, there would be almost no control on the microstructure of the synthesized powder via SHS process due to the very fast reactions with high transient reaction temperature $\left(\sim 2000{ }^{\circ} \mathrm{C}\right)[27]$. All these make the elemental synthesis an unfavorable process to produce nanocrystalline UHTCs.

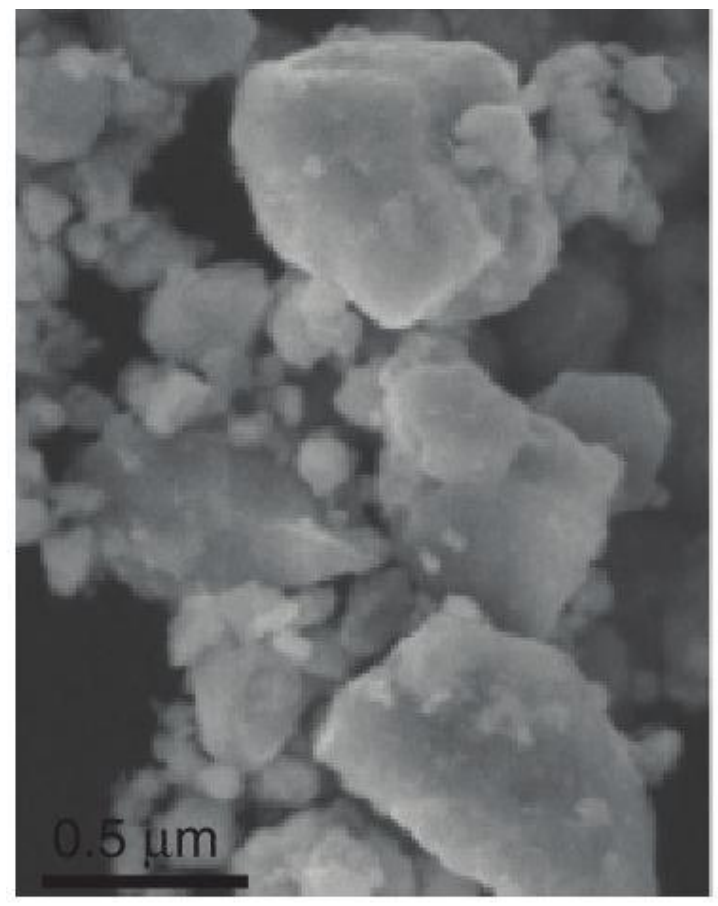

Figure 2.2: SEM image of synthesized $\mathrm{ZrB}_{2}+\mathrm{SiC}$ composite via SHS method [50]. 


\subsubsection{Vapor Phase Reaction}

Both carbides and borides of transition metals could be synthesized via vaporphase reaction method [53-55]. Eq. 2.6 shows the reduction of the gaseous transition metal chloride and boron trichloride with hydrogen gas.

$\mathrm{MCl}_{4}(\mathrm{~g})+2 \mathrm{BCl}_{3}(\mathrm{~g})+5 \mathrm{H}_{2}(\mathrm{~g}) \rightarrow \mathrm{MB}_{2}+10 \mathrm{HCl}$

Eq. 2.7 shows the formation of transition metal carbides through the reaction between the gaseous transition metal chlorides with gaseous hydrocarbons (e.g., propene).

$3 \mathrm{MCl}_{4}(\mathrm{~g})+\mathrm{C}_{3} \mathrm{H}_{6}(\mathrm{~g})+3 \mathrm{H}_{2}(\mathrm{~g}) \rightarrow 3 \mathrm{MC}+12 \mathrm{HCl}$

However, as earlier mentioned in section 2.1.3 this method suffers from some disadvantages such as high cost of the gaseous precursors and equipment and also safety concerns with using such flammable gases (e.g., $\mathrm{CH}_{4}$ ) and the byproduct of highly corrosive $\mathrm{HCl}$.

\subsubsection{Carbothermal and Borothermal Reduction Reactions}

Carbothermal reduction reaction (CTR) is commonly used for commercial production of the UHTC carbides and borides. Compared with the methods explained previously, CTR reaction is low cost, scalable and environmentally friendly.

Example CTR reactions for formation of carbides and borides could be written as follows, assuming product of $\mathrm{MC}$ and $\mathrm{MB}_{2}$ :

$$
\begin{aligned}
& \mathrm{MO}_{2}+3 \mathrm{C} \rightarrow \mathrm{MC}(\mathrm{s})+2 \mathrm{CO}(\mathrm{g}) \\
& \mathrm{MO}_{2}(\mathrm{~s})+\mathrm{B}_{2} \mathrm{O}_{3}(\mathrm{~s})+5 \mathrm{C}(\mathrm{s}) \rightarrow \mathrm{MB}_{2}(\mathrm{~s})+5 \mathrm{CO}(\mathrm{g})
\end{aligned}
$$

The transition metal oxides need to react with carbon and carbon plus boron trioxide to from UHTC carbides and borides, respectively. 
Borothermal reduction reaction (BTR) is another method used to synthesize UHTC borides. In this method the transition metal oxide reacts with B to from boride as shown below [56][57]:

$\mathrm{MO}_{2}(\mathrm{~s})+4 \mathrm{~B}(\mathrm{~s}) \rightarrow \mathrm{MB}_{2}(\mathrm{~s})+\mathrm{B}_{2} \mathrm{O}_{2}(\mathrm{~g})$

The reaction temperature for Eq. 2.10 could further decrease by adding carbon to help reducing the metal oxide[57]:

$\mathrm{MO}_{2}(\mathrm{~s})+2 \mathrm{~B}(\mathrm{~s})+2 \mathrm{C}(\mathrm{s}) \rightarrow \mathrm{MB}_{2}(\mathrm{~s})+2 \mathrm{CO}(\mathrm{g})$

$\mathrm{B}_{4} \mathrm{C}$ can also be used instead of elemental boron in the above reaction [31] However, similar to elemental boron, $\mathrm{B}_{4} \mathrm{C}$ is also expensive especially for the ones with smaller particle size. In comparison $\mathrm{B}_{2} \mathrm{O}_{3}$ is much less expensive and could be used as $\mathrm{B}$ source for the synthesis of UHTC borides via CTR reaction (see Eq. 2.9).

In conventional CTR processing method used for synthesis of UHTC carbides and borides, very high temperature and long holding times on the order of several hours are required due to the non-homogenous mixture of coarse reactants, which result in formation of micron-sized particles instead of uniform UHTC nanopowders. On the other hand, CTR reaction can use soluble precursor materials that can offer intimate, molecular mixing of reactants. This would result in lower CTR temperatures and shorter dwell time giving rise to formation of UHTC powders with smaller particle size. Moreover, more uniform powders would form via solution processing followed by CTR thanks to the homogeneous distribution of all reactants at molecular level.

It should also be mentioned that there would be a large choices of precursors and processing conditions for CTR, which offers the flexibility to have better control on the 
morphology and stoichiometry of the synthesized powders, and is not applicable in the earlier mentioned methods.

\subsubsection{Alkali Metal Reduction}

Alkali metal reduction reaction (AMR) method has been used for the synthesis of UHTC diborides before. In this approach, the alkali metals or their active compounds such as sodium borohydride $\left(\mathrm{NaBH}_{4}\right)$ are used to react with transition metal chlorides in order to form UHTC diborides. The overall AMR reaction is written as below $[58,59]$

$\mathrm{MCl}_{4}+2 \mathrm{NaBH}_{4} \rightarrow \mathrm{MB}_{2}+2 \mathrm{NaCl}+2 \mathrm{HCl}+3 \mathrm{H}_{2}$

The reaction above occurs at low temperatures, while at higher temperatures $\left(>500{ }^{\circ} \mathrm{C}\right)$ $\mathrm{NaBH}_{4}$ starts to decompose (see Eq. 2.13) and the metal chlorides will react with decomposition products of $\mathrm{NaBH}_{4}$ sodium hydride $(\mathrm{NaH})$ and boron hydride $\left(\mathrm{BH}_{3}\right)$ in order to form metal diborides (see Eq. 2.14).

$\mathrm{NaBH}_{4} \rightarrow \mathrm{BH}_{3}+\mathrm{NaH}$

Eq. 2.13

$\mathrm{MCl}_{4}+2 \mathrm{NaH}+2 \mathrm{BH}_{3} \rightarrow \mathrm{MB}_{2}+2 \mathrm{NaCl}+2 \mathrm{HCl}+3 \mathrm{H}_{2}$

This method provides some advantages such as lower reaction temperature $\left(<1000{ }^{\circ} \mathrm{C}\right)$, which would help obtaining very small crystallite size in range of few nanometers. However, there are also a few difficulties associated with this approach. For example, alkali borohydrides, which are used as the reducing agent as well as the boron source, may bring safety concerns. Moreover, both transition metal chlorides and alkali borohydride are sensitive to air/moisture. Therefore, rigorous atmosphere control is required in order to prevent their reaction with air/moisture, otherwise the product of the 
AMR reaction might contain metal oxides instead of pure borides. Additionally, as can be seen in Eq. 2.14 alkali halides are the byproduct of the AMR reaction, which need to get removed by washing the products via water.

\subsection{Synthesis of Ternary UHTCs}

Preparing solid solutions and composites of UHTC carbides and borides enable flexibility in tuning the composition and properties such as mechanical, thermal and chemical properties $[9,60][24]$. The solid solutions and/or composites of UHTC borides and carbides often show the potential to be used for certain aerospace applications thanks to the improved mechanical or chemical properties [24][61]. For example, Mroz [61] reported that $(\mathrm{Ti}, \mathrm{Zr}) \mathrm{C}$ and $(\mathrm{Ti}, \mathrm{Zr}) \mathrm{B}_{2}$ solid solutions show better mechanical properties (e.g., higher hardness) compared with the end members for each system (see Figure 2.3).

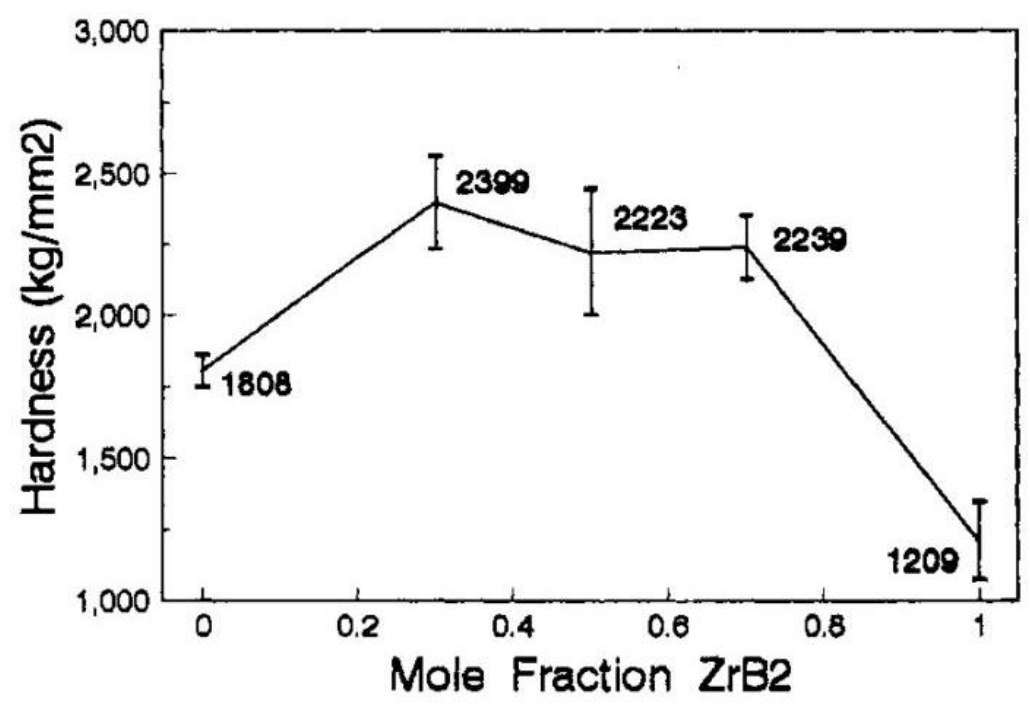

Figure 2.3: Hardness of single-phase $\mathrm{TaZrB}_{2}$ solid solution with different compositions[61]

For thermal properties, Andrievskii et al. [15] studied the melting points for different compositions of (Ta,Hf)C solid solutions. It was found that $\mathrm{Ta}_{0.8} \mathrm{Hf}_{0.2} \mathrm{C}$ has higher melting point $\left(\sim 4010{ }^{\circ} \mathrm{C}\right)$ than both pure $\mathrm{HfC}$ and TaC. Additionally, Monteverde 
et al.[62] reported that addition of 10 vol.\% $\mathrm{HfB}_{2}$ into $\mathrm{ZrB}_{2}+15 \mathrm{vol} . \% \mathrm{SiC}$ enhanced the thermal shock resistance of the sintered ceramic from $385{ }^{\circ} \mathrm{C}$ to $475{ }^{\circ} \mathrm{C}$ through formation of $(\mathrm{Zr}, \mathrm{Hf}) \mathrm{B}_{2}$ solid solution during the consolidation process. For chemical property, Zhang et al. [20] performed oxidation tests on sintered (Ta,Hf)C solid solutions with different compositions such as $\mathrm{Ta}_{0.5} \mathrm{Hf}_{0.5} \mathrm{C}$ using a plasma gun. The oxidation test results showed that the formed oxide layer on the surface of the sintered $\mathrm{Ta}_{0.5} \mathrm{Hf}_{0.5} \mathrm{C}$ sample is noticeably thinner than those formed on the surfaces of the sintered pure TaC and $\mathrm{HfC}$, suggesting better oxidation resistance for the system of $\mathrm{Ta}_{0.5} \mathrm{Hf}_{0.5} \mathrm{C}$ under certain testing condition.

Table 2.1: The thickness of oxide layers formed at $\sim 2720{ }^{\circ} \mathrm{C}$ after different times [20]

\begin{tabular}{|c|c|c|c|c|c|}
\hline Unit: $\boldsymbol{\mu m}$ & PT & T8H2 & T5H5 & T2H8 & PH \\
\hline $1 \mathrm{~min}$ & $35.99 \pm 2.33$ & $19.74 \pm 1.00$ & $9.00 \pm 0.44$ & $20.30 \pm 2.29$ & $57.28 \pm 3.44$ \\
\hline $3 \mathrm{~min}$ & $73.36 \pm 6.64$ & $29.18 \pm 1.43$ & $15.73 \pm 1.09$ & $50.54 \pm 3.43$ & $151.05 \pm 2.86$ \\
\hline 5 min & $305.20 \pm 11.47$ & $39.64 \pm 1.91$ & $28.46 \pm 1.41$ & $101.04 \pm 2.36$ & $189.78 \pm 2.72$ \\
\hline
\end{tabular}

PT: Pure TaC

$\mathrm{T} 8 \mathrm{H} 2: \mathrm{Ta}_{80} \mathrm{Hf}_{20} \mathrm{C}$ solid solution

T5H5: $\mathrm{Ta}_{50} \mathrm{Hf}_{50} \mathrm{C}$ solid solution

T2H8: $\mathrm{Ta}_{20} \mathrm{Hf}_{80} \mathrm{C}$ solid solution

PH: Pure HfC 
In another example, Talmy et al. [63] observed that addition of $\mathrm{TaB}_{2}$ to $\mathrm{ZrB}_{2}-\mathrm{SiC}$ composite would improve the oxidation resistance at temperatures up to $1400{ }^{\circ} \mathrm{C}$. All these motivate the research on synthesis and processing of ternary UHTCs.

\subsubsection{Previous Study on Synthesis of Ternary UHTC Carbides and Borides}

As discussed earlier, synthesis of binary UHTC powders has been extensively studied. However, there have not been many studies on the synthesis of ternary UHTC carbides and borides powders. It should be noted that there are some studies on synthesis of bulk UHTC solid solutions and/or composites from binary carbides and borides using high temperature and/or high pressure processes. For example, Valvoda et al. [64] synthesized (Ta,Hf)C solid solution by annealing the $\mathrm{TaC}$ and $\mathrm{HfC}$ cold pressed powder mixture for 200 hours at $1900{ }^{\circ} \mathrm{C}$. Ghaffari et al. [65] fabricated bulk $\mathrm{Ta}_{0.8} \mathrm{Hf}_{0.2} \mathrm{C}$ in the presence of molybdenum disilicide $\left(\mathrm{MoSi}_{2}\right)$ sintering aid by pressureless sintering at $2000{ }^{\circ} \mathrm{C}$ for 1 hour using a micron-sized mixture of TaC-HfC ceramic powders. Ghaffari et al. [66] also fabricated bulk TaC-HfC solid solution at $1650{ }^{\circ} \mathrm{C}$ for 5 minutes under pressure of $30 \mathrm{MPa}$ using the spark plasma sintering (SPS) method.

However, these methods could only produce bulk ceramic materials with relatively coarse scale of mixing. On the other hand, as mentioned before, obtaining UHTC powders with reduced particle size will help achieving finer microstructure of the fabricated parts, and it also helps simplify the post synthesis processing such as milling/grinding and improves the sintering activity. Additionally, powders enable flexibility for different applications such as input materials for coatings via plasma spray. 
There are some limited studies on synthesis of ternary UHTC carbides and borides powders. For example, Patsera et al. [52] produce ( $\mathrm{Ta}, \mathrm{Zr}) \mathrm{C}$ solid solution using self-propagating high temperature synthesis (SHS) of mechanically activated Ta-Zr-C mixture. However, this method suffers from some drawbacks such as long ball milling process and introduction of impurities. Moreover, there would be no control on the morphology of the synthesized powders, which is not favorable. Gaballa et al. $[19,67]$ has synthesized $\mathrm{Ta}_{0.8} \mathrm{Hf}_{0.2} \mathrm{C}$ ceramic powders with particle size of $\sim 1 \mu$ via ball milling $4 \mathrm{TaC}$ HfC mixture for 18 hours. However, in addition to not achieving nano-sized (Ta,Hf)C solid solution, long milling procedure and introduction of impurities make this method less industrial desirable for adoption. Simoneko et al. [16] has successfully synthesized highly dispersed $\mathrm{Ta}_{0.8} \mathrm{Hf}_{0.2} \mathrm{C}$ solid solutions using sol-gel method followed by carbothermal reduction reaction (sol-gel/CTR), that produces homogenous mixture of metal oxides and carbon precursors. The gel is pyrolyzed in an inert atmosphere to remove hydrogen and water to produce finely mixed oxide-carbon, which was finally heat treated at higher temperatures (e.g., $1500{ }^{\circ} \mathrm{C}$ ) for CTR to happen. During CTR, carbon reduces the $\mathrm{Hf}-\mathrm{Ta}$ oxides and $\mathrm{Ta}_{0.8} \mathrm{Hf}_{0.2} \mathrm{C}$ ternary solid solution powders were obtaind. However, the use of vacuum $\left(\sim 10^{-6} \mathrm{MPa}\right)$ as well as expensive organometallic precursors makes their method less attractive. Recently Jiang et al. [18] has synthesized nano-sized $\mathrm{Ta}_{0}{ }_{8} \mathrm{Hf}_{0.2} \mathrm{C}$ solid solution powders via solvothermal treatment followed by CTR using inorganic precursors. Nonetheless, the use of non-aqueous solvents, the high cost of autoclave instrument, and the safety concern with autoclave operation make this method less economically favorable. 
The synthesis of ternary UHTC borides powders has not been investigated as much as ternary UHTC carbides. Mroz [61] has synthesized (Ti,Zr) $\mathrm{B}_{2}$ solid solution powders $(7-10 \mu \mathrm{m})$ from a mixture of the metal oxides and boron in a continuous graphite furnace at $1975{ }^{\circ} \mathrm{C}$. Nevertheless, apart from not achieving uniform nano/submicronsized solid solution powders, the use of very high BTR temperature of $1975{ }^{\circ} \mathrm{C}$ is not desirable. Xie et al. [26] has studied the $\mathrm{TaB}_{2}-\mathrm{ZrB}_{2}$ synthesis via sol-gel/CTR method. However, despite the use of the expensive organometallic precursors and non-aqueous solvents, only a $\mathrm{TaB}_{2}-\mathrm{ZrB}_{2}$ two-phase composite powder was obtained despite temperature as high as $1800{ }^{\circ} \mathrm{C}$.

\subsubsection{Challenges with Synthesis of $\mathrm{Ta}_{\mathrm{x}} \mathrm{Hf}_{1-\mathrm{x}} \mathrm{C}$ and $\mathrm{Ta}_{\mathrm{x}} \mathrm{Hf}_{1-\mathrm{xB}} \mathrm{B}_{2}$ Solid Solution Powders} via Aqueous Solution Processing/CTR Method

Compared with other methods to synthesize ternary nano-sized UHTCs, the aqueous solution processing/CTR method has several advantages. First, solution processing offers ability to achieve uniform molecular mixture of precursors, which increases reactivity of precursors and the possibility to produce high purity products due to avoidance of mechanical milling that introduces impurities. Moreover, aqueous solution processing is cheap and does not have safety concerns with waste disposal as non-aqueous solution processing does. As described before, aqueous solution processing will be followed with subsequent heat treatment of pyrolysis and CTR. The advantages of using CTR over other methods have been discussed in details in section 2.2.3. However, although aqueous solution processing/CTR has noticeable advantages over other 
methods, there are several challenges for synthesis of ternary $\operatorname{Ta}_{x} \mathrm{Hf}_{1-\mathrm{x}} \mathrm{C}$ and $\operatorname{Ta}_{\mathrm{x}} \mathrm{Hf}_{1-\mathrm{x}} \mathrm{B}_{2}$ solid solution powders using this method.

\subsubsection{Phase Separation of TaC-HfC}

Both HfC and TaC have NaCl-type crystal structure (B1, Fm $3 \mathrm{~m}$ ), in which the carbon atoms are accommodated into the octahedral interstitial sites (see Figure 2.4). In addition to their identical crystal structure, these carbides have a very similar lattice

parameters $\left(\mathrm{a}_{\mathrm{HfC}}=4.46 \AA\right.$ and $\left.\mathrm{a}_{\mathrm{TaC}}=4.44 \AA\right)$. Therefore, theoretically they can form continuous solid solutions at elevated temperatures thanks to their similar crystal structure and lattice parameters.

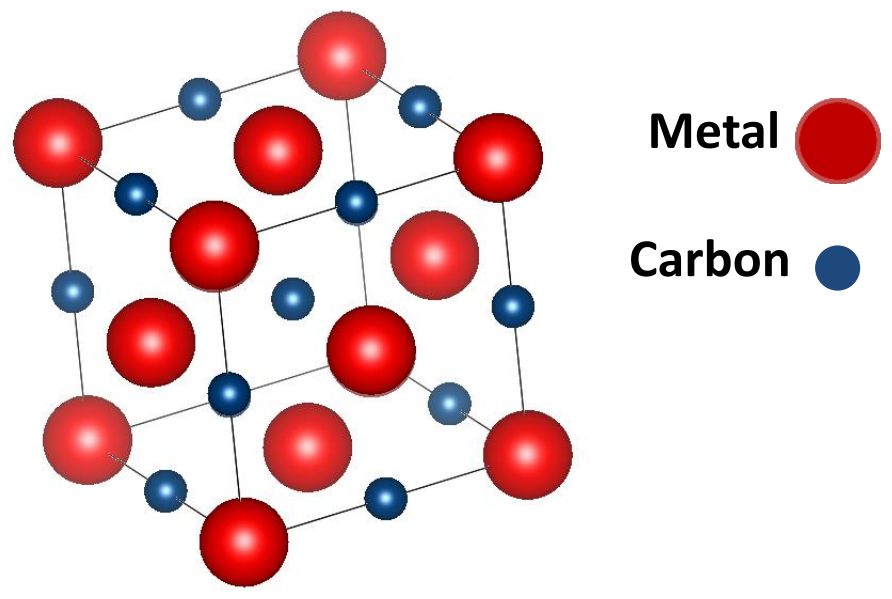

Figure 2.4: NaCl-type crystal structure

However, according to the TaC-HfC phase diagram (see Figure 2.5), there is a miscibility gap at temperatures below $887^{\circ} \mathrm{C}$, which suggests that at lower temperatures a composite of TaC-HfC would be energetically more stable than the uniform solid solution for a large composition range (e.g., at room temperature $\mathrm{x}$ is between $\sim 0.05$ and 
0.98). Hence, it is critical to control the synthesis processing to avoid the phase separation from uniform solid solution, which is a thermodynamically favorable process at lower temperatures.

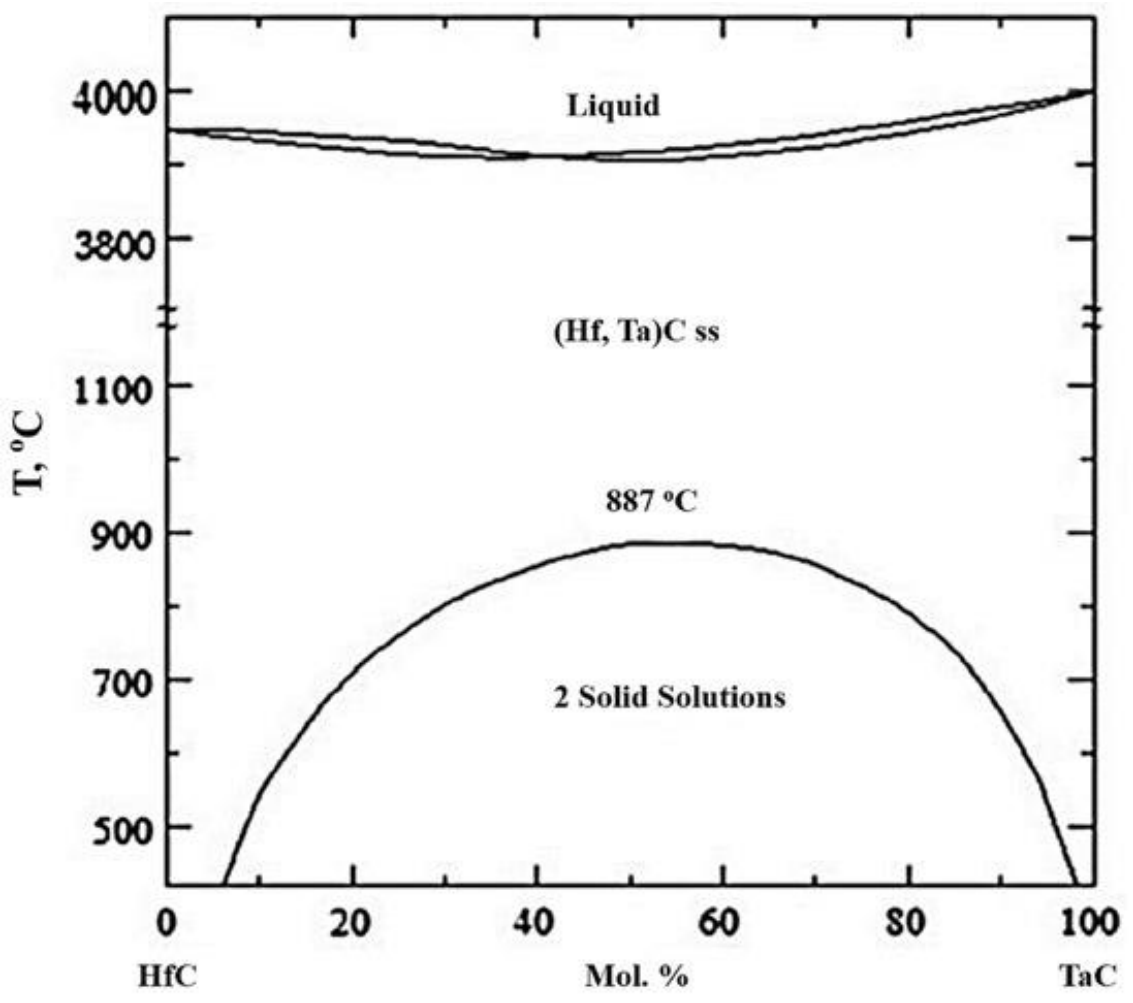

Figure 2.5: Phase diagram of TaC-HfC system [68]

On the other hand, during the CTR process, hafnium oxide $\left(\mathrm{HfO}_{2}\right)$ and tantalum pentoxide $\left(\mathrm{Ta}_{2} \mathrm{O}_{5}\right)$ should react with carbon to form $\mathrm{Ta}_{\mathrm{x}} \mathrm{Hf}_{1-\mathrm{x}} \mathrm{C}$ solid solutions. However, formation of a single-phase $\mathrm{Ta}_{\mathrm{x}} \mathrm{Hf}_{1-\mathrm{x}} \mathrm{C}$ solid solution via CTR is complicated due to noticeable differences in reactivity of $\mathrm{HfO}_{2}$ and $\mathrm{Ta}_{2} \mathrm{O}_{5}$ with carbon, which is also related to the low solubility of those two oxides in each other. Such a difference always leads to the formation of individual $\mathrm{TaC}$ and $\mathrm{HfC}$ powders. For example, Simoneko et al. [16] has shown that under the same $\mathrm{pCO}$ of $10^{-5} \mathrm{MPa}, \mathrm{TaC}$ could form at $\sim 1000 \mathrm{~K}$, while the temperature for $\mathrm{HfC}$ to form in similar atmosphere is $~ 1400 \mathrm{~K}$ (see Figure 2.6). Therefore 
during the CTR process $\mathrm{TaC}$ can form at much lower temperature than $\mathrm{HfC}$ leading to formation of phase-separated TaC-HfC composite instead of single-phase $\mathrm{Ta}_{\mathrm{x}} \mathrm{Hf}_{1-\mathrm{x}} \mathrm{C}$ solid solution powders. It should be mentioned that the difference between the reactivity of the $\mathrm{HfO}_{2}$ and $\mathrm{Ta}_{2} \mathrm{O}_{5}$ with carbon decreases by reducing the pCO. This is why Simoneko et al. [16] applied vacuum during the CTR process for the synthesis of $\mathrm{Ta}_{0.8} \mathrm{Hf}_{0.2} \mathrm{C}$ solid solution powders. However, as already discussed applying vacuum is not favorable for industry production. Moreover, despite the use of vacuum during the CTR process, they were not successful to prevent the phase separation when the CTR heating rate was too slow $(<100 \mathrm{~K} / \mathrm{min})$.

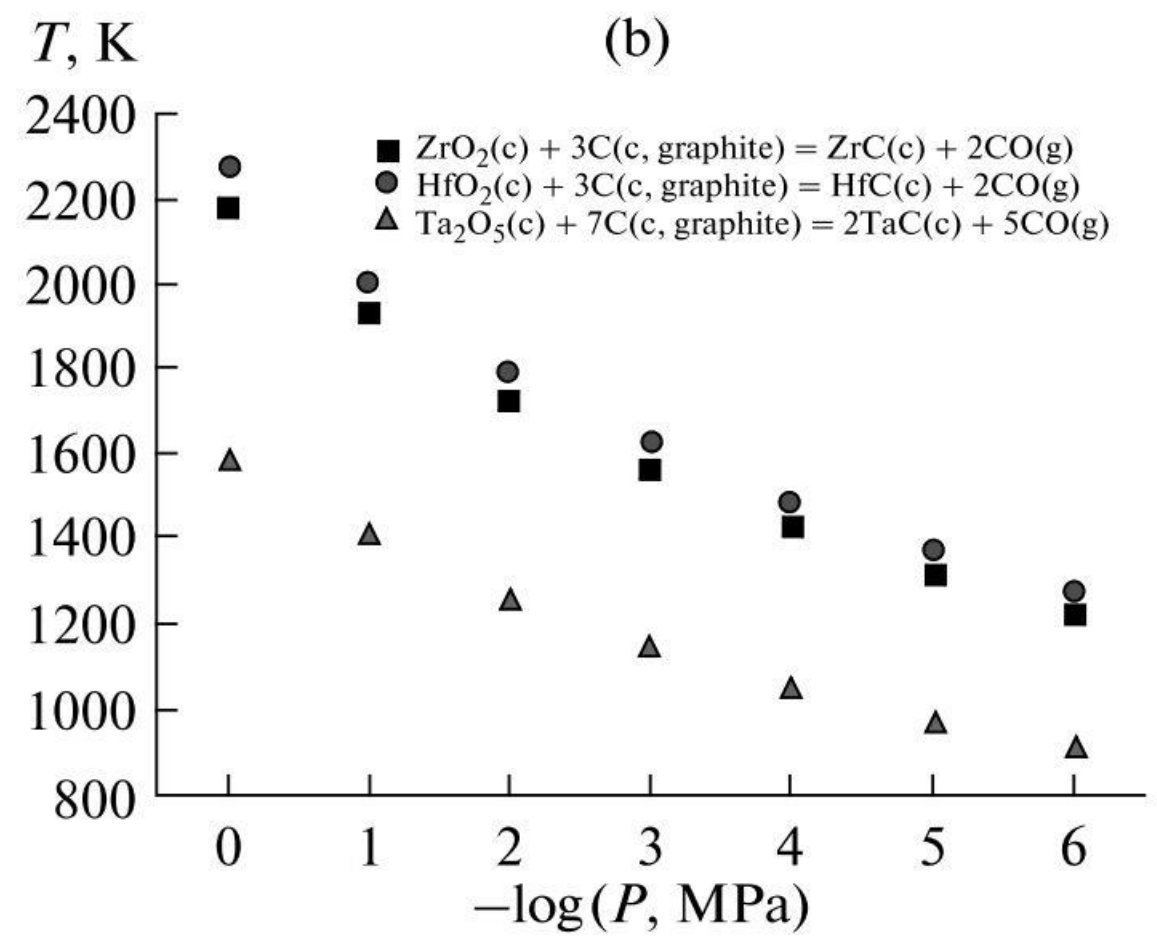

Figure 2.6: Equilbrium temperatures of $\mathrm{TaC}$ and $\mathrm{HfC}$ formation via CTR under different pressures[16] 


\subsubsection{Phase Separation of $\mathrm{TaB}_{2}-\mathrm{HfB}_{2}$}

Continuous solid solutions can form among diborides of group IV and V at higher temperatures $\left(>\sim 1400{ }^{\circ} \mathrm{C}\right)$ due to several reasons: First, there is a small difference between their atomic radii $(<10 \%)$, second, the borides of group IV and V have the same crystal structure ( $\mathrm{AlB}_{2}$-type (hexagonal, $\left.\mathrm{P} 6 / \mathrm{mmm}\right)$ ) and similar lattice parameters (e.g., $\mathrm{a}_{\mathrm{HfC}}=3.141 \AA$ and $\mathrm{aTaC} 3.088 \AA$ ). (Please see Figure 2.7 that shows the AlB2-type crystal structure with $\mathrm{P} 6 / \mathrm{mmm}$ symmetry for the majority of transition metal diborides such as $\mathrm{TaB}_{2}, \mathrm{HfB}_{2} \mathrm{ZrB}_{2}, \mathrm{TiB}_{2}, \mathrm{NbB}_{2}$.) However, although these borides should form continuous solid solution, phase separation was observed for the boride previously. For example, Xie et al. $[26,27]$ studied the synthesis of $\mathrm{TaB}_{2}-\mathrm{ZrB}_{2}$ powder via sol-gel/CTR method and observed obvious phase separation of two individual binary diborides despite the carefully adopted sol-gel reaction route involving organometallic precursors and nonaqueous solvents: Instead of a uniform single phase $\mathrm{Ta}{ }_{0.25} \mathrm{Zr}_{0.75} \mathrm{~B}_{2}$ solid solution powder, only a $\mathrm{TaB}_{2}-\mathrm{ZrB}_{2}$ two-phase composite powder was obtained at temperature as high as $1800{ }^{\circ} \mathrm{C}$. Therefore, phase separation, which was noted in $(\mathrm{Ta}, \mathrm{Zr}) \mathrm{B}_{2}$ system might also be encountered in the ( $\mathrm{Ta}, \mathrm{Hf}) \mathrm{B}_{2}$ system due to the very similar physical-chemical properties of $\mathrm{Zr}$ and $\mathrm{Hf}$. 


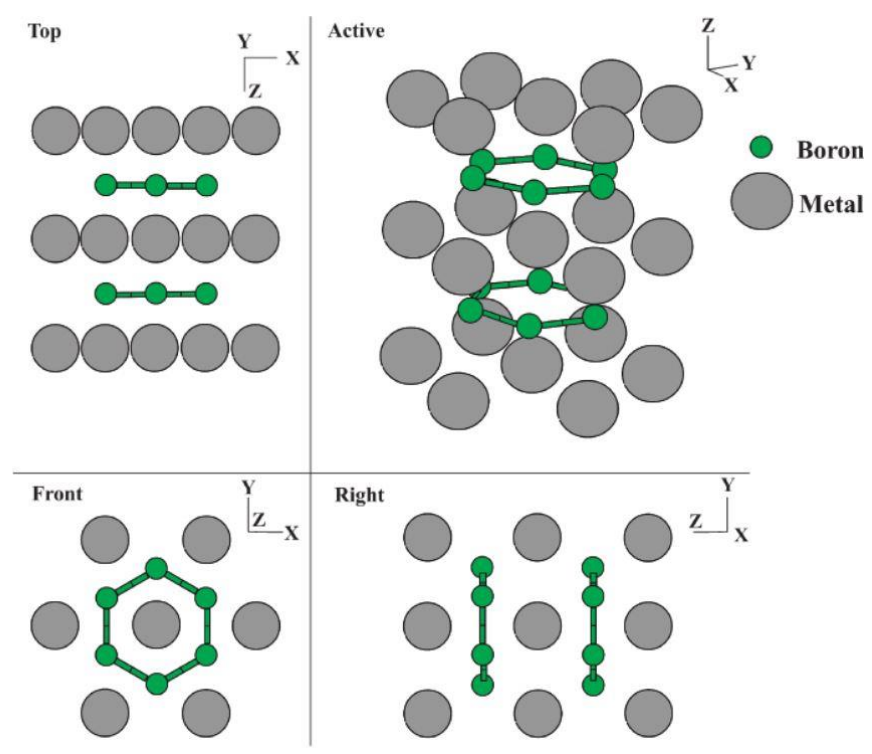

Figure 2.7: $\mathrm{AlB}_{2}$ crystal structure showing P6/mmm symmetry.[24]

\subsubsection{Microstructural Non-uniformity in UHTC Borides}

As already discussed, for synthesis of boron-containing ceramics such as UHTC borides using CTR method, $\mathrm{B}_{2} \mathrm{O}_{3}$ is the favorable boron precursor as it is much less expensive when compared with elemental boron. However, rapid coarsening of boron containing high temperature ceramics such as $\mathrm{B}_{4} \mathrm{C}$ is reported to happen due to the liquid $\mathrm{B}_{2} \mathrm{O}_{3}$, which remains in the system even at moderate temperatures [69]. Moreover, due to rapid evaporation of boron trioxide at temperatures above $1100{ }^{\circ} \mathrm{C}$, excess amount of $\mathrm{B}_{2} \mathrm{O}_{3}$ is often added to compensate for boron loss during the synthesis process. This excess liquid $\mathrm{B}_{2} \mathrm{O}_{3}$ presents at elevated temperatures facilitates mass transport leading to excessive grain growth. However, observation of morphological non-uniformity during the synthesis of boron-containing ceramics including UHTC borides are not limited to the synthesis methods in which $\mathrm{B}_{2} \mathrm{O}_{3}$ is used as the boron source. For example, Zhang et al. [31] synthesized $\mathrm{TaB}_{2}$ powders using $\mathrm{Ta}_{2} \mathrm{O}_{5}, \mathrm{~B}_{4} \mathrm{C}$ and graphite at $1600{ }^{\circ} \mathrm{C}$. However, they also observed a significant non-uniformity in $\mathrm{TaB}_{2}$ product morphology including both 
needle-like $(5 \mu \mathrm{m})$ and round particles $(0.4 \mu \mathrm{m})$. Guo et al. [70] has synthesized $\mathrm{ZrB}_{2}$ powders via $\mathrm{BTR}$ method at $1550{ }^{\circ} \mathrm{C}$ using $\mathrm{ZrO}_{2}$ and $\mathrm{B}$ as the zirconium and boron sources. However, despite the use of boron instead of $\mathrm{B}_{2} \mathrm{O}_{3}$, they also observed noticeable coarsening of the synthesized $\mathrm{ZrB}_{2}$ powders $(\sim 2-3 \mu \mathrm{m})$. These observations could be explained by considering the side reactions that might occur during the synthesis process of these borides. For example, for the synthesis of $\mathrm{ZrB}_{2}$ via the BTR method, it has been shown that $\mathrm{ZrO}_{2}$ could react with elemental boron to form liquid $\mathrm{B}_{2} \mathrm{O}_{3}$ phase at temperatures below $1200^{\circ} \mathrm{C}$ based on the following reaction:

$3 \mathrm{ZrO}_{2}(\mathrm{~s})+10 \mathrm{~B}(\mathrm{~s}) \rightarrow 3 \mathrm{ZrB}_{2}(\mathrm{~s})+2 \mathrm{~B}_{2} \mathrm{O}_{3}(\mathrm{l})$

Therefore, the formation of liquid $\mathrm{B}_{2} \mathrm{O}_{3}$ during the BTR process seems inevitable. To deal with this, Guo et al. proposed a two-step BTR route, in which the sample was washed with hot water after 2 hours of BTR reaction at $1000{ }^{\circ} \mathrm{C}$ to remove the excess $\mathrm{B}_{2} \mathrm{O}_{3}$. The residual $\mathrm{B}_{2} \mathrm{O}_{3}$ was further eliminated by heat treating the sample at higher temperature of $1550{ }^{\circ} \mathrm{C}$ for one hour to remove the remained residual $\mathrm{B}_{2} \mathrm{O}_{3}$. Compared with the sample synthesized in a single step BTR at $1550{ }^{\circ} \mathrm{C}$ for one hour, this sample contains smaller particles $(0.4-0.7 \mu \mathrm{m}$ vs $2-3 \mu \mathrm{m})$. However, this method still could not lead to synthesis of nanocrystalline $\mathrm{ZrB}_{2}$ due to the further annealing at higher temperature of $1550{ }^{\circ} \mathrm{C}$.

For the synthesis of $\mathrm{TaB}_{2}$ using $\mathrm{Ta}_{2} \mathrm{O}_{5}, \mathrm{~B}_{4} \mathrm{C}$ and graphite the reaction might happen via two different routes:

single-step route:

$$
\mathrm{Ta}_{2} \mathrm{O}_{5}(\mathrm{~s})+\mathrm{B}_{4} \mathrm{C}(\mathrm{s})+4 \mathrm{C}(\mathrm{s}) \rightarrow 2 \mathrm{TaB}_{2}(\mathrm{~s})+5 \mathrm{CO}(\mathrm{g})
$$


two-step route:

$3 \mathrm{Ta}_{2} \mathrm{O}_{5}(\mathrm{~s})+5.5 \mathrm{~B}_{4} \mathrm{C}(\mathrm{s}) \rightarrow 6 \mathrm{TaB}_{2}(\mathrm{~s})+5 \mathrm{~B}_{2} \mathrm{O}_{3}+5 \mathrm{CO}(\mathrm{g})$

$\mathrm{Ta}_{2} \mathrm{O}_{5}(\mathrm{~s})+2 \mathrm{~B}_{2} \mathrm{O}_{3}(\mathrm{~s})+11 \mathrm{C} \rightarrow 2 \mathrm{TaB}_{2}(\mathrm{~s})+11 \mathrm{CO}(\mathrm{g})$

Eq. 2.18

Eq. 2.16 is thermodynamically favorable at temperatures above $1064{ }^{\circ} \mathrm{C}$ when $\mathrm{pCO}=1 \mathrm{~atm}$, while $\Delta \mathrm{G}^{\circ}$ for the Eq. 2.17 is negative at all temperatures, which makes this reaction thermodynamically favorable at all temperatures. Therefore, $\mathrm{B}_{2} \mathrm{O}_{3}$ would always form during the synthesis procedure despite the use of $\mathrm{B}_{4} \mathrm{C}$ as the boron source.

All these observations confirm that $\mathrm{B}_{2} \mathrm{O}_{3}$ (as a boron precursor or reaction byproduct) is the main factor responsible for the abnormal grain growth of the UHTC borides during the synthesis process. 
Chapter III: Morphological Variation in the Formation of $\mathrm{B}_{4} \mathrm{C}$ via CTR

This chapter details the study on synthesis and understanding the morphological variation of $\mathrm{B}_{4} \mathrm{C}$ during the CTR process.

\subsection{Introduction}

Boron carbide $\left(\mathrm{B}_{4} \mathrm{C}\right)$ is considered as one of the hardest materials known after diamond and cubic boron nitride (c-BN). Possessing this interesting quality paves the way for use of $\mathrm{B}_{4} \mathrm{C}$ in different applications, such as abrasive materials for polishing, lapping, cutting tools and ceramic armor for protecting civilian and armed forces $[29,44]$ Reducing $\mathrm{B}_{4} \mathrm{C}$ particle size to the submicron range is desirable as it helps improve mechanical properties of the sintered ceramics. For example, Moshtaghioun et al. [71] showed that by reducing the $\mathrm{B}_{4} \mathrm{C}$ grain size from $17.2 \mu \mathrm{m}$ to $690 \mathrm{~nm}$, the experimentally measured hardness increased from $29 \pm 2$ to $34 \pm 2 \mathrm{GPa}$, which is consistent with the Hall-Petch equation. Reducing $\mathrm{B}_{4} \mathrm{C}$ particle size is also beneficial because it helps simplify the post-synthesis processing such as milling/grinding, and improve the sintering activity.

Different methods, such as elemental synthesis [34,72,73], magnesiothermic reduction, carbothermal reduction (CTR) [40,41], chemical vapor deposition (CVD) $[34,72]$, have been used to synthesize fine submicron and even nano $\mathrm{B}_{4} \mathrm{C}$ powders. Among them, elemental synthesis is not economically favorable for industrial manufacturing due to the high cost of elemental boron and high synthesis temperature $\left(1800-2200^{\circ} \mathrm{C}\right)[73]$. For magnesiothermic reduction method, the final synthesized powders are generally contaminated with magnesium compounds, which cannot be easily 
removed even by applying hot acids[35,40,72,74,75]. CVD method also is not suitable due to the high cost of gaseous materials and complex equipment [34].

Among all these methods, CTR is most commonly carried out due to its costeffectiveness and uncomplicated equipment. Additionally, the CTR method provides the greatest flexibility to modify the starting materials and processing conditions to control the product microstructure (e.g., particle size and uniformity) and composition. Eq. 3.1 is the general reaction for the synthesis of $\mathrm{B}_{4} \mathrm{C}$ using the CTR method:

$$
2 \mathrm{~B}_{2} \mathrm{O}_{3}(\mathrm{l}, \mathrm{g})+7 \mathrm{C}(\mathrm{s})=\mathrm{B}_{4} \mathrm{C}(\mathrm{s})+6 \mathrm{CO}(\mathrm{g})
$$

Synthesis of $\mathrm{B}_{4} \mathrm{C}$ submicron and nanoparticles using CTR method has been studied for some time $[40,41,43,47,76]$. Weimer et al. [40,41] have synthesized fine uniform $\mathrm{B}_{4} \mathrm{C}$ particles $(\sim 50 \mathrm{~nm})$ at $1900^{\circ} \mathrm{C}$ in a graphite transport reactor using rapid $\mathrm{CTR}$ reaction of $\mathrm{B}_{2} \mathrm{O}_{3}$ and cornstarch. Miler et al. [42] also have synthesized submicron $\mathrm{B}_{4} \mathrm{C}$ particles $(\sim 0.4 \mu \mathrm{m})$ through rapid CTR reaction of boric acid and carbon black at $1750^{\circ} \mathrm{C}$ in a specially-designed graphite furnace. Yet, Kakiage et al. [45] synthesized micronsized $\mathrm{B}_{4} \mathrm{C}$ powders using PVA and boric acid through conventional $\mathrm{CTR}$ at a low temperature of $1250^{\circ} \mathrm{C}$.

However, there are not enough studies on in-depth examinations of the interrelationships between composition-processing-microstructure for $\mathrm{B}_{4} \mathrm{C}$ formation via CTR. For example, large variation exists in the literature concerning $\mathrm{B}_{4} \mathrm{C}$ synthesis condition via CTR: $\mathrm{B}_{4} \mathrm{C}$ powder with fine particle size of $\sim 50 \mathrm{~nm}$ was synthesized at a very high temperature of $1900^{\circ} \mathrm{C}[40,41]$, whereas coarse $\sim 5 \mu \mathrm{m} \quad \mathrm{B}_{4} \mathrm{C}$ powder was synthesized at a very modest temperature of $1250^{\circ} \mathrm{C}$ [45] using essentially the same kinds of starting materials. How to explain such seemingly counter-intuitive observation was 
unclear. Another example is related to the large variability in the morphology of synthesized $\mathrm{B}_{4} \mathrm{C}$ powders: different size and shaped particles from tens of micron-sized elongated platelets to micron/submicron-sized polyhedral particles and even nano uniaxial particles all appeared in a relatively pure $\mathrm{B}_{4} \mathrm{C}$ product synthesized at $1450^{\circ} \mathrm{C}$ from homogenous precursors, as reported in our previous work [74]. Such an observation also seems to occur in some other studies on the synthesis of $\mathrm{B}_{4} \mathrm{C}$ powders $[28,30,69,77]$, but how to explain such variation in the product morphology was also unclear.

Hence, understanding all these is critical to improve control of $\mathrm{B}_{4} \mathrm{C}$ production with desired particle size and morphology for industrial applications. In this study, the effects of CTR processing conditions (i.e., temperature, time and heating rate), atmosphere (i.e., argon flow rate), $\mathrm{B}_{2} \mathrm{O}_{3}: \mathrm{C}$ molar ratio, precursors type and moisture absorption of pyrolyzed powders are investigated. The most critical factors influencing the uniformity and morphology of $\mathrm{B}_{4} \mathrm{C}$ powders are identified. The variation in morphology development is explained according to considerations from CTR reaction kinetics, and the most favorable condition to obtain uniform-sized fine $\mathrm{B}_{4} \mathrm{C}$ powders is recommended based on observations in this study.

\subsection{Experimental}

For $\mathrm{B}_{4} \mathrm{C}$ synthesis, the method follows typical solution processing $[43,45-$ 47,74,76] Boric acid (99.99\%, Alfa Aesar \# 36771) was used as a boron source. For the carbon precursor, sucrose (99.5\%, SIGMA \# S9378) and polyvinyl alcohol (PVA, 9899\%, Alfa Aesar \# 41243) were used as low and high molecular weight carbon sources, respectively. Table 3.1 shows the weight ratio of boric acid, sucrose/PVA and expected $\mathrm{B}_{2} \mathrm{O}_{3}: \mathrm{C}$ molar ratios for all recipes. 
Table 3.1: Weight ratio of boric acid, sucrose /PVA for three different recipes

\begin{tabular}{|c|c|c|}
\hline Recipe \# & $\mathrm{H}_{3} \mathrm{BO}_{3}: \mathrm{C}_{12} \mathrm{H}_{22} \mathrm{O}_{11}$ weight ratio & Expected $\mathrm{B}_{2} \mathrm{O}_{3}: \mathrm{C}$ molar ratioa \\
\hline R4 & $1: 0.81:$ & $2: 7^{b}$ \\
\hline $\mathrm{R} 16$ & 1.2 & $1.33: 7^{\mathrm{c}}$ \\
\hline \multicolumn{3}{|c|}{$\mathrm{H}_{3} \mathrm{BO}_{3}$ : PVA weight ratio } \\
\hline RP1 & $: \quad 3.1$ & $1.77: 7$ \\
\hline
\end{tabular}

a. Expected $\mathrm{B}_{2} \mathrm{O}_{3}: \mathrm{C}$ molar ratio before $\mathrm{CTR}$ assuming no $\mathrm{C}$ and $\mathrm{B}_{2} \mathrm{O}_{3}$ loss in pyrolysis.

b. The molar ratio is stoichiometric according to reaction (1)

c. R16 is carbon rich according to reaction (1)

Boric acid and sucrose/PVA were dissolved in deionized hot water and dried at temperatures up to $200^{\circ} \mathrm{C}$ in air. The dried boric acid-sucrose and boric acid-PVA gel were then pyrolyzed following our previous work [74] and Kakiage et al. [45], respectively, to remove water and other volatile species and produce finely mixed $\mathrm{B}_{2} \mathrm{O}_{3}$ C. CTR of pyrolyzed powders was carried out at temperatures in the range of $1150^{\circ} \mathrm{C}$ to $1750^{\circ} \mathrm{C}$ for different holding times in flowing argon atmosphere in a tube furnace. The typical heating rate was $10^{\circ} \mathrm{C} / \mathrm{min}$ and typical argon flow rate was $80 \mathrm{cc} / \mathrm{min}$. Moreover, a higher argon flow rate of $800 \mathrm{cc} / \mathrm{min}$ was also applied to study the effect of argon flow rate on $\mathrm{B}_{4} \mathrm{C}$ product morphology. Due to limited heating/cooling capability for the tube furnace used, a ceramic micro-reactor set up was designed to realize CTR with a very fast heating rate (measured up to $\sim 400^{\circ} \mathrm{C} / \mathrm{min}$, named rapid heating rate $\mathrm{CTR}$ hereafter). Figure 3.1 shows the schematic of the set up. The set up consists of $6.35 \mathrm{~mm}$ OD one-end closed alumina tube to carry the pyrolyzed powders. The open end of the alumina tube was hinged to a T-connector to provide gas inlet and outlet (through another $3.18 \mathrm{~mm}$ OD alumina tube). The tube furnace was preheated to $1750^{\circ} \mathrm{C}$ and the micro-reactor set up 
was pushed into the hot zone to achieve a very high heating rate. The sample was held in the hot zone of the furnace for 3 minutes and withdrawn. Table 3.2 shows the summary of all experimental conditions conducted in this work.
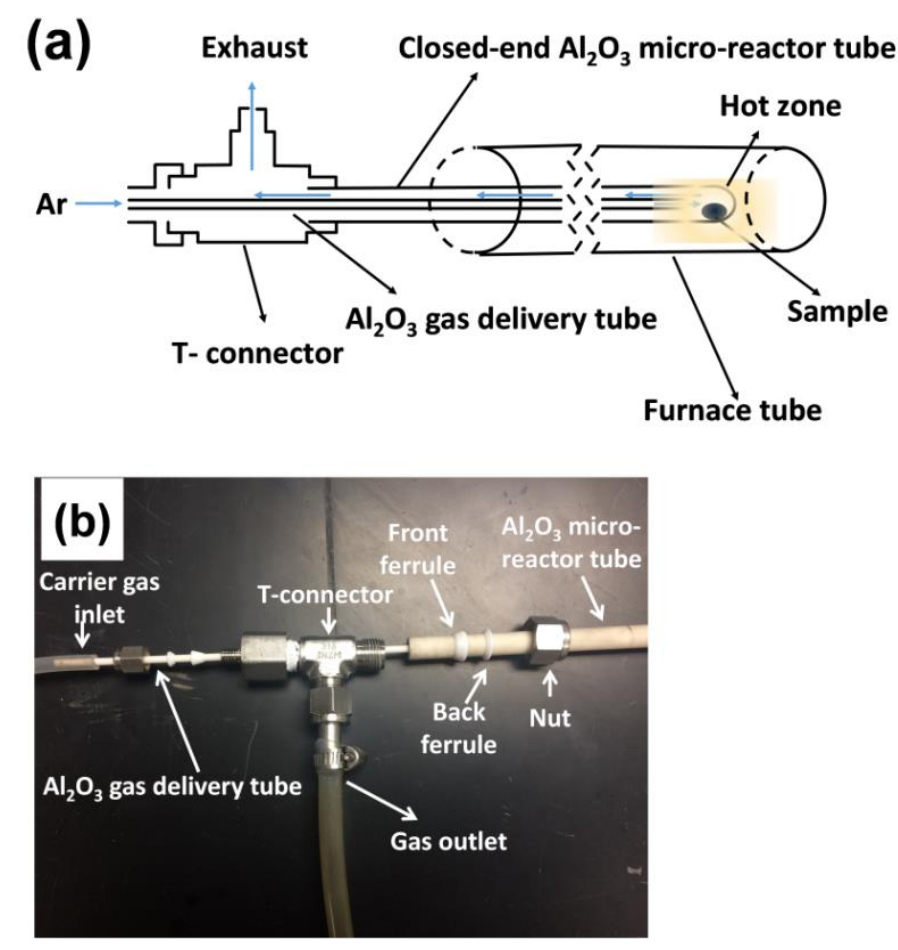

Figure 3.1: Schematic (a) and exploded view (b) of the set-up (micro-reactor) for rapid heating rate CTR experiment.

Table 3.2: Summary of the experimental conditions in this work

\begin{tabular}{cccccc}
\hline $\begin{array}{c}\text { Sampl } \\
\text { e \# }\end{array}$ & Recipe & $\begin{array}{c}\text { CTR } \\
\text { temperature }\end{array}$ & $\begin{array}{c}\text { CTR } \\
\text { holding time }\end{array}$ & $\begin{array}{c}\text { CTR } \\
\text { heating rate }\end{array}$ & $\begin{array}{c}\text { Ar } \\
\text { flow rate }\end{array}$ \\
\hline 1 & $\mathrm{R} 4$ & $1750^{\circ} \mathrm{C}$ & $3 \mathrm{mins}$ & $400^{\circ} \mathrm{C} / \mathrm{min}$ & $80 \mathrm{cc} / \mathrm{min}$ \\
2 & $\mathrm{R} 4$ & $1450^{\circ} \mathrm{C}$ & $2 \mathrm{hrs}$ & $10^{\circ} \mathrm{C} / \mathrm{min}$ & $80 \mathrm{cc} / \mathrm{min}$ \\
3 & $\mathrm{R} 4$ & $1450^{\circ} \mathrm{C}$ & $2 \mathrm{hrs}$ & $10^{\circ} \mathrm{C} / \mathrm{min}$ & $800 \mathrm{cc} / \mathrm{min}$ \\
4 & $\mathrm{R} 4$ & $1450^{\circ} \mathrm{C}$ & $20 \mathrm{mins}$ & $10^{\circ} \mathrm{C} / \mathrm{min}$ & $80 \mathrm{cc} / \mathrm{min}$ \\
5 & $\mathrm{R} 4$ & $1350^{\circ} \mathrm{C}$ & $2 \mathrm{hrs}$ & $10^{\circ} \mathrm{C} / \mathrm{min}$ & $80 \mathrm{cc} / \mathrm{min}$ \\
6 & $\mathrm{R} 4$ & $1350^{\circ} \mathrm{C}$ & $20 \mathrm{mins}$ & $10^{\circ} \mathrm{C} / \mathrm{min}$ & $80 \mathrm{cc} / \mathrm{min}$ \\
7 & $\mathrm{R} 4$ & $1250^{\circ} \mathrm{C}$ & $5 \mathrm{hrs}$ & $10^{\circ} \mathrm{C} / \mathrm{min}$ & $80 \mathrm{cc} / \mathrm{min}$ \\
8 & $\mathrm{R} 4$ & $1150^{\circ} \mathrm{C}$ & $24 \mathrm{hrs}$ & $10^{\circ} \mathrm{C} / \mathrm{min}$ & $80 \mathrm{cc} / \mathrm{min}$ \\
9 & $\mathrm{R} 16$ & $1450^{\circ} \mathrm{C}$ & $2 \mathrm{hrs}$ & $10^{\circ} \mathrm{C} / \mathrm{min}$ & $80 \mathrm{cc} / \mathrm{min}$ \\
10 & $\mathrm{R} 16$ & $1250^{\circ} \mathrm{C}$ & $2 \mathrm{hrs}$ & $10^{\circ} \mathrm{C} / \mathrm{min}$ & $80 \mathrm{cc} / \mathrm{min}$ \\
11 & $\mathrm{RP} 1$ & $1300^{\circ} \mathrm{C}$ & $5 \mathrm{hrs}$ & $10^{\circ} \mathrm{C} / \mathrm{min}$ & $80 \mathrm{cc} / \mathrm{min}$ \\
\hline
\end{tabular}


CTR reaction products were characterized by X-ray diffraction (Siemens D5000) for phase identification. The kinetic data for the formation of $\mathrm{B}_{4} \mathrm{C}$ powder was obtained following the method reported by Weimer et al. [41] based on composition information, which was obtained by applying the Rietveld profile analysis method using Maud software (version 2.0, University of Trento, Lutterotti et al. [78]This method is a whole pattern fitting approach and the refinement occurs by modifying the parameters, such as lattice constants, atomic position, scale factor (to modify the peaks intensities) ,etc. [79] It is assumed in this study that carbon is either released as carbon monoxide (CO) or reacts to form $\mathrm{B}_{4} \mathrm{C}$ or remains as residual carbon. Having said that, the fractional carbon conversion $(\alpha)$ can be calculated from the relative amount of $\mathrm{B}_{4} \mathrm{C}$ and carbon as obtained from quantitative analysis (an example of fractional carbon conversion calculation is Supplementary Materials (1)). In addition, Raman micro-spectroscopy on post CTR samples was also carried out for phase identification in local regions (down to $\sim 10 \mu \mathrm{m}$ diameter range) using an Ar ion laser (Spectra Physics, model 177G02) with a wave length of $514.5 \mathrm{~nm}$. The morphology and particle size of the synthesized powders were studied by a scanning electron microscope (SEM JEOL JSM-6330F). To further investigate the microstructural evolution during the CTR process, a focused ion beam (FIB, JOEL JIB 4500 multibeam) was used to prepare cross sections on the B4C micronsized polyhedral particles in the partially reacted sample, followed by SEM analysis.

\subsection{Results}

\subsubsection{Impacts of CTR Temperature and Time}

Figure 3.2 shows the SEM images of synthesized $\mathrm{B}_{4} \mathrm{C}$ powders from the same batch using recipe $\mathrm{R} 4$ via $\mathrm{CTR}$ at $1450^{\circ} \mathrm{C}$ for 2 hours. The XRD pattern confirms the 
high purity of this sample (see Figure 3.3). On the other hand, as reported before [74] significant non-uniformity in $\mathrm{B}_{4} \mathrm{C}$ product morphology including 10 to 30 micron-sized elongated platelets (see Figure $3.2(\mathrm{~b})$ ), submicron-sized $(<1 \mu \mathrm{m})$ polyhedral particles (see Figure $3.2(\mathrm{c}))$, and also nanoparticles $(\sim 50-80 \mathrm{~nm}$, see Figure 3.2(d)) can all be observed in this sample.
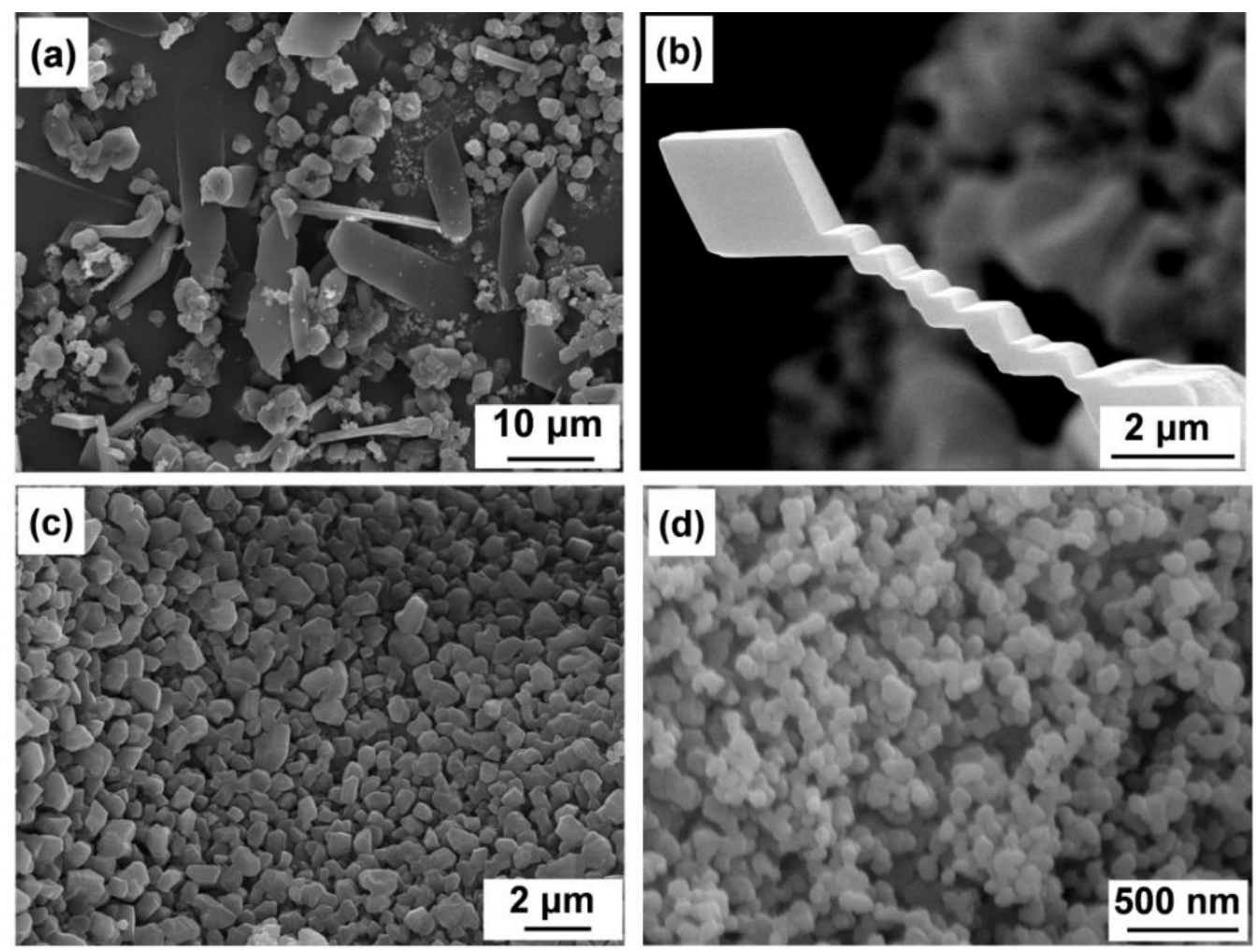

Figure 3.2: SEM micrographs of synthesized $\mathrm{B}_{4} \mathrm{C}$ powders via CTR at $1450^{\circ} \mathrm{C}$ for 2 hours from recipe $\mathrm{R} 4$ (boric acid : sucrose weight ratio $1: 0.81$ ) showing significant non-uniformity in morphology such as micron sized elongated platelets ( $a$ and b), sized particles (c), and nanoparticles (d). 


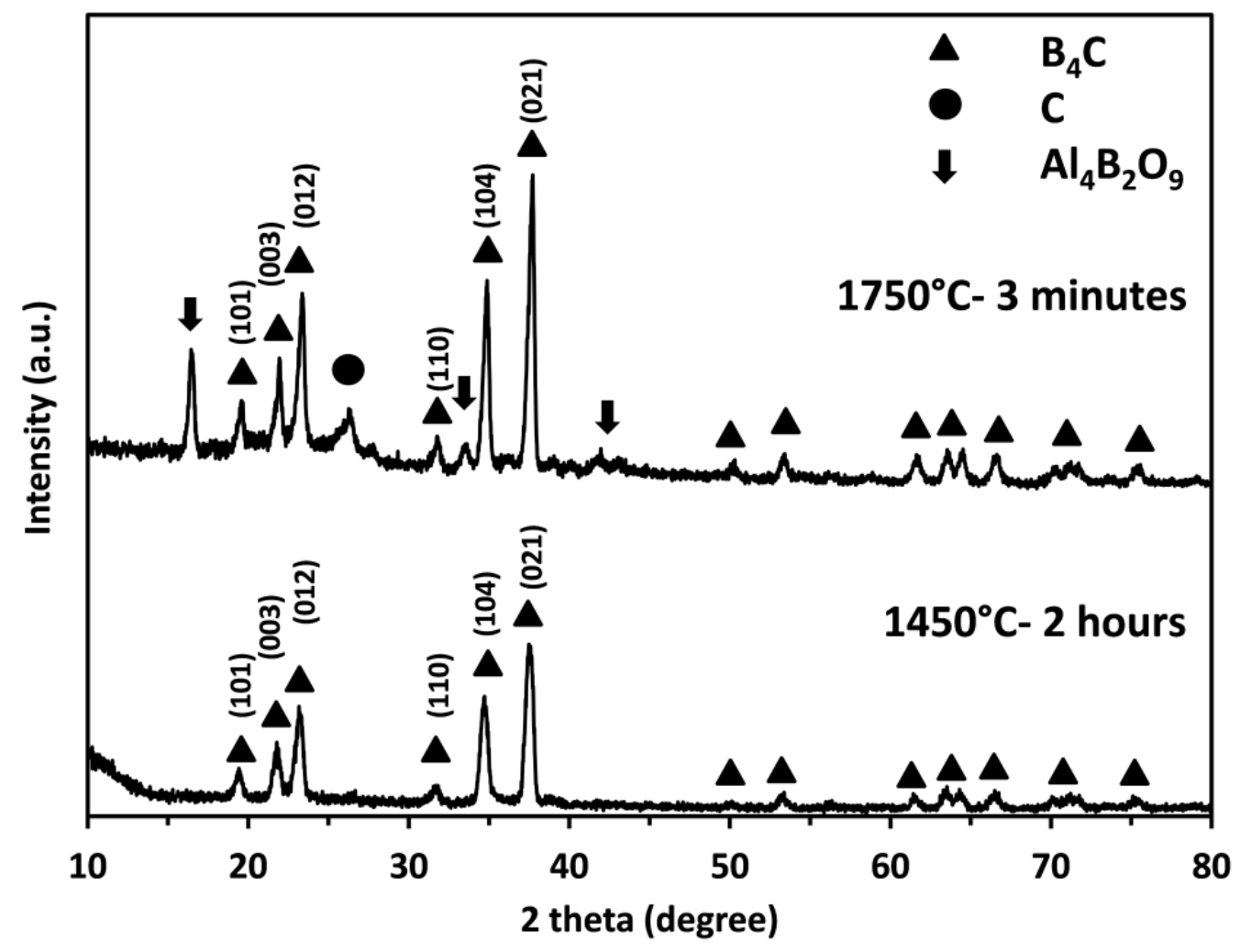

Figure 3.3: XRD patterns of synthesized $\mathrm{B}_{4} \mathrm{C}$ powders via $\mathrm{CTR}$ at $1450^{\circ} \mathrm{C}$ and $1750^{\circ} \mathrm{C}$ for holding time of 2 hours and 3 minutes respectively from recipe $\mathrm{R} 4$ (starting boric acid : sucrose molar ratio $=1: 0.81)$.

Figure 3.4 shows the SEM images of the reaction product obtained from the same recipe $\mathrm{R} 4$ after $\mathrm{CTR}$ at $1450^{\circ} \mathrm{C}$ for only 20 minutes, which is partially reacted based on XRD. On the other hand, for a short CTR holding time of 20 minutes, significant nonuniformity in morphology is already prevalent and all types of morphologies, including elongated platelets, can be observed, as shown in Figure 3.4 (a-c). 

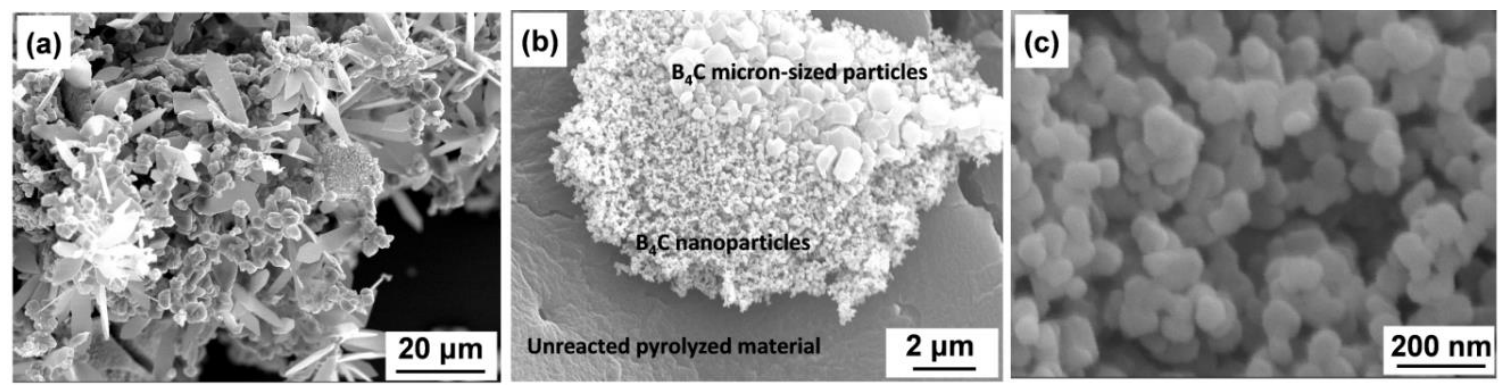

Figure 3.4: SEM micrographs of synthesized $\mathrm{B}_{4} \mathrm{C}$ powders via CTR at $1450^{\circ} \mathrm{C}$ for 20 minutes from recipe $\mathrm{R} 4$ (boric acid : sucrose weight ratio $1: 0.81$ ) showing significant non-uniformity in morphology including micron sized elongated platelets (a), micron and nano-sized polyhedral particles (b), and nanoparticles (c).

Figure 3.5 shows the SEM images of the reaction product using recipe R4 via $\mathrm{CTR}$ at $1250^{\circ} \mathrm{C}$ for 2 hours. Contrary to conventional expectation of smaller particle size at lower temperature, the results show the formation of micron-sized $\mathrm{B}_{4} \mathrm{C}$ particles on the surface of unreacted pyrolyzed powders decorated with nanobelts and nanowires. Additionally, none of the uniaxial nanoparticles as observed before in Figure 3.2(d) were noticed anywhere in this sample. Generally, as a high level of overview, significant nonuniformity in $\mathrm{B}_{4} \mathrm{C}$ product morphology (as shown in Figure 3.2-Figure 3.4) has been observed by the authors for a broad range of CTR temperatures $\left(\sim 1150-1625^{\circ} \mathrm{C}\right)$ and holding times ( 10 minutes-24 hours), and such non-uniformity in product morphology also seems to occur in other studies $[28,30]$. 

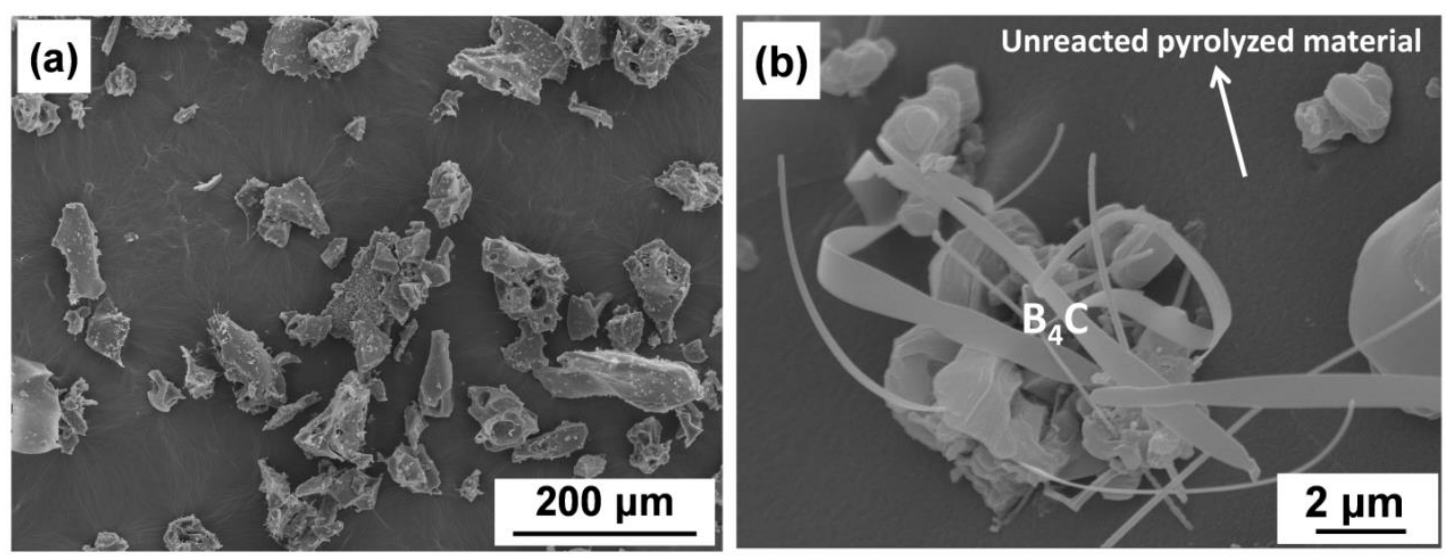

Figure 3.5: SEM micrographs of CTR product at $1250^{\circ} \mathrm{C}$ for 2 hours from recipe R4 (boric acid : sucrose weight ratio $1: 0.81$ ) showing heterogeneous nucleation of $\mathrm{B}_{4} \mathrm{C}$ particles on the surface of a pyrolyzed particle (a), and nucleated micron-sized $\mathrm{B}_{4} \mathrm{C}$ polyhedral particle decorated with nanobelts and nanowires (b).

Figure 3.6 shows SEM images of the rapid heating rate CTR product obtained at $1750^{\circ} \mathrm{C}$ for 3 minutes from the same pyrolyzed material using the micro-reactor described in the experimental section. The product shows uniform $\mathrm{B}_{4} \mathrm{C}$ powders without any large irregular thin elongated platelets or uniaxial nanoparticles. The particle size of the synthesized $\mathrm{B}_{4} \mathrm{C}$ powder is around $400 \mathrm{~nm}$ (estimated from SEM image). The XRD for this sample is given in Figure 3.3, showing primarily $\mathrm{B}_{4} \mathrm{C}$ with a trace of unreacted carbon. Diffraction peaks corresponding to line compound of tetra aluminum diboron oxide $\left(\mathrm{Al}_{4} \mathrm{~B}_{2} \mathrm{O}_{9}\right)$ with JCPDS No. 98-002-7010 were also observed as a contaminant due to side reaction between alumina (from micro-reactor wall) and $\mathrm{B}_{2} \mathrm{O}_{3}$. 


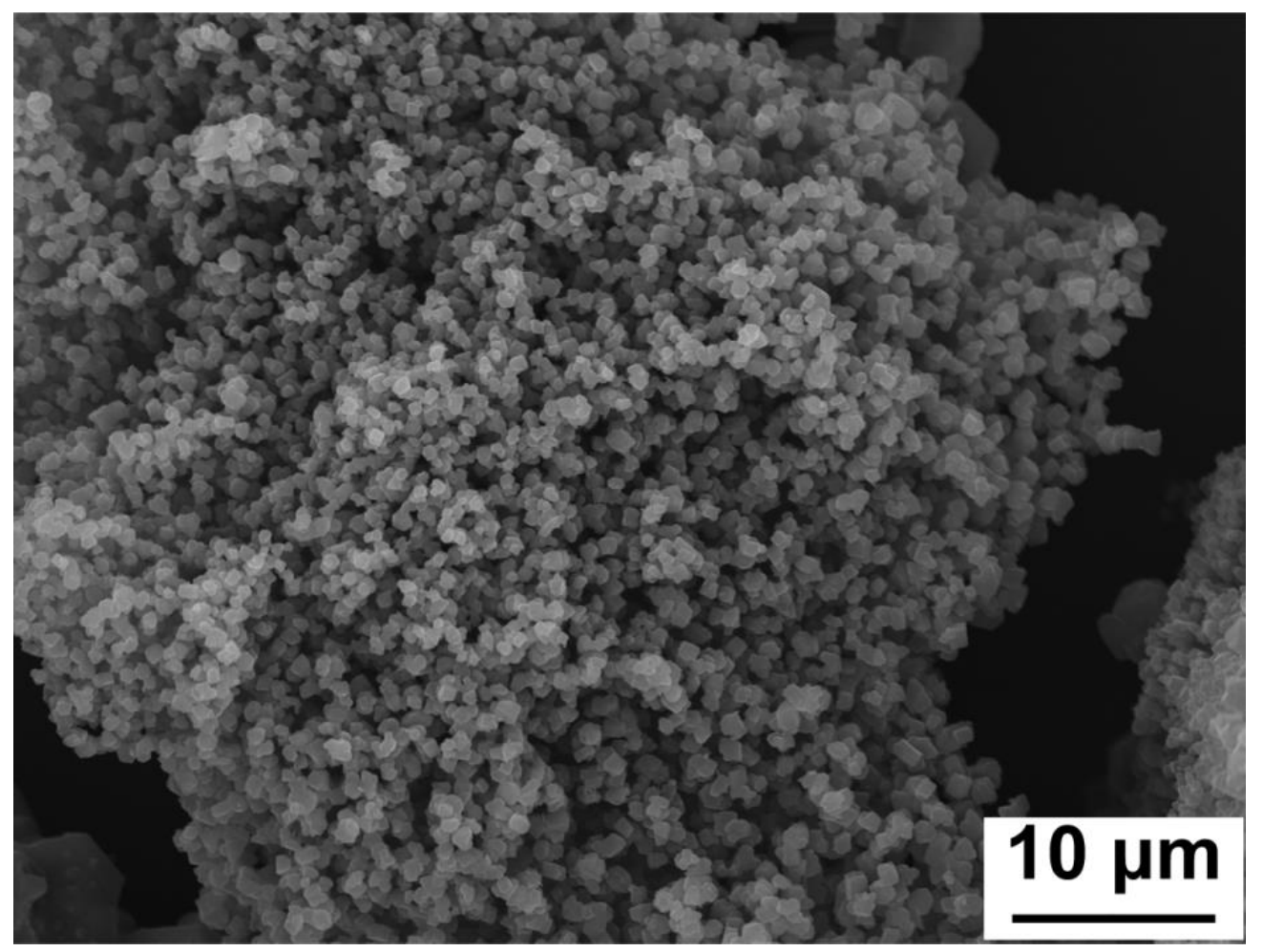

Figure 3.6: SEM micrographs of synthesized $\mathrm{B}_{4} \mathrm{C}$ via rapid heating rate $\mathrm{CTR}$ at $1750^{\circ} \mathrm{C}$ for 3 minutes from recipe $\mathrm{R} 4$ (boric acid : sucrose weight ratio $1: 0.81$ ).

\subsubsection{Impacts of Atmosphere (Ar flow rate)}

Figure 3.7 (a) and Figure 3.7 (b) show low-magnification SEM images of the $\mathrm{B}_{4} \mathrm{C}$ powders synthesized via CTR at $1450^{\circ} \mathrm{C}$ for 2 hours in argon flow rates of $80 \mathrm{cc} / \mathrm{min}$ and $800 \mathrm{cc} / \mathrm{min}$ respectively. As can be seen, micron-sized thin elongated platelets and polyhedral particles still can be observed in the $\mathrm{B}_{4} \mathrm{C}$ product morphology synthesized in high argon flow rate of $800 \mathrm{cc} / \mathrm{min}$. However, compared to $80 \mathrm{cc} / \mathrm{min}$, this sample shows better uniformity and contains, on average, smaller particles. 

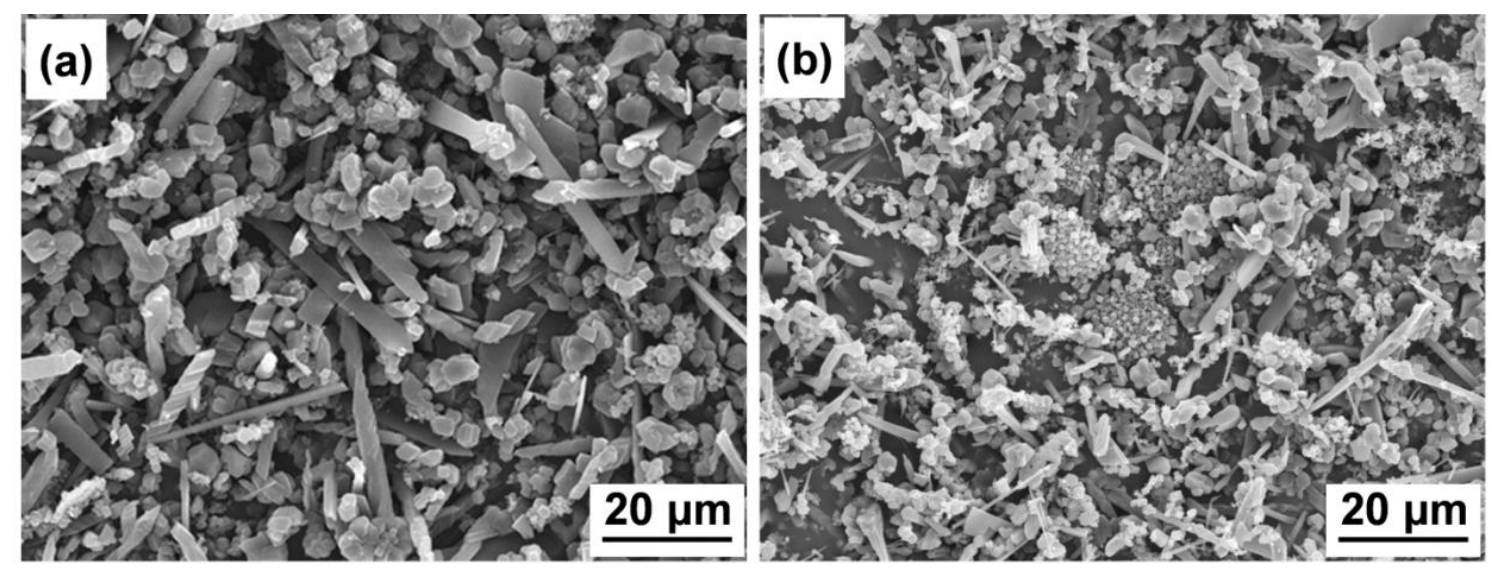

Figure 3.7: SEM micrographs of synthesized $\mathrm{B}_{4} \mathrm{C}$ powders via CTR at $1450^{\circ} \mathrm{C}$ for 2 hours from recipe R4 (boric acid: sucrose weight ratio $1: 0.81$ ) under argon flow rate of $80 \mathrm{cc} / \mathrm{min}(\mathrm{a})$, and $800 \mathrm{cc} / \mathrm{min}(\mathrm{b})$.

\subsubsection{Impacts of $\mathrm{B}_{2} \mathrm{O}_{3}$ : C Molar Ratio}

Figure 3.8 (a) and Figure 3.8 (b) show the SEM images of the $\mathrm{B}_{4} \mathrm{C}$ powders synthesized via CTR at $1450^{\circ} \mathrm{C}$ for 2 hours using recipes $\mathrm{R} 4$ and $\mathrm{R} 16$ (lower $\mathrm{B}_{2} \mathrm{O}_{3}$ : C molar ratio) respectively. Although the CTR process for both recipes was carried out at the same temperature and time, the sample with the lower $\mathrm{B}_{2} \mathrm{O}_{3}$ : C molar ratio (i.e., carbon rich sample) contains smaller particles with more uniformity. However, the X-ray pattern showed that the lower $\mathrm{B}_{2} \mathrm{O}_{3}$ : $\mathrm{C}$ molar ratio results in significant residual carbon in the final $\mathrm{B}_{4} \mathrm{C}$ product [74] 

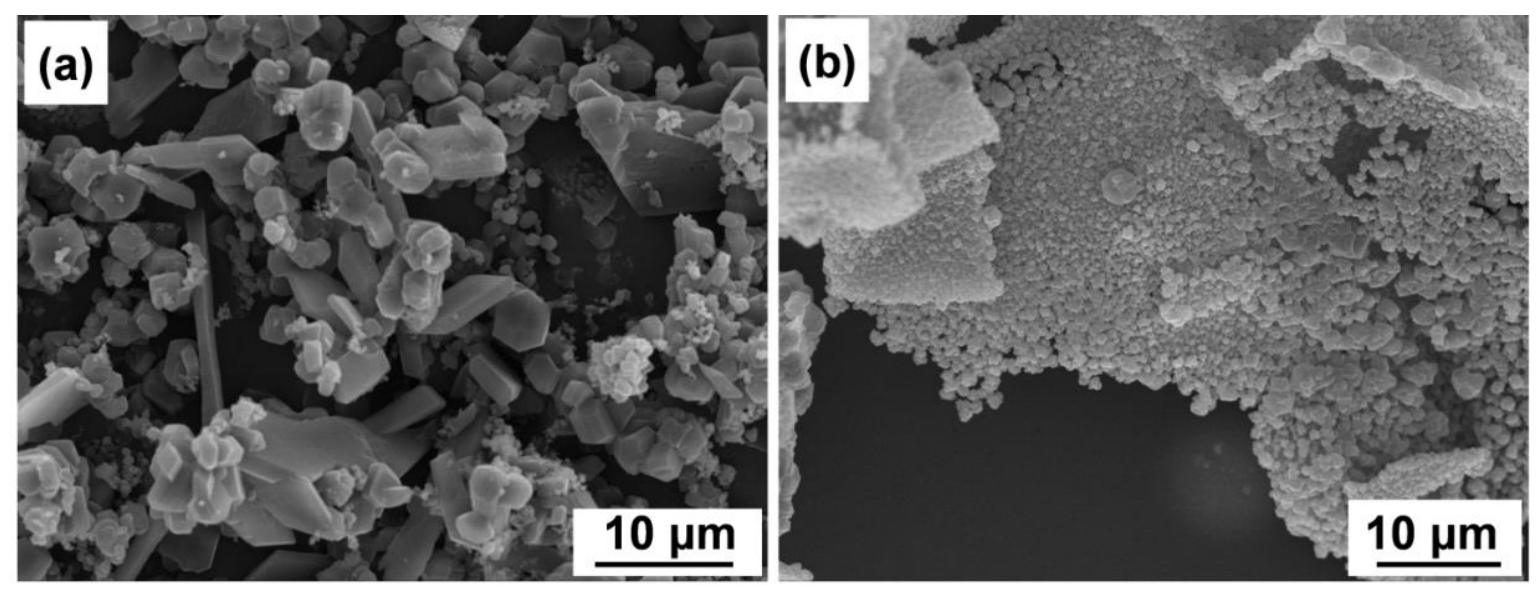

Figure 3.8: SEM micrographs of synthesized $\mathrm{B}_{4} \mathrm{C}$ via CTR at $1450^{\circ} \mathrm{C}$ for 2 hours from recipe R4 (boric acid : sucrose weight ratio $1: 0.81$ ) (a), and recipe R16 (boric acid : sucrose weight ratio $1: 1.2)(b)$.

\subsubsection{Impacts of Carbon Precursor Type}

Figure 3.9 shows the SEM image of the synthesized $\mathrm{B}_{4} \mathrm{C}$ powders via CTR at $1300^{\circ} \mathrm{C}$ for 5 hours using boric acid-PVA as boron and carbon sources in which PVA as a polymer has higher molecular weight of $11000-31000 \mathrm{~g} / \mathrm{mol}$, compared to sucrose (molecular weight of $342 \mathrm{~g} / \mathrm{mol}$ ). XRD suggests the sample is only partially converted. Nevertheless, the morphology is still highly non-uniform and similar to the synthesized $\mathrm{B}_{4} \mathrm{C}$ powders after $\mathrm{CTR}$ at $1250^{\circ} \mathrm{C}$ for 2 hours using recipe $\mathrm{R} 4$ with sucrose as the carbon precursor: micron-sized $(\sim 5 \mu \mathrm{m}) \mathrm{B}_{4} \mathrm{C}$ polyhedral particles along with smaller ones $(\sim 0.5-$ $1 \mu \mathrm{m})$ were formed heterogeneously on the surface of pyrolyzed powders and no $\mathrm{B}_{4} \mathrm{C}$ nanoparticles were detected. 

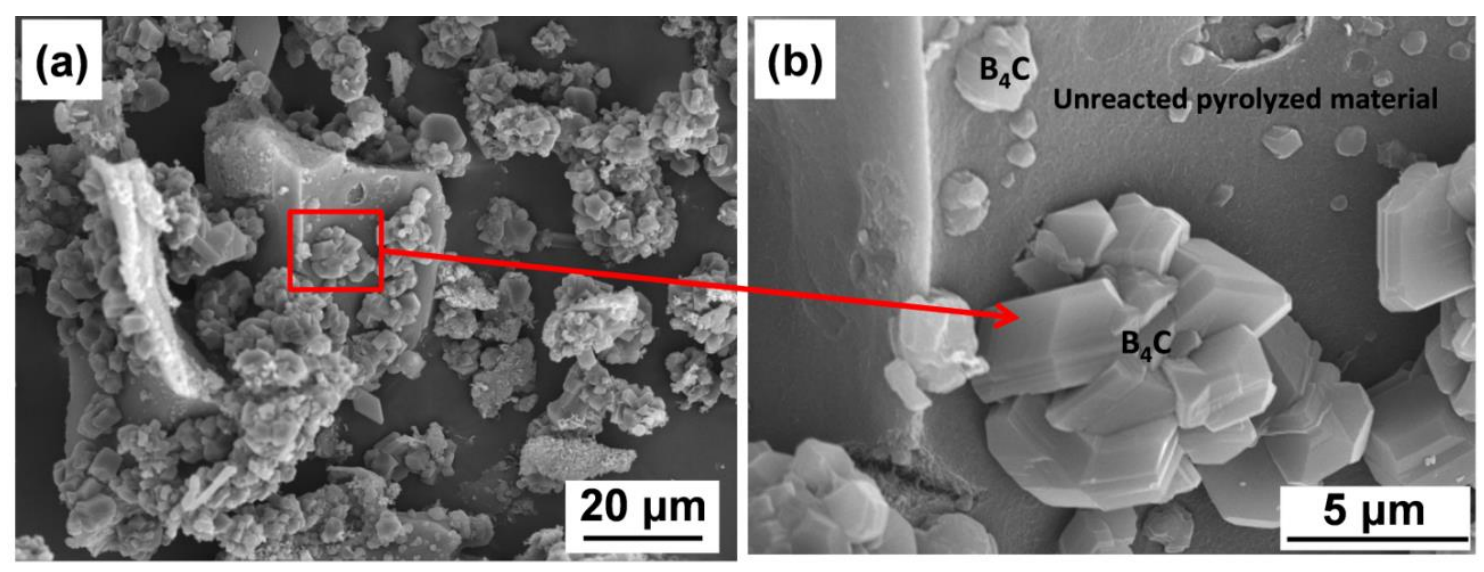

Figure 3.9: SEM micrographs of CTR product at $1300^{\circ} \mathrm{C}$ for 5 hours from recipe RP1 using PVA as carbon precursor (boric acid : PVA weight ratio $1: 3.1$ ).

3.3.5 Impacts of Aging after CTR (For Partially Reacted Sample that Still Contains $\mathrm{B}_{2} \mathrm{O}_{3}$

Figure 3.10 (a) is the SEM image of the partially reacted sample heat treated at $1350^{\circ} \mathrm{C}$ for 20 minutes showing unreacted pyrolyzed powders decorated with some layered structures. In comparison, Figure 3.10 (b) shows the SEM image of this sample after aging for 6 months. After aging, the morphology changed dramatically: the powder surface became decorated with highly crystalline $\sim 5-10$ micron-sized particles. To find out what these crystals are, Raman micro-spectrometry measurement was done by focusing the laser on one of the formed crystals (see Figure 3.11). Two Raman peaks were detected at peak shifts of $\sim 500$ and $880 \mathrm{~cm}^{-1}$ which match with the strongest Raman peaks for boric acid [80]. 

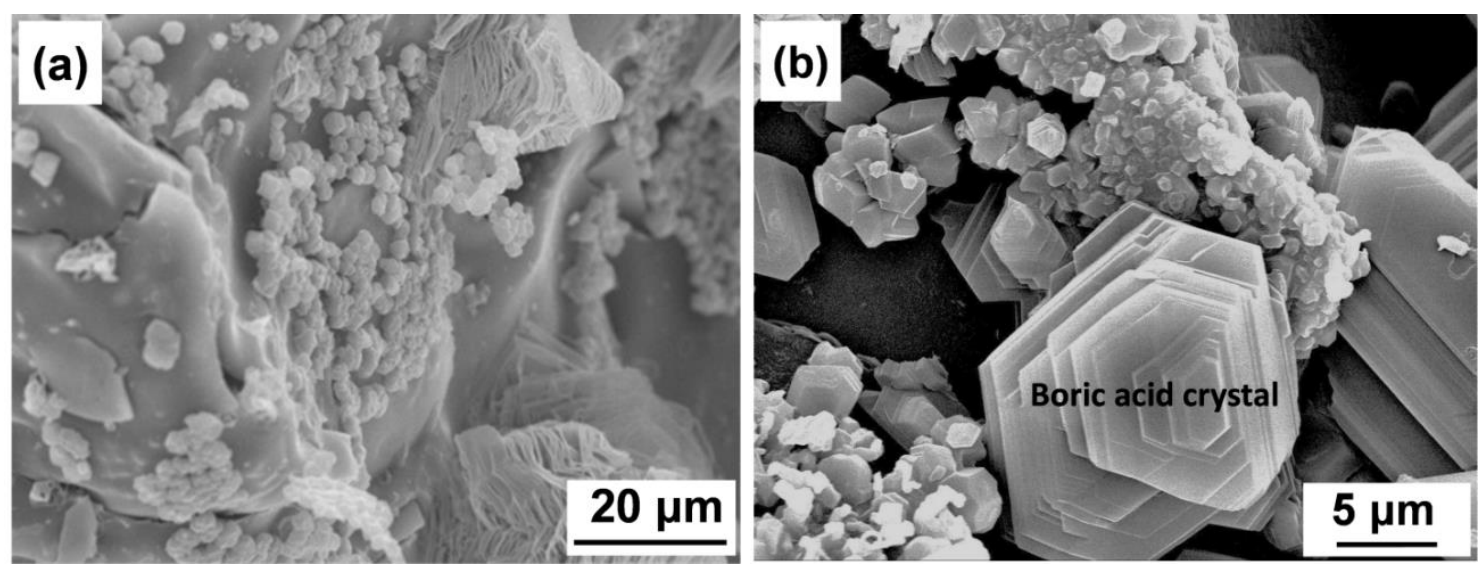

Figure 3.10: SEM micrographs of synthesized $\mathrm{B}_{4} \mathrm{C}$ after CTR at $1350^{\circ} \mathrm{C}$ for 20 minutes from recipe R4 (boric acid : sucrose weight ratio $1: 0.81$ ) before aging (a), and after aging for 6 months (b).

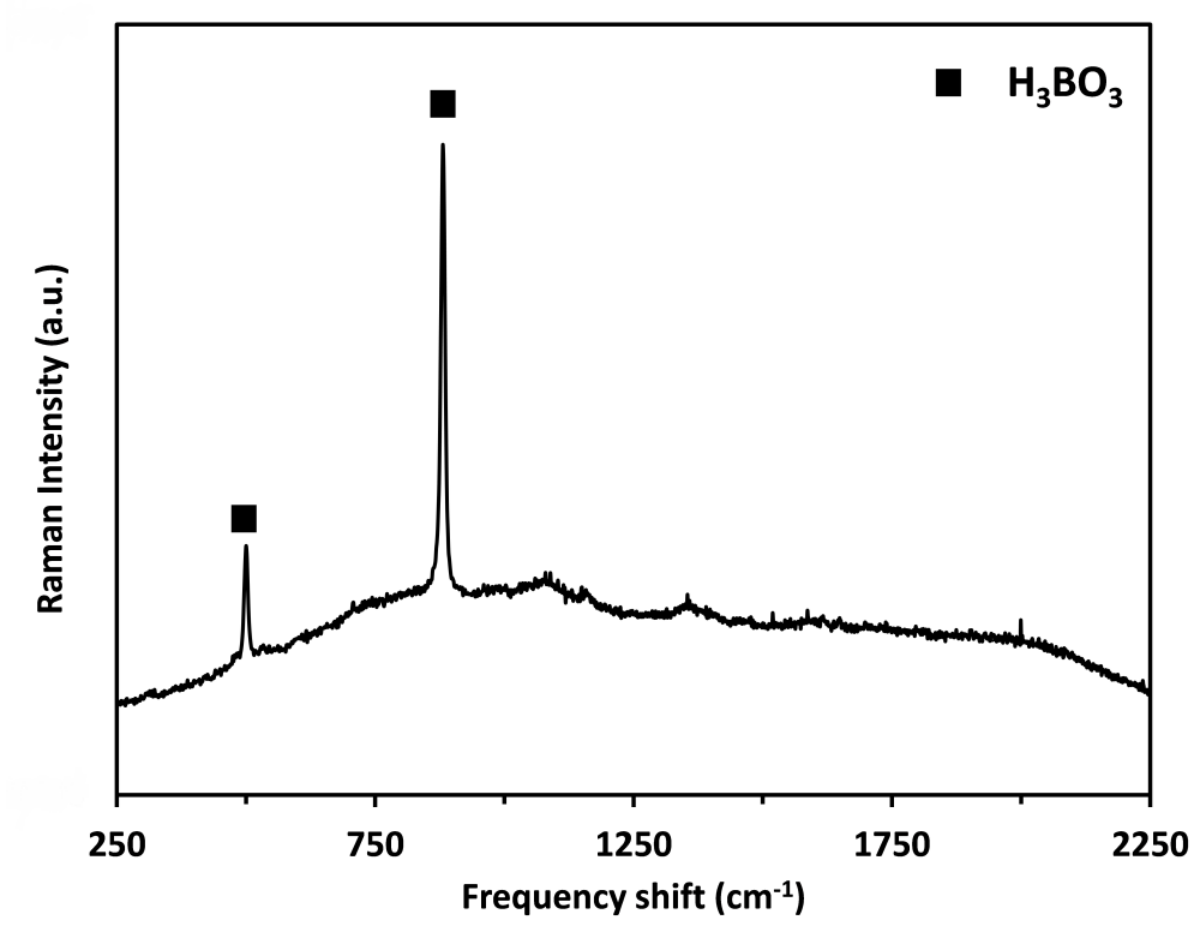

Figure 3.11: Raman spectra of the formed crystal in post CTR sample at $1350^{\circ} \mathrm{C}$ for 20 minutes from recipe $\mathrm{R} 4$ ((boric acid : sucrose weight ratio $1: 0.81$ ).

\subsection{Discussion}

To explain such non-uniformity in the formation of $\mathrm{B}_{4} \mathrm{C}$ powders via $\mathrm{CTR}$ and quest for better control of product morphology, some understanding about kinetics and mechanism of $\mathrm{B}_{4} \mathrm{C}$ formation via CTR reaction is essential. During the CTR process, 
at temperatures above the melting point of $\mathrm{B}_{2} \mathrm{O}_{3}\left(\sim 450^{\circ} \mathrm{C}\right)$, carbon particles are dispersed into the liquid $\mathrm{B}_{2} \mathrm{O}_{3}$ and depending on CTR temperature, the reaction could occur through the liquid-solid, gas-liquid-solid, or even gas-solid phase by nucleation and later growth of nuclei. The generalized mathematical formula for nucleation and growth model is given by Erofeyev et al. [81]:

$\ln (1-\alpha)=-(\mathrm{kt})^{\mathrm{m}}$

Where $\alpha$ is the fraction of conversion, $k$ is the reaction rate constant, $t$ is the reaction time and $m$ is the exponent parameter, which can accept values of 1-4 depending on the nucleation rate, growth geometry, and the nature of the reaction rate limiting step $[82,83]$.

Due to the presence of liquid $\mathrm{B}_{2} \mathrm{O}_{3}$ during the CTR process, the diffusion rate of reactants to the favorable reaction sites could be assumed to be fast enough and the CTR reaction for the formation of $\mathrm{B}_{4} \mathrm{C}$ would be interface-controlled, i.e., the arrangement of $\mathrm{B}-\mathrm{C}$ atoms to form $\mathrm{B}_{4} \mathrm{C}$ at the $\mathrm{B}_{2} \mathrm{O}_{3}-\mathrm{C}$ interface would be the rate limiting step. Based on Hulbert et al. [83] when the reaction is interface-controlled, $\mathrm{m}$ could accept values of 3-4 for 3D growth (e.g., sphere) depending on nucleation rate: $\mathrm{m}$ is considered as 4 when the nucleation rate is constant and 3 when the nucleation rate is zero, i.e., instant nucleation at the beginning and saturation of active sites.

Figure 3.12 shows the plot of the reaction rate constant $(\mathrm{k})$ in natural log versus inverse temperature compiled from different groups, including the present study $[28,30,41]$. The reaction rate constant $k$ was estimated by fitting the kinetic data, in particular, fraction of conversion $\alpha$ into Eq. 3.2 for the case of $\mathrm{m}=4$ assuming constant nucleation rate. The data for fraction of conversion $\alpha$ were either calculated based on 
the Rietveld QXRD method (see supplementary materials (1)) or taken directly from the original papers $[28,30]$.

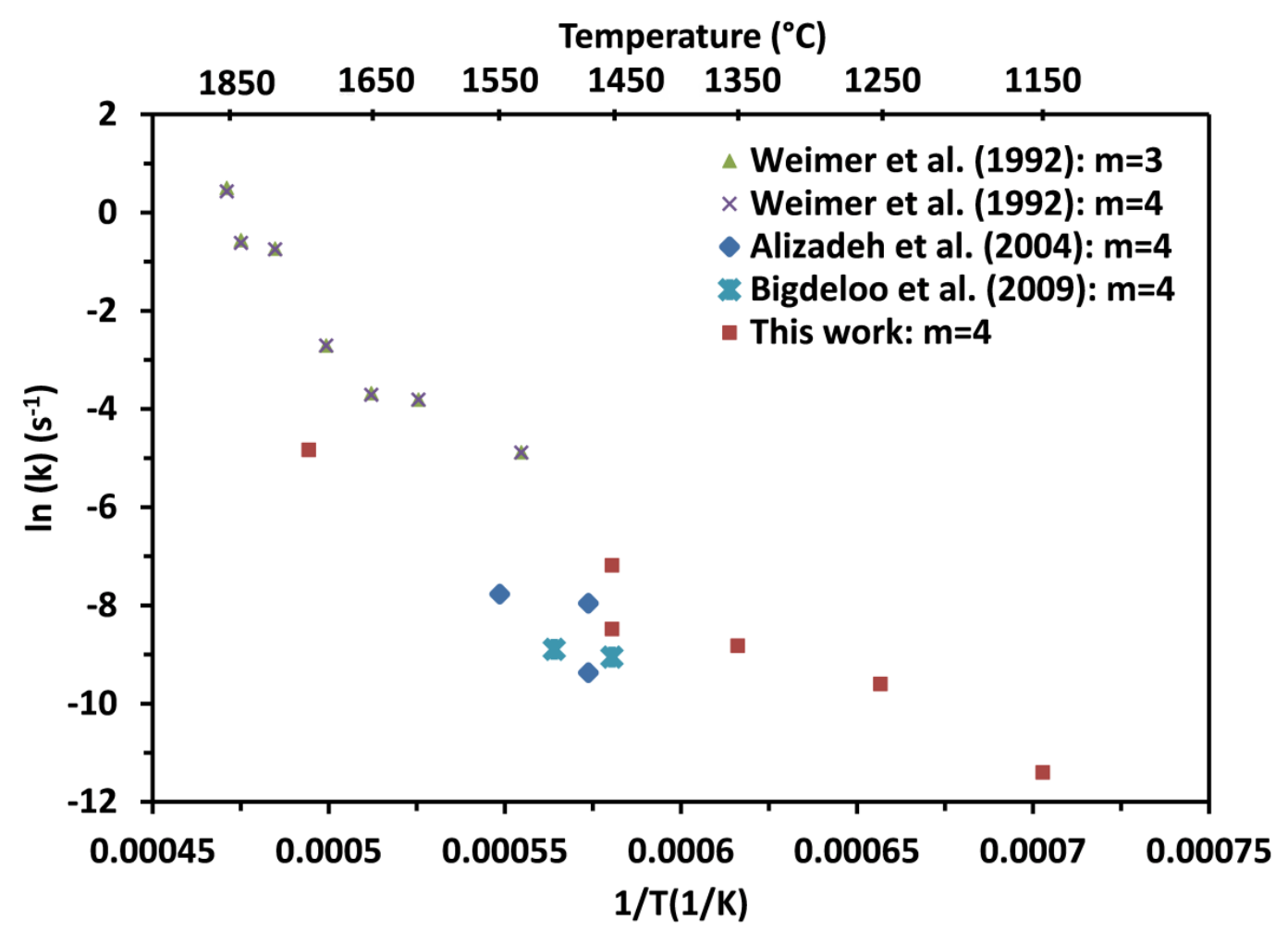

Figure 3.12: Plot of natural log of fitted reaction rate constant $\mathrm{k}$ (in unit of sec-1), $\ln (\mathrm{k})$, versus inverse temperature for formation of $\mathrm{B}_{4} \mathrm{C}$ via $\mathrm{CTR}$ for different data in the literature (i.e., Weimer (1992) [41] , Alizade et al. (2004) [28], Bigdeloo et al. (2009) [30] ), and the current study

Such assumption of $\mathrm{m}=4$ is reasonable, especially at low to intermediate temperatures, since partially reacted CTR samples do not appear to have instant nucleation/saturation of fine, nano $\mathrm{B}_{4} \mathrm{C}$ throughout (e.g., see Figure 3.5). On the other hand, $\mathrm{B}_{4} \mathrm{C}$ nanoparticles were observed in both samples that were heat treated at $1450^{\circ} \mathrm{C}$ for a short holding time of 20 minutes and long holding time of 2 hours. This strongly suggests constant nucleation under that reaction condition (see Figure 3.2 (d) and $3.4(\mathrm{c}))$. 
It is noted that for the kinetic data by Weimer et al. [30] rate constants are calculated for both the case of $\mathrm{m}=4$ assuming constant nucleation rate, as well as the case for $\mathrm{m}=3$, which assumes instant nucleation/site saturation. The later $(\mathrm{m}=3)$ was adopted by Weimer et al.[30]based on the high reaction temperature used and short reaction time within minutes or even seconds. However, the present authors feel that $\mathrm{m}=4$ probably better describes the CTR reaction kinetics, especially at temperature $<\sim 1800^{\circ} \mathrm{C}$ with partial reaction and gradual formation of nuclei even after minutes or longer of reaction time. Based on

Figure 3.12 all available kinetic data, including the present study, are in good agreement with each other $[28,30,41]$ regardless of what type of starting precursors or the reaction temperature/time was used. Such consistency suggests the same underlying reaction mechanism dominating in a wide temperature range from $~ 1100$ $1800^{\circ} \mathrm{C}$. Similar to the observation by Weimer et al. [41] the slope for the natural log of rate constant versus inverse temperature seems to show an abrupt change from above $\sim 1800^{\circ} \mathrm{C}$ : the estimated activation energy above $\sim 1800^{\circ} \mathrm{C}$ is $\sim 820 \mathrm{~kJ} / \mathrm{mol}$ [41] , while below is $327 \mathrm{~kJ} / \mathrm{mol}$ using all data available. The fundamental reason behind this change is not exactly clear at this moment [41].

Nevertheless, as explained, within a large processing window, the reaction appears to follow the same mechanism containing nucleation and growth. Eq. 3.3 shows the nucleation rate based on classical nucleation theory [84].

$\mathrm{I}=\mathrm{I}_{0} \mathrm{~N}_{\mathrm{s}} \exp \left(-\frac{\Delta \mathrm{G}^{*}}{\mathrm{kT}}\right)$

where $\mathrm{I}_{0}$ is frequency of adding one more atom to a nucleus, $\mathrm{N}_{\mathrm{s}}$ is the available nucleation site density and $\Delta G^{*}$ is the nucleation barrier. Different from the 
solidification/precipitation-types of phase transformation in which undercooling is required for the formation of the new phase, the CTR reaction is highly endothermic, i.e., the enthalpy change is positive. Therefore, the driving force for the CTR reaction becomes larger ( $\Delta \mathrm{G}$ becomes more negative) by increasing the temperature. Simple analysis of this case suggests that the nucleation barrier $\left(\Delta G^{*}\right)$ would decrease with increasing temperature (see Supplementary Materials (1)). On the other hand, by assuming that the available nucleation site density is constant for all samples (i.e., $\mathrm{N}_{\mathrm{s}}$ is fixed), it can be concluded from equation (3.3) that the nucleation rate would increase with increasing the CTR temperature. Hence, at low CTR temperatures, a small amount of $\mathrm{B}_{4} \mathrm{C}$ nuclei will form at the favorable reaction sites since the nucleation rate is very slow. After nucleation, CTR proceeds via growth, i.e., attachment of B-C atoms to favorable sites of existing $\mathrm{B}_{4} \mathrm{C}$ nuclei, sometimes leading to one-dimensional growth, as observed for nanowires (see Figure 3.5(b)).

Figure 3.13 shows a schematic illustrating the CTR reaction limited by slow nucleation at low temperatures from the liquid $\mathrm{B}_{2} \mathrm{O}_{3}$-solid carbon intimate mixture. The schematic is supported by actual observation of samples after partial CTR reaction. For example,

Figure 3.13(d) shows the SEM image of the reaction product after CTR at $1150^{\circ} \mathrm{C}$ for 24 hours $(\alpha=0.026)$ from R4. It illustrates the spread out of individual $\sim 5-10$ micronsized $\mathrm{B}_{4} \mathrm{C}$ crystals embedded and emerging out from the surface of pyrolyzed materials. Further examination of these micron-sized $\mathrm{B}_{4} \mathrm{C}$ crystals was done by preparing a cross section and analyzing the junction between pyrolyzed materials and 
the formed $\mathrm{B}_{4} \mathrm{C}$ polyhedral particle using FIB, as shown in Figure 3.14. This image together with Figure 3.13 clearly suggests that during CTR, $\mathrm{B}_{4} \mathrm{C}$ crystals preferably form on the surface of pyrolyzed materials and they grow along certain orientation(s) (as shown by the flat interfaces between $\mathrm{B}_{4} \mathrm{C}$ crystal and surrounding pyrolyzed material). At the same time, the pyrolyzed material nearby gets consumed and recedes.

(a)

(b)
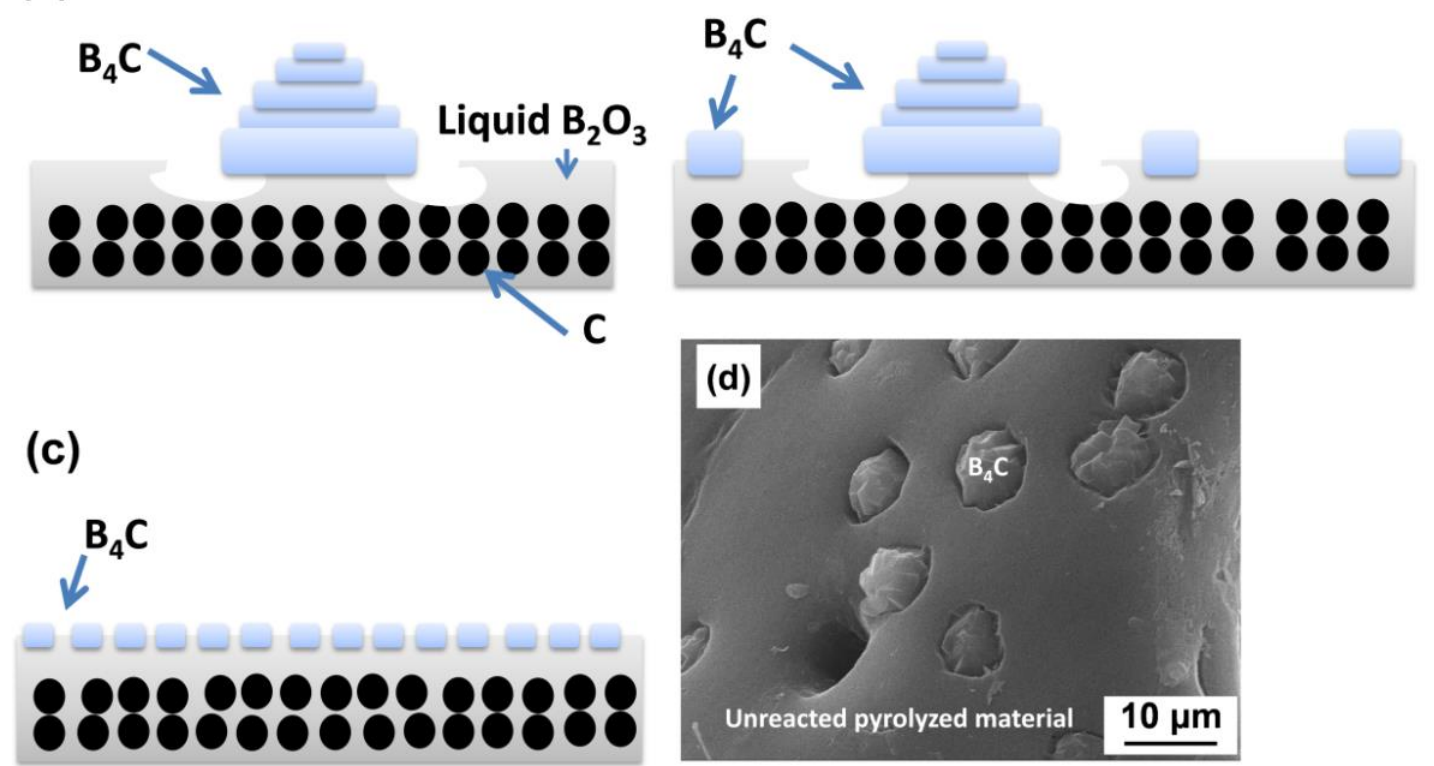

(c)

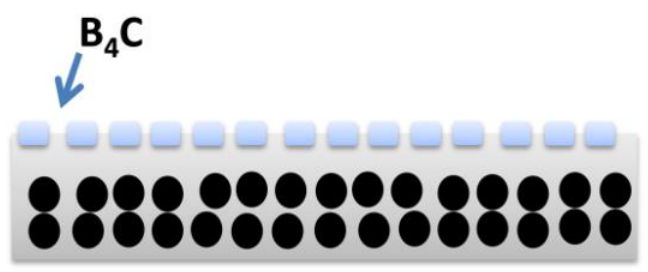

Unreacted pyrolyzed material

Figure 3.13: Schematic of nucleation and growth process via CTR at low CTR temperature (e.g., $1150^{\circ} \mathrm{C}$, which favors growth due to very slow nucleation and results in formation of huge micron-sized $\mathrm{B}_{4} \mathrm{C}$ particles) (a), intermediate CTR temperature (e.g., $1450^{\circ} \mathrm{C}$ when nucleation and growth rates are comparable, resulting in formation of huge $\mathrm{B}_{4} \mathrm{C}$ micron-sized particles accompanied with nanoparticles) (b), very high CTR temperature (e.g., $>1800^{\circ} \mathrm{C}$ which favors nucleation and results in formation of uniform-sized fine $\mathrm{B} 4 \mathrm{C}$ particles (c), and SEM micrograph of the CTR product at $1150^{\circ} \mathrm{C}$ for 24 hours from recipe $\mathrm{R} 4$ (boric acid : sucrose weight ratio $1: 0.81$ ) showing micron-sized heterogeneously distributed $\mathrm{B}_{4} \mathrm{C}$ particles emerging from the surrounding pyrolyzed materials $(d)$ 


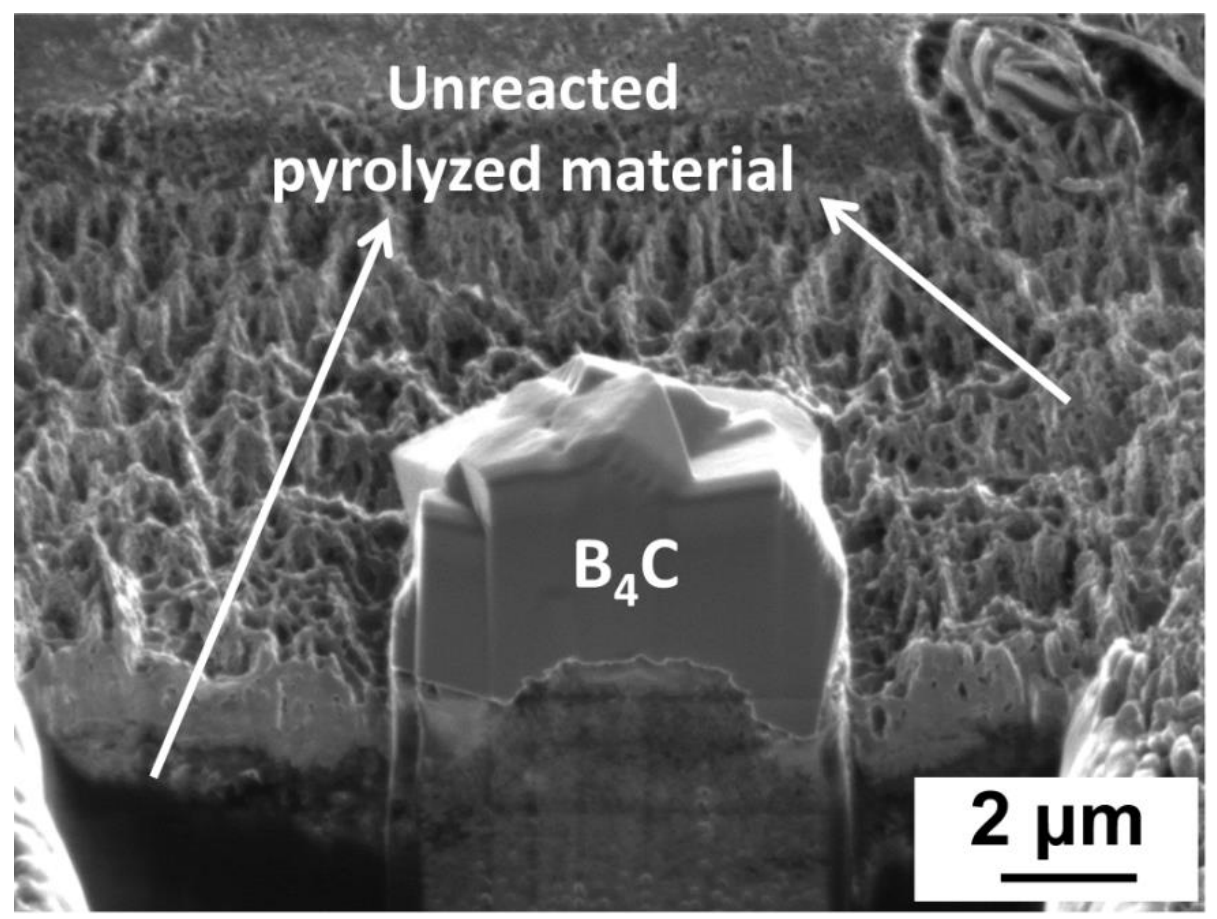

Figure 3.14: FIB micrograph of the junction between pyrolyzed materials and synthesized micron-sized $\mathrm{B}_{4} \mathrm{C}$ polyhedral particle at $1150^{\circ} \mathrm{C}$ for 24 hours.

When the temperature increases to the intermediate range (e.g., $1450^{\circ} \mathrm{C}$ ) the nucleation barrier will decrease (see Supplementary Materials (1)) and, as a result, the nucleation rate will increase. Hence, the $\mathrm{B}_{4} \mathrm{C}$ particles become spaced closer to each other, and in some regions even very fine and uniform nanoparticles are formed due to continuous nucleation. However, the nucleation rate is not high enough to form all the nuclei in the early stage of reaction. Therefore, similar to lower CTR temperatures, CTR also proceeds via growth of formed nuclei, still leading to the formation of micron-sized faceted particles and even elongated platelets (see Figure 2(a-b)). Overall, because the CTR reaction proceeds via both new nucleation and growth of existing ones, the product displays a large variation in morphology, as shown before for the $1450^{\circ} \mathrm{C} / 20$ minutes and $1450^{\circ} \mathrm{C} / 2$ hours samples. 
When the CTR temperature increases further, such as for the sample after CTR at $1750^{\circ} \mathrm{C}$ for 3 minutes, nucleation will be fast due to high reaction temperature and it occurs throughout the pyrolyzed material, as illustrated in the schematic in Figure 3.13. As a result, the sample contains uniform-sized $\mathrm{B}_{4} \mathrm{C}$ powders, while the short, yet still 3minute reaction time, probably explains why the particles are submicron instead of nanosize. Therefore, to obtain uniform nanoparticles while maintaining complete reaction, the synthesis condition of even higher CTR temperatures but shorter CTR holding times needs to be adopted. In fact, Weimer et al. [40] successfully synthesized very fine uniform $\sim 50 \mathrm{~nm}$ particles via $\mathrm{CTR}$ at $1900^{\circ} \mathrm{C}$ and above for less than 3 seconds.

The above discussion shows CTR reaction temperature and associated total reaction time have a dominating role on the product morphology, including uniformity and it can be understood well from the kinetics point of view.

For the influence of Argon flow rate, the calculated free energy change of reaction (1) for different hypothetical carbon monoxide partial pressures using data from JANAF Thermochemical Tables [85] (see Figure S1.3 in Supplementary Materials (1)) shows that, by reducing $\mathrm{pCO}$, the driving force at the same CTR temperature becomes larger ( $\Delta \mathrm{G}$ becomes more negative). It can be easily seen from equation S1.2 in Supplementary Materials (1) that, at a fixed CTR reaction temperature, with increasing driving force via lowering $\mathrm{pCO}$, the nucleation barrier $\Delta \mathrm{G}^{*}$ would decrease. Hence, according to equation 3.3, the nucleation rate would increase. This explains the experimental observation, as shown for Figure 3.7: with higher Argon flow rate of $800 \mathrm{cc} / \mathrm{min}$ versus $80 \mathrm{cc} / \mathrm{min}$, the effective CO partial pressure was decreased. As a result, the nucleation rate become 
faster accompanied by less growth, leading to much smaller and more uniformly shaped $\mathrm{B}_{4} \mathrm{C}$ powders.

For the influence of $\mathrm{B}_{2} \mathrm{O}_{3}: \mathrm{C}$ molar ratio, the observation of finer and more uniform $\mathrm{B}_{4} \mathrm{C}$ for lower $\mathrm{B}_{2} \mathrm{O}_{3}$ : $\mathrm{C}$ ratio (see Figure 3.8(b)) could be explained by the existence of $\mathrm{B}_{2} \mathrm{O}_{3}$ as a liquid during the CTR reaction. Liquid $\mathrm{B}_{2} \mathrm{O}_{3}$ greatly facilitates the mass transfer during CTR via the growth mechanism, leading to the formation of huge, tens of micron-sized elongated platelets. On the other hand, $\mathrm{B}_{2} \mathrm{O}_{3}$ may also function as a flux that promotes coarsening of $\mathrm{B}_{4} \mathrm{C}$ particles [45] (i.e., smaller $\mathrm{B}_{4} \mathrm{C}$ particles merge together into larger $\mathrm{B}_{4} \mathrm{C}$ particles). That lower amount of $\mathrm{B}_{2} \mathrm{O}_{3}$ leading to uniform and smaller $\mathrm{B}_{4} \mathrm{C}$ particles is noticeable at low CTR temperatures. Figure 3.15 shows the SEM image of synthesized $\mathrm{B}_{4} \mathrm{C}$ at $1250^{\circ} \mathrm{C}$ for 5 hours using recipe $\mathrm{R} 16$. For this sample a significant portion of the $\mathrm{B}_{4} \mathrm{C}$ product contains uniform submicron-sized particles ( $\sim 200 \mathrm{~nm})$. On the other hand for the sample synthesized using the $\mathrm{B}_{2} \mathrm{O}_{3}$-rich recipe of $\mathrm{R} 4$ at the same CTR temperature $\left(1250^{\circ} \mathrm{C}\right)$, no nano/submicron particles were noticed (see Figure 3.5).
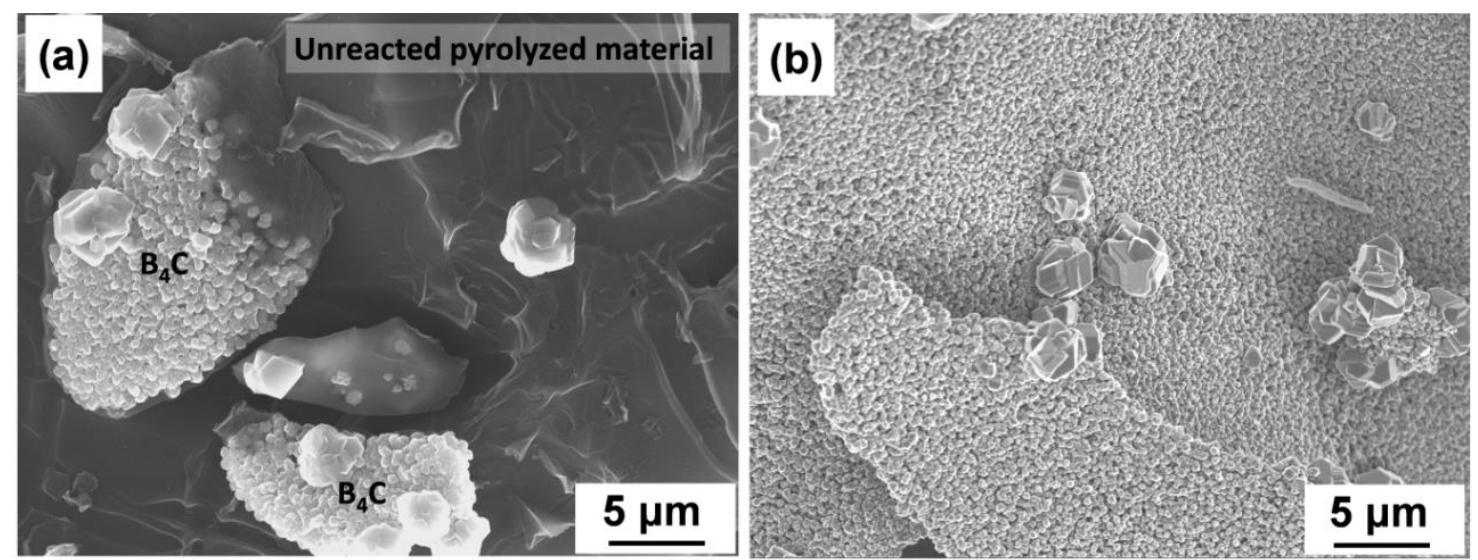

Figure 3.15: SEM micrographs of CTR product at $1250^{\circ} \mathrm{C}$ for 5 hours from recipe R16 (boric acid : sucrose weight ratio $1: 1.2$ ) showing heterogeneous nucleation of submicron and micron $\mathrm{B}_{4} \mathrm{C}$ particles on the surface of pyrolyzed material (a), and uniform submicron $\mathrm{B}_{4} \mathrm{C}$ particles (b). 
For the carbon precursor type, as shown before, even by using the high molecular weight PVA polymer as a carbon source, the CTR products still show the formation of heterogeneously distributed $\mathrm{B}_{4} \mathrm{C}$ crystals with micron-sized particles, similar to the sucrose-boric acid mixture, despite the differences in CTR temperature and precursors. Fundamentally, the morphology of synthesized $\mathrm{B}_{4} \mathrm{C}$ powders is still primarily determined by the temperature-time effect. This in fact is consistent with the observation by Miller et al. [42]: even with the powder mixture of boric acid and carbon black, uniform submicron $\mathrm{B}_{4} \mathrm{C}$ particles were obtained after $\mathrm{CTR}$ at $1750^{\circ} \mathrm{C}$ for 2 minutes.

Finally, for the moisture effect, Figure 3.10(b) and Figure 3.11 show that for partially reacted samples, product morphology would change dramatically, accompanied by the formation of boric acid during aging. This leads to an experiment in which a few grams of pyrolyzed powder from recipe R4 were exposed to the air for 15 days. Figure 3.16 shows almost $12 \%$ weight gain for the pyrolyzed powders after 15 days of aging. Figure 3.17 shows the XRD pattern for the pyrolyzed powders before and after aging. As can be seen in Figure 3.17, the sample contains significant amount of crystalline boric acid after the 15-day exposure, while no trace of boric acid peaks were detected earlier before aging. 


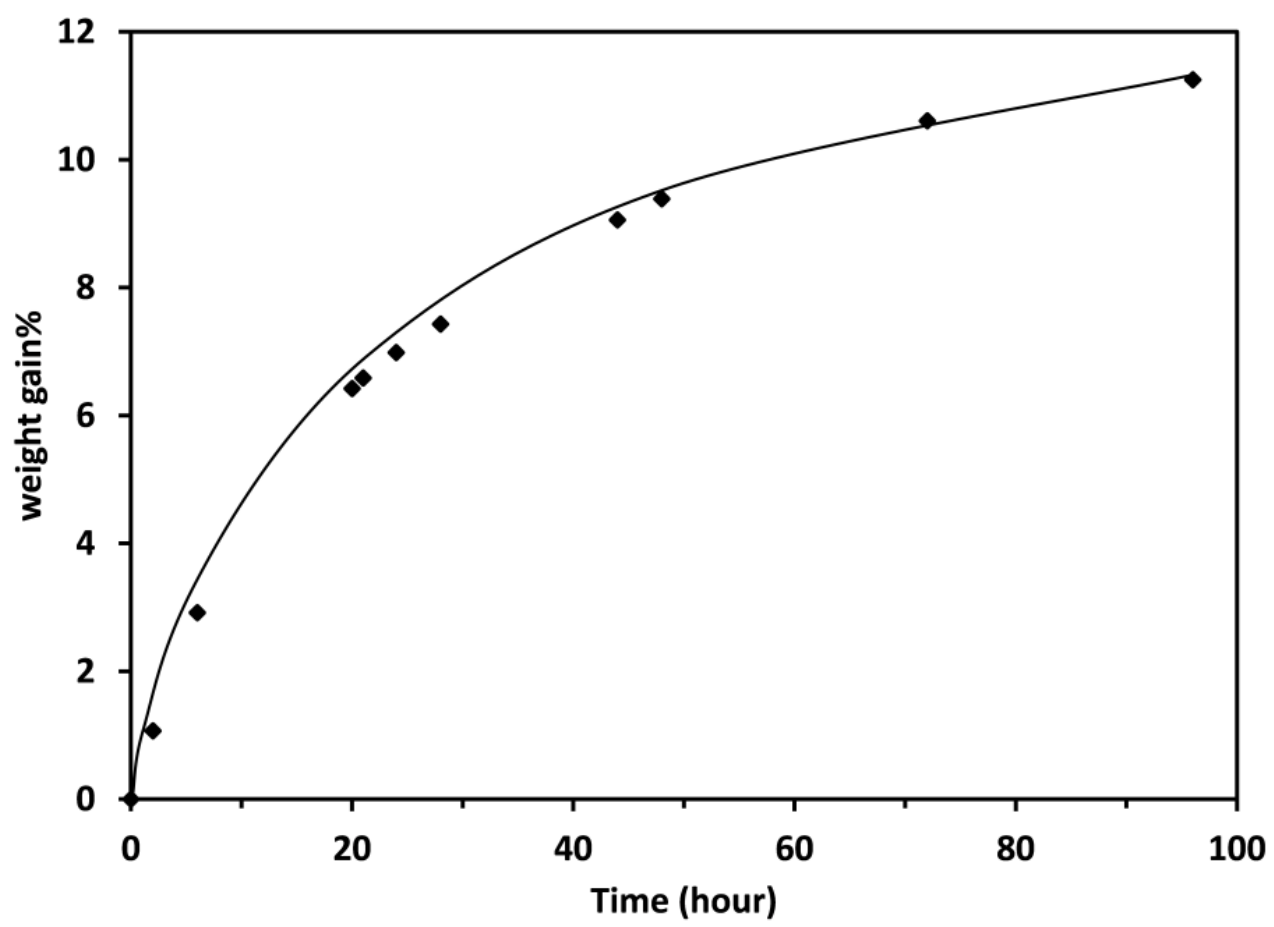

Figure 3.16: Weight gain of pyrolyzed recipe R4 versus time after exposure to the air for 15 days.

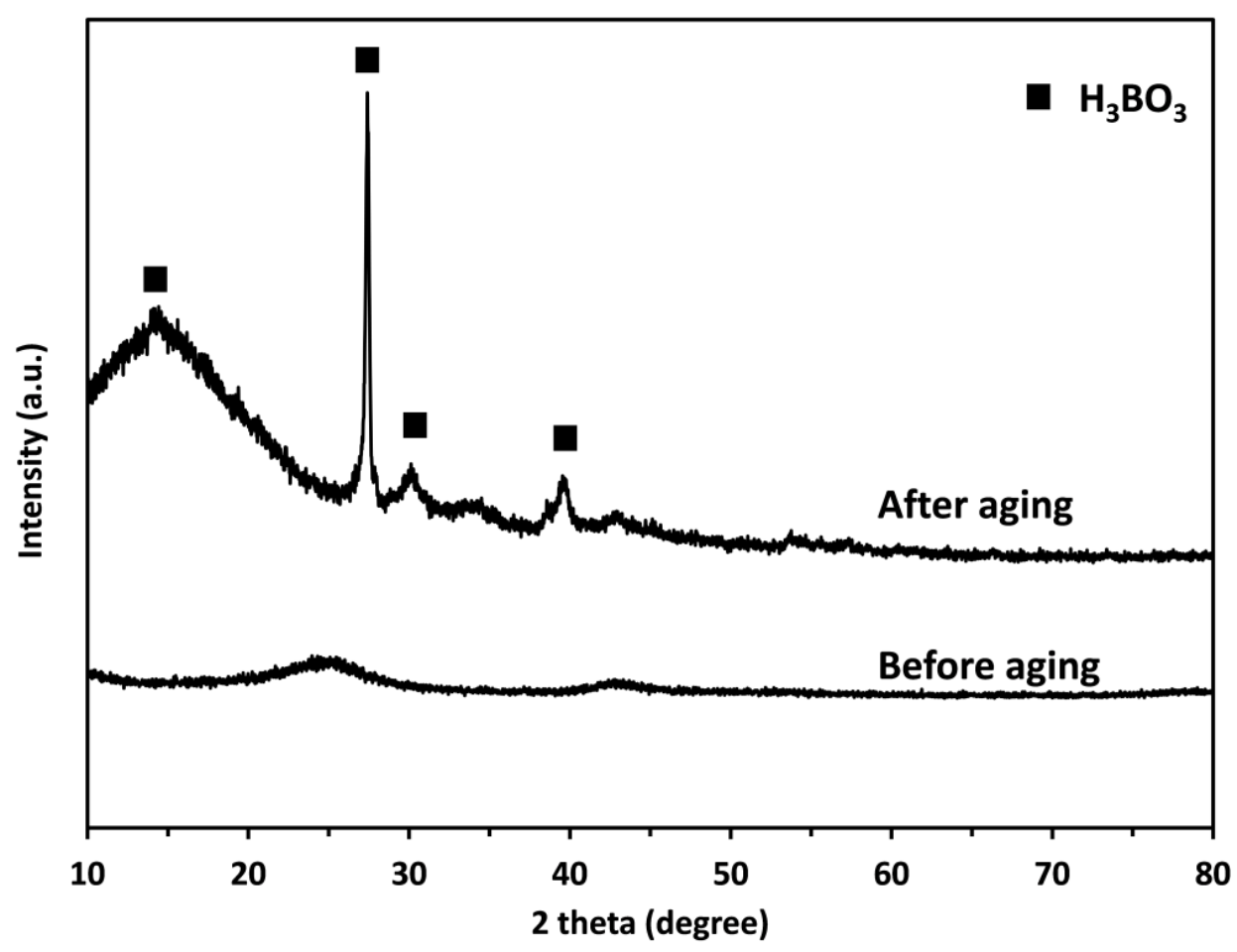

Figure 3.17: Figure.17. XRD pattern of pyrolyzed powders from recipe R4 (starting boric acid : sucrose molar ratio $=1: 0.81$ ) before and after 15 days of aging. 
Figure 3.18 shows SEM images for the sample before and after 15 days of aging in the air. These results indicate that the pyrolyzed sample containing amorphous $\mathrm{B}_{2} \mathrm{O}_{3}$ and C obtained from solution processing and subsequent pyrolysis heat-treatment readily absorbs moisture to form boric acid and gains weight, leading to global segregation of $\mathrm{B}_{2} \mathrm{O}_{3}$ and $\mathrm{C}$. Therefore, there is a need for greater care to control the moisture adsorption when studying the $\mathrm{B}_{4} \mathrm{C}$ formation process due to the dramatic effect on reaction yield and scale of mixing.
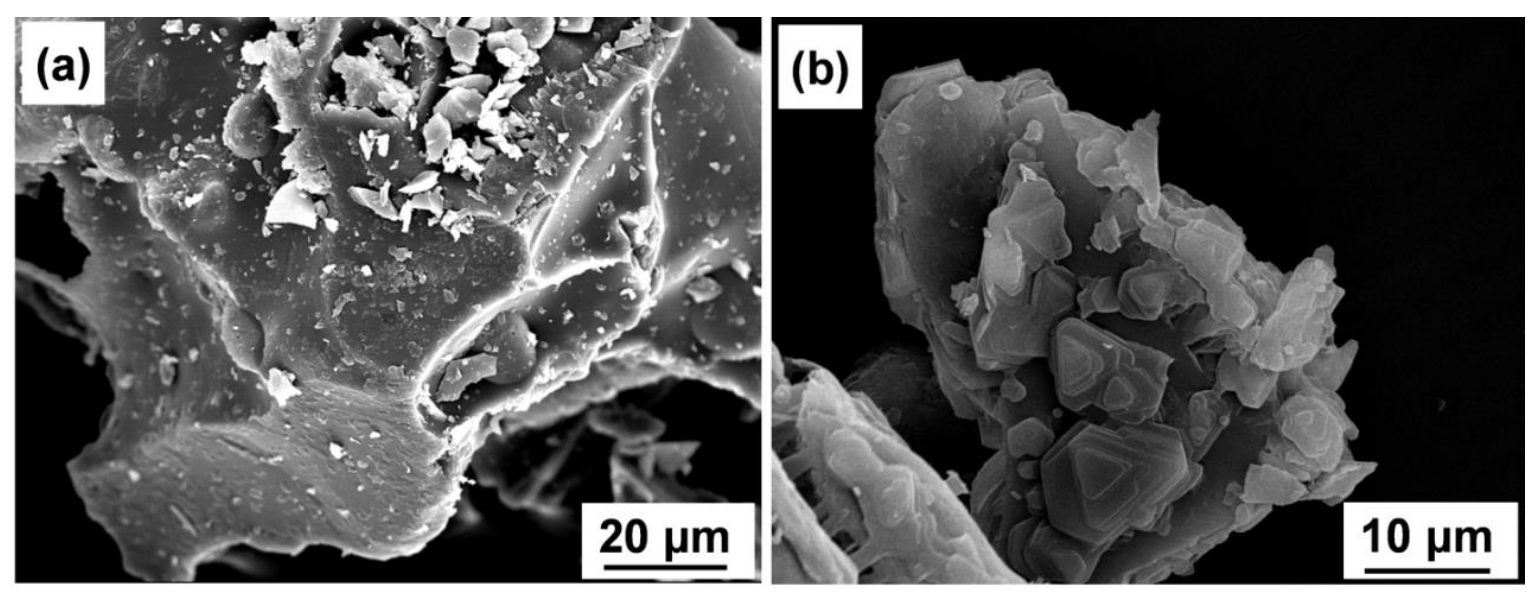

Figure 3.18: SEM micrographs of pyrolyzed recipe R4 (boric acid : sucrose weight ratio $1: 0.81$ ) before aging (a), and after aging (b).

\subsection{Conclusion}

Uniform submicron-sized $\mathrm{B}_{4} \mathrm{C}$ powders have been synthesized via a rapid heating rate carbothermal reduction reaction of the $\mathrm{B}_{2} \mathrm{O}_{3}-\mathrm{C}$ mixture obtained from water-soluble boric acid and sucrose. The morphology of $\mathrm{B}_{4} \mathrm{C}$ product powders is deteremined primarily by reaction kinetics. At low CTR temperatures, due to low nucleaton rate, CTR reaction proceeds primarily via growth at favorable sites leading to significant nonuniformity ,including nanobelts and micron-sized particles. At very high CTR temperatures $\left(>\sim 1750^{\circ} \mathrm{C}\right)$ reaction proceeds primarily via nucleation leading to uniform 
particles. At intermidiate CTR temperatures, mixed mechasnism of both nucleation and growth leads to variety of morphologies. Very high CTR temperatures $\left(>\sim 1750^{\circ} \mathrm{C}\right)$ with very short holding time (within minutes) appears to be the most effective condition in producing uniform nano/submicorn sized $\mathrm{B}_{4} \mathrm{C}$ particles. Other factors, such as $\mathrm{CTR}$ atmosphere and composition, also have effects on the product morphology: higher Ar flow rate lowers $\mathrm{pCO}$ and leads to faster nucleation rate and better product uniformity. On the other hand, lower boric acid: sucrose weight ratio limits coarsening, which helps yield more uniform product but at the expense of increased residual carbon. Finally, $\mathrm{B}_{2} \mathrm{O}_{3}$ in both the pyrolyzed material and partially reacted products readily absorb moisture to form boric acid that not only causes weight change but also dramatically influences the micromorphology. Thisneeds to be managed carefully to in order to produce $\mathrm{B}_{4} \mathrm{C}$ or to study its formation process.

\subsection{Supplementary Materials(1)}

\subsubsection{Example Showing Definition of the (carbon) Fractional Conversion $(\alpha)$}

The (carbon) fractional conversion $(\alpha)$ was calculated following Weimar et al. (1992) [8]:

$$
\alpha=\frac{\left[B_{4} C\right]}{\left[B_{4} C\right]+\frac{1}{7}[C]}
$$

Take the example for the sample after CTR at $1350^{\circ} \mathrm{C}$ for 2 hours:

Rietveld analysis, using Maud software gave the relative weight fraction of $\mathrm{B}_{4} \mathrm{C}$ and carbon to be:

$$
\frac{W t \% B_{4} C}{W t \% C}=63 / 37
$$


$\mathrm{B}_{4} \mathrm{C}$ molar weight is $55.25 \mathrm{~g} / \mathrm{mole}$ and carbon molar weight is $12.01 \mathrm{~g} / \mathrm{mole}$

Fractional conversion is calculated as:

$\alpha=\frac{[63 / 55.25]}{[63 / 55.25]+\frac{1}{7}[37 / 12.01]}$

$=\sim 72 \%$

The calculated $\alpha$ for all samples in this study are summarized in Table S1.1:

Table S1.1: Kinetic Results for recipe R4 (boric acid : sucrose weight ratio $1: 0.81$ )

\begin{tabular}{ccc}
\hline Temperature $\left({ }^{\circ} \mathbf{C}\right)$ & Time $(\mathbf{s})$ & Carbon conversion (a) \\
\hline 1150 & 36000 & 0.026 \\
1250 & 18000 & 0.890 \\
1350 & 7200 & 0.722 \\
1450 & 7200 & 0.993 \\
1450 & 1200 & 0.500 \\
1750 & 180 & 0.985 \\
\hline
\end{tabular}

3.6.2 Critical Nucleus Size and Free Energy Change for the Formation of $\mathrm{B}_{4} \mathrm{C}$ from $\mathrm{B}_{2} \mathrm{O}_{3}-\mathrm{C}$ Mixture

The following provides a quick analysis of the critical nucleus size and nucleation barrier for the formation of $\mathrm{B}_{4} \mathrm{C}$ nucleus from a fine mixture of $\mathrm{B}_{2} \mathrm{O}_{3}$ and carbon. Figure $\mathrm{S} 1.1$ (a) shows liquid $\mathrm{B}_{2} \mathrm{O}_{3}$ region in close contact with carbon at the surface, as in pyrolyzed sample, before nucleation. Figure $\mathrm{S} 1.1(\mathrm{~b})$ shows a small $\mathrm{B}_{4} \mathrm{C}$ nucleus formed at the interface between liquid $\mathrm{B}_{2} \mathrm{O}_{3}$ and carbon on the pyrolyzed particle surface. (The assumption of nucleation at the surface is supported by the SEM observations for 
partially converted samples as shown before for Figures 13(b) and 14 and associated discussion.)
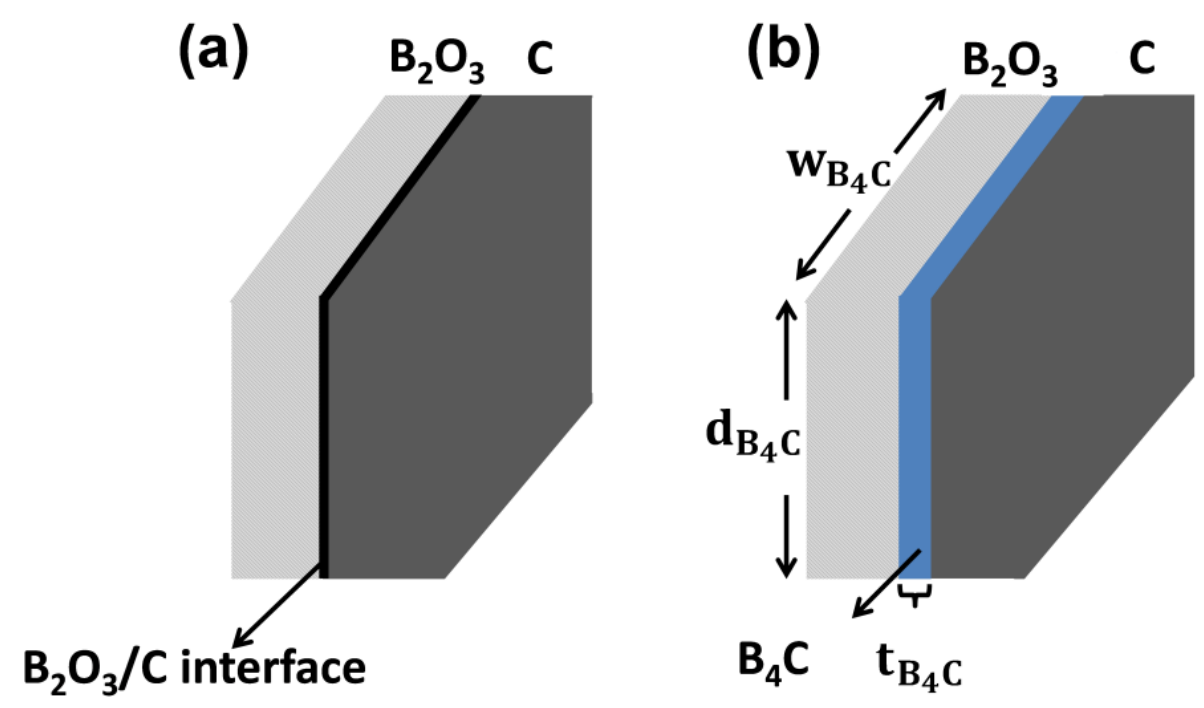

Figure S1.1: Schematic for the formation of $\mathrm{B}_{4} \mathrm{C}$ nucleus at the interface of $\mathrm{B}_{2} \mathrm{O}_{3}$ and $\mathrm{C}$ near the surface of the pyrolyzed material

Define the following parameters:

$\mathrm{V}_{\mathrm{B}_{4} \mathrm{C}}$ is the volume of the $\mathrm{B}_{4} \mathrm{C}$ nucleus

$\mathrm{d}_{\mathrm{B}_{4} \mathrm{C}}$ is the depth of the $\mathrm{B}_{4} \mathrm{C}$ nucleus

$\Delta G_{V}$ is the volume free energy change for the CTR reaction to form $\mathrm{B}_{4} \mathrm{C}$

$\gamma_{\alpha / \beta}$ is the interfacial energy between phase $\alpha$ and phase $\beta$

$t_{B_{4} C}$ is the thickness of the $\mathrm{B}_{4} \mathrm{C}$ nucleus 
$w_{B_{4} C}$ is the length of the interface between $\mathrm{B}_{2} \mathrm{O}_{3}$ and $\mathrm{C}$

$T_{e q}$ is the equilibrium reaction temperature, i.e., the temperature at which the free energy change for CTR reaction is zero for a given fixed $\mathrm{CO}$ partial pressure (pCO)

The free energy change in nucleation process will be:

$\Delta \mathrm{G}=\Delta \mathrm{G}_{\mathrm{v}} \mathrm{V}_{\mathrm{B}_{4} \mathrm{C}}+\mathrm{d}_{\mathrm{B}_{4} \mathrm{C}} \cdot \mathrm{w}_{\mathrm{B}_{4} \mathrm{C}} \cdot\left(\gamma_{\mathrm{B}_{2} \mathrm{O}_{3} / \mathrm{B}_{4} \mathrm{C}}+\gamma_{\mathrm{B}_{4} \mathrm{C} / \mathrm{C}}-\gamma_{\mathrm{B}_{2} \mathrm{O}_{3} / \mathrm{C}}\right)$

Because during $\mathrm{B}_{4} \mathrm{C}$ nucleation, new interfaces of $\mathrm{B}_{2} \mathrm{O}_{3} / \mathrm{B}_{4} \mathrm{C}$ and $\mathrm{B}_{4} \mathrm{C} / \mathrm{C}$ are created while the original interface of $\mathrm{B}_{2} \mathrm{O}_{3} / \mathrm{C}$ is eliminated locally, as assumed in the schematic.

To derive the critical nucleus size, it is also assumed that:

There is a linear relationship between nucleus depth $\left(d_{B_{4} C}\right)$ and nucleus width $\left(t_{B_{4} C}\right)$, i.e., $t_{B_{4} C}=c \cdot d_{B_{4} C}$ which is rational considering that the CTR has to happen near the $\mathrm{B}_{2} \mathrm{O}_{3} / \mathrm{C}$ interface and the release of $\mathrm{CO}$ through the pyrolyzed material.

$\Delta \mathrm{G}=\Delta \mathrm{G}_{\mathrm{v}} \cdot \mathrm{d}_{\mathrm{B}_{4} \mathrm{C}} \cdot \mathrm{w}_{\mathrm{B}_{4} \mathrm{C}} \cdot \mathrm{t}_{\mathrm{B}_{4} \mathrm{C}}+\mathrm{d}_{\mathrm{B}_{4} \mathrm{C}} \cdot \mathrm{w}_{\mathrm{B}_{4} \mathrm{C}} \cdot\left(\gamma_{\mathrm{B}_{2} \mathrm{O}_{3} / \mathrm{B}_{4} \mathrm{C}}+\gamma_{\mathrm{B}_{4} \mathrm{C} / \mathrm{C}}-\gamma_{\mathrm{B}_{2} \mathrm{O}_{3} / \mathrm{C}}\right)$

$\Delta \mathrm{G}=\mathrm{c} \cdot \mathrm{w}_{\mathrm{B}_{4} \mathrm{C}} \cdot \Delta \mathrm{G}_{\mathrm{v}}\left(\mathrm{d}_{\mathrm{B}_{4} \mathrm{C}}\right)^{2} \cdot+\left(\gamma_{\mathrm{B}_{2} \mathrm{O}_{3} / \mathrm{B}_{4} \mathrm{C}}+\gamma_{\mathrm{B}_{4} \mathrm{C} / \mathrm{C}}-\gamma_{\mathrm{B}_{2} \mathrm{O}_{3} / \mathrm{C}}\right) \cdot \mathrm{w}_{\mathrm{B}_{4} \mathrm{C}} \cdot \mathrm{d}_{\mathrm{B}_{4} \mathrm{C}}$

To find the critical condition:

$$
\begin{aligned}
& \frac{\mathrm{d} \Delta \Delta}{\mathrm{d}\left(\mathrm{d}_{\mathrm{B}_{4} \mathrm{C}}\right)}=2 \mathrm{c} \cdot \mathrm{w}_{\mathrm{B}_{4} \mathrm{C}} \cdot \Delta \mathrm{G}_{\mathrm{v}} \cdot \mathrm{d}_{\mathrm{B}_{4} \mathrm{C}}+\mathrm{w}_{\mathrm{B}_{4} \mathrm{C}} \cdot\left(\gamma_{\mathrm{B}_{2} \mathrm{O}_{3} / \mathrm{B}_{4} \mathrm{C}}+\gamma_{\mathrm{B}_{4} \mathrm{C} / \mathrm{C}}-\gamma_{\mathrm{B}_{2} \mathrm{O}_{3} / \mathrm{C}}\right)=0 \\
& -\left(\gamma_{\mathrm{B}_{2} \mathrm{O}_{3} / \mathrm{B}_{4} \mathrm{C}}+\gamma_{\mathrm{B}_{4} \mathrm{C} / \mathrm{C}}-\gamma_{\mathrm{B}_{2} \mathrm{O}_{3} / \mathrm{C}}\right)=\Delta \gamma \rightarrow \\
& \mathrm{d}_{\mathrm{B}_{4} \mathrm{C}} *=-\frac{\left(\gamma_{\mathrm{B}_{2} \mathrm{O}_{3} / \mathrm{B}_{4} \mathrm{C}}+\gamma_{\mathrm{B}_{4} \mathrm{C} / \mathrm{C}}-\gamma_{\mathrm{B}_{2} \mathrm{O}_{3} / \mathrm{C}}\right)}{2 \mathrm{c} \cdot \Delta \mathrm{G}_{\mathrm{v}}} \\
& \mathrm{d}_{\mathrm{B}_{4} \mathrm{C}} * \frac{\Delta \gamma}{2 \mathrm{c} \cdot \Delta \mathrm{G}_{\mathrm{v}}}
\end{aligned}
$$


As a result:

$$
\Delta \mathrm{G}^{*}=-\frac{\Delta \gamma^{2}}{4 \mathrm{c} \cdot \Delta \mathrm{G}_{\mathrm{v}}} \cdot \mathrm{w}_{\mathrm{B}_{4} \mathrm{C}}
$$

On the other hand, as can be seen in Figure $\mathrm{S} 2.2, \Delta G_{v}$ is a function of $\Delta T\left(\Delta G_{v} \propto \Delta T\right)$

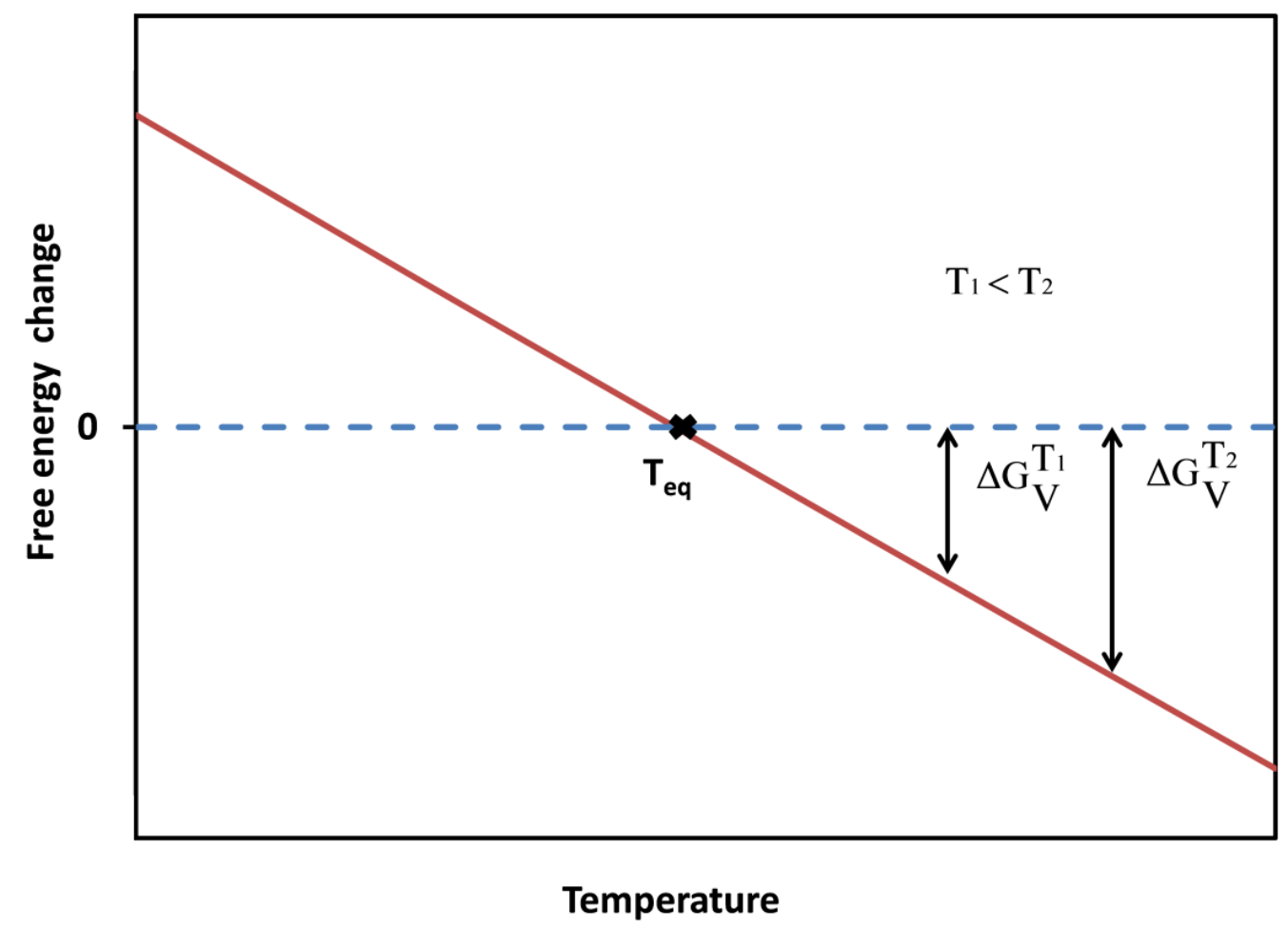

Figure.S1.2.Volume free energy change as a function of temperature. The temperature at which $\Delta G_{f}=0$ is considered as the equilibrium temperature $\left(\mathrm{T}_{\mathrm{eq}}\right)$.

Hence, $\Delta G^{*}$ is inversely proportional to $\Delta T$ :

$\Delta \mathrm{G}^{*} \propto \frac{1}{\Delta \mathrm{G}_{\mathrm{v}}} \rightarrow \Delta \mathrm{G}^{*} \propto \frac{1}{\Delta \mathrm{T}}=\frac{1}{\mathrm{~T}-\mathrm{T}_{\mathrm{eq}}}$ 


\subsubsection{Change of Free Energy of Formation for the CTR Reaction Eq. 3.1}

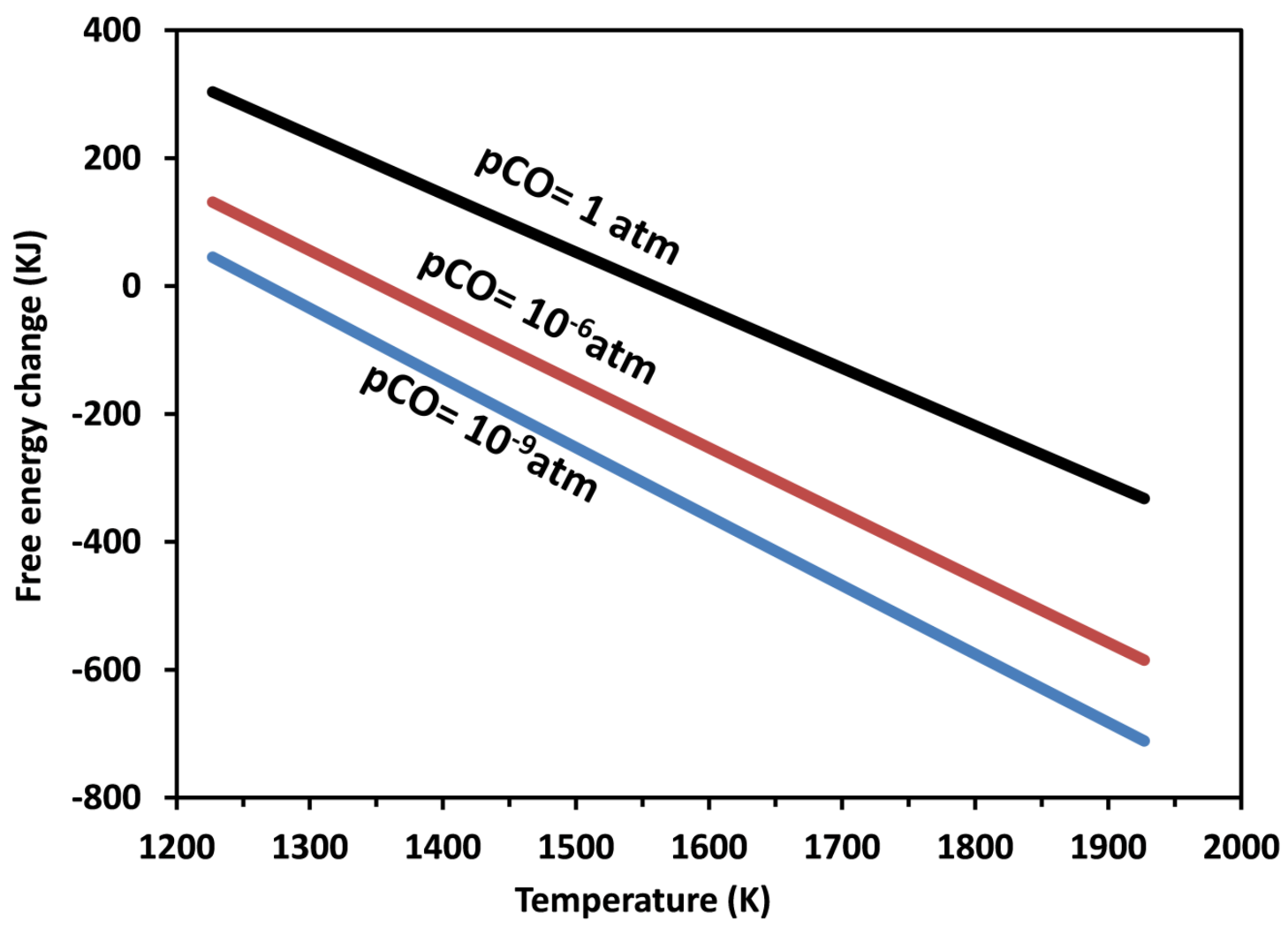

Figure S1.3: Change of free energy of formation for the CTR reaction Eq. 3.1 with temperature at different $\mathrm{pCO}$. 
Chapter IV: Controlling Phase Separation of $\mathrm{Ta}_{x} \mathrm{Hf}_{1-\mathrm{x}} \mathrm{C}$ Solid Solution Nano-powders during Synthesis via CTR

This chapter details the study on synthesis and controlling the phase separation of $\mathrm{Ta}_{\mathrm{x}} \mathrm{Hf}_{1-\mathrm{x}} \mathrm{C}$ solid solution powders during the CTR process.

\subsection{Introduction}

Among all ultrahigh temperature ceramics (UHTCs), hafnium carbide (HfC, $\left.\mathrm{T}_{\mathrm{m}}=3900{ }^{\circ} \mathrm{C}\right)$ and tantalum carbide $\left(\mathrm{TaC}, \mathrm{T}_{\mathrm{m}}=3880{ }^{\circ} \mathrm{C}\right)$ are of particular interest due to their extremely high melting points, high hardness (TaC: 19 GPa and HfC: 20 GPa), and high electrical and thermal conductivity and are promising candidates for many important applications that may need to tolerate temperatures above $2000{ }^{\circ} \mathrm{C}$ $[86][6][7][8][9]$. Previous studies show that by tailoring the composition (e.g., via using alloying elements), ternary UHTC solid solutions and related composites could provide even better properties than simple binary UHTCs, such as further improved oxidation resistance and/or mechanical properties[9][65][87][15][16]. In addition to optimizing the composition, reducing the particle size of these materials from micron to submicron or nanometer range $(\sim 100 \mathrm{~nm})$ provides additional benefits in terms of simplified postsynthesis processing and improved mechanical properties [86][88][14]. All these motivate the research on the synthesis of nano-scale $\mathrm{Ta}_{\mathrm{x}} \mathrm{Hf}_{1-\mathrm{x}} \mathrm{C}(0<\mathrm{x}<1)$ ternary solid solution and related composite powders.

Although the synthesis of $\mathrm{Ta}_{\mathrm{x}} \mathrm{Hf}_{1-\mathrm{x}} \mathrm{C}$ solid solution/composite powders has been studied for some time, the methods reported in the literature all suffer from some drawbacks, such as high cost, inferior product quality and/or concerns with process 
safety[16][67][18][19]. In addition, it is noted that all powder syntheses reported in the literature are performed on a single, Ta-rich composition of $\mathrm{Ta}_{0.8} \mathrm{Hf}_{0.2} \mathrm{C}$, while there is no study on the synthesis of $\mathrm{Hf}$ richer compositions such as $\mathrm{Ta}_{0.5} \mathrm{Hf}_{0.5} \mathrm{C}$, which sometimes shows even better mechanical properties [89] and oxidation resistance[20]. Because of these, there is a need for better synthesis methods to produce nanocrystalline $\mathrm{Ta}_{1-\mathrm{x}} \mathrm{Hf}_{\mathrm{x}} \mathrm{C}$ powders, especially for those with alternative compositions.

However, examination of the TaC-HfC system suggests some challenges regarding controlling the exact phase(s) that would be obtained: The TaC-HfC phase diagram available shows that the two individual carbides would form a continuous solid solution at high temperature[67]. However, there is also a wide miscibility gap with critical temperatures of $\sim 887^{\circ} \mathrm{C}$, which suggests that at a lower temperature a TaC-HfC two-phase composite would be energetically more stable than the uniform solid solution over a large composition range for $\mathrm{Ta}_{\mathrm{x}} \mathrm{Hf}_{1-\mathrm{x}} \mathrm{C}$ (e.g., at room temperature $x$ is between $\sim 0.05$ to $\sim 0.98$ ). This means uniform, single-phase $\mathrm{Ta}_{\mathrm{x}} \mathrm{Hf}_{1-\mathrm{x}} \mathrm{C}$ solid solution powder, even after it is formed at a higher temperature, would have a tendency to go through phase separation under certain conditions such as slow cooling to room temperature. Because solid solution and related two-phase composite often offer different properties [90], understanding when and how the phase separation would occur and learning to control it during the synthesis of $\mathrm{Ta}_{\mathrm{x}} \mathrm{Hf}_{1-\mathrm{x}} \mathrm{C}$ nano powders is expected to bring significant new insights to the general field of nano science and engineering and help understand other related systems [91][92].

In this paper, the authors report a low-cost synthesis method to produce nanosized $\mathrm{Ta}_{\mathrm{x}} \mathrm{Hf}_{1-\mathrm{x}} \mathrm{C}$ solid solution and related nanocomposite powders through aqueous 
solution-based processing starting from inorganic metal salts of tantalum pentachloride $\left(\mathrm{TaCl}_{5}\right)$ and hafnium tetrachloride $\left(\mathrm{HfCl}_{4}\right)$ and soluble hydrocarbon (e.g., sucrose) as the metal and carbon precursors, respectively. The simple equipment and cost-effectiveness of the CTR reaction are preserved in this method to convert the metal and carbon precursors into metal carbide(s). In addition, the precursors and processing conditions could also be easily modified for CTR reaction, which enables better control of product morphology, composition, and phase. For the current system, the initial step of solution processing would yield a fine, even nano-scale mixture of Ta-Hf oxide(s) and carbon, which would then go through the CTR reaction in which oxides of tantalum and hafnium are reduced by carbon to form carbide(s), and the overall CTR reaction (assuming formation of a single-phase solid solution) can be written as below:

$\mathrm{xTa}_{2} \mathrm{O}_{5}+2(1-\mathrm{x}) \mathrm{HfO}_{2}+(6+\mathrm{x}) \mathrm{C}=2 \mathrm{Ta}_{\mathrm{x}} \mathrm{Hf}_{1-\mathrm{x}} \mathrm{C}+(\mathrm{x}+4) \mathrm{CO}$

Eq. 4.1

As mentioned before, due to the presence of a miscibility gap in the TaC-HfC system, the ternary $\mathrm{Ta}_{\mathrm{x}} \mathrm{Hf}_{1-\mathrm{x}} \mathrm{C}$ powder may exist as a uniform solid solution, a nanocomposite of individual carbide phases, or their mixture. Therefore, particular focus was given to revealing the effects of various factors from starting composition to processing conditions on promoting/inhibiting phase separation in the TaC-HfC system, and the fundamental understanding generated is expected to guide synthesizing nanopowders for other multicomponent materials.

\subsection{Experimental}

For $\mathrm{Ta}_{\mathrm{x}} \mathrm{Hf}_{1-\mathrm{x}} \mathrm{C}$ powder synthesis, the starting metal precursors used are tantalum pentachloride $\left(\mathrm{TaCl}_{5}, 99.8 \%\right.$, Alfa Aesar \# 14164) and hafnium tetrachloride $\left(\mathrm{HfCl}_{4}\right.$, 98+\%, Alfa Aesar \# 11834). Sucrose (99.5\%, SIGMA \# S9378) and phenolic resin 
(Plenco, 14353, R5420) were used as carbon sources for the aqueous and non-aqueous systems, respectively. Totally, five recipes were adopted, as summarized in Table. For recipes $\mathrm{R} 6, \mathrm{R} 7, \mathrm{R} 11$, and $\mathrm{R} 13$ that are aqueous-based, $\mathrm{TaCl}_{5}$ and $\mathrm{HfCl}_{4}$ were hydrolyzed separately in DI water giving fine white tantalum oxychloride $\left(\mathrm{TaOCl}_{3}\right)$ precipitate and colorless water-soluble hafnium oxychloride $\left(\mathrm{HfOCl}_{2}\right)$. The aqueous solution and suspension were mixed, and then sucrose was added. For recipe R10 that is organic solvent-based, $\mathrm{TaCl}_{5}$ and $\mathrm{HfCl}_{4}$ were dissolved together into 1-pentanol (99+\%, Alfa Aesar \# 30898) at room temperature forming a translucent solution, followed by addition of phenolic resin, which was pre-dissolved in a co-solvent of ethanol $(99.5+\%$, Acros Organics \#61509-0020) at concentration of $0.02 \mathrm{~g} / \mathrm{ml}$.

Table 4.1: weight ratio of $\mathrm{TaCl}_{5}, \mathrm{HfCl}_{4}$ and sucrose $\left(\mathrm{C}_{12} \mathrm{H}_{22} \mathrm{O}_{11}\right)$ or phenolic resin $\left(\left(\mathrm{C}_{6} \mathrm{H}_{6} \mathrm{O} \cdot \mathrm{CH}_{2} \mathrm{O}\right)_{\mathrm{x}}\right)$ and expected Ta : $\mathrm{Hf}$ : C molar ratio used in this study

\begin{tabular}{llll}
\hline Recipe \# & Solvent & $\mathrm{TaCl}_{5}: \mathrm{HfCl}_{4}: \mathrm{C}_{12} \mathrm{H}_{22} \mathrm{O}_{11}: \mathrm{H}_{2} \mathrm{O}$ & Expected Ta $: \mathrm{Hf}: \mathrm{C}^{\mathrm{a}}$ \\
& & weight ratio & $4: 1: 17$ \\
\hline $\mathrm{R} 6$ & DI water & $4.47: 1: 3.54: 93.66$ & $1: 1: 6.50$ \\
\hline $\mathrm{R} 7$ & DI water & $1.11: 1: 1.35: 19.70$ & $1: 1: 4.87$ \\
\hline $\mathrm{R} 11$ & DI water & $1.11: 1: 1.01: 19.70$ & $4: 1: 12.75$ \\
\hline $\mathrm{R} 13$ & DI water & $4.47: 1: 2.65: 93.66$ & \\
\hline
\end{tabular}

$\mathrm{TaCl}_{5}: \mathrm{HfCl}_{4}:\left(\mathrm{C}_{6} \mathrm{H}_{6} \mathrm{O} \cdot \mathrm{CH}_{2} \mathrm{O}\right)_{\mathrm{x}}:$

1-Pentanol : Ethanol weight ratio

\begin{tabular}{ll}
\hline R10 & 1-Pentanol $1.11: 1: 2.18: 197.16: 81.57$ \\
& \& Ethanol
\end{tabular}

a: The carbon yield in pyrolysis at $700{ }^{\circ} \mathrm{C}$ is considered as $18 \%$ for sucrose and $35 \%$ for phenolic resin, respectively, based on TGA results. 
For all recipes, the obtained mixed solution/suspension was stirred continuously on a hot plate set at $300{ }^{\circ} \mathrm{C}$ (the solution temperature was $\sim 100{ }^{\circ} \mathrm{C}$ ) using a magnetic stir bar until they were completely dried. Then, the dried precursor's mixtures were pyrolyzed at $700{ }^{\circ} \mathrm{C}$ for 1 hour in argon (UHP grade, Airgas) with a flow rate of $80 \mathrm{cc} / \mathrm{min}$ in a tube furnace with an inner diameter of $40 \mathrm{~mm}$. During the pyrolysis process, precursors lose low molecular weight species (e.g., water, carbon monoxide, and hydrogen chloride) to yield uniform amorphous (as shown later) $\mathrm{Ta}_{2} \mathrm{O}_{5}-\mathrm{HfO}_{2}-\mathrm{C}$ fine mixtures. Most of the subsequent CTR heat treatments were performed isothermally in a tube furnace at 1500$1700{ }^{\circ} \mathrm{C}$ for different holding times in flowing argon atmosphere. Due to the limited heating/cooling capability for the tube furnace used (up to $10^{\circ} \mathrm{C} / \mathrm{min}$ ), in some cases, a graphite rope was connected to a graphite boat containing the pyrolyzed powders and extended to the exhaust end of the tube furnace. The graphite rope was used to quickly pull the sample into and, later, out of the hot zone of the tube furnace preheated to CTR reaction temperature (e.g., $1600{ }^{\circ} \mathrm{C}$ ) to investigate the effect of high heating/cooling rate (measured up to $\sim 500{ }^{\circ} \mathrm{C} / \mathrm{min}$ ) during the CTR process, as illustrated in the schematic in Figures S2.1(a) and S2.1(b) (see supplementray materials(2)). Additionally, in order to study the effect of electric field on the formation of $\mathrm{Ta}_{0.5} \mathrm{Hf}_{0.5} \mathrm{C}$ solid solution/nanocomposite powders, CTR of the pyrolyzed powder from recipe R7 was also performed in a spark plasma sintering (SPS) system (Thermal Technologies, Model 10-4, Santa Rosa, CA, USA) under vacuum (base pressure of $2 \times 10^{-2}$ torr) at $1600{ }^{\circ} \mathrm{C}$ with a low applied pressure of $5 \mathrm{MPa}$ in a $20 \mathrm{~mm}$ diameter graphite die set. To investigate the impact of the pressure alone on the phase formation/separation of $\mathrm{Ta}_{0.5} \mathrm{Hf}_{0.5} \mathrm{C}$ powder, CTR of the R7 pyrolyzed powder was also carried out in the same SPS system but with 
two boron nitride $(\mathrm{BN})$ disks touching the graphite die punches so that the $\mathrm{BN}$ disks would block the electric current from flowing through the sample (See Figure S2.1(c) in the supplementray materials(2)). All pyrolyzed and CTR reaction products were characterized by X-ray diffraction (Siemens D5000) for phase identification. The morphology and particle size of the synthesized powders were studied by scanning electron microscope (SEM JEOL JSM-6330F) and transmission electron microscope (TEM Phillips CM-200). Thermogravimetric analysis (TGA) was carried out for some samples in the air with the constant heating rate of $10^{\circ} \mathrm{C} / \mathrm{min}$ to determine the excess carbon content.

\subsection{Results and Discussion}

\subsubsection{Characterization of Pyrolyzed Material}

Figure 4(a) and (b) show the XRD patterns of the samples from recipe R6 (Ta to Hf molar ratio of $4: 1$, or abbreviated as $\mathrm{Ta}: \mathrm{Hf}=4: 1$ in this paper) and $\mathrm{R} 7(\mathrm{Ta}: \mathrm{Hf}=1$ : 1), respectively, after pyrolysis at $700{ }^{\circ} \mathrm{C}$ for 1 hour, indicating the formation of amorphous Ta and Hf oxides and carbon mixture after pyrolysis. This is favorable since crystallization of the Ta and Hf oxides might be accompanied by more segregation in oxides and negatively affects the homogeneity of the pyrolyzed material. The SEM image for the pyrolyzed powders gives an estimate for the particle size of $\sim 50-100 \mu \mathrm{m}$ with relatively dense structure (see Figure 4.2 (a) for the sample from recipe R6). 


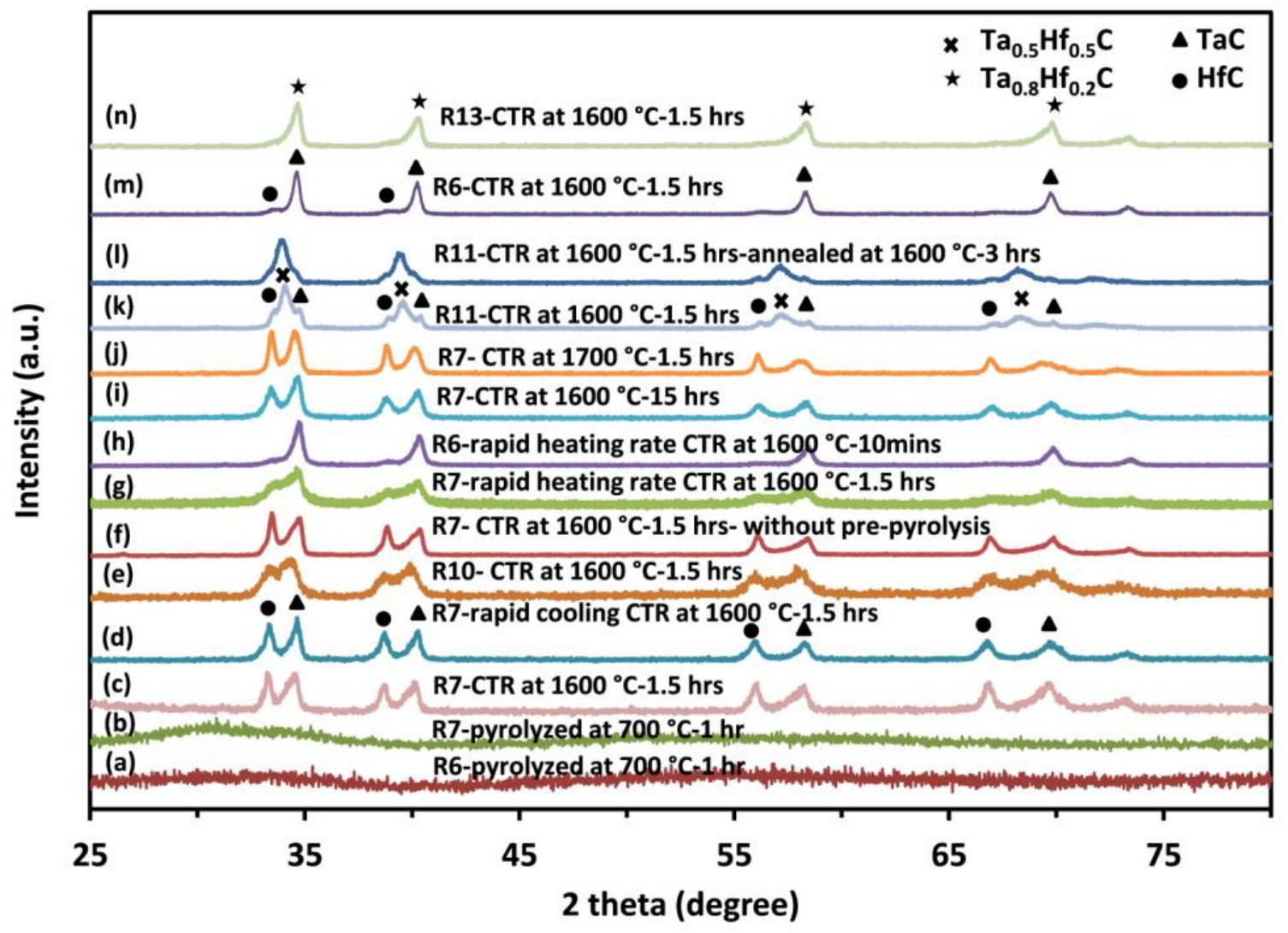

Figure 4.1:XRD patterns of synthesized powders for all recipes with different CTR conditions in a tube furnace. 

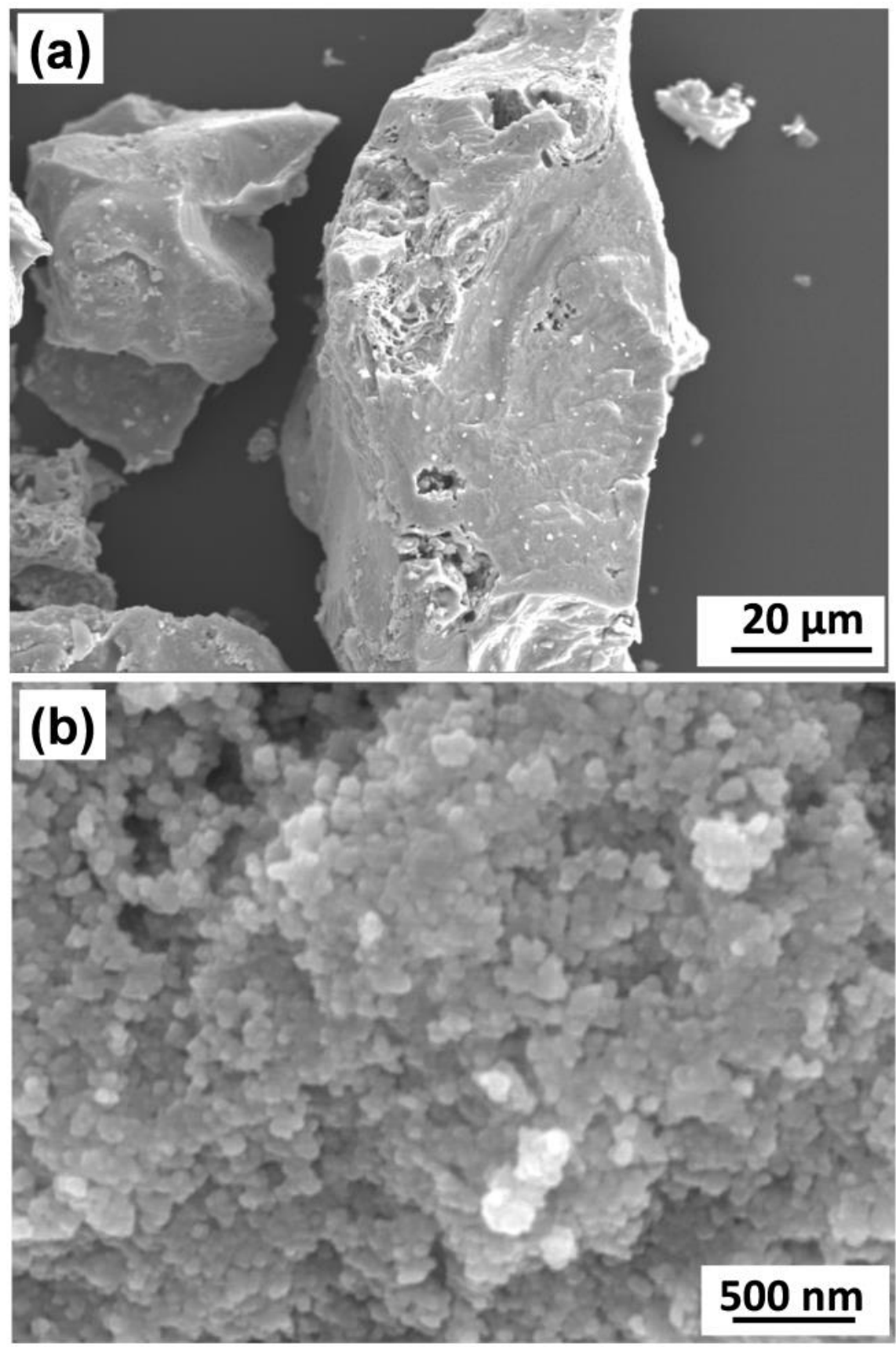

Figure 4.2: SEM micrographs of (a) pyrolyzed powders at $700{ }^{\circ} \mathrm{C}$ for one hour from recipe R6 (Ta : $\mathrm{Hf}=$ of $4: 1$ ) showing formation of $50-100 \mu \mathrm{m}$-sized particles with low porosity (b) synthesized powders via CTR at $1600{ }^{\circ} \mathrm{C}$ for 1.5 hour from recipe $\mathrm{R} 7(\mathrm{Ta}: \mathrm{Hf}=1: 1)$ showing the formation of uniform nano-sized powders $(\sim<100 \mathrm{~nm})$. It is noted that this sample is actually phase separated into $\mathrm{TaC}$ and HfC, as indicated by XRD (see Figure 4.1(c)). 


\subsubsection{Observation of Phase Separation}

To illustrate the possibility of forming phase-separated TaC-HfC nanocomposite powder, Figure 4.1(c) shows the XRD pattern for a sample from recipe R7 $(\mathrm{Ta}: \mathrm{Hf}=1$ : 1) synthesized via $\mathrm{CTR}$ at $1600{ }^{\circ} \mathrm{C}$ for 1.5 hours. Instead of forming a uniform, singlephase $\mathrm{Ta}_{0.5} \mathrm{Hf}_{0.5} \mathrm{C}$ solid solution powder, distinct peaks corresponding to individual $\mathrm{HfC}$ (JCPDS \#98-008-5664) and TaC (JCPDS \#98-008-5806) phases were observed for this sample. In addition, no other crystalline phases were identified by XRD. Figure 4.2 (b) is the SEM image of this sample, showing the formation of relatively uniform nano-sized ( 50-100 nm) powder even though the sample is a composite of two individual carbide phase(s), as suggested by XRD. Understanding and controlling of phase separation

Upon carefully reviewing the TaC-HfC system, it is realized that there are several factors with respect to processing conditions and/or starting recipe that might contribute to the formation of separate $\mathrm{TaC}$ and $\mathrm{HfC}$ phases at CTR temperature of $\sim 1600{ }^{\circ} \mathrm{C}$, which is well above the critical temperature of $887{ }^{\circ} \mathrm{C}$ for the system. In the following, the results of a systematic study aimed at understanding the effects of those factors on controlling the phase(s) formed will be presented, and the implications of the experimental observations will also be discussed.

\subsubsection{Effect of CTR cooling rate}

The first factor studied is cooling rate after the CTR heat treatment. This is because the CTR temperature of $\sim 1600{ }^{\circ} \mathrm{C}$ is well above the TaC-HfC system critical temperature. Therefore, it is possible that uniform solid solution powder could first form during CTR reaction. Then, upon slow cooling (e.g., at $\sim 10{ }^{\circ} \mathrm{C} / \mathrm{min}$ ) inside the tube furnace, the uniform solid solution may go through phase separation (e.g., via nucleation- 
growth or spinodal decomposition) and give a powder that becomes a two-phase mixture of $\mathrm{TaC}$ and $\mathrm{HfC}$. To test such a hypothesis, a sample from recipe $\mathrm{R} 7$ (Ta: $\mathrm{Hf}=1: 1$ ) was synthesized via CTR at $1600{ }^{\circ} \mathrm{C}$ for 1.5 hours, followed by rapid cooling. The fast cooling rate, estimated to be $\sim 500{ }^{\circ} \mathrm{C} / \mathrm{min}$, was realized by pulling the graphite sample boat directly out from the hot zone of the tube furnace to the cold zone $\left(\sim 80{ }^{\circ} \mathrm{C}\right)$ after CTR at $1600{ }^{\circ} \mathrm{C}$ for the designated time, as described in the experimental section. The expectation was that if the sample obtained using $\sim 50$ times faster cooling rate contains more solid solution comparing with the sample conventionally cooled at $10{ }^{\circ} \mathrm{C} / \mathrm{min}$, it would support the hypothesis that $\mathrm{Ta}_{1-\mathrm{x}} \mathrm{Hf}_{\mathrm{x}} \mathrm{C}$ solid solution forms first under the CTR condition and then goes through phase separation in the slow cooling stage.

Figure 4.1(d) shows the XRD pattern for this sample with rapid cooling after CTR: Individual $\mathrm{TaC}$ and $\mathrm{HfC}$ peaks are still clearly visible without any hint of solid solution formation. Comparing XRD for this sample with the sample cooled at the normal rate of $10{ }^{\circ} \mathrm{C} / \mathrm{min}$ (see figure $4.1(\mathrm{c})$ ), it is concluded that significantly faster cooling after CTR does not help prevent phase separation. The implication is that for the $\mathrm{Ta}_{0.5} \mathrm{Hf}_{0.5} \mathrm{C}$ sample from recipe $\mathrm{R} 7$, only individual carbides are formed after CTR at $1600{ }^{\circ} \mathrm{C}$ for 1.5 hours, while the expected $\mathrm{Ta}_{0.5} \mathrm{Hf}_{0.5} \mathrm{C}$ single-phase solid solution has not been formed yet under this condition, probably due to the slow diffusion process, and the obtained nano powder remains phase separated upon cooling to room temperature.

\subsubsection{Effects of Solvent, Pre-pyrolysis, and CTR Heating Rate}

The second factor studied is related to solution processing. As mentioned in the introduction, uniform single-phase nano-sized $\mathrm{Ta}_{0.8} \mathrm{Hf}_{0.2} \mathrm{C}$ solid solution powders had been synthesized by other researchers via CTR using precursors obtained from organic 
solvent-based sol-gel or solvothermal processes [16][18]. In comparison, for the current study, recipes such as $\mathrm{R} 7$ are water based. It was observed that upon addition of $\mathrm{TaCl}_{5}$ to DI water, hydrolysis is very fast, leading to instantaneous precipitation of fine $\mathrm{TaOCl}_{3}$ particles. On the other hand, $\mathrm{HfCl}_{4}$ dissolves completely in water and forms a uniform and colorless solution. As a result, it is possible that the observation of separate $\mathrm{TaC}$ and $\mathrm{HfC}$ phases in the CTR product might have originated from the precipitation of $\mathrm{TaOCl}_{3}$ upon fast $\mathrm{TaCl}_{5}$ hydrolysis. This could lead to the loss of homogeneity of the liquid solution and cause large segregation of Ta-rich and Hf-rich regions persisting in subsequent steps of drying, pyrolysis, and finally CTR. Because of the large scale of separation caused by rapid $\mathrm{TaCl}_{5}$ hydrolysis and precipitation, it would take a longer time for Ta and $\mathrm{Hf}$ to inter-diffuse to obtain a uniform solid solution powder.

Thus, in order to test the hypothesis that a uniform liquid solution based on organic solvents, as adopted in other studies, would help reduce or even eliminate separation of $\mathrm{Ta}$ and $\mathrm{Hf}$ oxides in the solution processing (and later separation of carbides after CTR), less polar, organic solvent of 1-pentanol was used to reduce the rate of $\mathrm{TaCl}_{5}$ hydrolysis, as described before for recipe R10 with the same Ta : Hf molar ratio of $1: 1$ as R7. This time, unlike when using water as the solvent, both $\mathrm{TaCl}_{5}$ and $\mathrm{HfCl}_{4}$ dissolve completely in 1-pentanol and form a uniform, translucent, light yellow-colored solution without any precipitation. However, the XRD pattern for the sample after CTR at 1600 ${ }^{\circ} \mathrm{C}$ for 1.5 hours (Figure 4.1(e)) shows partially overlapping but still separated diffraction peaks corresponding to slightly Hf-doped $\mathrm{TaC}$ and Ta-doped HfC phases. Such an observation suggests the use of an organic solvent (and resulting slower hydrolysis) may 
help but is unlikely to be the critical factor to prevent phase separation of $\mathrm{TaC}$ and $\mathrm{HfC}$ for the final carbide products.

Similarly, the influence of removing the pre-pyrolysis step (i.e., the $700{ }^{\circ} \mathrm{C} / 1 \mathrm{~h}$ heat treatment to convert the dried material from solution processing to intimate oxidescarbon mixture) and adoption of very fast heating rate (up to $\sim 500{ }^{\circ} \mathrm{C} / \mathrm{min}$ ) for $\mathrm{CTR}$ have also been explored for the same recipe R7. (Please refer to supplemental materials section (b) for detailed discussion of the rationale of studying these two factors), and their results are briefly summarized as in Figure 4.1(f) and (g), respectively. Essentially, neither factor prevents the phase separation under the condition explored.

The observations that none of the factors discussed so far prevents the formation of separate $\mathrm{TaC}$ and $\mathrm{HfC}$ phases under the CTR condition explored (e.g., $1600{ }^{\circ} \mathrm{C} / 1.5$ hrs) are attributed to the combined effect of several factors: First, there is very low affinity between the oxide precursors of $\mathrm{Ta}_{2} \mathrm{O}_{5}$ and $\mathrm{HfO}_{2}$. To the best of the authors' knowledge, there is no binary phase diagram published for $\mathrm{Ta}_{2} \mathrm{O}_{5}$ and $\mathrm{HfO}_{2}$. Nevertheless, the available phase diagram for the $\mathrm{Ta}_{2} \mathrm{O}_{5}-\mathrm{ZrO}_{2}$ [93] system shows that $\mathrm{ZrO}_{2}$ has almost zero solubility of $\mathrm{Ta}_{2} \mathrm{O}_{5}$ while $\mathrm{Ta}_{2} \mathrm{O}_{5}$ can only accommodate $\mathrm{ZrO}_{2}$ up to $\sim 2 \mathrm{~mol} . \%$. Due to the close chemical and physical similarity of $\mathrm{Zr}$ and $\mathrm{Hf}$, it is reasonable to assume similar behavior for the $\mathrm{Ta}_{2} \mathrm{O}_{5}-\mathrm{HfO}_{2}$ system, that is $\mathrm{Ta}_{2} \mathrm{O}_{5}$ and $\mathrm{HfO}_{2}$ would have very low affinity for each other and do not form a solid solution with appreciable solubility[94]. The implication is that, despite the careful efforts in solution processing to mix Ta and Hf salts uniformly (e.g., via the use of an organic solvent), the oxides of tantalum and hafnium, which can exist in amorphous form, will always segregate into 
separate $\mathrm{Ta}_{2} \mathrm{O}_{5}$ and $\mathrm{HfO}_{2}$ regions. Second, the CTR reaction under the conditions explored is rather fast. One evidence for this claim is given in Figure 4.1(h), which shows the XRD pattern for a sample from recipe R6 (Ta: Hf = $4: 1$ ) synthesized via rapid heating CTR at $1600{ }^{\circ} \mathrm{C}$ for a short time of only 10 minutes: Both TaC and HfC formed individually after only 10 minutes of CTR without any trace of remaining oxides at that temperature. (Note Figures like Figure 4.1(h) have been shrunk vertically for plotting purpose, which makes minor peaks corresponding to HfC less visible.) The combined effect of those two factors mentioned above is that the segregated (amorphous) $\mathrm{Ta}_{2} \mathrm{O}_{5}$ and $\mathrm{HfO}_{2}$ regions will always go through separate $\mathrm{CTR}$ reactions to form $\mathrm{TaC}$ and $\mathrm{HfC}$ phases. Then rely on inter-diffusion of $\mathrm{Ta}$ and $\mathrm{Hf}$ in the high-temperature carbide phases to form a uniform, single-phase solid solution ternary carbide. On the other hand, the inter-diffusion of Ta and Hf at these temperatures can be slow [95], which explains why separate $\mathrm{TaC}$ and $\mathrm{HfC}$ remain even though the CTR temperature is significantly above the miscibility gap.

\subsubsection{Effects of CTR Temperature and Holding Time}

As explained above, due to the low affinity between $\mathrm{Ta}_{2} \mathrm{O}_{5}$ and $\mathrm{HfO}_{2}$ and the large difference in driving force for the formation of $\mathrm{TaC}$ and $\mathrm{HfC}$ (see supplementary materials(2)), the two carbides would always form individually in CTR; then the solid solution forms via inter-diffusion between them, which can take a significant time. As a result, the formation of $\mathrm{Ta}_{\mathrm{x}} \mathrm{Hf}_{1-\mathrm{x}} \mathrm{C}$ single-phase solid solution is expected to improve when using higher CTR temperatures and/or longer CTR dwell times. Indeed, Figure 4.3

(a) shows the XRD patterns (showing a zoomed section) for a sample from the Ta- rich recipe $\mathrm{R} 6(\mathrm{Ta}: \mathrm{Hf}=4: 1)$ after $\mathrm{CTR}$ at $1500{ }^{\circ} \mathrm{C}$ for 3 hours and the same sample after 
additional annealing at $1600{ }^{\circ} \mathrm{C}$ for 10 hours in argon. The as-synthesized sample after CTR at $1500{ }^{\circ} \mathrm{C}$ for 3 hours shows clear separation of TaC and $\mathrm{HfC}$ phases, while after the additional annealing at $1600{ }^{\circ} \mathrm{C}$ for 10 hours, the individual $\mathrm{TaC}$ and $\mathrm{HfC}$ diffraction peaks merged completely to ones that correspond to a uniform, single-phase solid solution of $\mathrm{Ta}_{0.8} \mathrm{Hf}_{0.2} \mathrm{C}$. However, it is noted that there are limitations on the use of higher CTR temperature or very long CTR dwell time to help the formation of a single-phase solid solution powders. First, they would lead to excessive grain growth, which is undesirable for the purpose of synthesizing nano-sized solid powders. Figure 4.3 (b) shows the SEM images of the sample from recipe R6 obtained from CTR at $1500{ }^{\circ} \mathrm{C}$ for 3hours, while Figure 4.3 (c) is for the same sample after additional annealing at $1600{ }^{\circ} \mathrm{C}$ for 10 hours to convert the two-phase composite powder into a single-phase solid solution powder. All particles experience significant coarsening with primary grain size increased from $\sim 50 \mathrm{~nm}$ to up to $\sim 500 \mathrm{~nm}$. Second, higher temperature or longer time would add to energy consumption and process cost. Last but not least, for the certain compositions, it may not be effective: Take the example of a Hf-richer sample from recipe $\mathrm{R} 7(\mathrm{Ta}: \mathrm{Hf}=1: 1)$, even 15 hours of $\mathrm{CTR}$ at $1600{ }^{\circ} \mathrm{C}$ or higher $\mathrm{CTR}$ temperature of $1700{ }^{\circ} \mathrm{C}$ did not seem to prevent the phase separation of $\mathrm{TaC}$ and $\mathrm{HfC}$, as shown in Figure 4.1(i) and (j), respectively. 

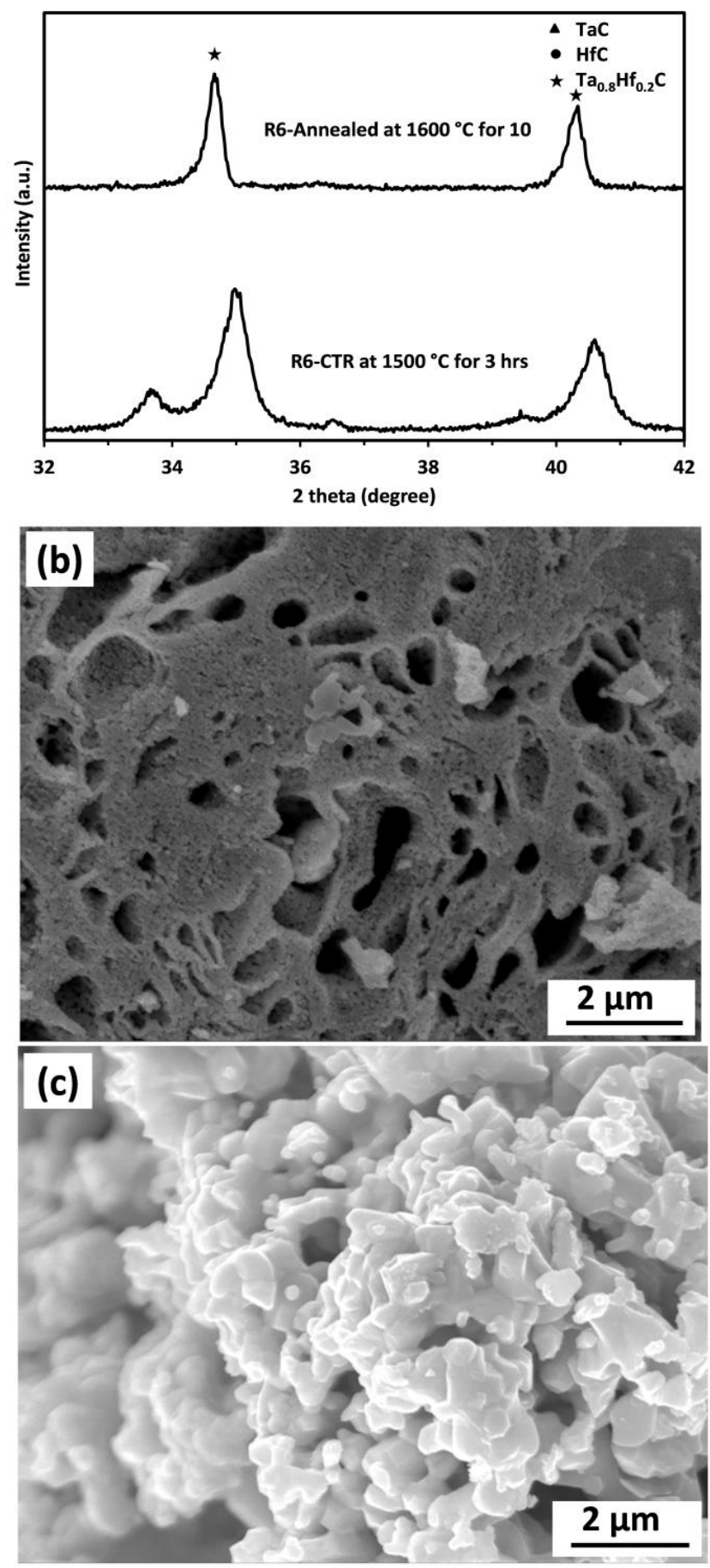

Figure 4.3: (a) XRD pattern for the sample from recipe $\mathrm{R} 6$ ( $\mathrm{Ta}: \mathrm{Hf}=4: 1$ ) synthesized via CTR at $1500{ }^{\circ} \mathrm{C}$, annealed for 10 hours at $1600{ }^{\circ} \mathrm{C}$ (b) SEM image of this sample before annealing showing the formation of uniform nano-sized powders (c) after annealing at $1600{ }^{\circ} \mathrm{C}$ for 10 hours indicating a noticeable grain growth. 


\subsubsection{Effect of Excess (amorphous) Carbon Content}

The seeming difficulty in obtaining single-phase $\mathrm{Ta}_{\mathrm{x}} \mathrm{Hf}_{1-\mathrm{x}} \mathrm{C}$ nano solid solution powders prompts additional analysis of the various samples obtained. Figure 4.4 (a) and (b) are the TEM images for the sample from recipe $\mathrm{R} 7(\mathrm{Ta}: \mathrm{Hf}=1: 1)$ synthesized via CTR at $1600{ }^{\circ} \mathrm{C}$ for 1.5 hours. The images confirm the synthesized TaC-HfC composite powders are nano-grained with a primary particle size of $\sim 50 \mathrm{~nm}$, which is consistent with SEM observation (see Figure 4.2 (b)). In addition, the images also suggest that each of the nano carbide particles seems to have a low-atomic-mass shell over it. (Highresolution TEM and EDS will be needed to characterize the solid solution nano powders further.) In addition, TGA analysis of this sample in air, as shown in Figure 4.5 (a), indicates that the sample has carbon excess of $\sim 9.5 \mathrm{wt} . \%$. Because XRD pattern for that sample (see Figure 4.1(c)) did not show the presence of any crystalline carbon, carbon must exist in amorphous form, and it is likely that the observed amorphous shell is amorphous carbon on the surface of individual $\mathrm{TaC} / \mathrm{HfC}$ nanoparticles.

Considering that i) $\mathrm{Ta}_{2} \mathrm{O}_{5}-\mathrm{HfO}_{2}$ immiscibility and fast CTR kinetics lead to the formation of individual $\mathrm{TaC}$ and $\mathrm{HfC}$ phases and ii) excessive (amorphous) carbon might exist as shells over those individual carbide nanoparticles, the effect of excess carbon content (or starting composition) on phase separation of $\mathrm{TaC}$ and $\mathrm{HfC}$ in the synthesis was investigated. The hypothesis was that the excess carbon in the form of (amorphous) carbon shell over the individual carbide phases might dramatically inhibit the interdiffusion of $\mathrm{Ta}$ and $\mathrm{Hf}$ cations between $\mathrm{HfC}$ and $\mathrm{TaC}$ grains and, as a result, slow the solid solution formation. To test this hypothesis, a sample from recipe R11 with lower carbon content than recipe $\mathrm{R} 7$ but the same Ta : Hf molar ratio of $1: 1$ was synthesized 
via solution processing and subsequent CTR at $1600{ }^{\circ} \mathrm{C}$ for 1.5 hours. Figure $4.1(\mathrm{k})$ gives the XRD pattern for this sample: Individual peaks corresponding to phase-separated HfC and $\mathrm{TaC}$ along with $\mathrm{Ta}_{0.5} \mathrm{Hf}_{0.5} \mathrm{C}$ solid solution peaks in between, as expected from Vegard's law, were all detected. TGA for this sample indicates it indeed has a lower excess carbon content of $\sim 4.6 \mathrm{wt} . \%$, consistent with the lower carbon recipe R11 used (see Figure 4.5(b)). Therefore, it is evident that lower excess carbon content dramatically improves the inter-diffusion and the formation of a solid solution. Further annealing of this sample for an additional 3 hours enhances the solid solution formation noticeably with the individual carbide peaks almost disappearing, as shown in Figure 4.1(1). In comparison, as mentioned before for figure 4.1 (i), for a sample from recipe of R7 (Ta : $\mathrm{Hf}=1: 1)$ with higher starting sucrose content, CTR for 15 hours at $1600{ }^{\circ} \mathrm{C}$ did not give the same effect in promoting the formation of a uniform solid solution phase. 

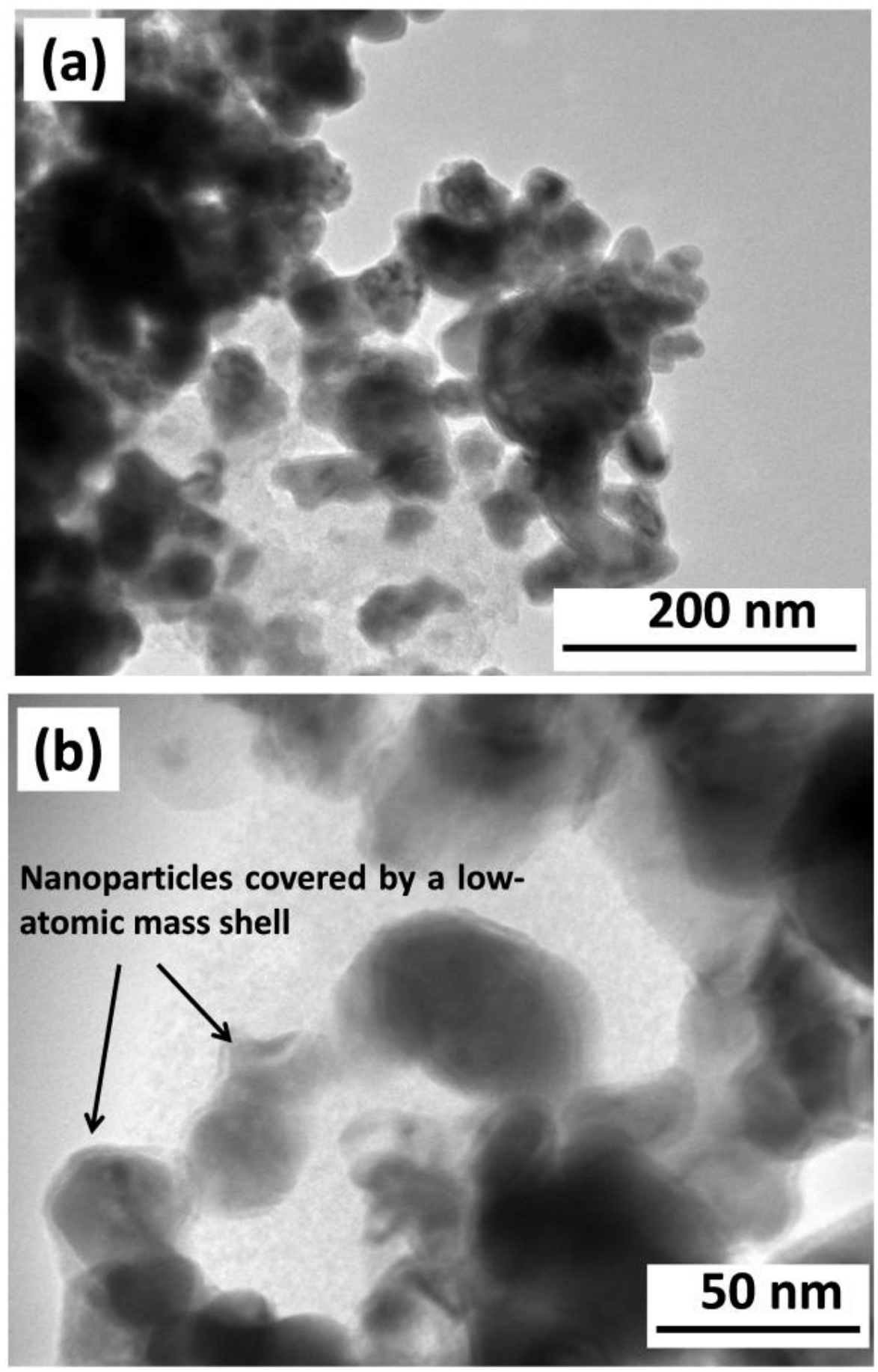

Figure 4.4: TEM images of TaC-HfC nanocomposite powders synthesized via CTR at $1600{ }^{\circ} \mathrm{C}$ for 1.5 hours from recipe $\mathrm{R} 7$ ( $\mathrm{Ta}: \mathrm{Hf}=1: 1$ ) showing the formation of nano-sized particles $(\sim<50 \mathrm{~nm})$ often covered by a low-atomic mass shell that is assumed to be amorphous carbon. 

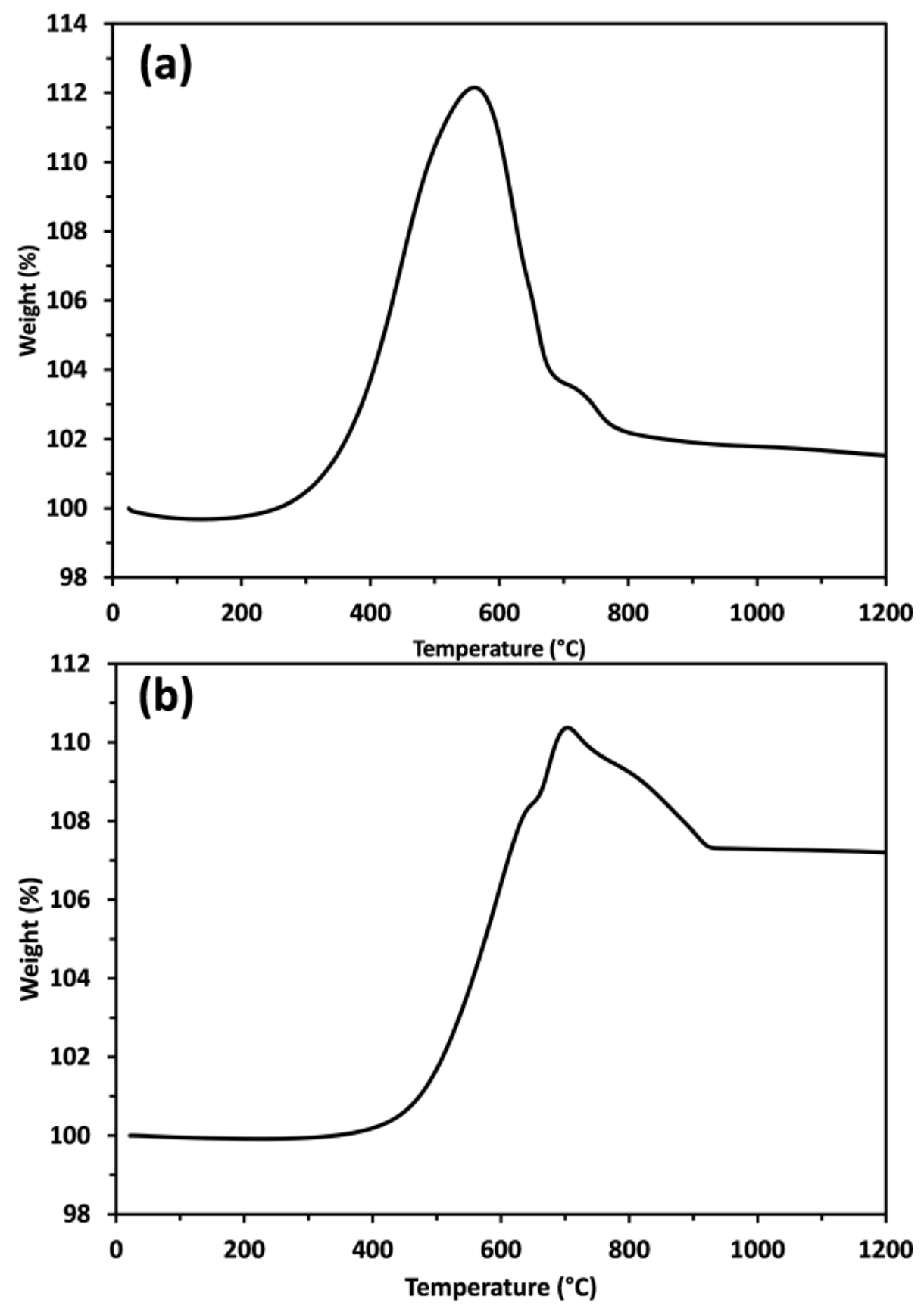

Figure 4.5: TGA analysis in air of synthesized powders at $1600^{\circ} \mathrm{C}$ via $\mathrm{CTR}$ in the tube furnace from aqueous recipes of (a) $\mathrm{R} 7$ (Ta: $\mathrm{Hf}: \mathrm{C}=1: 1: 6.5$ before CTR) and (b) R11 (Ta: Hf : C = $1: 1: 4.87$ before CTR). 
These results suggest that excess carbon content seems to play a dominating role in determining the phase separation in $\mathrm{Ta}_{\mathrm{x}} \mathrm{Hf}_{1-\mathrm{x}} \mathrm{C}$ synthesis via $\mathrm{CTR}$ reaction: Excess carbon would slow down the inter-diffusion dramatically and greatly inhibit the solid solution formation leading to the formation of individual $\mathrm{TaC}$ and $\mathrm{HfC}$ phases. The excess carbon effect may also help explain the variations between observations made in this study and those reported in the literature. For example, Jiang et al. [18] reported the formation of single-phase $\mathrm{Ta}_{0.8} \mathrm{Hf}_{0.2} \mathrm{C}$ solid solution powder after $1600{ }^{\circ} \mathrm{C} / 1$ hour $\mathrm{CTR}$, while in this study, when using recipe R6 with the same target Ta : Hf molar ratio, minor peaks corresponding to HfC were observed (see Figure 4.1(m)). To further confirm this explanation, experiments using an aqueous-based recipe $\mathrm{R} 13(\mathrm{Ta}: \mathrm{Hf}=4: 1)$ with reduced carbon content were carried out. For this sample, the peaks corresponding to HfC were disappeared and merged with $\mathrm{TaC}$ peaks (see Figure 4.1(n)). However, it should be noted that the observed peaks in Figure 4.1(n) do not have the symmetric shape. This non-symmetric distribution in the peak profile can be due to the chemical variation such as inhomogeneity of the solid solution. The lattice parameter (a) for this sample was calculated to be $\sim 0.4486 \mathrm{~nm}$ using the peaks positions in Figure 4.1 (n), which is close to $\mathrm{Ta}_{0.8} \mathrm{Hf}_{0.2} \mathrm{C}$ solid solution lattice parameter as expected from the Vegard's law and the reported JCPDS card $(\mathrm{a}=0.4487 \mathrm{~nm}$, \# 00-064-0146).

Hence, it is advised that in future synthesis great attention should be given to precisely control and optimize carbon precursor content in starting materials for the synthesis of $\mathrm{Ta}_{x} \mathrm{Hf}_{1-\mathrm{x}} \mathrm{C}$ powders: A significant amount of excess carbon would make the uniform solid solution phase difficult to obtain, while too low carbon content might risk incomplete CTR and excessive oxide remaining in the product. It is also noted that the 
observation concerning the dramatic influence of excess carbon on Ta and $\mathrm{Hf}$ cation inter-diffusion may also throw light into understanding the large variation in sintering kinetics observed for TaC-HfC materials.

\subsubsection{Effect of DC Electric Field and Applied Pressure}

Finally, as stated, the authors also performed CTR using pyrolyzed powders from recipe $\mathrm{R} 7(\mathrm{Ta}: \mathrm{Hf}=1: 1)$ in an SPS instrument at $1600{ }^{\circ} \mathrm{C}$ for 15 minutes with a low applied pressure of $5 \mathrm{MPa}$. The purpose was to find out the effect of the external electrical field on the phase formation/separation for $\mathrm{Ta}_{\mathrm{x}} \mathrm{Hf}_{1-\mathrm{x}} \mathrm{C}$ nano powder materials, and it was inspired by the reported advantages of applying electric field and pressure in SPS on accelerating mass transport and sintering kinetics for ceramic materials [89][90][66][96]. The SPS temperature, time, and pressure were all intentionally kept at the low end to avoid excessive sintering/grain growth since the goal was to synthesize $\mathrm{Ta}_{\mathrm{x}} \mathrm{Hf}_{1-\mathrm{x}} \mathrm{C}$ nanopowders and not to sinter the powders into a dense ceramic body. Figure 4.6 (a) shows the XRD pattern for this sample. The diffraction peaks corresponding to individual $\mathrm{TaC}$ and $\mathrm{HfC}$ phases disappeared completely, while the peaks corresponding to the single-phase $\mathrm{Ta}_{0.5} \mathrm{Hf}_{0.5} \mathrm{C}$ solid solution (matching JCPDS card \#98-005-4915 and the expectation from Vegard's law) were observed. The SEM image of this sample shows the formation of fine uniform powder with a grain size of $\sim 100 \mathrm{~nm}$ (see 4.7 (a)). EDS analysis confirmed the Ta : Hf atomic ratio of 1 to 1 , while carbon to total metal (Ta plus Hf) atomic ratio is much higher than 1 to 1 , which is consistent with the TGA result for other samples from recipe R7 (see Figure 4.5 (a)). In comparison, when SPS was

carried out at the same temperature of $1600{ }^{\circ} \mathrm{C}$ but only for 1 minute, the XRD pattern 
shows the formation of clearly phase separated $\mathrm{TaC}$ and $\mathrm{HfC}$ without the detectable amount of either carbide solid solution or oxides. The results from these two experiments suggest that the condition provided by SPS greatly accelerates the inter-diffusion between $\mathrm{TaC}$ and $\mathrm{HfC}$ and promotes the formation of single-phase $\mathrm{Ta}_{\mathrm{x}} \mathrm{Hf}_{1-\mathrm{x}} \mathrm{C}$ solid solution; only $\sim 15$ minutes of isothermal hold is required to achieve the transformation from individual carbides to the solid solution phase, and the solid solution phase would remain upon cooling to room temperature.

In order to confirm if the above observation of accelerated solid solution formation in SPS using sample from recipe R7 is due to the electric field alone and not the low pressure (5 MPa) applied in SPS, another experiment was performed in the SPS at the same temperature of $1600{ }^{\circ} \mathrm{C}$ for the same time of 15 minutes under an even higher pressure of $10 \mathrm{MPa}$. As described before in the experimental section, for this time, the pyrolyzed powders, instead of touching the graphite die punches directly, were sandwiched between two insulating BN disks (see Figure S2.1(c) in the supplementary materials section (2)) so that almost no DC electrical current would pass through the sample. The XRD pattern for this sample is given in 4.6(b). Diffraction peaks corresponding to individual $\mathrm{TaC}$ and $\mathrm{HfC}$ were clearly observed with no hint of any solid solution formation. Hence, it is concluded that the applied pressure (5-10 MPa) does not play a major role in forming of single-phase $\mathrm{Ta}_{0.5} \mathrm{Hf}_{0.5} \mathrm{C}$ solid solution powder, and it is the applied DC electrical field that helps the inter-diffusion between TaC and $\mathrm{HfC}$ and accelerates the solid solution formation process. Simple estimation shows that the $\mathrm{Ta}^{+4} / \mathrm{Hf}^{+4}$ migration length due to the DC electrical field at $1600{ }^{\circ} \mathrm{C}$ for 15 minutes (as used for the CTR via SPS experiment) would be only on the order of $\sim 1 \mathrm{~nm}$, which is 
much shorter than the particle radius. (The readers could refer to supplemental materials (2) for details of the estimation.) Such an analysis suggests that the acceleration of $\mathrm{Ta}_{0.5} \mathrm{Hf}_{0.5} \mathrm{C}$ solid solution formation from individual $\mathrm{TaC}$ and $\mathrm{HfC}$ carbide phases in as short as 15 minutes when using SPS could not be due to the drift effect. Therefore, it is hypothesized that high concentration of vacancies are created under the high current/high flux condition of SPS, which speeds up the diffusion of cations.

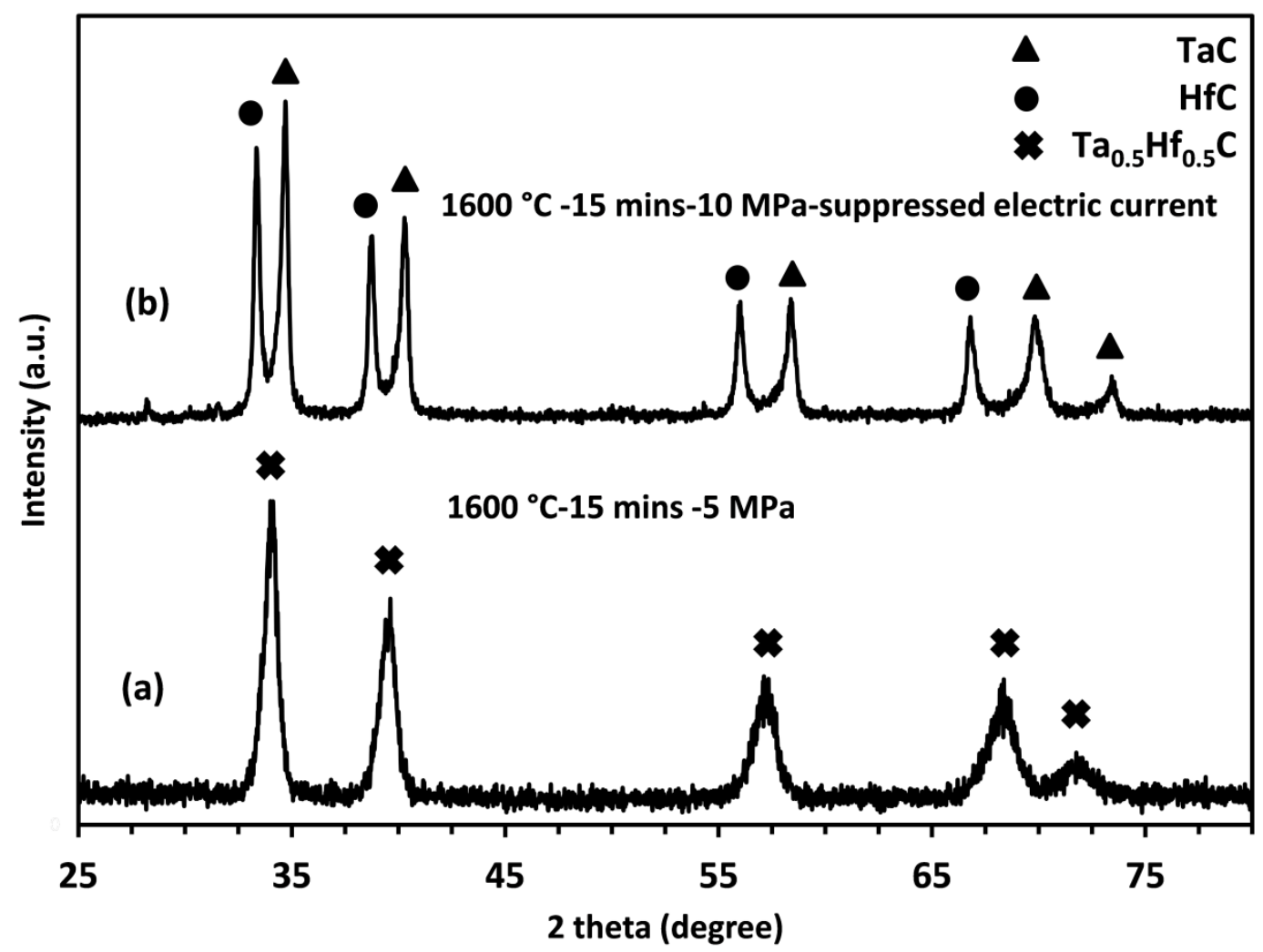

Figure 4.6: XRD patterns of synthesized powders from aqueous recipe $\mathrm{R} 7(\mathrm{Ta}: \mathrm{Hf}=1: 1)$ via CTR in the SPS instrument at $1600{ }^{\circ} \mathrm{C}$ for 15 minutes: (a) under pressure of $5 \mathrm{MPa}$ with current passing through the sample, (b) under pressure of $10 \mathrm{MPa}$ while the electric current passing through the sample was suppressed using BN disks as insulator.

However, it should be noted that, while applied DC electrical field accelerates the mass transport and faster inter-diffusion and facilitate faster formation of uniform solid solution, it has limitation in that the applied DC electrical field also leads to more 
coarsening of the particles. As shown from the SEM image for the sample synthesized via CTR in SPS at $1600{ }^{\circ} \mathrm{C}$ for 15 minutes under the pressure of $5 \mathrm{MPa}$ (see Figure 4.7 (a)): the grain size for the powder is $\sim 100 \mathrm{~nm}$, which is significantly larger than both the sample obtained with BN disks suppressing the electric current during SPS (see Figure 4.7 (b)) showing grain size of only $\sim 50 \mathrm{~nm}$ and the conventional $1600{ }^{\circ} \mathrm{C} / 1.5$ hours CTR sample showing grain size of $50 \mathrm{~nm}$ (see for example Figure 4.3 (b)). The obtained result is also consistent with earlier reports that SPS greatly accelerated the sintering for UHTC such as TaC and HfC compared with conventional sintering [89][90][66][96].
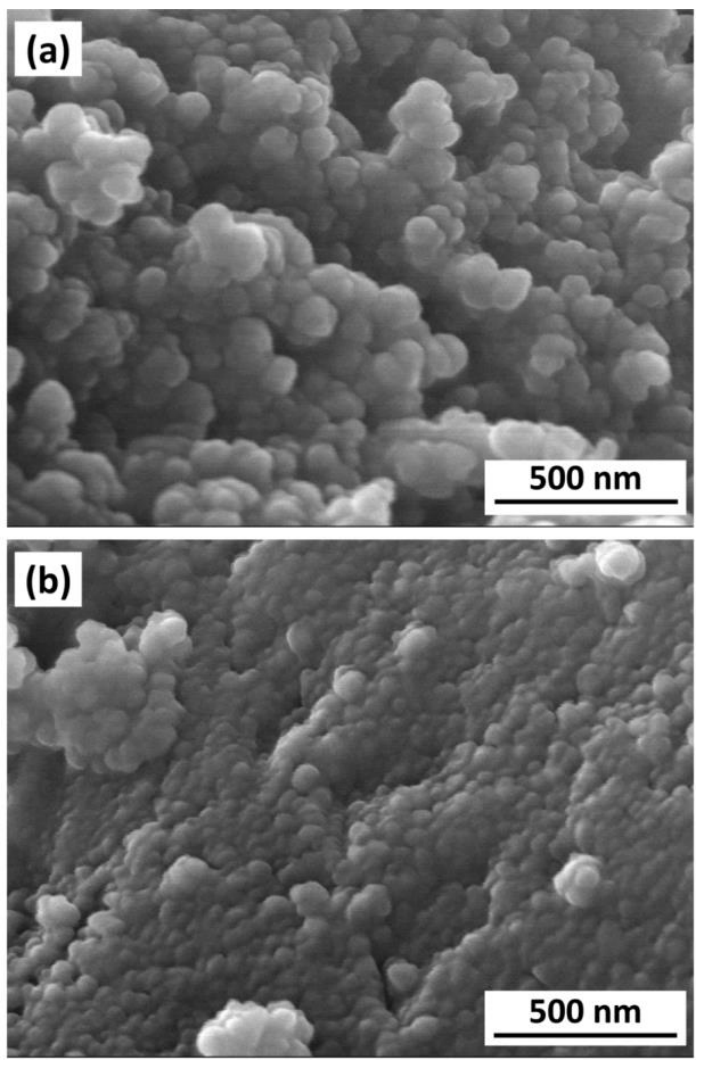

Figure 4.7: SEM micrographs of synthesized powders from recipe R7 (Ta : Hf $=1: 1)$ via CTR in the SPS instrument at $1600{ }^{\circ} \mathrm{C}$ for 15 minutes: (a) under pressure of $5 \mathrm{MPa}$ with electric current passing through the sample, (b) under pressure of $10 \mathrm{MPa}$ while electric current passing through the sample was suppressed using BN disks as insulator. Note that both samples consist of uniform fine powders. However, coarsening due to the electric current passing through the sample is noticeable for (a). 


\subsection{Conclusions}

In this work, the synthesis of the nanocrystalline Ta1-xHfxC solid solution and related nanocomposite powders was achieved using aqueous solution-based processing from low-cost $\mathrm{TaCl}_{5}, \mathrm{HfCl}_{4}$, and carbon sources of sucrose followed by pyrolysis and CTR. Phase separation of $\mathrm{TaC}$ and $\mathrm{HfC}$ was observed for Hf-richer samples of $\mathrm{Ta} 0.5 \mathrm{Hf} 0.5 \mathrm{C}$ regardless of varying processing parameters such as CTR reaction temperature, holding time, and cooling/heating rates as well as solvent type. The strong tendency for forming phase-separated TaC-HfC nano powders composites instead of uniform solid solution powders is attributed to the difference in reactivity between oxides of $\mathrm{Ta}_{2} \mathrm{O}_{5}$ and $\mathrm{HfO}_{2}$ and carbon, which is also related to the immiscibility of those two oxides. Such a difference always leads to the formation of individual $\mathrm{TaC}$ and $\mathrm{HfC}$ nanopowders even after a relatively short CTR time (e.g., 10 minutes at $1600{ }^{\circ} \mathrm{C}$ ). On the other hand, it was discovered that reducing the excess carbon content or the application of a DC electrical field (as through the use of SPS) would significantly accelerate the diffusion and help the formation of single-phase $\mathrm{Ta}_{0.5} \mathrm{Hf}_{0.5} \mathrm{C}$ solid solution powders. (Readers may also refer to Table S2.1 in the supplementary materials for a summary of experimental observation and their implications.) This study illustrates the complexity of the composition-processing-structure relationship during synthesis of multicomponent UHTC nanomaterials. The knowledge generated about how to understand and control phase separation during the synthesis of nano-sized $\mathrm{Ta}_{\mathrm{x}} \mathrm{Hf}_{1-\mathrm{x}} \mathrm{C}$ single-phase solid solution versus two-phase composite powders would enhance understanding of other related phenomena as encountered in sintering of these materials as well as the synthesis of other related multicomponent UHTC materials. 


\subsection{Supplementary Materials (2)}

4.5.1 Schematic(s) of the Set-up(s) used in this Study for Powder Synthesis via Rapid Heating/Cooling Rate CTR and SPS

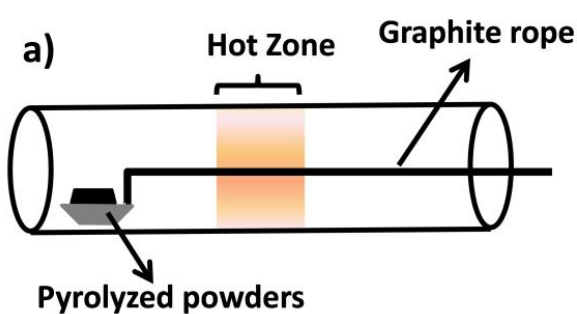

c)

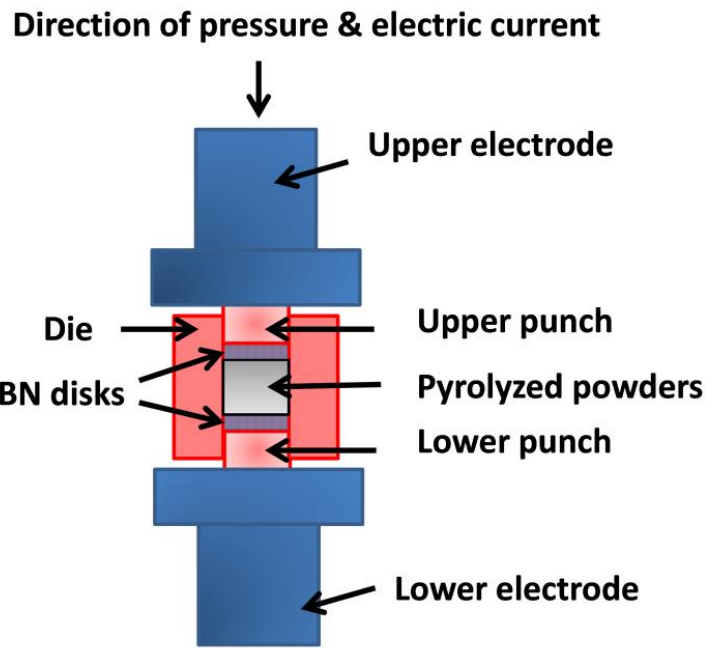

Figure S2.1: Schematic of the set-up for the (a) and (b) rapid heating/cooling rate CTR experiment and (c) schematic of the modified SPS set-up for powder synthesis with suppression of electric current flow via placement of the pyrolyzed powders within the graphite die between two BN disks touching the graphite punches.

\subsubsection{Effect of Pre-Pyrolysis and CTR Heating Rate on Phase Separation}

The influence of the pre-pyrolysis step was also investigated in this study. As mentioned in the experimental section, after solution processing, a separate pre-pyrolysis step at $700{ }^{\circ} \mathrm{C}$ for 1 hour in an inert atmosphere was carried out to remove volatile species (e.g., $\mathrm{H}_{2}, \mathrm{HCl}$, and $\mathrm{CO}$ ) from the dried products and obtain a fine mixture of amorphous $\mathrm{Ta}_{2} \mathrm{O}_{5}-\mathrm{HfO}_{2}$ and carbon. To test if the observation of separate $\mathrm{TaC}$ and $\mathrm{HfC}$ phases is a result of this separate pre-pyrolysis step (that might augment the extent of separation between Ta and Hf oxide regions before CTR), direct CTR heat treatment at $1600{ }^{\circ} \mathrm{C}$ for 1.5 hours was carried out for a dried sample from recipe $\mathrm{R} 7$ (Ta : Hf = $1: 1$ ) without going through the separate pre-pyrolysis step. The result is shown in Figure 
4.1(f) in the main text: Again the observation of well-separated individual $\mathrm{TaC}$ and $\mathrm{HfC}$ diffraction peaks indicates that the pre-pyrolysis does not matter in determining whether the end product is a uniform solid solution or a composite of individual carbides.

On the other hand, researchers had previously noticed the large difference in the chemical reactivities of $\mathrm{Ta}_{2} \mathrm{O}_{5}$ and $\mathrm{HfO}_{2}$ with carbon to form $\mathrm{TaC}$ and $\mathrm{HfC}$ : Figure $\mathrm{S} 2$ shows the calculated standard Gibbs free energy change for the formation of both $\mathrm{TaC}$ and $\mathrm{HfC}$ via CTR reactions using thermochemical data of pure substances assuming $p \mathrm{CO}$ of $1 \mathrm{~atm}$. The plot shows that CTR for $\mathrm{Ta}_{2} \mathrm{O}_{5}$ to form $\mathrm{TaC}$ can occur at much lower temperatures than for $\mathrm{HfO}_{2}$ : For example at $1800 \mathrm{~K}\left(1527^{\circ} \mathrm{C}\right)$, the standard Gibbs free energy change $\left(\Delta \mathrm{G}^{\circ}\right)$ for $\mathrm{CTR}$ of $\mathrm{Ta}_{2} \mathrm{O}_{5}$ to form $\mathrm{TaC}$ is $\sim-173 \mathrm{KJ} / \mathrm{mol}$, which is thermodynamically favored, while $\Delta \mathrm{G}^{\circ}$ for $\mathrm{HfC}$ is still positive $(\sim 48 \mathrm{KJ} / \mathrm{mol})$. Because of this difference in oxides reactivity with carbon to form carbides, it was hypothesized that when using typical slow heating (e.g., $\sim 10{ }^{\circ} \mathrm{C} / \mathrm{min}$ ) for $\mathrm{CTR}, \mathrm{Ta}_{2} \mathrm{O}_{5}$ would start to react first with carbon to form $\mathrm{TaC}$ at lower temperature, while $\mathrm{HfO}_{2}$ could not form until the temperature becomes much higher. Such a difference in reactivities might lead to separation of $\mathrm{TaC}$ from other phases. On the other hand, if the heating rate before CTR is high, it is hypothesized that both $\mathrm{Ta}_{2} \mathrm{O}_{5}$ and $\mathrm{HfO}_{2}$ would reach above the CTR equilibrium temperature in a very short time, and CTR would occur at the same time preventing the phase separation of individual carbides. In fact, it was reported that fast heating rate of $100{ }^{\circ} \mathrm{C} / \mathrm{min}$ for $\mathrm{CTR}$ seemed to enable the formation of uniform $\mathrm{Ta}_{0.8} \mathrm{Hf}_{0.2} \mathrm{C}$ solid solution powder at a temperature as low as $1500{ }^{\circ} \mathrm{C}$.

In order to test this hypothesis of very high heating rate prevents TaC-HfC phase separation, a sample from recipe $\mathrm{R} 7(\mathrm{Ta}: \mathrm{Hf}=1: 1)$ was subjected to $\mathrm{CTR}$ at $1600{ }^{\circ} \mathrm{C}$ 
for 1.5 hours with rapid heating $\left(\sim 500^{\circ} \mathrm{C} / \mathrm{min}\right)$ as explained in the experimental section. The XRD pattern for this sample is given in Figure $4.1(\mathrm{~g})$ in the main text showing partially overlapping yet still separated XRD peaks, which suggests that fast heating seems to help somewhat, but it could not completely prevent the phase separation of TaC and HfC phases.

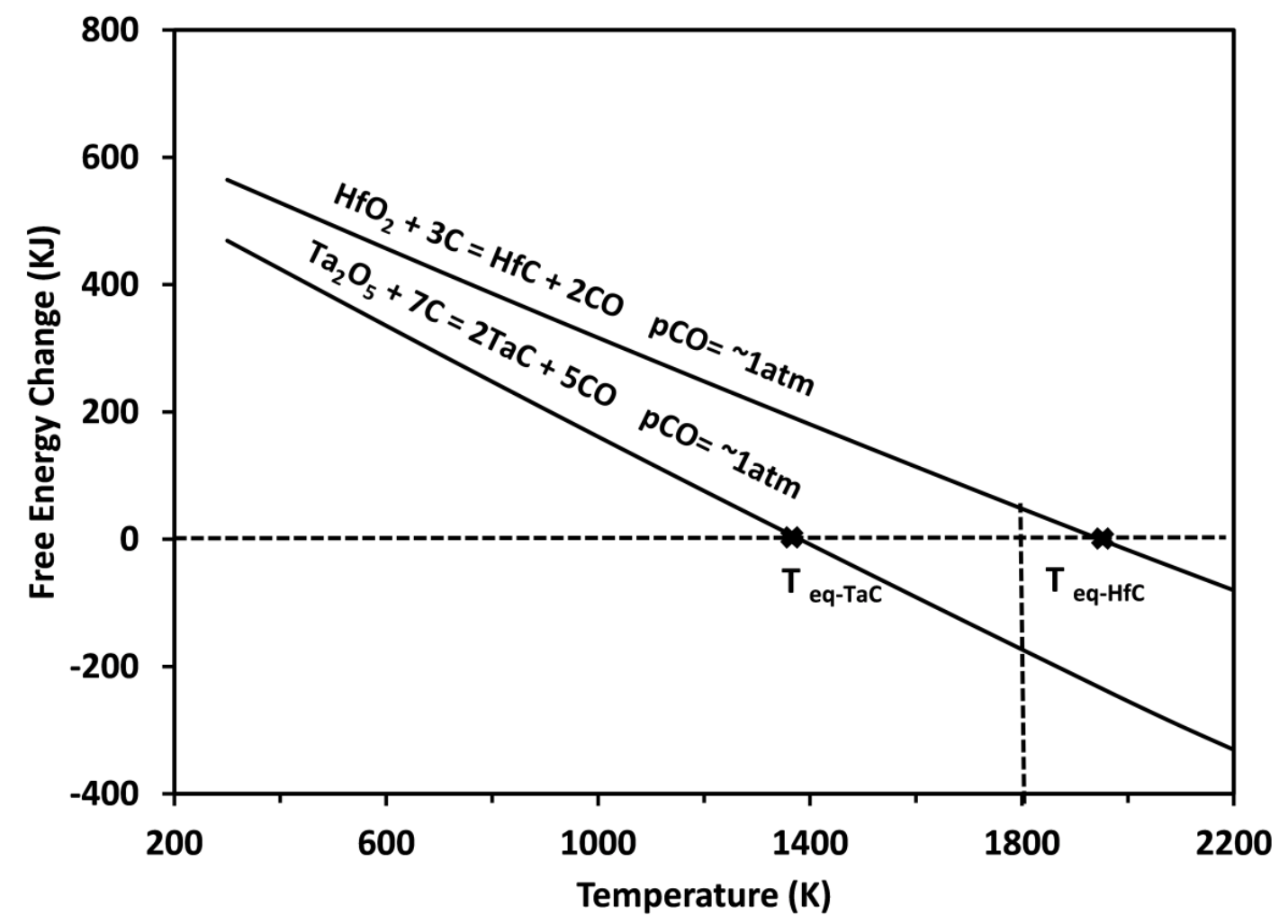

Figure S2.2: Gibbs free energy change as a function of temperature at $\mathrm{pCO}=1 \mathrm{~atm}$. The temperature at which $\Delta G=0$ is considered as the equilibrium temperature $\left(\mathrm{T}_{\mathrm{eq}}\right)$.

\subsubsection{Estimation of $\mathrm{Ta}^{+4} / \mathrm{Hf}^{+4}$ Migration Length due to the DC Electrical Field}

To understand the electrical field effect on carbide solid solution formation, it is noted that, apart from the concentration gradient, electric field can also act as a driving force for the motion of atoms/ions. The application of a DC electric field $E$ will cause a drift motion of ions (in this case $\mathrm{Ta}^{4+}$ and $\mathrm{Hf}^{4+}$ ) with an average drift velocity of $\bar{v}$ : 


$$
\bar{v}=\mu \cdot E
$$

where $\mu$ is the mobility for the species of interest. As a first approximation, the total cation flux $\left(J_{t}\right)$ would be the diffusion flux due to the concentration gradient plus the flux caused by the electric field:

$\mathbf{J}_{\mathrm{t}}=\mathbf{J}_{\text {diffusion }}+\mathbf{J}_{\text {drift }}=-\mathrm{D} \frac{\partial \mathrm{C}}{\partial \mathrm{x}}+\overline{\mathrm{v}} \mathrm{C}$

where $D$ is the diffusion coefficient and $C$ is the concentration of diffusing atoms. Based on Einstein's relation, ion mobility and diffusion coefficient are related by:

$$
\frac{\mu}{\mathrm{D}}=\frac{\mathrm{q}}{\mathrm{kT}}
$$

where $q$ is the electrical charge of the ion $\left(4 \times 1.6 \times 10^{-19} \mathrm{C}\right.$ for $\mathrm{Ta}^{4+}$ and $\left.\mathrm{Hf}^{4+}\right), k$ is the Boltzmann's constant and $T$ is the absolute temperature. Here, the mobility of Ta cations at $1600{ }^{\circ} \mathrm{C}$ can be estimated: Consider the observation that a uniform solid solution with primary particle size of $\sim 500 \mathrm{~nm}$ was formed from a 4TaC-1HfC phase separated sample after diffusion at $1600{ }^{\circ} \mathrm{C}$ for 10 hours (Please see SEM image and related XRD patterns for the sample from recipe R6 synthesized via CTR at $1500{ }^{\circ} \mathrm{C}$ for $3 \mathrm{~h}$, which was then annealed for 10 hours at $1600{ }^{\circ} \mathrm{C}$, as given in Figure 4.3 in the main text.), the interdiffusion coefficient ( $\widetilde{D}$ ) can be estimated using:

$$
x=\sqrt{\tilde{D} t}
$$

where $t$ is the annealing time, which is $36000 \mathrm{sec}$ (10 hours), and $x$ is the diffusion plength, which is assumed to be the average grain size of $\sim 500 \mathrm{~nm}$. The effective inter- 
diffusion coefficient was estimated to be on the order of $7 \times 10^{-18} \mathrm{~m}^{2} \mathrm{~s}^{-1}$. It is recognized that the estimated $\tilde{D}$ is for the specific composition of $\mathrm{Ta}_{0.8} \mathrm{Hf}_{0.2} \mathrm{C}$ from recipe R6. Nevertheless, because the system of TaC-HfC forms a continuous solution at high temperature, and the diffusion coefficients for Ta and Hf are similar, the relative change in $\tilde{D}$ with respect to concentration would not be very large, and roughly the same number could be used to estimate the mobility for the composition of $\mathrm{Ta}_{0.5} \mathrm{Hf}_{0.5} \mathrm{C}$. Therefore, using equation (S2.3), the ion mobility could be estimated to be $1.7 \times 10^{-16} \mathrm{~m}^{2} \mathrm{~V}^{-1} \mathrm{~s}^{-1}$. Consider the distance between the two graphite punches is $\sim 0.001 \mathrm{~m}$ and the voltage $U$ was kept constant of $5.7 \mathrm{~V}$ during the SPS heat treatment, the DC electric field would be:

$\mathrm{E}=\frac{\mathrm{U}}{\mathrm{d}}=\frac{5.7}{0.001}=5700 \mathrm{v} / \mathrm{m}$

Therefore, using equation (S2.1), the drift velocity $\bar{v}$ can be estimated as $1.0 \times 10^{-12}$ $\mathrm{ms}^{-1}$. Hence, the $\mathrm{Ta}^{+4} / \mathrm{Hf}^{+4}$ migration length due to the DC electrical field at $1600{ }^{\circ} \mathrm{C}$ for 15 minutes (as used for the CTR via SPS experiment) would be only on the order of $\sim 1$ $\mathrm{nm}$, which is much shorter than the particle radius. 


\subsubsection{Summary of Experimental Observation and Their Implications}

Table S2.2: Summary of experimental observation and their implications

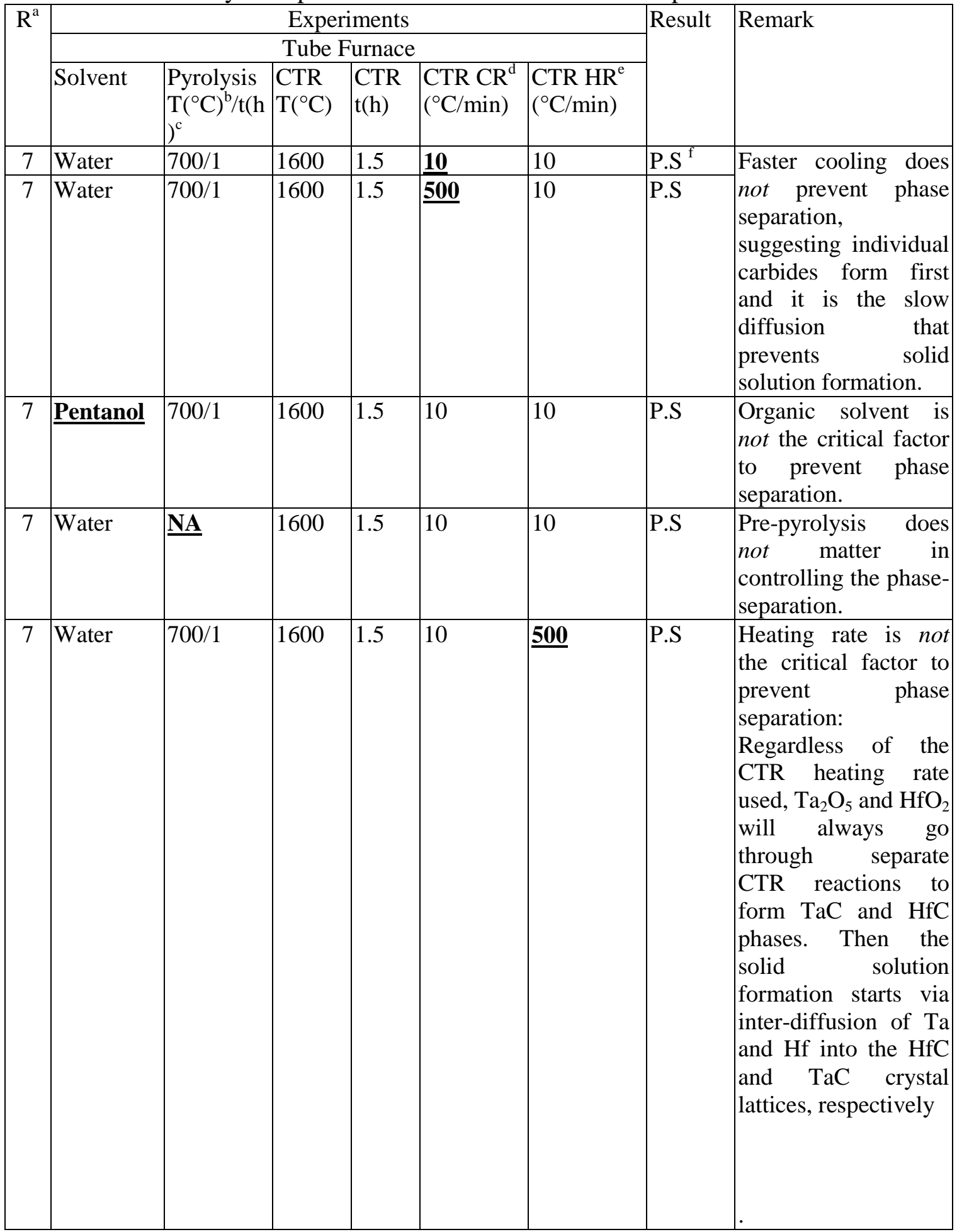




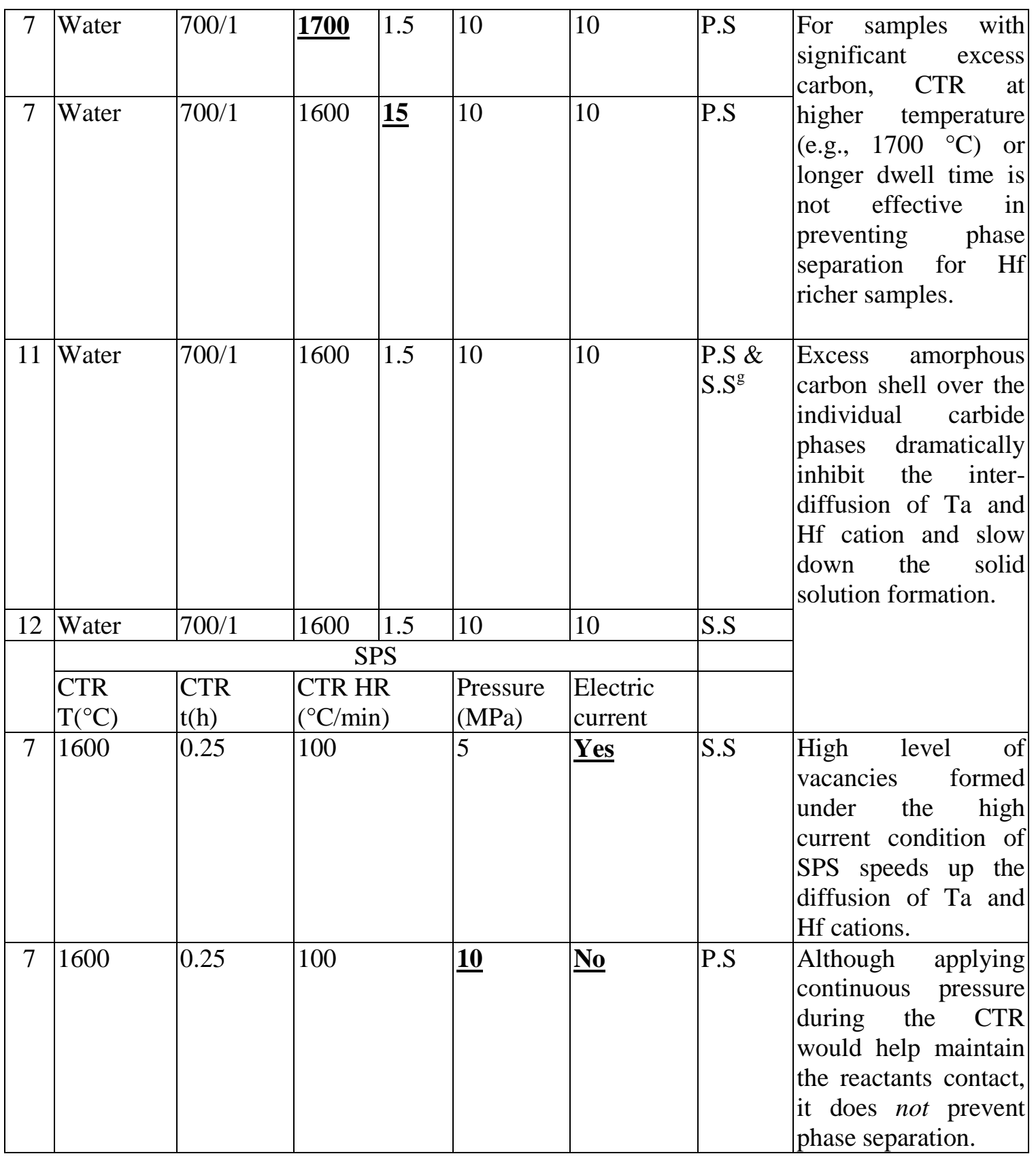

a: Recipe b: Temperature c: Time d:Cooling Rate e:Heating Rate f:Phase-

Separated

$\mathrm{g}:$ Solid Solution 
Chapter V: Phase Control during Synthesis of Nanocrystalline Ultrahigh

Temperature Tantalum-Hafnium Diboride Powders

This chapter details the study on controlling the phase separation of $\mathrm{Ta}_{\mathrm{x}} \mathrm{Hf}_{1-\mathrm{x}} \mathrm{B}_{2}$ solid solution powders during the synthesis process via CTR and AMR methods.

\subsection{Introduction}

Borides, carbides and nitrides of group IV-V transition metals are considered as ultrahigh temperature ceramics (UHTCs). Recently, a great deal of attention has been paid to boride UHTCs due to their excellent thermal and chemical stability, high hardness, good thermal shock resistance and decent electrical conductivity. Among all boride UHTCs, hafnium diboride $\left(\mathrm{HfB}_{2}, \mathrm{~T}_{\mathrm{m}}=3250{ }^{\circ} \mathrm{C}\right)$ and zirconium diboride $\left(\mathrm{ZrB}_{2}\right.$, $\mathrm{T}_{\mathrm{m}}=3000{ }^{\circ} \mathrm{C}$ ) are of particular interest because they maintain their strength at elevated temperatures (e.g., $1200{ }^{\circ} \mathrm{C}$ ), have high resistivity to erosion/corrosion, and also form stable high melting point oxides (e.g., $\mathrm{HfO}_{2}, \mathrm{~T}_{\mathrm{m}}=2758{ }^{\circ} \mathrm{C}$ ). Hence, they are promising candidates for ultrahigh temperature aerospace applications such as rocket propulsion, hypersonic flight and atmospheric reentry.[26,60,86,87,97,98]

However, despite the outstanding properties mentioned above, non-ideal oxidation resistance is one of the major issues limiting the use of $\mathrm{HfB}_{2}$ and $\mathrm{ZrB}_{2}$. For example, in a scenario such as hypersonic flight vehicles in the upper atmosphere, hafnium oxide $\left(\mathrm{HfO}_{2}\right)$ and zirconium oxide $\left(\mathrm{ZrO}_{2}\right)$ may become nonstoichiometric under low oxygen partial pressure conditions by forming oxygen lattice vacancies, which would enable significant oxygen ion transportation throughout the oxide layer and facilitate the 
oxidation process. Another issue with these ceramics is their low fracture toughness, amounting to serious concerns with reliability under severe thermal shock and cyclic loading conditions. [26][25][24][99]

Previous studies have found that properties of binary UHTCs including borides could be further improved in terms of oxidation resistance and/or mechanical properties by tailoring the composition, such as using alloying elements to form solid solutions or composites. [20,65,87,100,101] In particular, researchers have observed that addition of $\mathrm{TaB}_{2}$ could enhance the oxidation resistance of $\mathrm{HfB}_{2}$ and $\mathrm{ZrB}_{2}$ by forming tantalum pentoxide $\mathrm{Ta}_{2} \mathrm{O}_{5}\left(\mathrm{~T}_{\mathrm{m}}=1880{ }^{\circ} \mathrm{C}\right)$ during oxidation, which has a lower melting point than $\mathrm{HfO}_{2}\left(\mathrm{~T}_{\mathrm{m}}=2758{ }^{\circ} \mathrm{C}\right)$ and $\mathrm{ZrO}_{2}\left(\mathrm{~T}_{\mathrm{m}}=2715^{\circ} \mathrm{C}\right)$. Hence, during the oxidation process at high temperatures $\mathrm{Ta}_{2} \mathrm{O}_{5}$ melts before $\mathrm{HfO}_{2} / \mathrm{ZrO}_{2}$ and helps the formation of an oxide layer with higher density. On the other hand, introduction of $\mathrm{Ta}^{5+}$, which has a higher valence than $\mathrm{Zr}^{4+} / \mathrm{Hf}^{4+}$ would decrease the oxygen vacancy concentration in $\mathrm{HfO}_{2} / \mathrm{ZrO}_{2}$ and, as a result, reduce the oxygen ion transportation through the oxide layer and slow down the oxidation process. [97][26][25]

In addition to composition, particle size of the synthesized powders is also critical since reducing the size from micron to submicron or even nano $(<100 \mathrm{~nm})$ range could benefit post-synthesis processing by reducing the need for extensive milling/grinding and/or decreasing the sintering temperature/time. Achieving finer microstructure for sintered parts could also lead to improved mechanical properties due to the grain size reduction.[14,86,102][74] All these motivate the research on the synthesis of submicron/nano-sized $\mathrm{Ta}_{1-\mathrm{x}} \mathrm{Hf}_{\mathrm{x}} \mathrm{B}_{2}$ and $\mathrm{Ta}_{1-\mathrm{x}} \mathrm{Zr}_{\mathrm{x}} \mathrm{B}_{2}$ ternary solid solution and related composite powders. 
Although synthesis of boride UHTC powders has been studied before $[26][103][104][105]$, most of the reported methods suffer from some disadvantages, such as inferior product quality, high cost, or concerns with process safety. Moreover, those reported methods were mainly used to synthesize binary UHTC borides and very limited effort has been devoted to the synthesis of ternary UHTC boride solid solution or composite powders. To the best of authors' knowledge, only Xie et al. [26][27] has synthesized $\mathrm{TaB}_{2}-\mathrm{ZrB}_{2}$ powders using typical sol-gel method [106,107] followed by carbothermal reduction reaction (CTR) at temperatures up to $1800{ }^{\circ} \mathrm{C}$ under flowing argon. However, the high cost of the organometallic precursors, the use of non-aqueous solvents, and related issues with waste disposal make that method less favorable. In addition, it is noted that despite the phase diagram suggesting complete solid-solution formation at the CTR temperature (e.g., $~ 1400-1800^{\circ} \mathrm{C}$ ) [108], only a $\mathrm{TaB}_{2}-\mathrm{ZrB}_{2}$ twophase composite powder was obtained instead of a uniform single phase $\operatorname{Ta}_{0.25} \mathrm{Zr}_{0.75} \mathrm{~B}_{2}$ solid solution powder.

In this study, the authors chose the target system of $\mathrm{Ta}_{0.5} \mathrm{Hf}_{0.5} \mathrm{~B}_{2}$ since $\mathrm{HfB}_{2}$ could form a higher melting point composite/solid solution with $\mathrm{TaB}_{2}$ thanks to its higher melting point when compared with $\mathrm{ZrB}_{2}$. Moreover, there is no report on the synthesis of nanocrystalline powders of $\mathrm{Ta}_{0.5} \mathrm{Hf}_{0.5} \mathrm{~B}_{2}$ single phase solid solution or related composites. Two methods were adopted for the synthesis. The first, named CTR-based method, starts from aqueous solution processing of low-cost tantalum pentachloride $\left(\mathrm{TaCl}_{5}\right)$, hafnium tetrachloride $\left(\mathrm{HfCl}_{4}\right)$, water soluble hydrocarbon of sucrose and boron trioxide $\left(\mathrm{B}_{2} \mathrm{O}_{3}\right)$ as the metal, carbon and boron sources, respectively. It then resorts to subsequent heat treatment(s) of the solution processed products to convert the precursors into an intimate, 
molecular-scale mixture of (amorphous) metal oxides, boron trioxide, and carbon that reacts further at high temperature (e.g., $1500{ }^{\circ} \mathrm{C}$ or higher) through the carbothermal reduction reaction (CTR) to yield the desired boride(s) with emission of carbon monoxide (CO) gas. A representative CTR reaction for the formation of a metal diboride $\mathrm{MB}_{2}$ from the corresponding oxide $\mathrm{M}_{\mathrm{x}} \mathrm{O}_{\mathrm{y}}, \mathrm{B}_{2} \mathrm{O}_{3}$, and carbon can be written as below:

$$
\mathrm{M}_{x} \mathrm{O}_{y}+x \mathrm{~B}_{2} \mathrm{O}_{3}+(3 x+y) C \rightarrow x \mathrm{MB}_{2}+(3 x+y) \mathrm{CO}
$$

The second synthesis method is based on alkali metal reduction (AMR) reaction in which the same low-cost metal precursors of $\mathrm{TaCl}_{5}$ and $\mathrm{HfCl}_{4}$ are directly reduced by a strong alkali metal-based reducing agent such as sodium borohydride $\left(\mathrm{NaBH}_{4}\right)$ without the intermediate step of oxide formation. Previous studies have shown that binary transition diborides (e.g., $\mathrm{ZrB}_{2}$ and $\mathrm{TiB}_{2}$ ) could be synthesized using AMR of metal halides (e.g., $\mathrm{ZrCl}_{4}$ and $\mathrm{TiCl}_{4}$ ) [59][104]. As an example, the overall reaction for the formation of $\mathrm{ZrB}_{2}$ via $\mathrm{AMR}$ is written as below:

$\mathrm{ZrCl}_{4}+2 \mathrm{NaBH}_{4} \rightarrow \mathrm{ZrB}_{2}+2 \mathrm{NaCl}+3 \mathrm{H}_{2}$ Eq. 5.2

It should be mentioned that AMR reactions as written above are only a simplification because at elevated temperatures $\left(>500{ }^{\circ} \mathrm{C}\right), \mathrm{NaBH}_{4}$ may decompose and form sodium hydride $(\mathrm{NaH})$ and boron hydride $\left(\mathrm{BH}_{3}\right)$ and the actual process would be more complex. Nevertheless, there has been no study on the synthesis of ternary transition diboride solid solution powders using the AMR method and this is explored in this study. For both synthesis methods, the synthesized powders were characterized using various techniques with the focus on understanding and controlling the formation of a single phase boride 
UHTC solid solution powder versus a two boride composite powder in the synthesis process.

\subsection{Experimental}

In this study, totally, five recipes were adopted, as summarized in Table 5.1 . Recipe R8 and R9 are for the synthesis of $\mathrm{Ta}_{0.5} \mathrm{Hf}_{0.5} \mathrm{~B}_{2}$ using the first CTR-based method. The starting metal precursors used are tantalum pentachloride $\left(\mathrm{TaCl}_{5}, 99.8 \%\right.$, Alfa Aesar \# 14164) and hafnium tetrachloride $\left(\mathrm{HfCl}_{4}, 98+\%\right.$, Alfa Aesar \# 11834), while sucrose (99.5\%, Sigma \# S9378) and boron trioxide $\left(\mathrm{B}_{2} \mathrm{O}_{3}, 98.5 \%\right.$, Alfa Aesar \# 12290) were used as the carbon and boron sources, respectively. In terms of processing sequence, $\mathrm{TaCl}_{5}$ and $\mathrm{HfCl}_{4}$ were hydrolyzed separately in DI water giving a fine white tantalum oxychloride $\left(\mathrm{TaOCl}_{3}\right)$ precipitate suspension and a colorless hafnium oxychloride $\left(\mathrm{HfOCl}_{2}\right)$ solution, respectively, which were then mixed with sucrose and $\mathrm{B}_{2} \mathrm{O}_{3}$. The obtained mixed suspensions were stirred continuously on a hot plate using a magnetic stir bar until they get dried (the solution temperature was measured to be $\left.\sim 100{ }^{\circ} \mathrm{C}\right)$.

Table 5.1: Molar ratio of the starting materials for all recipes

\begin{tabular}{lccc}
\hline Recipe \# & Solvent & Catalyst & $\mathrm{TaCl}_{5}: \mathrm{HfCl}_{4}: \mathrm{C}_{12} \mathrm{H}_{22} \mathrm{O}_{11}: \mathrm{B}_{2} \mathrm{O}_{3}$ molar ratio \\
\hline R8 & DI water & NA & $1: 1: 1.14: 3.4$ \\
R9 & DI water & $\mathrm{Cu}^{*}$ & $1: 1: 1.14: 3.4$ \\
\hline R14 & NA & NA & $\mathrm{TaCl}_{5}: \mathrm{HfCl}_{4}: \mathrm{NaBH}_{4}$ molar ratio \\
R17 & NA & NA & $1: 1: 6$ \\
R18 & NA & NA & $0: 1: 8$ \\
\hline
\end{tabular}

* $\mathrm{Cu}$ added at weight ratio of $2 \%$ with respect to total weight of dried precursor powders obtained from aqueous solution processing followed by drying on a hot 
The dried samples were then placed in a graphite boat and heat treated in a tube furnace at temperatures in the range of $\sim 1500-1600{ }^{\circ} \mathrm{C}$ in flowing argon atmosphere (UHP grade, Airgas) at a flow rate of $\sim 80 \mathrm{cc} / \mathrm{min}$ and heating/cooling rate of $10^{\circ} \mathrm{C} / \mathrm{min}$. During the heat treatment, the dried materials first go through pyrolysis at $\sim 400-600{ }^{\circ} \mathrm{C}$ during the heating stage to remove low molecular weight species such as water, carbon monoxide $(\mathrm{CO})$, and other volatile organic species and yield a mixture of oxides and carbon. As the furnace temperature increases further to $\sim 1500{ }^{\circ} \mathrm{C}$ or higher, the CTR reaction between oxides and carbon occurs (e.g., see Eq. 5.1) to produce the boride phase(s). For samples based on recipe R9, Cu metal powder (Fisher Chemical \# 10965) as a potential catalyst or, more precisely, diffusion promoter, was also added to the dried sample followed by grinding and thorough mixing using a mortar and pestle prior to the CTR heat treatment.

For the second synthesis method based on alkali metal reduction or AMR process, the metal precursors were kept the same, while sodium borohydride $\left(\mathrm{NaBH}_{4}, 98+\%\right.$, Acros Organics \# 13432) was used as both the reducing agent and the boron source. Recipe R14 targets $\mathrm{Ta}_{0.5} \mathrm{Hf}_{0.5} \mathrm{~B}_{2}$, while R17 and R18 target pure $\mathrm{HfB}_{2}$ and $\mathrm{TaB}_{2}$, respectively for comparison purpose. The metal salt of $\mathrm{TaCl}_{5}$ and/or $\mathrm{HfCl}_{4}$ together with $\mathrm{NaBH}_{4}$ powders, were mixed using a mortar and pestle in a glove box (VAC Nexus I, Hawthorne, CA, USA) to avoid precursors reacting with/absorbs oxygen and/or moisture. Then, the mixed powders were poured into a graphite boat with a graphite cap. To achieve subsequent AMR reaction, the samples in the graphite boat were heat treated isothermally in a tube furnace at $700{ }^{\circ} \mathrm{C}$ for 24 hours in argon (UHP grade, Airgas) with a flow rate of $\sim 80 \mathrm{cc} / \mathrm{min}$. The obtained powders were then washed several times with hot 
water $\left(\sim 70{ }^{\circ} \mathrm{C}\right)$ to remove impurities such as sodium chloride $(\mathrm{NaCl})$. After having washed the samples, the products were separated by pouring off the water from the top of the container.

All products obtained from the two synthesis methods were characterized by Xray diffraction (Siemens D5000) for phase identification. Scanning electron microscope (SEM JEOL JSM-6330F) and transmission electron microscope (TEM Phillips CM-200) were used to study the morphology and particle size of the synthesized powders. In addition, BET surface area of selected synthesized powders was measured with a Micromeritics TriStar II (TriStar II 3020 V1.03) gas adsorption analyzer. Thermogravimetric analysis (TGA) was carried out for selected powders in the air with the constant heating rate of $10{ }^{\circ} \mathrm{C} / \mathrm{min}$ to determine the oxidation resistance.

\subsection{Results and Discussion}

5.3.1 Phase Separation in $\mathrm{Ta}_{0.5} \mathrm{Hf}_{0.5} \mathrm{~B}_{2}$ Powders for CTR-based Method and its Mitigation

Figure 5.1 (a) illustrates the XRD pattern for a sample from recipe R8 after CTR at $1500{ }^{\circ} \mathrm{C}$ for 3 hours. Based on the Ta-Hf-B ternary phase diagram [108] a continuous solid solution of $\mathrm{Ta}_{0.5} \mathrm{Hf}_{0.5} \mathrm{~B}_{2}$ should form at this CTR temperature. However, herein, two sets of distinct diboride peaks are observed: One set of diffraction peaks corresponds very well with the JCPDS for $\mathrm{HfB}_{2}$ (JCPDS\# 98-008-5316), suggesting almost pure $\mathrm{HfB}_{2}$, while the other set suggests $\mathrm{TaB}_{2}$ (JCPDS\# 98-008-5398) but with peaks shifting consistently towards lower $2 \theta$ angles compared with pure $\mathrm{TaB}_{2}$. The implication of such an observation is that, contrary to the expectation of a single-phase solid solution, which should give a single set of merged peaks located in between corresponding $\mathrm{HfB}_{2}$ and 
$\mathrm{TaB}_{2}$ diffraction peaks, a two-phase mixture of $\mathrm{HfB}_{2}$ and Ta-rich $\mathrm{Ta}_{1-x} \mathrm{Hf}_{x} \mathrm{~B}_{2}$ ( $x$ estimated to be $\sim 0.38$ using Vegard's law) is obtained. This observation is similar to that from Xie et al.'s earlier attempt on synthesizing $\mathrm{TaB}_{2}-\mathrm{ZrB}_{2}$ powders, [26] for which instead of a single phase $\mathrm{Ta}_{0.25} \mathrm{Zr}_{0.75} \mathrm{~B}_{2}$ solid solution, two-phase composite powders of (almost) pure $\mathrm{ZrB}_{2}$ along with solid solution $\left(\mathrm{Ta}_{1-x} \mathrm{Zr}_{x}\right) \mathrm{B}_{2}$ ( $x$ estimated by the present authors to be 0.65) were obtained despite the fact that Xie et al. started from careful sol-gel processing of organometallic $\mathrm{Ta}, \mathrm{Zr}$, and $\mathrm{B}$ precursors dissolved in organic solvents followed by heat treatments including CTR (e.g., at $1600-1800{ }^{\circ} \mathrm{C}$ for 2 hours). It is noted that two small peaks corresponding to TaC (JCPDS\# 98-000-9884) could be observed at $2 \theta$ between $34-42^{\circ}$ for the XRD pattern in Figure 4.1(a). This is attributed to slight boron deficiency due to $\mathrm{B}_{2} \mathrm{O}_{3}$ evaporation during the CTR process at high temperatures $\left(1500{ }^{\circ} \mathrm{C}\right.$ in this case). 


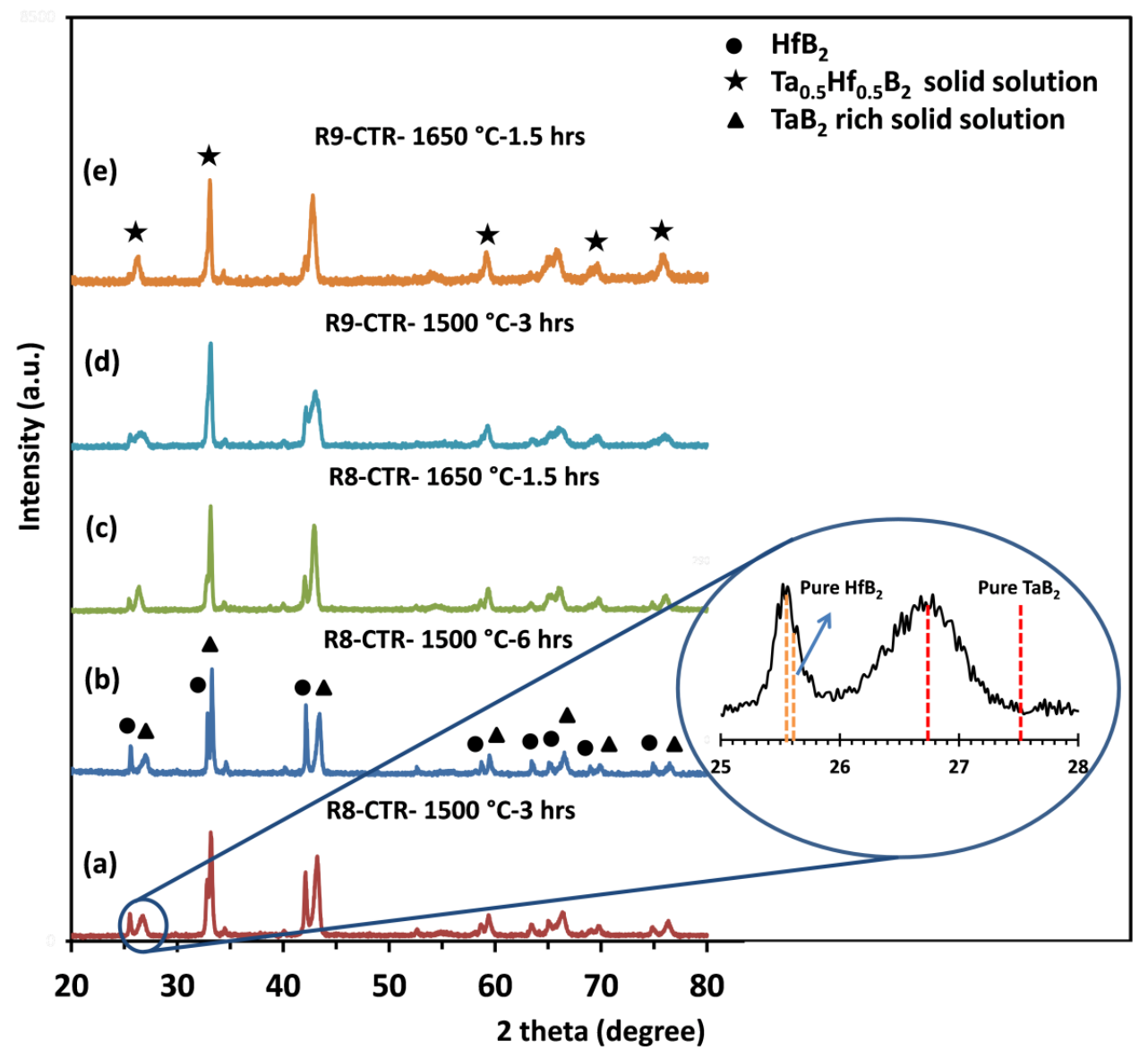

Figure 5.1: XRD patterns of all samples synthesized via CTR method from different recipes at various temperature and time.

Figure 5.2 (a) is the SEM image of this sample showing the formation of uniform submicron-sized $(\sim 200-300 \mathrm{~nm})$ powder despite the sample is actually a composite of $\mathrm{HfB}_{2}$ and Ta-rich $\mathrm{Ta}_{1-x} \mathrm{Hf}_{x} \mathrm{~B}_{2}(x \approx 0.38)$ solid solution as suggested by $\mathrm{XRD}$. Because increasing the CTR dwell time to 6 hours at $1500{ }^{\circ} \mathrm{C}$ for a sample from the same recipie R8 did not seem to make much difference in reducing the extent of phase separation between the two diborides (see Figure 5.1 (b)), the CTR temperature was increased to accelerate the diffusion rate in the hope to achieve a single phase solid solution.

Figure 5.1(c) shows the XRD pattern for a sample from recipe R8 after CTR at $1650{ }^{\circ} \mathrm{C}$ for 1.5 hours. The merging of diffraction peaks appear more obvious and the 
relative intensity for $\mathrm{HfB}_{2}$ peaks becomes weaker, but significant residual $\mathrm{HfB}_{2}$ can still be observed. In addition, due to the higher CTR temperature used, the SEM images for that sample show noticeable grain growth with particle size increasing to $\sim 300-400 \mathrm{~nm}$ (see Figure 5.2 (b)). Therefore, concerns with excessive grain growth put an upper limit on the CTR temperature that could be applied in the pursuit of single-phase diboride solid solution powders with nano-sized grains.
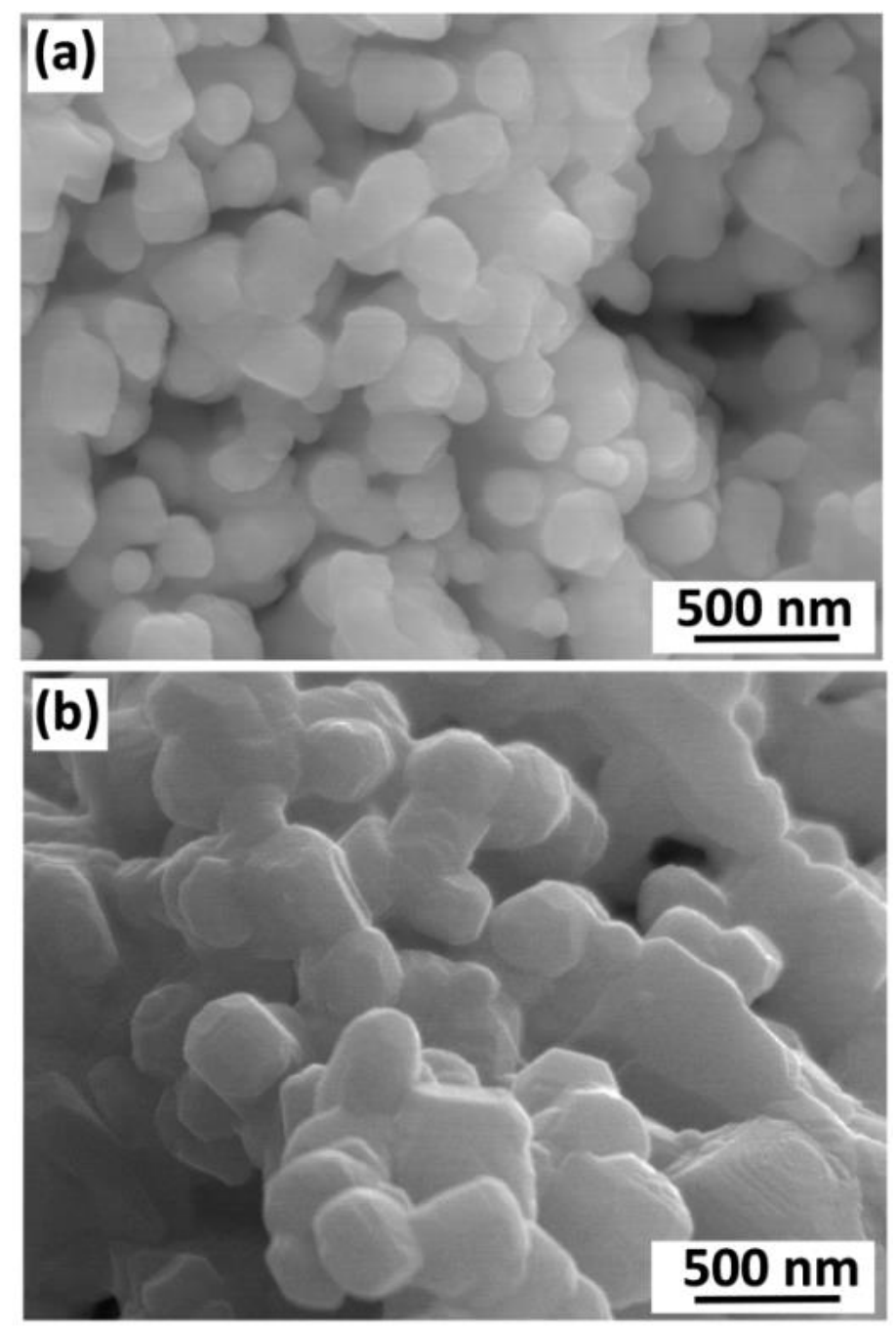

Figure 5.2: SEM micrographs of synthesized powders from recipe R8 via the CTR-based method at (a) $1500{ }^{\circ} \mathrm{C}$ for 3 hours and (b) $1650{ }^{\circ} \mathrm{C}$ for 1.5 hours. Both samples shows relatively uniform submicron-sized particles with coarsening due to the higher CTR temperature more noticeable for the $1650{ }^{\circ} \mathrm{C} / 1.5$ hours sample. 
As to the origin for the persistent phase separation into two individual diborides during the synthesis of $\mathrm{Ta}_{1-x} \mathrm{Hf}_{x} \mathrm{~B}_{2}$ (as well as $\mathrm{Ta}_{1-x} \mathrm{Zr}_{x} \mathrm{~B}_{2}$ ) powders, it is noted that our previous study on a similar $\mathrm{Ta}_{1-x} \mathrm{Hf}_{x} \mathrm{C}$ system [9] had shown that although according to the TaC-HfC phase diagram, $\mathrm{Ta}_{1-x} \mathrm{Hf}_{x} \mathrm{C}$ solid solutions should form at temperatures above $887^{\circ} \mathrm{C}$, this process is noticeably limited by the slow diffusion of the cations. Therefore, TaC-HfC two-phase composite powders instead of single phase solid solution powders are usually obtained from the CTR-based synthesis method. For the current boride system, as mentioned, the Ta-Hf-B phase diagram indicates complete solid solution at temperatures such as $1500{ }^{\circ} \mathrm{C}$ and above. [108] However, the results exhibited in Figure 5.1 (a-c) suggest that $\mathrm{TaB}_{2}-\mathrm{HfB}_{2}$ system seems to have the same issue with slow cation diffusion. In fact, it was found in this study that for samples from the same recipe $\mathrm{R} 8$, CTR reaction to form the individual $\mathrm{TaB}_{2}$ and $\mathrm{HfB}_{2}$ phases finishes within $\sim 15$ minutes at $1600{ }^{\circ} \mathrm{C}$ (see Figure S3.1 in supplementary materials (3)). Therefore, it is the relatively slow interdiffusion of $\mathrm{Ta}$ and $\mathrm{Hf}$ cations between the two individual diborides (i.e., $\mathrm{TaB}_{2}$ and $\mathrm{HfB}_{2}$ ) relative to the fast $\mathrm{CTR}$ reactions (i.e., between $\mathrm{Ta}$ and $\mathrm{Hf}$ and $\mathrm{B}$ oxides and carbon to form $\mathrm{TaB}_{2}$ and $\mathrm{HfB}_{2}$ individually) that limits the formation of the uniform single-phase diboride solid solution such as $\mathrm{Ta}_{0.5} \mathrm{Hf}_{0.5} \mathrm{~B}_{2}$.

Also similar to the observed persistent phase separation for the TaC-HfC system, the underlying reason for the tendency of $\mathrm{Ta}_{2} \mathrm{O}_{5}$ and $\mathrm{HfO}_{2}$ to react separately with carbon as well as $\mathrm{B}_{2} \mathrm{O}_{3}$ via CTR to form phase separated composite of $\mathrm{HfB}_{2}$ and Ta-rich $\mathrm{Ta}_{1-}$ ${ }_{x} \mathrm{Hf}_{x} \mathrm{~B}_{2}$ can be attributed to several factors: First, the oxides of $\mathrm{Ta}_{2} \mathrm{O}_{5}$ and $\mathrm{HfO}_{2}$ have very low solubility of each other, which means before CTR, the two oxides have great tendency to separate from each other, especially at higher temperature (e.g., > 1000 ${ }^{\circ} \mathrm{C}$ ) 
when they evolve to be crystalline from the amorphouse state after solution processing. [26][100][27][109] Although there is no published phase diagram for $\mathrm{Ta}_{2} \mathrm{O}_{5}-\mathrm{HfO}_{2}$, literature suggests $\mathrm{Ta}_{2} \mathrm{Hf}_{6} \mathrm{O}_{17}$ is reported to be the only composition in-between the two ends (i.e., $\mathrm{Ta}_{2} \mathrm{O}_{5}$ and $\mathrm{HfO}_{2}$ ) for the Ta-Hf-O system and it forms only at very high temperatures (above $1800{ }^{\circ} \mathrm{C}$ ) [110]. In this study, the authors also annealed a $50: 50$ mixture (by molar) from $\mathrm{TaCl}_{5}$ and $\mathrm{HfCl}_{4}$ solution processing at $1500{ }^{\circ} \mathrm{C}$ in air for 6 hours. The XRD result shows the formation of crystalline $\mathrm{Ta}_{2} \mathrm{O}_{5}$ and $\mathrm{HfO}_{2}$ without any sign of significant solid solution formation (i.e., no shift in XRD peaks corresponding to $\mathrm{Ta}_{2} \mathrm{O}_{5}$ and $\mathrm{HfO}_{2}$, see Figure S3.2 in supplementary materials (3)). These, together with the low mutual solubility in the system of $\mathrm{Ta}_{2} \mathrm{O}_{5}$ and $\mathrm{ZrO}_{2},[109]$ which should have great similarity to $\mathrm{HfO}_{2}$, lead to the conclusion that $\mathrm{Ta}_{2} \mathrm{O}_{5}$ and $\mathrm{HfO}_{2}$ have very limited solubility of each other and the two oxides tend to separate from each other during heat treatment at elevated temperatures (e.g., $>\sim 1500{ }^{\circ} \mathrm{C}$ ). Second, there is also a significant difference between $\mathrm{Ta}_{2} \mathrm{O}_{5}$ versus $\mathrm{HfO}_{2}$ in terms of their reactivity with carbon as well as $\mathrm{B}_{2} \mathrm{O}_{3}$ to form $\mathrm{TaB}_{2}$ and $\mathrm{HfB}_{2}$, respectively. To illustrate this, Figure 5.3 shows the calculated standard Gibbs free energy change for the formation of both $\mathrm{TaB}_{2}$ and $\mathrm{HfB}_{2}$ via CTR reaction using thermochemical data of pure substances [111] assuming $p \mathrm{CO}$ to be $1 \mathrm{~atm}$. The plot indicates that the CTR reaction for $\mathrm{Ta}_{2} \mathrm{O}_{5}$ to react with carbon and $\mathrm{B}_{2} \mathrm{O}_{3}$ to form $\mathrm{TaB}_{2}$ could occur at much lower temperatures compared to $\mathrm{HfO}_{2}$. For example, at $1500 \mathrm{~K}\left(1227^{\circ} \mathrm{C}\right)$, the standard Gibbs free energy change $\left(\Delta \mathrm{G}^{\circ}\right)$ for CTR of $\mathrm{Ta}_{2} \mathrm{O}_{5}-\mathrm{B}_{2} \mathrm{O}_{3}$ is $-179 \mathrm{KJ} / \mathrm{mol}$, while this number for $\mathrm{HfB}_{2}$ is still positive $(239 \mathrm{KJ} / \mathrm{mol})$ suggesting that at $1500 \mathrm{~K}$ under standard pressure, the CTR reaction for $\mathrm{TaB}_{2}$ formation 
is energetically favorable and could proceed, while it is thermodynamically forbidden for $\mathrm{HfB}_{2}$.

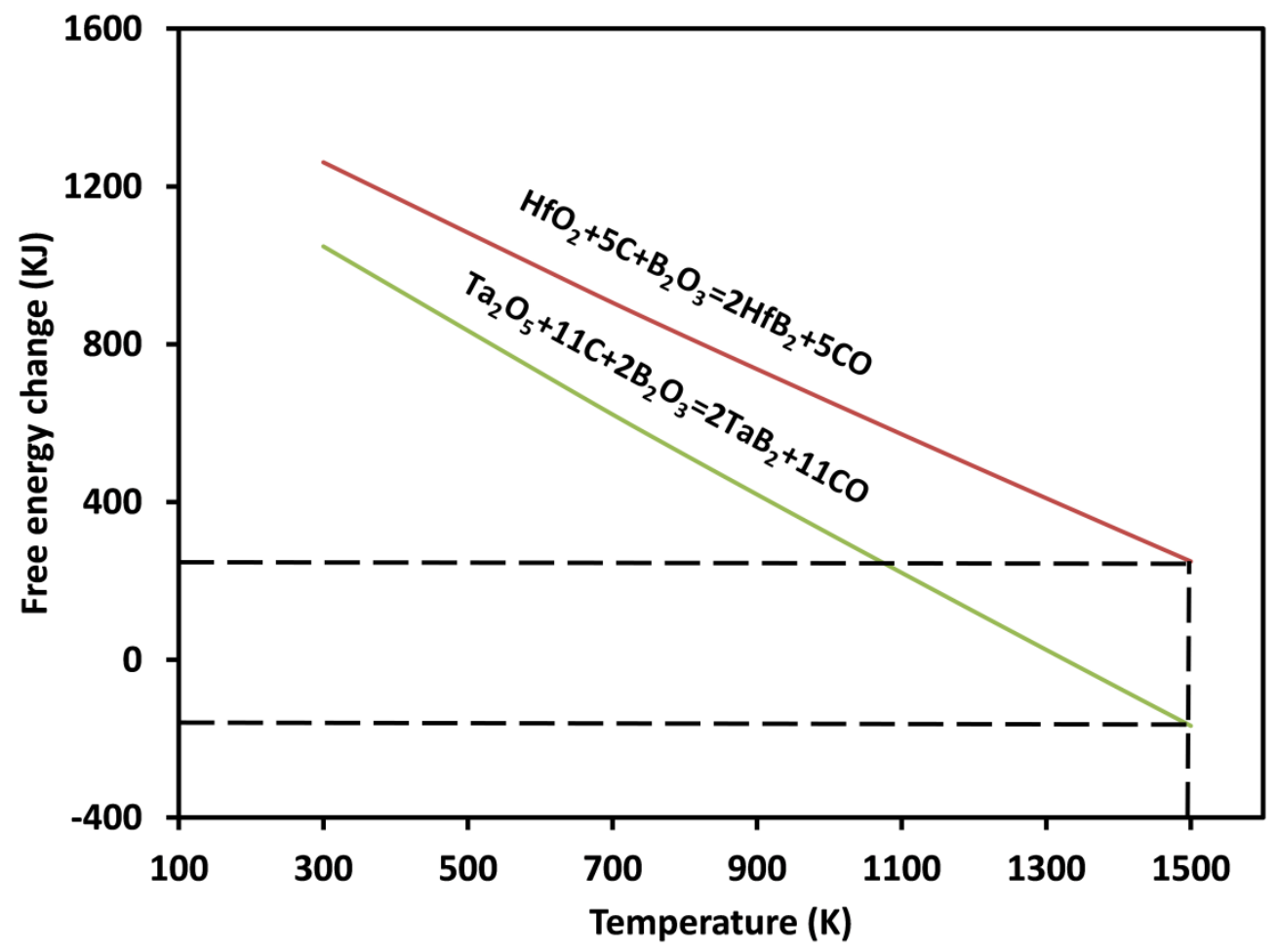

Figure 5.3: Calculated standard Gibbs free energy change as a function of temperature at $p \mathrm{CO}=1 \mathrm{~atm}$ for the formation of $\mathrm{TaB}_{2}$ and $\mathrm{HfB}_{2}$ from carbothermal reduction (CTR) reaction.

Because of these factors, i.e., the low solubility of $\mathrm{Ta}_{2} \mathrm{O}_{5}$ and $\mathrm{HfO}_{2}$ in each other and the large difference between $\mathrm{Ta}_{2} \mathrm{O}_{5}$ versus $\mathrm{HfO}_{2}$ in their reactivity with carbon and $\mathrm{B}_{2} \mathrm{O}_{3}$ to form the corresponding diborides, $\mathrm{Ta}_{2} \mathrm{O}_{5}$ and $\mathrm{HfO}_{2}$ always go through separate CTR reactions to form $\mathrm{TaB}_{2}$ and $\mathrm{HfB}_{2}$. Upon extended heat treatment at high temperature, these borides start to inter-diffuse to gradually form the ternary solid solution. It is worth mentioning that, as already explained in the experimental section, the hydrolysis of $\mathrm{TaCl}_{5}$ in DI water is indeed very fast giving rise to the formation of a suspension of fine $\mathrm{TaOCl}_{3}$ precipitates, while $\mathrm{HfCl}_{4}$ dissolves completely in DI water forming a uniform colorless $\mathrm{HfOCl}_{2}$ solution. These observations raise the concern that 
the phase separation into individual diborides $\left(\mathrm{TaB}_{2}\right.$ and $\left.\mathrm{HfB}_{2}\right)$ observed during the CTR might originate from the difference in hydrolysis behaviors of $\mathrm{TaCl}_{5}$ and $\mathrm{HfCl}_{4}$, i.e., the precipitation of $\mathrm{TaOCl}_{3}$ and resulting separation from the mixed solution. However, it is noted that even when using the delicate sol-gel processing starting from expensive organometallic precursors and less polar organic solvents, as carried out by Xie et al. that completely avoid separation in the solution processing stage, persistent phase separation between $\mathrm{TaB}_{2}$ and $\mathrm{ZrB}{ }_{2}$ still occurred after $\mathrm{CTR}$ for the synthesis of $\mathrm{TaB}_{2}-\mathrm{ZrB}_{2}$ powders [26][27], which should be very similar to the current $\mathrm{TaB}_{2}-\mathrm{HfB}_{2}$ system given the great similarity between Hf and Zr. On the other hand, the current authors also had studied the effect of solution processing of $\mathrm{TaCl}_{5}$ and $\mathrm{HfCl}_{4}$ on the phase separation for a similar TaC-HfC system in a previous work [10]. The results showed that althgouh using sol-gel method did prevent the separation of Ta and Hf species during the solution processing stage, it did not prevent phase separation during subsequent CTR to form carbides, especially for intermediate compositions such as $\mathrm{Ta}_{50} \mathrm{Hf}_{50} \mathrm{C}$ with comparable $\mathrm{Ta}$ and $\mathrm{Hf}$ molar content. These lead to the conclusion that solution processing condition is not the key to preventing phase separation of individual binary diborides during CTR reaction for the current $\mathrm{TaB}_{2}-\mathrm{HfB}_{2}$ system.

Therefore, in order to obtain single-phase $\mathrm{Ta}_{1-x} \mathrm{Hf}_{x} \mathrm{~B}_{2}$ solid solution powders using the CTR-based synthesis method for such a system, it seems necessary to accelerate the inter-diffusion between the two individual diborides. To achieve this, the authors hypothesized that the presence of a liquid phase "catalyst" or diffusion promoter during the CTR process might help accelerate the diffusion leading to the formation of singlephase solid solution at lower CTR temperatures and/or for shorter holding times. 
Figure 5.1 (d) shows the XRD pattern for a sample after CTR at $1500{ }^{\circ} \mathrm{C}$ for 3 hours from recipe $\mathrm{R} 9$, which is identical to recipe $\mathrm{R} 8$ with the exception that 2 wt.\% $\mathrm{Cu}$ metal powders was added to the dried precursor powders (obtained from aqueous solution processing followed by drying on an hot plate) as the "catalyst" or diffusion promoter. Compared to the sample without $\mathrm{Cu}$ at the same CTR temperature and time (see Figure 5.1(a)), the sample with $\mathrm{Cu}$ addition shows much greater extent of solid solution formation with diffraction peaks of $\mathrm{HfB}_{2}$ decreased significantly, while the peaks for Tarich solid solution shift more towards lower $2 \theta$ angle and broaden and merge more with the $\mathrm{HfB}_{2}$ peaks, suggesting more $\mathrm{Hf}$ incorporation into the lattice (see Figure 5.1 (a) vs. Figure 5.1(d)). When the CTR temperature was increased further to $1650{ }^{\circ} \mathrm{C}$, as shown in Figure 5.1 (e), the individual $\mathrm{HfB}_{2}$ and Ta-rich $\mathrm{TaB}_{2}$ peaks have almost completely merged together, implying that $\mathrm{Ta}_{0.5} \mathrm{Hf}_{0.5} \mathrm{~B}_{2}$ solid solution powder with very little residual $\mathrm{HfB}_{2}$ phase has been successfully prepared. Compared to the sample from recipe R8 synthesized via CTR under the same condition (see Figure 5.1 (c)), the samples show better results in terms of solid solution formation. It is noted that for both samples, no $\mathrm{Cu}$ were detected. This suggests most of the $\mathrm{Cu}$ added had evaporated, which is reasonable due to its low melting point $\left(\sim 1085^{\circ} \mathrm{C}\right)$ and relatively high vapor pressure. On the other hand, although $\mathrm{Cu}$ addition seems to facilitate inter-diffusion of cations and formation of solid solution, characterization of the samples microstructure indicates that it also leads to coarsening of the obtained powders. As shown from the SEM images for the sample from recipe $\mathrm{R} 9$ synthesized via $\mathrm{CTR}$ at $1650{ }^{\circ} \mathrm{C}$ for 1.5 hours, the particle size for the powder increased to $\sim 600-700 \mathrm{~nm}$ (see Figure 5.4 (a)), which is significantly larger than the sample obtained from recipe $\mathrm{R} 8$ (without $\mathrm{Cu}$ ) synthesized at the same CTR 
temperature and time showing particle size of $\sim 300-400 \mathrm{~nm}$ (see Figure 5.4 (b)). This, similar to the adoption of higher CTR temperature, shows the limitation with the CTRbased method in trying to obtain single-phase solid solution nanocrystalline powders.

Finally, it is noted that other than copper metal, some other additives or "catalysts" as potential liquid diffusion promoters during CTR had also been considered. However, due to drawbacks such as high vapor pressure (e.g., molten salt of sodium chloride or $\mathrm{NaCl}$ ) or reactivity with carbon (e.g., silicon) and/or boron (e.g., iron), those other additives did not yield as significant results as copper.
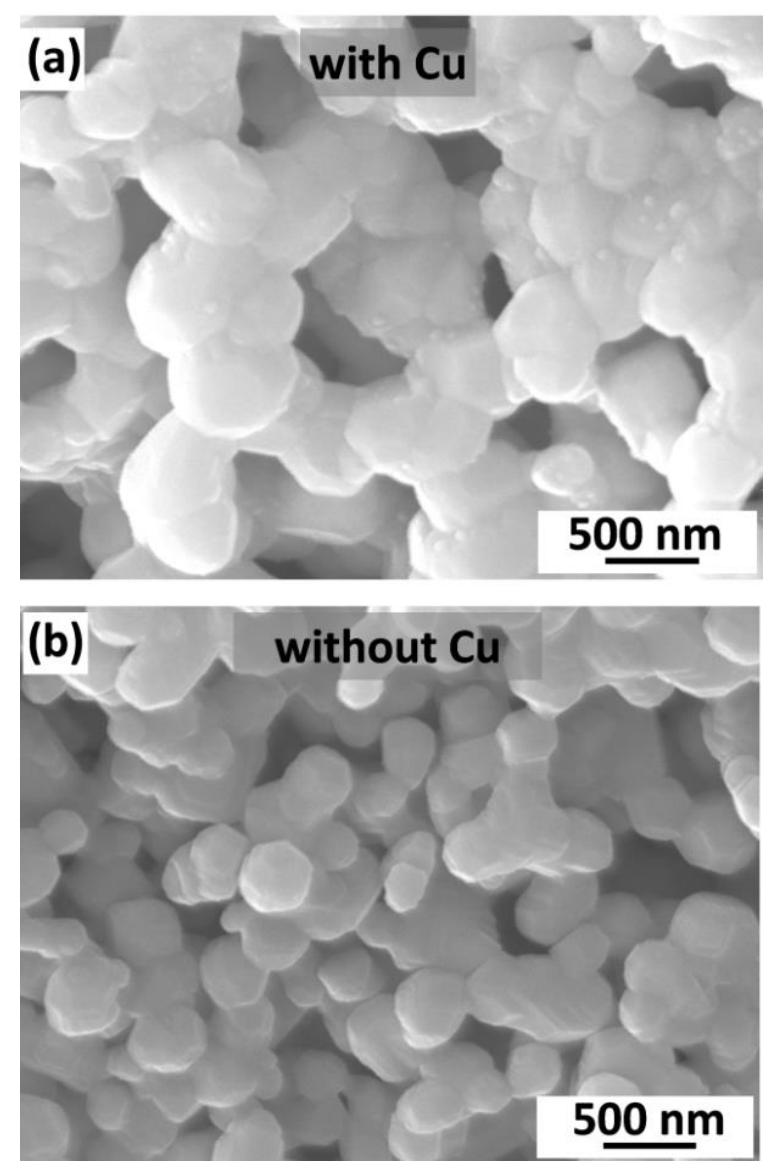

Figure 5.4: SEM micrographs of synthesized powders after CTR at $1650^{\circ} \mathrm{C}$ for 1.5 hours from (a) recipe $\mathrm{R} 9$, which contains copper metal $(\mathrm{Cu})$ as a "catalyst" or, more precisely, a diffusion promoter and (b) recipe $\mathrm{R} 8$, which does not contain $\mathrm{Cu}$, respectively. Particle coarsening due to the presence of the liquid $\mathrm{Cu}$ as a diffusion promoter during the CTR process is noticeable for the sample from recipe $\mathrm{R} 9$ with $\mathrm{Cu}$ (a). 


\subsubsection{Preparation of Nanocrystalline $\mathrm{Ta}_{0.5} \mathrm{Hf}_{0.5} \mathrm{~B}_{2}$ Solid Solution Powders via AMR Method}

From the previous section, it is seen that for the CTR-based method, the $\mathrm{TaCl}_{5}$ and $\mathrm{HfCl}_{4}$ precursors go through solution-based processing and turn into (amorphous) oxides of $\mathrm{Ta}_{2} \mathrm{O}_{5}$ and $\mathrm{HfO}_{2}$. that react further with carbon as well as $\mathrm{B}_{2} \mathrm{O}_{3}$ in subsequent high temperature carbothermal reduction reaction or CTR to form the diborides. However, as mentioned, $\mathrm{Ta}_{2} \mathrm{O}_{5}$ and $\mathrm{HfO}_{2}$ have very low affinity for each other and do not readily form a solid solution, while they also have very different reactivity with carbon and $\mathrm{B}_{2} \mathrm{O}_{3}$. The result is that $\mathrm{Ta}_{2} \mathrm{O}_{5}$ and $\mathrm{HfO}_{2}$ would always react separately with carbon as well as $\mathrm{B}_{2} \mathrm{O}_{3}$ to form $\mathrm{TaB}_{2}$ and $\mathrm{HfB}_{2}$, which then need to inter-diffuse to each other at high temperatures to form theTa $a_{1-x} \mathrm{Hf}_{x} \mathrm{~B}_{2}$ solid solution phase, and the overall reaction for the formation of $(\mathrm{Ta}-\mathrm{Hf}) \mathrm{B}_{2}$ solid solution powder via CTR is a multi-step process. Although higher CTR temperature or the addition of a diffusion promoter (e.g., copper metal powder) seems to help accelerate the diffusion and solid solution formation, they result in undesirable grain coarsening, which is contrary to the objective of trying to obtain nanocrystalline diboride solid solution powders.

On the other hand, as mentioned in the introduction, the synthesis of metal diboride has also been achieved using the alkali metal reduction or AMR method. It is noted that during AMR the metal chlorides directly get reduced by a strong reducing agent such as $\mathrm{NaBH}_{4}$ and it does not involve the formation of metal oxides. Hence, the authors hypothesized that this AMR-based method might be applicable for the synthesis of nanocrystalline powders of single-phase ternary UHTC diboride solid solutions by 
completely avoiding the metal oxides formation stage and associated tendency for phase separation in the resulting ternary diborides.

Figure 5.5 (a) shows the XRD pattern for a pure HfB2 sample synthesized from $\mathrm{R} 17$ after $\mathrm{AMR}$ at $700{ }^{\circ} \mathrm{C}$ for 24 hours in a covered graphite boat in the flowing argon atmosphere. All diffraction peaks match JCPDS card \#98-008-5316 for $\mathrm{HfB}_{2}$, suggesting high product purity. The pattern shows dramatic peak broadening indicating the formation of very small grains on the order of $\sim 6 \mathrm{~nm}$ as estimated by Scherrer equation. Figure 5.5 (c) shows the XRD pattern for a pure $\mathrm{TaB}_{2}$ sample synthesized from recipe $\mathrm{R} 18$ via $\mathrm{AMR}$ also at $700{ }^{\circ} \mathrm{C}$ for 24 hours. The diffraction peaks match perfectly with JCPDS card \# 98-008-5398 for $\mathrm{TaB}_{2}$. However, compared with $\mathrm{HfB}_{2}$, peaks corresponding to $\mathrm{TaB}_{2}$ are broader suggesting the formation of even smaller grains (size estimated to be $\sim 3.5 \mathrm{~nm}$ ). In comparison, Figure 5.5 (b) shows the XRD pattern for a sample from recipe R14 synthesized via the AMR method also at $700{ }^{\circ} \mathrm{C}$ for 24 hours with the target composition of $\mathrm{Ta}_{0.5} \mathrm{Hf}_{0.5} \mathrm{~B}_{2}$. Unlike the samples synthesized from the CTR-based method, the diffraction peaks corresponding to individual $\mathrm{TaB}_{2}$ and $\mathrm{HfB}_{2}$ merged completely into a single set of broad peaks that correspond to $\mathrm{Ta}_{0.5} \mathrm{Hf}_{0.5} \mathrm{~B}_{2}$ solid solution (JCPDS \# 98-004-9539). The SEM image for this $\mathrm{Ta}_{0.5} \mathrm{Hf}_{0.5} \mathrm{~B}_{2}$ solid solution sample shows highly agglomerated powders with particle size of $\sim 50-100 \mathrm{~nm}$ (see Figure 5.6). The BET surface area for the sample is measured to be $4.9 \mathrm{~m}^{2} / \mathrm{g}$, and the estimated avarge particle size using this number is $\sim 100 \mathrm{~nm}$ (See supplementary materials (3)) for the calculation steps), which is consistent with the SEM observations (see Figure 5.6 (a)). Figure 5.6(b) shows the TEM image for this sample. It confirms the formation of nanopowders with individual grain size on the order of $\sim 3-5 \mathrm{~nm}$. 


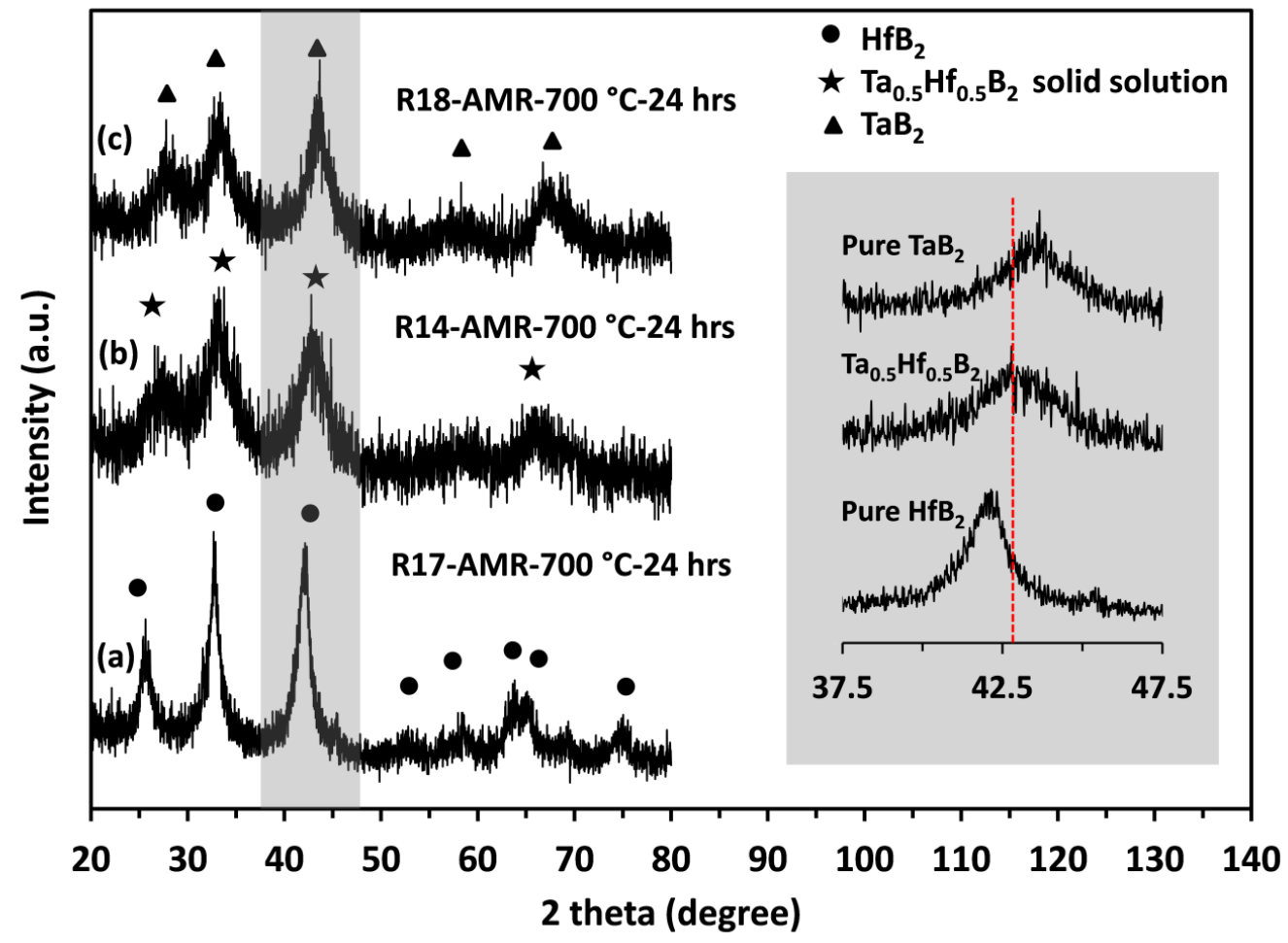

Figure 5.5: XRD patterns of three samples synthesized via the alkaline metal reduction (AMR) method from different recipes after the AMR reaction at $700{ }^{\circ} \mathrm{C}$ for 24 in close graphite boat in a tube furnace with flow argon atmosphere: (a) from recipe $\mathrm{R} 17$ targeting pure $\mathrm{HfB}_{2}$, (b) from recipe R14 targeting $\mathrm{Ta}_{0.5} \mathrm{Hf}_{0.5} \mathrm{~B}_{2}$, and (c) from recipe $\mathrm{R} 18$ targeting pure $\mathrm{TaB}_{2}$.

The measured $\mathrm{d}$-spacing from the lattice fringes is $\sim 0.34 \mathrm{~nm}$, as shown in Figure 5.6 (c), which is very close to that for the (0001) plane of $\mathrm{Ta}_{0.5} \mathrm{Hf}_{0.5} \mathrm{~B}_{2}$ (JCPDS\# 98004-9539). Overall, SEM and TEM analysis suggest uniform morphology for the obtained nanoparticles. Therefore, it appears that in order to obtain nanocrystalline single phase $\mathrm{Ta}_{1-x} \mathrm{Hf}_{x} \mathrm{~B}_{2}$ solid solution powders, the AMR-based method offers certain advantages over the CTR-based method as the former avoids the formation of oxides and the complication involving phase separation due to low solubility of $\mathrm{Ta}_{2} \mathrm{O}_{5}$ and $\mathrm{HfO}_{2}$ and the large difference in the oxides' reactivity against carbon and $\mathrm{B}_{2} \mathrm{O}_{3}$. 

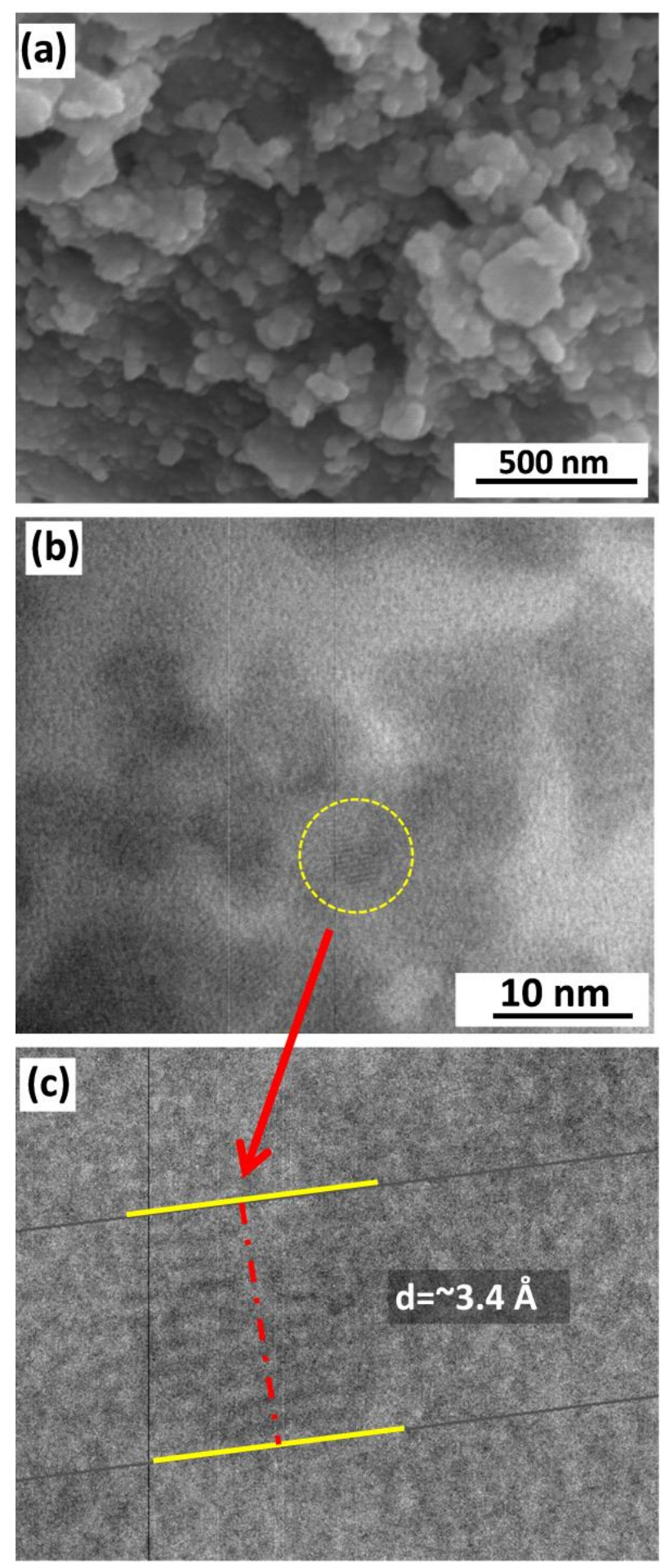

Figure 5.6: SEM (a) and TEM ( $b$ and c) micrographs of the synthesized powder via AMR reaction at $700{ }^{\circ} \mathrm{C}$ for 24 hours from recipe $\mathrm{R} 14$ showing the formation of uniform nanocrystalline $\mathrm{Ta}_{0.5} \mathrm{Hf}_{0.5} \mathrm{~B}_{2}$ solid solution powders with grain size much smaller than $\sim 50 \mathrm{~nm}$. The measured d-spacing of $\sim 0.34 \mathrm{~nm}$ from TEM is very close to the expected value for the (0001) plane of the $\mathrm{Ta}_{0.5} \mathrm{Hf}_{0.5} \mathrm{~B}_{2}$ solid solution. 
The oxidation resistance of $\mathrm{TaB}_{2}, \quad \mathrm{HfB}_{2}$, and $\mathrm{Ta}_{0.5} \mathrm{Hf}_{0.5} \mathrm{~B}_{2}$ solid solution nanopowders synthesized via the AMR method was evaluated using TGA in air and the results are shown in Figure S3.4 (see supplemnatry materials(3)). It shows that the $\mathrm{Ta}_{0.5} \mathrm{Hf}_{0.5} \mathrm{~B}_{2}$ solid solution powder does not offer dramatically improved oxidation resistance versus pure $\mathrm{HfB}_{2}$ (see Figure S3.4). In fact, the onset oxidation temperature for AMR synthesized $\mathrm{HfB}_{2}$ nanopowder is $\sim 700{ }^{\circ} \mathrm{C}$, while it is only $\sim 600{ }^{\circ} \mathrm{C}$ for $\mathrm{Ta}_{0.5} \mathrm{Hf}_{0.5} \mathrm{~B}_{2}$ (and $\sim 600{ }^{\circ} \mathrm{C}$ for $\mathrm{TaB}_{2}$ ). The lower oxidation onset temperature for $\mathrm{TaB}_{2}$ and $\mathrm{Ta}_{0.5} \mathrm{Hf}_{0.5} \mathrm{~B}_{2}$ nanopowder comparing with $\mathrm{HfB}_{2}$ is hypothesized to be related to the smaller grain size of the synthesized $\mathrm{TaB}_{2}$ and $\mathrm{Ta}_{0.5} \mathrm{Hf}_{0.5} \mathrm{~B}_{2}$ solid solution powders, which make the $\mathrm{Ta}_{0.5} \mathrm{Hf}_{0.5} \mathrm{~B}_{2}$ solid solution powder kinetically more susceptible to oxidation. This is supported by the XRD patterns for the samples showing higher crystallinity and narrower peaks for the $\mathrm{HfB}_{2}$ nanopowder versus both $\mathrm{TaB}_{2}$ and $\mathrm{Ta}_{0.5} \mathrm{Hf}_{0.5} \mathrm{~B}_{2}$ (see Figure 5.5). The air TGA results for the powders from AMR-based synthesis route also show that the weight gain was $46 \%, 36.28 \%$ and $41.73 \%$ for $\mathrm{TaB}_{2}, \mathrm{HfB}_{2}$ and $\mathrm{Ta}_{0.5} \mathrm{Hf}_{0.5} \mathrm{~B}_{2}$, respectively, which are reasonably close to the theoretical weight gain of $43.44 \%$ for pure $\mathrm{TaB}_{2}, 39.98 \%$ for pure $\mathrm{HfB}_{2}$ and $41.71 \%$ for $\mathrm{Ta}_{0.5} \mathrm{Hf}_{0.5} \mathrm{~B}_{2}$ solid solution.

Finally, as mentioned in the experimental section, when using the AMR method, the obtained powder had to be washed in hot water to remove the $\mathrm{NaCl}$ reaction product, which might cause partial oxidation of the sample. This might be one of the reasons that EDS analysis of the AMR powder contains relatively high oxygen content of $2 \mathrm{wt} \%$, which is equivalent to $\sim 8$ at.\%. It might also explain the relatively thick amorphous layer around the synthesized boride powders, as seen in the TEM in Figure 5.6(b). 
In order to check if the crystallinity of the nano diboride solid solution powders synthesized via the AMR method could be improved and also gain more understanding about the amorphous impurities (suspected to be $\mathrm{Na}$ and/or boron containing compounds such as $\mathrm{B}_{2} \mathrm{O}_{3}$ ) surrounding the nanopowders, $\mathrm{Ta}_{0.5} \mathrm{Hf}_{0.5} \mathrm{~B}_{2}$ solid solution (from R14) as well as $\mathrm{HfB}_{2}$ (from R17) powders from AMR (at $700{ }^{\circ} \mathrm{C}$ for $24 \mathrm{~h}$ ) were further annealed at $1500{ }^{\circ} \mathrm{C}$ for 3 hours in flowing argon. The XRD patterns for both samples show high intensity diffraction peaks suggesting a significant improvement in the crystallinity of the products after the annealing (see Figure 5.7 vs. Figure 5.5 for before the annealing). Furthermore, the XRD peaks for these samples after annealing are much narrower as compared to before annealing. This could be attributed to the grain growth during the annealing process, which was confirmed by comparing the SEM images of the samples before and after annealing, as shown in Figure 8: For both samples, the particles experience significant coarsening after the $1500{ }^{\circ} \mathrm{C} / 3$ hours annealing with individual grains grow from nanometer range to submicron range. 


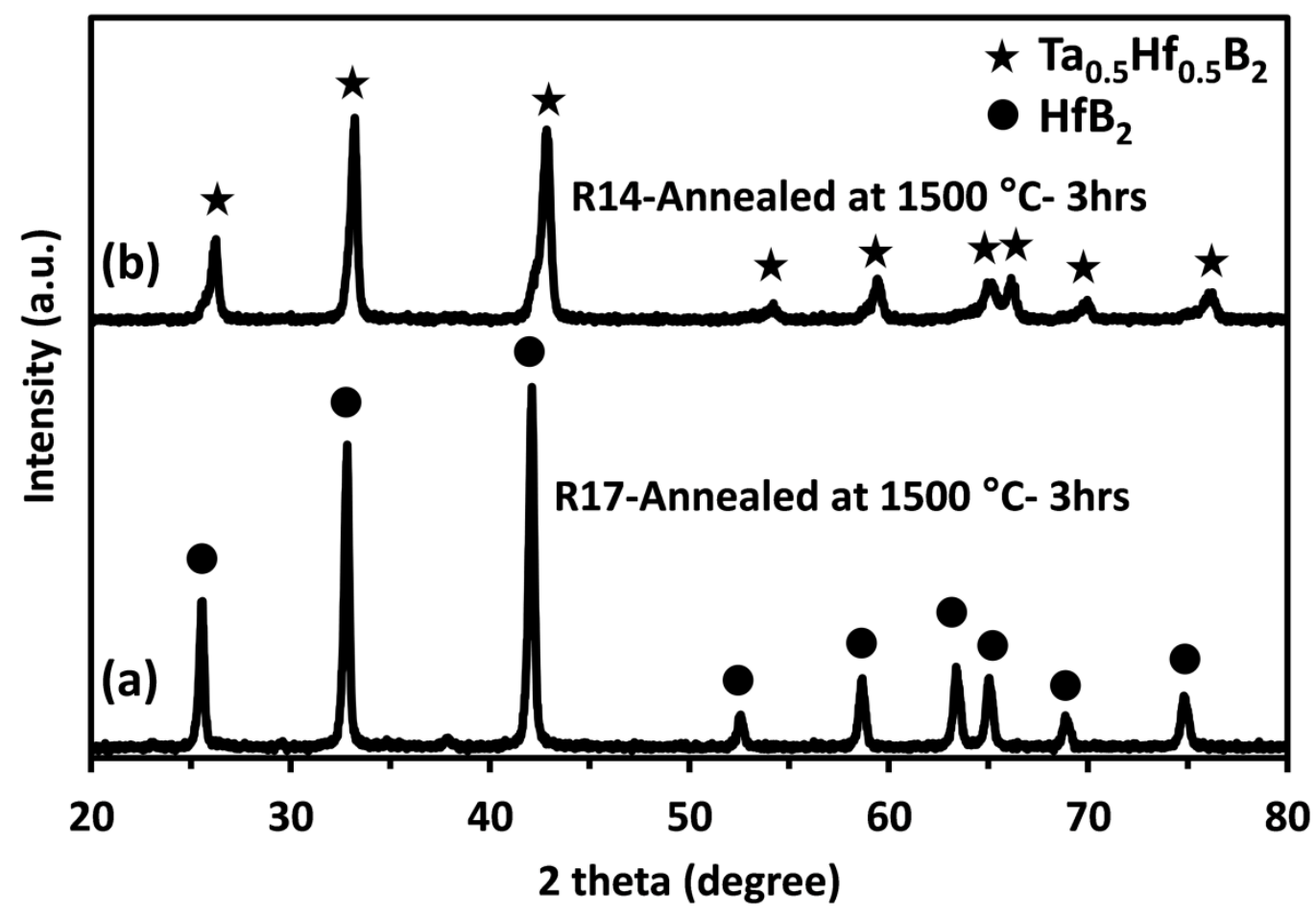

Figure 5.7: XRD patterns of two samples synthesized via the alkaline metal reduction (AMR) method at $700{ }^{\circ} \mathrm{C}$ for 24 hours and then annealed at $1500{ }^{\circ} \mathrm{C}$ for 3 hours in flow argon: (a) from recipe R17 targeting pure $\mathrm{HfB}_{2}$, (b) from recipe R14 targeting $\mathrm{Ta}_{0.5} \mathrm{Hf}_{0.5} \mathrm{~B}_{2}$ solid solution

In addition to the high annealing temperature used, grain growth of the diboride (including solid solution) powders can also be accelerated by the amorphous impurities (suspected to be $\mathrm{Na}$ and/or boron containing compounds such as $\mathrm{B}_{2} \mathrm{O}_{3}$ ) surrounding the crystalline diboride (solid solution) powders, as observed in TEM (see Figure 5.6). Such amorphous impurities are expected to turn into liquid form during heating and significantly promote mass transport. The significant weight loss of the samples observed after annealing $\left(\sim 35 \%\right.$ and $48 \%$ for $\mathrm{Ta}_{0.5} \mathrm{Hf}_{0.5} \mathrm{~B}_{2}$ solid solution and $\mathrm{HfB}_{2}$, respectively) could be associated with the evaporation of such amorphous impurities. It is worth noticing that the weight loss and also the grain growth of the $\mathrm{Ta}_{0.5} \mathrm{Hf}_{0.5} \mathrm{~B}_{2}$ solid solution are less than that of $\mathrm{HfB}_{2}$ (see Figure 5.8(c) and 5.8(d)). This could be due to the lower 
amount of $\mathrm{NaBH}_{4}$ used in recipe $\mathrm{R} 14$ than $\mathrm{R} 17$ resulting in formation of less amorphous impurities. The formation of the amorphous impurities and associated weight loss during high temperature annealing constitutes a limitation for the current AMR method and additional studies are required to further optimize the process and mitigate the impurity content.
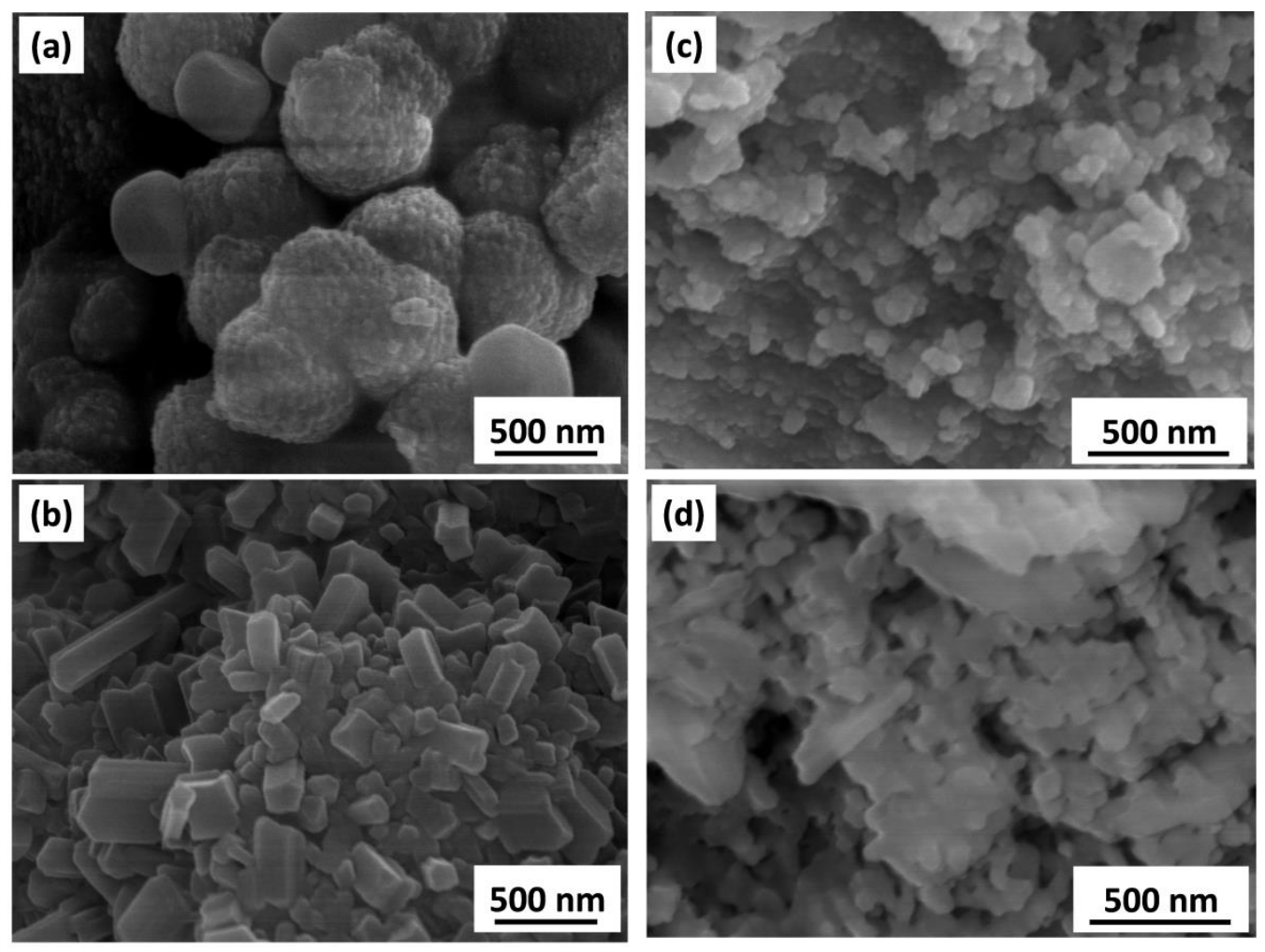

Figure 5.8: SEM micrographs of the $\mathrm{HfB}_{2}(\mathrm{a}, \mathrm{b})$ and $\mathrm{Ta}_{0.5} \mathrm{Hf}_{0.5} \mathrm{~B}_{2}$ solid solution (c, d) powders synthesized via the AMR method (at $700{ }^{\circ} \mathrm{C}$ for 24 hours) before $(\mathrm{a}, \mathrm{c})$ and after $(\mathrm{b}, \mathrm{d})$ the separate annealing at $1500{ }^{\circ} \mathrm{C}$ for 3 hours. The grains grow significantly after the $1500{ }^{\circ} \mathrm{C} / 3 \mathrm{~h}$ annealing for both $\mathrm{HfB}_{2}$ (from R17, compare (b) versus (a)) and $\mathrm{Ta}_{0.5} \mathrm{Hf}_{0.5} \mathrm{~B}_{2}$ solid solution (from R14, compare (d) versus (c)) samples.

Finally, it is recognized that the current study is confined to powder, while UHTC materials are mostly utilized as consolidated ceramic bodies. Therefore, additional study aimed at optimizing the processing to reduce the oxygen content need to be carried out. In addition, studies aimed at understanding the sintering behavior of the synthesized (Ta- 
Hf) $B_{2}$ solid solution nanopowders and the mechanical and chemical properties for the densified ceramic bodies will also be carried out in future to fully understand their properties including both advantages and disadvantages.

\subsection{Conclusions}

In this study, submicron-sized $\mathrm{TaB}_{2}-\mathrm{HfB}_{2}$ powders were synthesized via aqueous solution processing of low-cost $\mathrm{TaCl}_{5}, \mathrm{HfCl}_{4}$, sucrose and $\mathrm{B}_{2} \mathrm{O}_{3}$ as carbon and boron sources, respectively followed by CTR (e.g., at $1500{ }^{\circ} \mathrm{C}$ for 3 hours). Despite the phase diagram suggesting single phase solid solution formation, the products tend to contain two separate phases of Ta-rich $\mathrm{Ta}_{1-\mathrm{x}} \mathrm{Hf}_{\mathrm{x}} \mathrm{B}_{2}$ and almost pure $\mathrm{HfB}_{2}$. The tendency for the formation of phase separated $\mathrm{TaB}_{2}-\mathrm{HfB}_{2}$ composite powder is attributed to the low mutal solubility of $\mathrm{Ta}_{2} \mathrm{O}_{5}$ and $\mathrm{HfO}_{2}$, the large difference in reactivity of those oxides with carbon and $\mathrm{B}_{2} \mathrm{O}_{3}$ to form the corresponding diborides, and the slow cation (Ta and $\mathrm{Hf}$ ) inter-diffusion relative to the CTR reactions to form the individual borides. Although higher CTR temperature or addition of diffusion promoter such as copper metal powder during the CTR process help improve solid solution formation by accelerating the diffusion, they also lead to particle coarsening and deviate away from the goal of obtaining nanocrystalline $\mathrm{Ta}_{1-\mathrm{x}} \mathrm{Hf}_{\mathrm{x}} \mathrm{B}_{2}$ solid solution powders. In comparison, it was observed that direct reduction of $\mathrm{TaCl}_{5}$ and $\mathrm{HfCl}_{4}$ via the alkali metal reduction or AMR method by a strong reducing agent such as $\mathrm{NaBH}_{4}$ leads to the formation of a single phase Ta0.5Hf0.5B2 solid solution nanopowders. The relative success for the AMRbased method is attributed to the avoidance of tantalum and hafnium oxides formation and the associated complication involving boride phase separation in the CTR reaction, 
while the relatively low reaction temperature (e.g., $700{ }^{\circ} \mathrm{C}$ ) ensures the formation of nano-sized grains. Further studies aimed at otpmizing the synthesis process to improve purity and understanding the properties for the synthesized nanocrystalline single phase $\mathrm{Ta}_{1-\mathrm{x}} \mathrm{Hf}_{\mathrm{x}} \mathrm{B}_{2}$ solid solution powders especially their sinterability and the mechanical and chemical properties of the sintered ceramic bodies will be carried out in future.

\subsection{Supplementary Materials (3)}

5.5.1 XRD Pattern for the Synthesized Sample from Recipe R8 at $1600{ }^{\circ} \mathrm{C}$ for 15 Minutes

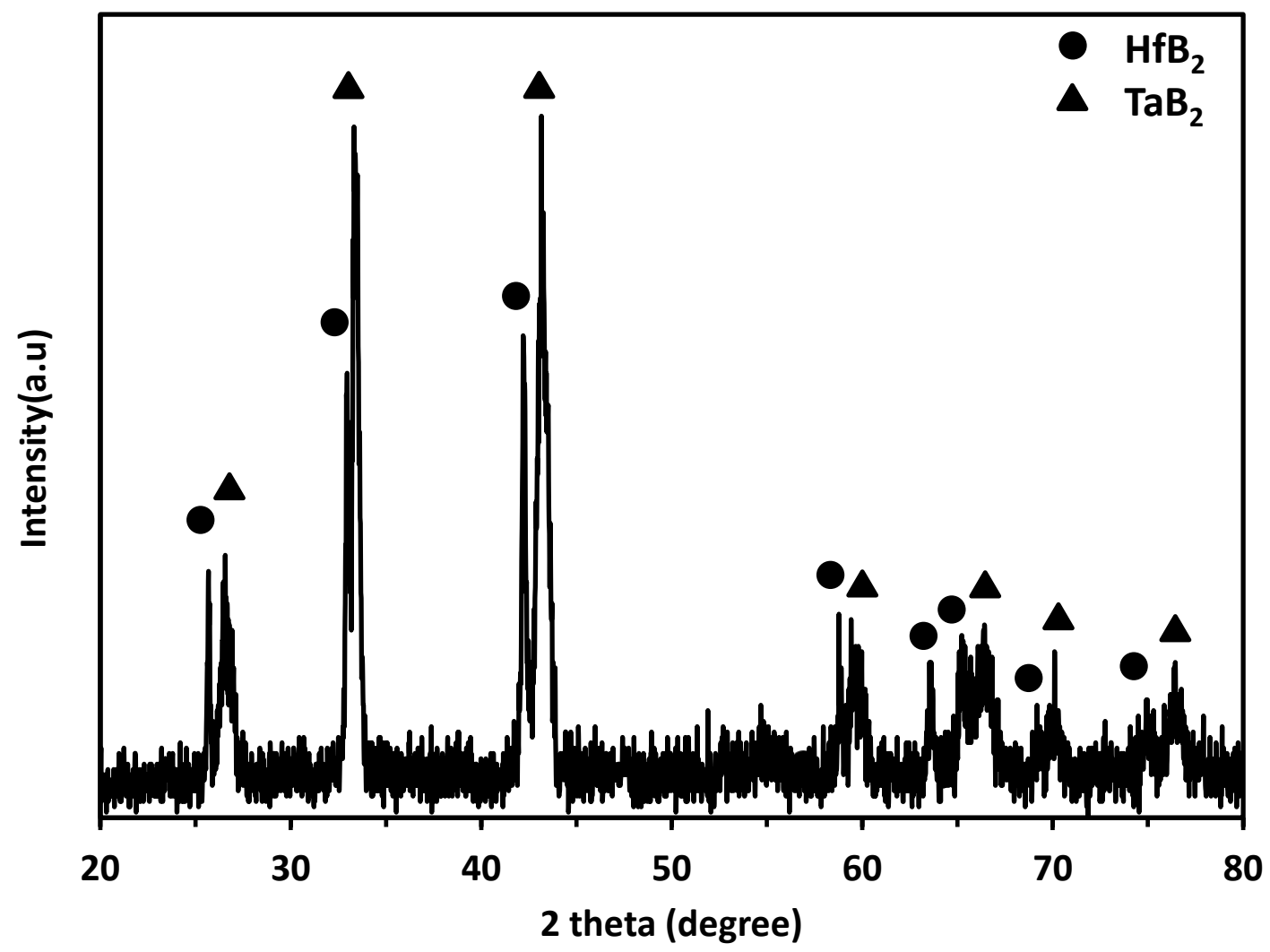

Figure S3.1: XRD pattern of the synthesized powders from recipe R8 (Ta: Hf molar ratio of 1:1) at $1600{ }^{\circ} \mathrm{C}$ for 15 minutes. 
5.5.2 Annealing of $\mathrm{Ta}_{2} \mathrm{O}_{5}-\mathrm{HfO}_{2}$ Mixture for 6 hours at $1500{ }^{\circ} \mathrm{C}$

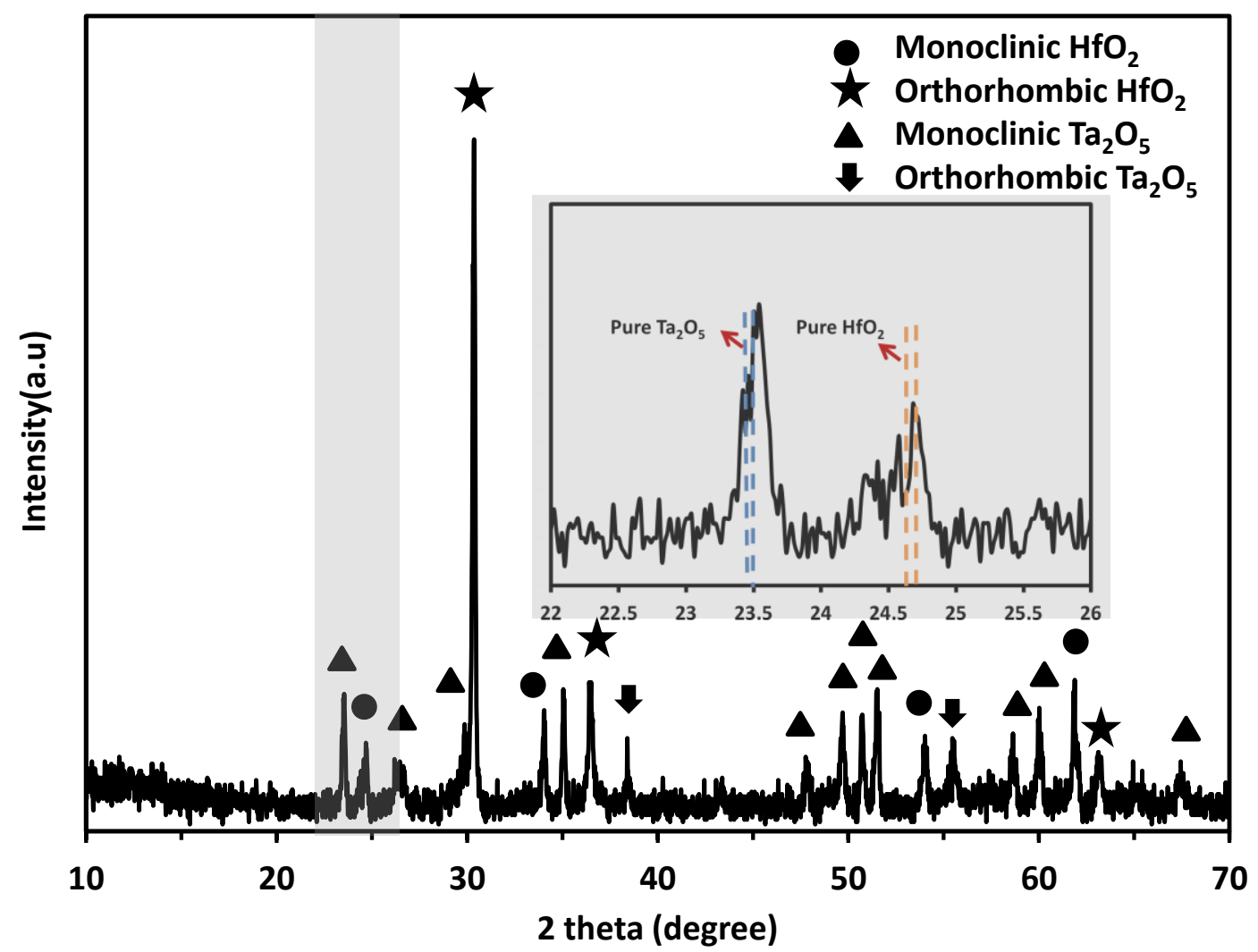

Figure S3.2: XRD pattern of the annealed $\mathrm{Ta}_{2} \mathrm{O}_{5}-\mathrm{HfO}_{2}$ mixture (Ta: $\mathrm{Hf}$ molar ratio of 1:1) at 1500 ${ }^{\circ} \mathrm{C}$ for 6 hours

5.5.3 BET Analysis of $\mathrm{Ta}_{0.5} \mathrm{Hf}_{0.5} \mathrm{~B}_{2}$ Solid Solution Powders Synthesized via AMR Method

Figure S3.3 shows the nitrogen gas adsorption-desorption isotherm for $\mathrm{Ta}_{0.5} \mathrm{Hf}_{0.5} \mathrm{~B}_{2}$ solid solution powders synthesized via AMR method. This plot displays the volume of nitrogen adsorbed versus relative pressure $\left(\mathrm{P} / \mathrm{P}_{0}\right)$. 


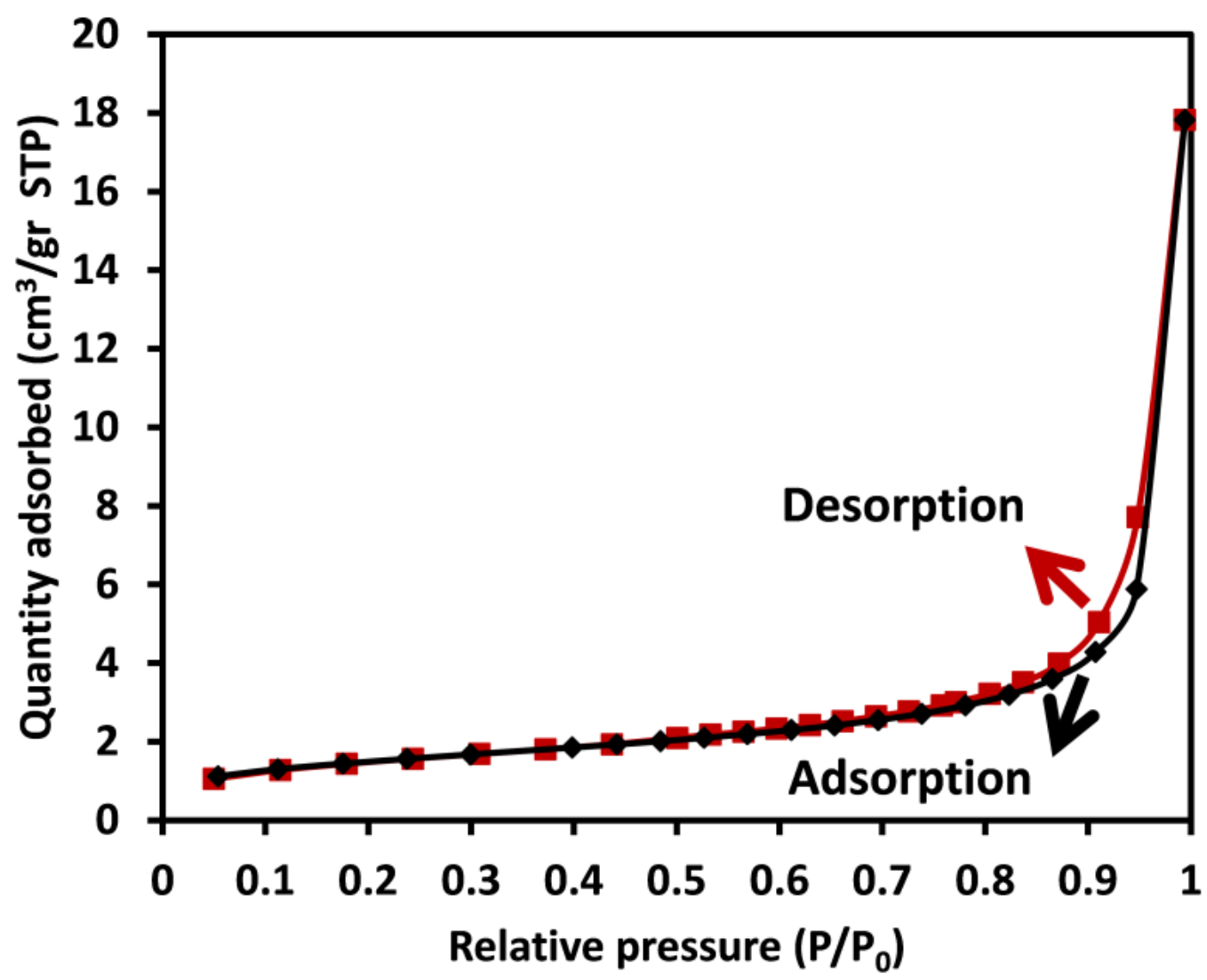

Figure S3.3: Nitrogen adsorption-desorption isotherm for $\mathrm{Ta}_{0.5} \mathrm{Hf}_{0.5} \mathrm{~B}_{2}$ solid solution powders synthesized via AMR method.

The correlation coefficient of the linear regression (r) was greater than 0.99 . The surface area and pore volume calculated from Figure $\mathrm{S} 3$ are $4.95 \mathrm{~m}^{2} / \mathrm{gr}$ and $0.027 \mathrm{~cm}^{3} / \mathrm{gr}$, respectively. These results suggest that the synthesized powders have low porosity, which is consistent with the SEM images for this sample.

The average particle size could be estimated using the equation below:

$$
\text { Average particle size }=\frac{6000}{\text { BET surface area }\left(\frac{\mathrm{m}^{2}}{\mathrm{gr}}\right) \times \operatorname{density~}\left(\frac{\mathrm{gr}}{\mathrm{cm}^{3}}\right)}
$$

The density of the $\mathrm{Ta}_{0.5} \mathrm{Hf}_{0.5} \mathrm{~B}_{2}$ solid solution was calculated using equation $\mathrm{S} 2$ : 
The densities of pure $\mathrm{HfB}_{2}$ and $\mathrm{TaB}_{2}$ are $11.2 \mathrm{~g} / \mathrm{cm}^{3}$ [24] and $12.6 \mathrm{~g} / \mathrm{cm}^{3}$ [98], respectively. Therefore for a composition of $\mathrm{Ta}_{0.5} \mathrm{Hf}_{0.5} \mathrm{~B}_{2}$ the density would be approximated as:

$\rho_{50.50}=(0.5 \times 11.2)+(0.5 \times 12.6)=11.9 \frac{\mathrm{gr}}{\mathrm{cm}^{3}}$

Hence, using equation $\mathrm{S} 1$ the calculated average particle size for $\mathrm{Ta}_{0.5} \mathrm{Hf}_{0.5} \mathrm{~B}_{2}$ solid solution powders is estimated to be $\sim 100 \mathrm{~nm}$.

\subsubsection{TGA Analysis of Boride Powders Synthesized via AMR Method}

The TGA test was carried out in air for binary $\mathrm{HfB}_{2}$ and $\mathrm{Ta}_{0.5} \mathrm{Hf}_{0.5} \mathrm{~B}_{2}$ solid solution powders synthesized via AMR method with heating rate of $10^{\circ} \mathrm{C} / \mathrm{min}$. The TGA analysis for these samples as shown in Figure $\mathrm{S} 3.4$ indicates that $\mathrm{Ta}_{0.5} \mathrm{Hf}_{0.5} \mathrm{~B}_{2}$ solid solution nanopowders did not show significantly enhanced oxidation resistance than nano $\mathrm{HfB}_{2}$ powder. This might be due to the different grain size of the synthesized $\mathrm{HfB}_{2}$ versus the $\mathrm{TaB}_{2}$ and $\mathrm{Ta}_{50} \mathrm{Hf}_{50} \mathrm{~B}_{2}$ powders. From XRD pattern (see Figure 5.5), it seemed that the $\mathrm{HfB}_{2}$ are better developed in crystallinity with larger grains than $\mathrm{TaB}_{2}$ and the $\mathrm{Ta}_{50} \mathrm{Hf}_{50} \mathrm{~B}_{2}$ solid solution powders. This may make the $\mathrm{TaB}_{2}$ and $\mathrm{Ta}_{50} \mathrm{Hf}_{50} \mathrm{~B}_{2}$ solid solution powders more susceptible to oxidation at elevated temperatures. The underlying reason for the difference in crystallinity and grain size is still under investigation.

In addition, as can be seen in Figure S3.4, there is a weight loss from room temperature up to $\sim 150{ }^{\circ} \mathrm{C}$ for all samples, which could be attributed to moisture removal. Based on the TGA results, the weight gain due to oxidation of binary $\mathrm{TaB}_{2}, \mathrm{HfB}_{2}$ and $\mathrm{Ta}_{50} \mathrm{Hf}_{50} \mathrm{~B}_{2}$ solid solution powders are $\sim 46 \%, 36.28 \%$ and $41.73 \%$, respectively (the baseline for the weight gain calculation was set a lower value after the initial weight loss caused by 
moisture removal). The obtained results are very close to the theoretical weight gain (43.44\% for pure $\mathrm{TaB}_{2}, 39.98 \%$ for pure $\mathrm{HfB}_{2}$ and $41.71 \%$ for $\mathrm{Ta}_{50} \mathrm{Hf}_{50} \mathrm{~B}_{2}$ solid solution).

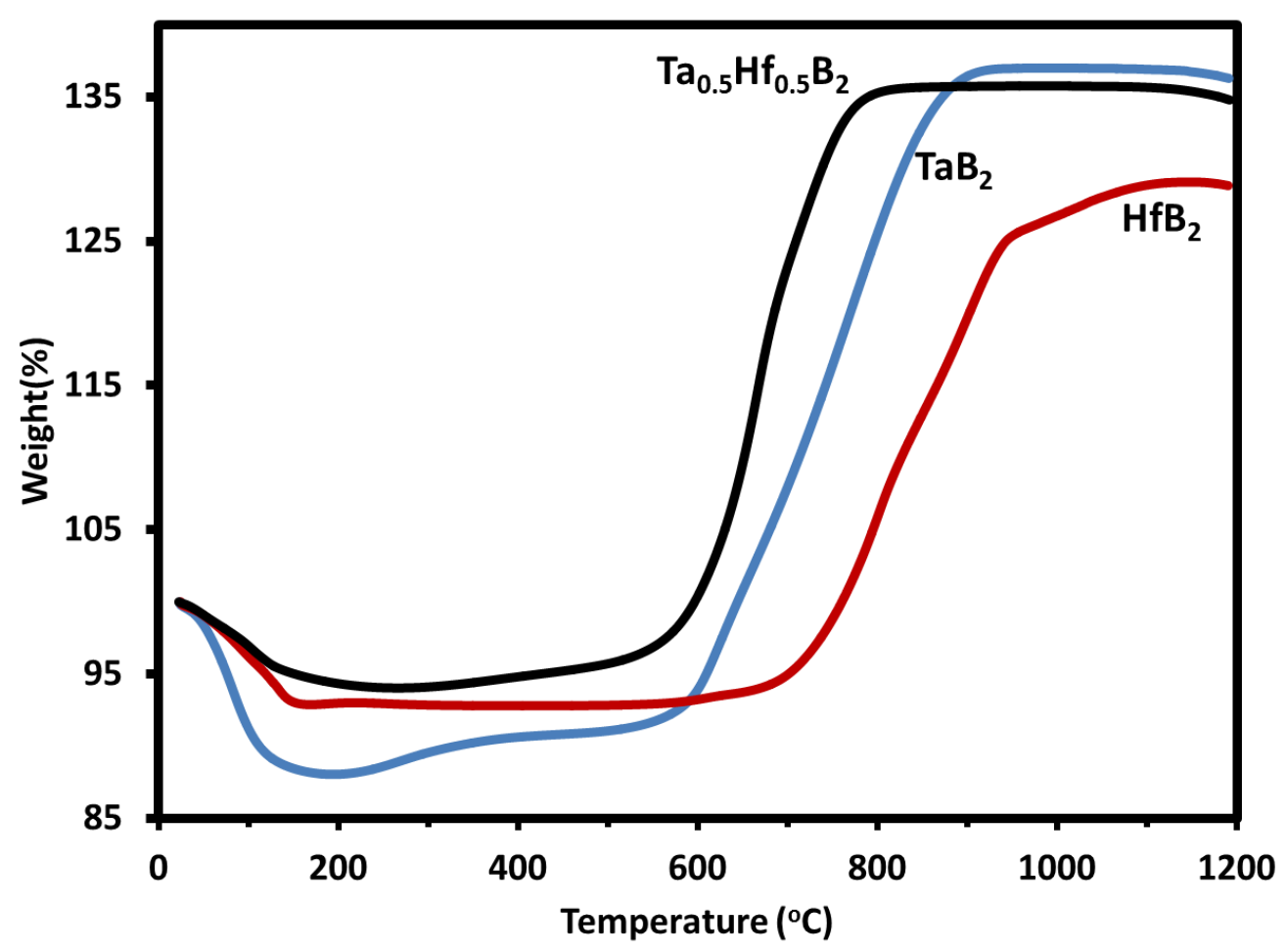

Figure S3.4: TGA analysis of synthesized $\mathrm{TaB}_{2}, \mathrm{HfB}_{2}$ and $\mathrm{Ta}_{0.5} \mathrm{Hf}_{0.5} \mathrm{~B}_{2}$ solid solution powders via AMR method in air. 
Chapter VI: Summary

\subsection{Synthesis of $\mathrm{B}_{4} \mathrm{C}$ Powders}

The present study investigated the synthesis of uniform submicron-sized $\mathrm{B}_{4} \mathrm{C}$ powders using CTR of finely mixed $\mathrm{B}_{2} \mathrm{O}_{3}$ and carbon obtained from low-cost watersoluble precursors. The effects of CTR thermal profile, CTR atmosphere and precursors on product phase purity and morphology were systematically studied. Major conclusions are again listed below:

- Morphology of $\mathrm{B}_{4} \mathrm{C}$ product from $\mathrm{CTR}$ is determined primarily by reaction kinetics: At low temperature (e.g., $1250{ }^{\circ} \mathrm{C}$ ), CTR reaction proceeds via heterogeneous nucleation and growth at favorable sites leading to significant nonuniformity including nanobelts and micron sized particles. At high temperatures (e.g., $1750^{\circ} \mathrm{C}$ ) the $\mathrm{CTR}$ reaction proceeds via homogenous nucleation with almost no growth leading to uniform particle and the exact size depend on reaction temperature/time. Very high temperatures $\left(>1800{ }^{\circ} \mathrm{C}\right)$ and very short dwell time (on the order of several seconds) could give rise to formation of uniform $\mathrm{B}_{4} \mathrm{C}$ nanoparticles. On the other hand at intermediate temperatures (e.g., $1450{ }^{\circ} \mathrm{C}$ ), mixed mechanism of both nucleation and growth leads to a great variety of morphologies.

- Other factors could also influence $\mathrm{B}_{4} \mathrm{C}$ product morphology to an extent: Higher argon flow rate/using vacuum would lower $\mathrm{pCO}$ resulting in faster reaction kinetics and, as a result, smaller and more uniform $\mathrm{B}_{4} \mathrm{C}$ particles. Moreover, more uniform $\mathrm{B}_{4} \mathrm{C}$ powders would be obtained using lower $\mathrm{B}_{2} \mathrm{O}_{3}: \mathrm{C}$ molar ratio. 
However, the amount of residual carbon in the final product powers would increase due to the insufficient $\mathrm{B}_{2} \mathrm{O}_{3}$.

- Moisture adsorption for both pyrolyzed powders, which contains carbon and $\mathrm{B}_{2} \mathrm{O}_{3}$ and final CTR product not only causes weight gain but also results in significant changes in micromorphology via the formation of boric acid crystals through the reaction of $\mathrm{B}_{2} \mathrm{O}_{3}$ including residual $\mathrm{B}_{2} \mathrm{O}_{3}$ in CTR products with moisture.

\subsection{Synthesis of $\mathrm{Ta}_{\mathrm{x}} \mathrm{Hf}_{1-\mathrm{x}} \mathrm{C}$ Nanopowders}

Synthesis of single-phase $\mathrm{Ta}_{\mathrm{x}} \mathrm{Hf}_{1-\mathrm{x}} \mathrm{C}$ solid solution nanopowders via CTR of finely mixed amorphous tantalum-hafnium oxide(s) and carbon obtained from a low-cost aqueous solution processing of $\mathrm{TaCl}_{5}, \mathrm{HfCl}_{4}$, and sucrose was studied. The influences of starting compositions and processing conditions on phase separation during the formation of carbide phase(s) were investigated and the major conclusions are again listed below:

- Despite the success with the synthesis of nano $\mathrm{Ta}_{0.8} \mathrm{Hf}_{0.2} \mathrm{C}$ solid solution powders, phase separation of TaC and $\mathrm{HfC}$ was observed in most cases for $\mathrm{Ta}_{0.5} \mathrm{Hf}_{0.5} \mathrm{C}$, in spite of varying parameters such as solvent used/hydrolysis rate, cooling rate, heating rate, and holding time.

- The strong tendency to form phase-separated TaC-HfC nano powder composites instead of nano $\mathrm{Ta}_{\mathrm{x}} \mathrm{Hf}_{1-\mathrm{x}} \mathrm{C}$ solid solution powders is believed to originate from the low affinity of $\mathrm{Ta}_{2} \mathrm{O}_{5}$ and $\mathrm{HfO}_{2}$ for each other, which leads to formation of individual $\mathrm{TaC}$ and $\mathrm{HfC}$ nano grains. These formed $\mathrm{TaC}$ and $\mathrm{HfC}$ nanopowders do not readily form uniform solid solution powders despite long holding above the critical temperature $\left(887^{\circ} \mathrm{C}\right)$ due to slow diffusion. 
- It was found that excess carbon has a dramatic effect on slowing down the interdiffusion of Ta and Hf and therefore delays the solid solution formation.

- When using SPS for conducting the CTR at low pressure (5 MPa) and low temperature $\left(1600{ }^{\circ} \mathrm{C}\right)$, uniform solid solution of $\mathrm{Ta}_{0.5} \mathrm{Hf}_{0.5} \mathrm{C}$ with nano grains was obtained, suggesting that electrical filed might significantly accelerate the cation diffusion through creation of high concentration of vacancies, which are created under the high current/high flux condition of SPS.

\subsection{Synthesis of $\mathrm{Ta}_{\mathrm{x}} \mathrm{Hf}_{1-\mathrm{x}} \mathrm{B}_{2}$ Nanopowders}

Synthesis of nanocrystalline $\mathrm{Ta}_{\mathrm{x}} \mathrm{Hf}_{1-\mathrm{x}} \mathrm{B}_{2}$ solid solution and composite powders using two low-cost methods of CTR and Alkali metal reduction reaction (AMR) were studied. The major conclusions are listed below:

- Submicron-sized $\mathrm{TaB}_{2}-\mathrm{HfB}_{2}$ composite powders were synthesized via aqueous solution processing of low-cost $\mathrm{TaCl}_{5}, \mathrm{HfCl}_{4}$, sucrose and $\mathrm{B}_{2} \mathrm{O}_{3}$ followed by CTR at $1500-1650{ }^{\circ} \mathrm{C}$ for different holding times from 10 minutes to 3 hours. However, phase separation of $\mathrm{TaB}_{2}$ and $\mathrm{HfB}_{2}$ was observed regardless of using various CTR temperatures and holding times.

- The tendency for formation of phase-separated $\mathrm{TaB}_{2}-\mathrm{HfB}_{2}$ submicron-sized composite powders could be due to the low affinity of $\mathrm{Ta}_{2} \mathrm{O}_{5}$ and $\mathrm{HfO}_{2}$ for each other and the difference in reactivity of the corresponding oxides with carbon, which give rise to phase separation of individual binary diborides even after long CTR time (e.g., $1500{ }^{\circ} \mathrm{C}$ for 6 hours). 
- Adding $\mathrm{Cu}$ during the CTR process noticeably improved solid solution formation thanks to faster diffusion with the presence of a liquid phase (metal).

- Direct reaction of $\mathrm{TaCl}_{5}$ and $\mathrm{HfCl}_{4}$ with $\mathrm{NaBH}_{4}$ leads to formation of single-phase $\mathrm{Ta}_{0.5} \mathrm{Hf}_{0.5} \mathrm{~B}_{2}$ solid solution nanopowders at a significantly lower temperature of $700{ }^{\circ} \mathrm{C}$ thanks to the avoidance of the tantalum and hafnium oxides formation and the associated CTR reaction.

\subsection{Recommendation for Future Work}

The present work developed low-cost methods for synthesis of highly applicable nanocrystalline ternary UHTC solid solution/composite powders with no composition constraints. Based on the current work, the author suggests the following future work to be undertaken:

\subsubsection{Synthesis of Nanocrystalline High Entropy UHTC Powders}

Preparation of high entropy alloys (HEAs) has attracted noticeable research interests. HEAs would form when five or more elements are mixed with equal concentrations (by molar) and produce single-phase solid solutions without any trace of intermetallic formation. These alloys have shown outstanding mechanical and physical properties [112][113]. The observation of such superior properties for HEAs motivates the research on study of high entropy UHTCs. The researchers believe that these ceramics may possess improved hardness and oxidation resistance. To the best of author's knowledge, high energy ball milling of UHTC powders mixture (a mixture of more than five binary UHTCs) for several hours followed by sintering via SPS at very high temperatures (e.g., 
$\sim 2000{ }^{\circ} \mathrm{C}$ ) is the only method known for the synthesis of these ceramics. However, the author believes that the low-cost methods developed in this thesis for the synthesis of ternary UHTC solid solutions (e.g., AMR method for synthesis of borides) could also be used for the synthesis of high entropy UHTCs.

6.4.2 Flash Sintering of the Synthesized Nanocrystalline $\mathrm{Ta}_{\mathrm{x}} \mathrm{Hf}_{1-\mathrm{x}} \mathrm{C}$ and $\mathrm{Ta}_{\mathrm{x}} \mathrm{Hf}_{1-\mathrm{x}} \mathrm{B}_{2}$ Solid Solution Powders

There are several studies on the sintering of UHTCs using various methods such as hot pressing, pressureless sintering and SPS. However, there are very few studies on the sintering of borides/carbides using flash sintering (FS) [115][116]. In this method sintering often occurs in a conventional furnace in combination with an electrical field, which is applied using a pair of electrodes. The applied electrical field and resulting current and furnace temperature can be easily controlled. This would allow better understanding of electrical field effect on the sintering process. Moreover, compared to SPS, FS requires shorter sintering time and lower furnace temperature (and sometimes no/less pressure), which makes this method more beneficial due to its lower cost and better energy efficiency. Therefore, the author believes that consolidation of the synthesized nanocrystalline $\mathrm{Ta}_{\mathrm{x}} \mathrm{Hf}_{1-\mathrm{x}} \mathrm{C}$ and $\mathrm{Ta}_{\mathrm{x}} \mathrm{Hf}_{1-\mathrm{x}} \mathrm{B}_{2}$ solid solution powders using $\mathrm{FS}$ would help achieving sintered parts with fine microstructures and as a result better mechanical properties. 


\section{REFERENCE}

[1] M.D. Sacks, C.-A. Wang, Z. Yang, A. Jain, Carbothermal reduction synthesis of nanocrystalline zirconium carbide and hafnium carbide powders using solutionderived precursors, J. Mater. Sci. 39 (2004) 6057-6066.

[2] J.-X. Liu, Y.-M. Kan, G.-J. Zhang, Synthesis of Ultra-fine Hafnium Carbide Powder and its Pressureless Sintering, J. Am. Ceram. Soc. 93 (2010) 980-986.

[3] R. Loehman, E. Corral, H. Dumm, P. Kotula, R. Tandon, Ultra high temperature ceramics for hypersonic vehicle applications., (2006) 46.

[4] S.N. Karlsdottir, J.W. Halloran, Rapid oxidation characterization of ultra-high temperature ceramics, J. Am. Ceram. Soc. 90 (2007) 3233-3238.

[5] R. Licheri, R. Orrù, A.M. Locci, G. Cao, Efficient synthesis/sintering routes to obtain fully dense ultra-high-temperature ceramics (UHTCs), Ind. Eng. Chem.

[6] R. Savino, M. De Stefano Fumo, D. Paterna, A. Di Maso, F. Monteverde, Arc-jet testing of ultra-high-temperature-ceramics, Aerosp. Sci. Technol. 14 (2010) 178187.

[7] S.R. Levine, E.J. Opila, M.C. Halbig, J.D. Kiser, M. Singh, J.A. Salem, Evaluation of ultra-high temperature ceramics foraeropropulsion use, J. Eur. Ceram. Soc. 22 (2002) 2757-2767.

[8] M.M. Opeka, I.G. Talmy, E.J. Wuchina, J. a. Zaykoski, S.J. Causey, Mechanical, Thermal, and Oxidation Properties of Refractory Hafnium and zirconium Compounds, J. Eur. Ceram. Soc. 19 (1999) 2405-2414.

[9] E. Wuchina, M. Opeka, S. Causey, K. Buesking, J. Spain, A. Cull, J. Routbort, F. Guitierrez-Mora, Designing for ultrahigh-temperature applications: The mechanical and thermal properties of $\mathrm{HfB}_{2}, \mathrm{HfC}_{\mathrm{x}}, \mathrm{HfN}_{\mathrm{x}}$ and $\alpha \mathrm{Hf}(\mathrm{N})$, J. Mater. Sci. 39 (2004) 5939-5949.

[10] J.F. Justin, A. Jankowiak, Ultra High Temperature Ceramics: Densification, Properties and Thermal Stability, J. AerospaceLab. (2011) 1-11.

[11] F. Bellosi, Alida, Monteverde, Ultra-High Temperature Ceramics: Microstructure Control and Properties Improvement Related to Materials Design and Processing Procedures, in: K. Fletcher. ESA SP-631. (Ed.), Therm. Prot. Syst. Hot Struct. Proc. 5th Eur. Work., Noordwijk, 2006.

[12] S.M. Johnson, M. Gasch, J.W. Lawson, M. Gusman, M.M. Stackpoole, Role of Microstructure on the Performance of UHTCs, (2010) 1-24. 
[13] S. Chen, D.Z. Wang, J.Y. Huang, Z.F. Ren, Synthesis and characterization of boron carbide nanoparticles, Appl. Phys. A Mater. Sci. Process. 79 (2004) 17571759 .

[14] J.A. Wollmershauser, B.N. Feigelson, E.P. Gorzkowski, C.T. Ellis, R. Goswami, S.B. Qadri, J.G. Tischler, F.J. Kub, R.K. Everett, An extended hardness limit in bulk nanoceramics, Acta Mater. 69 (2014) 9-16.

[15] R.A. Andrievskii, N.S. Strel'nikova, N.I. Poltoratskii, E.D. Kharkhardin, V.S. Smirnov, Melting Point in Systems ZrC-HfC, TaC-ZrC, TaC-HfC, Poroshkovaya Metall. 1 (1967) 85-88.

[16] E.P. Simonenko, N.A. Ignatov, N.P. Simonenko, Y.S. Ezhov, V.G. Sevastyanov, N.T. Kuznetsov, Synthesis of Highly Dispersed Super-refractory TantalumZirconium Carbide $\mathrm{Ta}_{4} \mathrm{ZrC}_{5}$ and Tantalum-Hafnium Carbide $\mathrm{Ta}_{4} \mathrm{HfC}_{5}$ via Sol-gel Technology, Russ. J. Inorg. Chem. 56 (2011) 1681-1687.

[17] Y.B. Barantseva, I.G., Paderno, V.N. and Paderno, Some physical properties of alloys of the systems $\mathrm{ZrC}-\mathrm{NbC}$ and TaC-HfC, Sov. Powder Metall. Met. Ceram. 6 (1967) 139-141.

[18] J. Jiang, S. Wang, W. Li, Preparation and Characterization of UltraHighTemperature Ternary Ceramics $\mathrm{Ta}_{4} \mathrm{HfC}_{5}$, J. Am. Ceram. Soc. 4 (2016) 1-4.

[19] O. Gaballa, B.A. Cook, A.M. Russell, Reduced-temperature processing and consolidation of ultra-refractory $\mathrm{Ta}_{4} \mathrm{HfC}_{5}$, Int. J. Refract. Met. Hard Mater. 41 (2013) 293-299.

[20] C. Zhang, High Temperature Oxidation Study of Tantalum Carbide-Hafnium Carbide Solid Solutions Synthesized by Spark Plasma Sintering, Ph.D. Thesis. Florida International University, Florida, USA. (2016).

[21] F. Monteverde, A. Bellosi, S. Guicciardi, Processing and properties of zirconium diboride-based composites, J. Eur. Ceram. Soc. 22 (2002) 279-288.

[22] W.A. Zdaniewski, Solid Solubility Effect on Properties of Titanium Diboride, J. Am. Ceram. Soc. 70 (1987) 793-797.

[23] C.C. SORRELL, V.S. STUBICAN, R.C. BRADT, Mechanical Properties of ZrC$\mathrm{ZrB} 2$ and ZrC-TiB2 Directionally Solidified Eutectics, J. Am. Ceram. Soc. 69 (1986) 317-321.

[24] W.G. Fahrenholtz, G.E. Hilmas, I.G. Talmy, J. a. Zaykoski, Refractory diborides of zirconium and hafnium, J. Am. Ceram. Soc. 90 (2007) 1347-1364.

[25] S.R. Levine, E.J. Opila, Tantalum addition to zirconium diboride for improved oxidation resistance, Nasa/Tm-2003-212483. (2003) 1-13. 
[26] Y. Xie, T.H. Sanders, R.F. Speyer, Solution-based synthesis of submicrometer $\mathrm{ZrB}_{2}$ and $\mathrm{ZrB}_{2}-\mathrm{TaB}_{2}$, J. Am. Ceram. Soc. 91 (2008) 1469-1474.

[27] Y. Xie, Solution-based Synthesis and Processing of Nanocrystalline ZrB2-based Composites, (2008) 1-160.

[28] A. Alizadeh, E. Taheri-Nassaj, N. Ehsani, Synthesis of boron carbide powder by a carbothermic reduction method, J. Eur. Ceram. Soc. 24 (2004) 3227-3234.

[29] T.R. Pilladi, K. Ananthansivan, S. Anthonysamy, Synthesis of boron carbide from boric oxide-sucrose gel precursor, Powder Technol. 246 (2013) 247-251.

[30] J.A. Bigdeloo, A.M. Hadian, Synthesis of High Purity Micron Size Boron Carbide Powder from $\mathrm{B}_{2} \mathrm{O}_{3} / \mathrm{C}$ Precursor, Int. J. Recent Trends Eng. 1 (2009).

[31] X. Zhang, G.E. Hilmas, W.G. Fahrenholtz, Synthesis, densification, and mechanical properties of $\mathrm{TaB}_{2}$, Mater. Lett. 62 (2008) 4251-4253.

[32] B. Chang, B.L. Gersten, S.T. Szewczyk, J.W. Adams, Characterization of boron carbide nanoparticles prepared by a solid state thermal reaction, Appl. Phys. A Mater. Sci. Process. 86 (2007) 83-87.

[33] J. Wei, B. Jiang, Y. Li, C. Xu, D. Wu, B. Wei, Straight boron carbide nanorods prepared from carbon nanotubes, J. Mater. Chem. 12 (2002) 3121-3124.

[34] T.S.R.C.M. A. K. Suri, C. Subramanian, J. K. Sonber, Synthesis and consolidation of boron carbide: a review, 2010.

[35] P. Singh, B. Singh, M. Kumar, A. Kumar, One step reduction of Boric Acid to boron carbide nanoparticles, Ceram. Int. 40 (2014) 15331-15334.

[36] G.R. Whitnah, W.C. Borgeson, H.E. Henjum, production of boron carbede whiskers, United States Patent Office, (1970).

[37] I.M.M. and B.G. Reuben, The Synthesis of Boron Carbide in an RF Plasma, J. Electrochem. Soc. 122 (1975) 806-811.

[38] A.O. Sezer, J.I. Brand, Chemical vapor deposition of boron carbide, Mater. Sci. Eng. B. 79 (2001) 191-202.

[39] S. Lee, J. Mazurowski, G. Ramseyer, P.A. Dowben, Characterization of boron carbide thin films fabricated by plasma enhanced chemical vapor deposition from boranes, J. Appl. Phys. 72 (1992) 4925-4933.

[40] A.W. Weimer, R.P. Roach, C.N. Haney, W.G. Moore, W. Rafaniello, Rapid carbothermal reduction of boron oxide in a graphite transport reactor, AIChE J. 37 (1991) 759-768. 
[41] A.W. Weimer, W.G. Moore, R.P. Roach, J.P. Hitt, R.S. Dixit, S.E. Pratsinis, Kinetics of Carbothermal Reduction Synthesis of Boron Carbide, J. Am. Ceram. Soc. 75 (1992) 2509-2514.

[42] S. Miller, F. Toksoy, W. Rafaniello, R. a. Haber, Submicron Boron Carbide Synthesis Through Rapid Carbothermal Reduction, Adv. Ceram. Armor. 8 (2013) 195-207.

[43] Y. Gao, A. Etzold, T. Munhollon, W. Rafaniello, R. Haber, Processing factors influencing the free carbon contents in boron carbide powder by rapid carbothermal reduction, Diam. Relat. Mater. 61 (2016) 14-20.

[44] Y. Gao, W. Rafaniello, M.F. Toksoy, T. Munhollon, R. Haber, Improvement of crystallization and particle size distribution of boric acid in the processing of a boron carbide precursor, RSC Adv. 5 (2015) 19067-19073.

[45] M. Kakiage, N. Tahara, S. Yanagidani, I. Yanase, H. Kobayashi, Effect of boron oxide/carbon arrangement of precursor derived from condensed polymer-boric acid product on low-temperature synthesis of boron carbide powder, J. Ceram. Soc. Japan. 119 (2011) 422-425.

[46] A. Najafi, F. Golestani-Fard, H.R. Rezaie, N. Ehsani, Effect of APC addition on precursors properties during synthesis of $\mathrm{B} 4 \mathrm{C}$ nano powder by a sol-gel process, J. Alloys Compd. 509 (2011) 9164-9170.

[47] A. Najafi, F. Golestani-Fard, H.R. Rezaie, N. Ehsani, A novel route to obtain B4C nano powder via sol-gel method, Ceram. Int. 38 (2012) 3583-3589.

[48] R. Ma, Y. Bando, High purity single crystalline boron carbide nanowires, Chem. Phys. Lett. 364 (2002) 314-317.

[49] S. Matsudaira, Tsuneaki, Itoh, Hideaki, Naka, Synthesis of niobium boride powder by solid state reaction between niobium and amorphous boron, J. Less Common Met. 155 (1989) 207-214.

[50] M.A. Avilés, J.M. Córdoba, M.J. Sayagués, M.D. Alcalá, F.J. Gotor, Mechanosynthesis of Hf1-xZrxB2 solid solution and Hf1-xZrxB2/SiC composite powders, J. Am. Ceram. Soc. 93 (2010) 696-702.

[51] D. Aĝaoĝullari, H. Gökçe, I. Duman, M.L. Öveçoĝlu, Characterization investigations of $\mathrm{ZrB} / \mathrm{ZrC}$ ceramic powders synthesized by mechanical alloying of elemental Zr, B and C blends, J. Eur. Ceram. Soc. 32 (2012) 1447-1455.

[52] E.I. Patsera, E.A. Levashov, V. V. Kurbatkina, D.Y. Kovalev, Production of ultrahigh temperature carbide ( $\mathrm{Ta}, \mathrm{Zr}) \mathrm{C}$ by self-propagating high-temperature synthesis of mechanically activated mixtures, Ceram. Int. 41 (2015) 8885-8893. 
[53] H.O. Pierson, A.W. Mullendore, chemical vapor deposition of $\mathrm{TiB}_{2}$ from diborane., Thin Solid Films. 72 (1980) 511-516.

[54] H.R. Baumgartner, R.A. Steiger, Sintering and Properties of Titanium Diboride Made from Powder Synthesized in a Plasma-Arc Heater, J. Am. Ceram. Soc. 67 (1984) 207-212.

[55] H. Zhao, B. Liu, K. Zhang, C. Tang, Microstructure analysis of zirconium carbide layer on pyrocarbon-coated particles prepared by zirconium chloride vapor method, Nucl. Eng. Des. 251 (2012) 443-448.

[56] and G.B. Peshev, P., L. Leyarovska, On the Borothermic Preparation of Vanadium, Niobium, and Tantalum Borides, J. Less Common Met. 15 (1968) 259267.

[57] Z. Jiang, W.E. Rhine, Preparation of titanium diboride from titanium alkoxides and boron powde, Chem. Mater. 4 (1992) 497-500.

[58] L. Chen, Y. Gu, L. Shi, Z. Yang, J. Ma, Y. Qian, Synthesis and oxidation of nanocrystalline $\mathrm{HfB}_{2}$, J. Alloys Compd. 368 (2004) 353-356.

[59] S.E. Bates, W.E. Buhro, C.A. Frey, S.M.L. Sastry, K.F. Kelton, Synthesis of titanium boride $(\mathrm{TiB})_{2}$ nanocrystallites by solution-phase processing, J. Mater. Res. 10 (1995) 2599-2612.

[60] E. Wuchina, E. Opila, M. Opeka, W. Fahrenholtz, I. Talmy, UHTCs: Ultra-High Temperature Ceramic Materials for Extreme Environment Applications, Electrochem. Soc. Interface. (2007) 30-36.

[61] C. Mroz, processing and properties of microcomposite $\mathrm{TiZrC}$ and $\mathrm{TiZrB}_{2}$ materials, Ceramic Engineering und Science Proceeding, 14 (1993) 725-735.

[62] F. Monteverde, L. Scatteia, Resistance to thermal shock and to oxidation of metal diborides-SiC ceramics for aerospace application, J. Am. Ceram. Soc. 90 (2007) $1130-1138$.

[63] S. Talmy, I. G., Zaykoski, J. A., Opeka, M. M., \& Dallek, Oxidation of ZrB2 ceramics modified with $\mathrm{SiC}$ and group IV-VI transition metal diborides, Electrochem. Soc. Proc. 12 (2001).

[64] V. Valvoda, L. Doviasoba, P. Karen, X-ray Diffraction Analysis of Diffusional Alloying of HfC and TaC, J. Mater. Sci. 20 (1985) 3605-3609.

[65] S.A. Ghaffari, M.A. Faghihi-Sani, F. Golestani-Fard, S. Ebrahimi, Pressureless sintering of $\mathrm{Ta}_{0.8} \mathrm{Hf}_{0.2} \mathrm{C}$ UHTC in the presence of $\mathrm{MoSi}_{2}$, Ceram. Int. 39 (2013) 1985-1989. 
[66] S. A. Ghaffari, M. A. Faghihi-Sani, F. Golestani-Fard, H. Mandal, Spark plasma sintering of TaC-HfC UHTC via disilicides sintering aids, J. Eur. Ceram. Soc. 33 (2013) 1479-1484.

[67] O.G. Gaballa, Processing development of 4TaC-HfC and related carbides and borides for extreme environments, Ph.D Thesis, Iowa State University, Iowa, USA. (2012).

[68] C. Zhang, A. Loganathan, B. Boesl, A. Agarwal, Thermal Analysis of Tantalum Carbide-Hafnium Carbide Solid Solutions from Room Temperature to $1400{ }^{\circ} \mathrm{C}$, Coatings. 7 (2017) 111.

[69] T. Kobayashi, K. Yoshida, T. Yano, Effects of heat-treatment temperature and starting composition on morphology of boron carbide particles synthesized by carbothermal reduction, Ceram. Int. 39 (2013) 597-603.

[70] W.M. Guo, G.J. Zhang, New borothermal reduction route to synthesize submicrometric $\mathrm{ZrB}_{2}$ powders with low oxygen content, J. Am. Ceram. Soc. 94 (2011) 3702-3705.

[71] B.M. Moshtaghioun, D. Gomez-Garcia, A. Dominguez-Rodriguez, R.I. Todd, Grain size dependence of hardness and fracture toughness in pure near fully-dense boron carbide ceramics, J. Eur. Ceram. Soc. (2016) 2-7.

[72] P. Murray, Low Temperature Synthesis of Boron Carbide Using a Polymer Precursor Powder Route, M.Sc Thesis, University of Birmingham, Birmingham, UK. (2011).

[73] S.T.B. and R. David, Methods for preparing boron carbide articles, U.S. Patent No: 3914371, (1975).

[74] P. Foroughi, Z. Cheng, From micron-sized particles to nanoparticles and nanobelts: structural non-uniformity in the synthesis of boron carbide by carbothermal reduction reaction, Adv. Ceram. Armor XI Ceram. Eng. Sci. Proc. 36 (2015) 51-62.

[75] a. M. Hadian, J. a. Bigdeloo, The effect of time, temperature and composition on boron carbide synthesis by sol-gel method, J. Mater. Eng. Perform. 17 (2008) 4449.

[76] A. Fathi, Synthesis of boron carbide nano particles using polyvinyl alcohol and boric acid, Ceram. - Silikáty. (2012) 32-35.

[77] C.H. Jung, M.J. Lee, C.J. Kim, Preparation of carbon-free B4C powder from $\mathrm{B}_{2} \mathrm{O}_{3}$ oxide by carbothermal reduction process, Mater. Lett. 58 (2004) 609-614. 
[78] L. Lutterotti, M. Bortolotti, G. Ischia, I. Lonardelli, H.R. Wenk, Rietveld texture analysis from diffraction images, Zeitschrift Fur Krist. Suppl. 1 (2007) 125-130.

[79] S. Zhang, W. Lu, C. Wang, Q. Shen, L. Zhang, Synthesis and characterization of $\mathrm{B}_{13} \mathrm{C}_{2}$ boron carbide ceramic by pulsed electric current sintering, Ceram. Int. 38 (2012) 895-900.

[80] R.R. Servoss, H.M. Clark, Vibrational spectra of normal and isotopically labeled boric acid, J. Chem. Phys. 26 (1957) 1157-1178.

[81] B. V. Erofe'ev, Generalized equation of chemical kinetics and its application in reactions involving solids, Compt Rend Acad Sci USSR. 52 (1946) 511-514.

[82] Z. Cheng, Reaction Kinetics and Structural Evolution for the Formation of Nanocrystalline Silicon Carbide via Carbothermal Reduction, M.Sc Thsis, Georgia Institute of Technology, Georgia, USA. (2004).

[83] S.F. Hulbert, Models for solid-state reactions in powdered compacts: a review, J. Br. Ceram. Soc. (1969) 11-20.

[84] X. Fu, J. Jiang, C. Liu, Z.Y. Yu, S. Lea, J. Yuan, Re-entrant-groove-assisted VLS growth of boron carbide five-fold twinned nanowires, Chinese Phys. Lett. 26 (2009).

[85] M. Chase, NIST-JANAF Thermochemical Tables, 4th Edition, J. Phys. Chem. Ref. Data, Monogr. 9. (1998) 1952.

[86] Z. Cheng, P. Foroughi, A. Behrens, Synthesis of nanocrystalline TaC powders via single-step high temperature spray pyrolysis from solution precursors, (2016) 8 11 .

[87] F. Arianpour, F. Golestanifard, H. Rezaie, M. Mazaheri, A. Celik, F. Kara, G. Fantozzi, Processing, phase evaluation and mechanical properties of MoSi2 doped 4TaC-HfC based UHTCs consolidated by spark plasma sintering, Int. J. Refract. Met. Hard Mater. 56 (2016) 1-7.

[88] P. Foroughi, Z. Cheng, Understanding the Morphological Variation in the Formation of B4C via Carbothermal Reduction Reaction, Ceram. Int. (2016) 1-10.

[89] O. Cedillos-Barraza, S. Grasso, N. Al Nasiri, D.D. Jayaseelan, M.J. Reece, W.E. Lee, Sintering behaviour, solid solution formation and characterisation of $\mathrm{TaC}$, HfC and TaC-HfC fabricated by spark plasma sintering, J. Eur. Ceram. Soc. 36 (2016) 1539-1548.

[90] C. Zhang, A. Gupta, S. Seal, B. Boesl, A. Agarwal, Solid solution synthesis of tantalum carbide-hafnium carbide by spark plasma sintering, J. Am. Ceram. Soc. (2017). 
[91] O. Adjaoud, G. Steinle-Neumann, B.P. Burton, A. Van De Walle, First-principles phase diagram calculations for the $\mathrm{HfC}-\mathrm{TiC}, \mathrm{ZrC}-\mathrm{TiC}$, and $\mathrm{HfC}-\mathrm{ZrC}$ solid solutions, Phys. Rev. B - Condens. Matter Mater. Phys. 80 (2009) 32-34.

[92] B. Schönfeld, M. Engelke, A. V. Ruban, Lack of support for adaptive superstructure NiPt7: Experiment and first-principles calculations, Phys. Rev. B Condens. Matter Mater. Phys. 79 (2009) 1-12.

[93] A.K. Bhattacharya, V. Shklover, W. Steurer, G. Witz, H. peter Bossmann, O. Fabrichnaya, $\mathrm{Ta}_{2} \mathrm{O}_{5}-\mathrm{Y}_{2} \mathrm{O}_{3}-\mathrm{ZrO}_{2}$ system: Experimental study and preliminary thermodynamic description, J. Eur. Ceram. Soc. 31 (2011) 249-257.

[94] G.D. Li, M. Wu, X. Xiong, Y.L. Wang, G.Y. Yang, Preparation and ablation properties of $\mathrm{ZrC}-\mathrm{TaC}$ co-deposition coating for carbon-carbon composites, Ceram. Trans. 248 (2014) 569-578.

[95] S. a. Ghaffari, M. a. Faghihi-Sani, F. Golestani-Fard, M. Nojabayy, Diffusion and solid solution formation between the binary carbides of $\mathrm{TaC}, \mathrm{HfC}$ and $\mathrm{ZrC}$, Int. J. Refract. Met. Hard Mater. 41 (2013) 180-184..

[96] Z.A. Munir, U. Anselmi-Tamburini, M. Ohyanagi, The effect of electric field and pressure on the synthesis and consolidation of materials: A review of the spark plasma sintering method, J. Mater. Sci. 41 (2006) 763-777.

[97] M.M. Opeka, I.. . Talmy, J. Zaykoski, Oxidation-based materials selection for $2000{ }^{\circ} \mathrm{C}+$ hypersonic aerosurfaces : Theoretical, J. Mater. Sci. 9 (2004) $5887-$ 5904.

[98] X. Zhang, G.E. Hilmas, W.G. Fahrenholtz, Synthesis, densification, and mechanical properties of $\mathrm{TaB}_{2}$, Mater. Lett. 62 (2008) 4251-4253.

[99] M. Asadikiya, Y. Zhong, Oxygen ion mobility and conductivity prediction in cubic yttria-stabilized zirconia single crystals, J. Mater. Sci. (2017) 1-11.

[100] C. Foroughi, P, Zhang, C, Agarwal, A, Cheng, Controlling phase separation of $\mathrm{Ta}_{\mathrm{x}} \mathrm{Hf}_{1-\mathrm{x}} \mathrm{C}$ solid solution nanopowders during carbothermal reduction synthesis, $\mathrm{J}$. Am. 100 (2017) 5056-5065.

[101] C. Zhang, B. Boesl, A. Agarwal, Oxidation resistance of tantalum carbide-hafnium carbide solid solutions under the extreme conditions of a plasma jet, Ceram. Int. (2017) $0-1$.

[102] P. Foroughi, Z. Cheng, Understanding the Morphological Variation in the Formation of B4C via Carbothermal Reduction Reaction, Ceram. Int. (2016).

[103] M.A. Avilés, J.M. Córdoba, M.J. Sayagués, F.J. Gotor, Mechanochemical synthesis of $\mathrm{Ti}_{1-\mathrm{x}} \mathrm{Zr}_{\mathrm{x}} \mathrm{B}_{2}$ and $\mathrm{Ti}_{1-\mathrm{x}} \mathrm{Hf}_{\mathrm{x}} \mathrm{B}_{2}$ solid solutions, Ceram. Int. 37 (2011) 18951904. 
[104] L. Chen, Y. Gu, Z. Yang, L. Shi, J. Ma, Y. Qian, Preparation and some properties of nanocrystalline $\mathrm{ZrB}_{2}$ powders, Scr. Mater. 50 (2004) 959-961.

[105] S. Venugopal, E.E. Boakye, A. Paul, K. Keller, P. Mogilevsky, B. Vaidhyanathan, J.G.P. Binner, A. Katz, P.M. Brown, Sol-Gel Synthesis and Formation Mechanism of Ultrahigh Temperature Ceramic: HfB 2, J. Am. Ceram. Soc. 97 (2014) 92-99.

[106] L.L. Hench, J.K. West, The Sol-Gel Process, Chem. Rev. 90 (1990) 33-72.

[107] O. Awadallah, Z. Cheng, Formation of sol-gel based $\mathrm{Cu}_{2} \mathrm{ZnSnS}_{4}$ thin films using ppm-level hydrogen sulfide, Thin Solid Films. 625 (2017) 122-130.

[108] Pierre V, Alan P, Okamoto H. ASM International, GeaugaCounty, OH; 1995

[109] A.K. Bhattacharya, V. Shklover, W. Steurer, G. Witz, H. peter Bossmann, O. Fabrichnaya, $\mathrm{Ta}_{2} \mathrm{O}_{5}-\mathrm{Y}_{2} \mathrm{O}_{3}-\mathrm{ZrO}_{2}$ system: Experimental study and preliminary thermodynamic description, J. Eur. Ceram. Soc. 31 (2011) 249-257.

[110] D. Sciti, L. Silvestroni, S. Guicciardi, D.D. Fabbriche, A. Bellosi, Processing, mechanical properties and oxidation behavior of $\mathrm{TaC}$ and $\mathrm{HfC}$ composites containing 15 vol\% $\mathrm{TaSi}_{2}$ or $\mathrm{MoSi}_{2}$, J. Mater. Res. 24 (2009) 2056-2065.

[111] Barin I, Platzki G. Thermochemical Data of Pure Substances, 3rdedn. Weinheim, Germany: VCH; 1995.

[112] J. Gild, Y. Zhang, T. Harrington, S. Jiang, T. Hu, M.C. Quinn, W.M. Mellor, N. Zhou, K. Vecchio, J. Luo, High-Entropy Metal Diborides: A New Class of HighEntropy Materials and a New Type of Ultrahigh Temperature Ceramics, Sci. Rep. 6 (2016) 2-11.

[113] H.K.D.H. Bhadeshia, High entropy alloys, Mater. Sci. Technol. 31 (2015) 11391141.

[115] E. Zapata-Solvas, S. Bonilla, P.R. Wilshaw, R.I. Todd, Preliminary investigation of flash sintering of SiC, J. Eur. Ceram. Soc. 33 (2013) 2811-2816.

[116] S. Grasso, T. Saunders, H. Porwal, O. Cedillos-Barraza, D.D. Jayaseelan, W.E. Lee, M.J. Reece, Flash Spark Plasma Sintering (FSPS) of Pure $\mathrm{ZrB}_{2}$, J. Am. Ceram. Soc. 97 (2014) 2405-2408. 


\section{APPENDIX}

Appendix 1: Preliminary Study on Modified Flash Sintering of $\mathrm{Ta}_{0.5} \mathrm{Hf}_{0.5} \mathrm{~B}_{2}$ solid solution nanopowders

Ultrahigh temperature ceramics (UHTCs) require high sintering temperature and long dwell time due to their extremely high melting point, strong covalent bonding and low self-diffusivity. UHTCs are typically densified by hot pressing at temperatures higher than $1600{ }^{\circ} \mathrm{C}$ and pressures of 20-30 MPa [1]. However, hot pressing cannot process samples with complex shapes and geometries. Recently, one type of field assisted sintering techniques named flash sintering (FS) has been used to densify high temperature ceramics such as yttria-stabilized zirconia (YSZ). FS is characterized by application of electrical field directly through the sample under no pressure.[2] In this technique sintering occurs very fast, sometimes within a few seconds, which helps prevent grain growth.

In 2010, Yang et al [3] showed that applying an electric field of $20 \mathrm{~V} / \mathrm{cm}$ could lower the sintering temperature of $3 \mathrm{YSZ}$ (3 mol\% yttria-stabilized zirconia) form $1400{ }^{\circ} \mathrm{C}$ to $1300{ }^{\circ} \mathrm{C}$. Cologna et al. [2] made a breakthrough based on Yang's study. They used the flash sintering method to consolidate $3 \mathrm{YSZ}$ in a few seconds at noticeably low temperature of $850{ }^{\circ} \mathrm{C}$ in presence of an electrical field equal to $100 \mathrm{~V} / \mathrm{cm}$. According to Cologna et al. the generated heat at the grain boundaries decreases the local resistance leading to a stronger joule heating which, in turn intensifies the localized heating at grain boundaries. Based on the Ohm's law, in constant voltage the generated power could be calculated as follows: 
$\mathrm{P}=\frac{\mathrm{V}^{2}}{\mathrm{R}}$

where $\mathrm{P}$ is the power dissipation, $\mathrm{V}$ is the applied voltage and $\mathrm{R}$ is the specimen resistance. As a first-order approximation, the total power dissipation could be rewritten as below:

$\mathrm{P}=\frac{\mathrm{V}^{2}}{\mathrm{R}_{\mathrm{C}}+\mathrm{R}_{\mathrm{GB}}}$

where $R_{C}$ is the sum of the crystal matrix resistance and $R_{G B}$ is the grain boundary resistance. Assuming that $\mathrm{R}_{\mathrm{GB}} \gg \mathrm{R}_{\mathrm{C}}$, then the power dissipation $(\mathrm{P})$ would be dominated by the grain boundaries. Hence, a local rise in temperature at grain boundaries will reduce $\mathrm{R}_{\mathrm{GB}}$ and increase power (see equation (2)), leading to increased temperature. Higher temperatures at grain boundaries would enhance the grain boundaries diffusion and as a result assist the sintering process.

For ceramics such as YSZ, which possess relatively high electrical resistivity high voltage is required in order to generate the necessary energy for triggering the "flash" or runaway process. While for $\mathrm{Ta}_{0.5} \mathrm{Hf}_{0.5} \mathrm{~B}_{2}$ solid solution, the "flash" process can be triggered at much lower voltages (less than $10 \mathrm{~V}$ ) due to its high electrical conductivity. Lower voltage is expected to result in more homogenous microstructure after sintering.

Here, the author reports the sintering of $\mathrm{Ta}_{0.5} \mathrm{Hf}_{0.5} \mathrm{~B}_{2}$ solid solution nanopowders (without any sintering aid) using a modified flash sintering technique, in which densification occurs in the presence of a DC electrical current in a short time of 5 minutes as a result of the joule heating effect. Low pressure of $\sim 10 \mathrm{MPa}$ was applied during the sintering process to ensure effective electrical contacts between the electrodes and the 
sample and also the particles. Figure A1 shows the set-up used in this study for the sintering process.

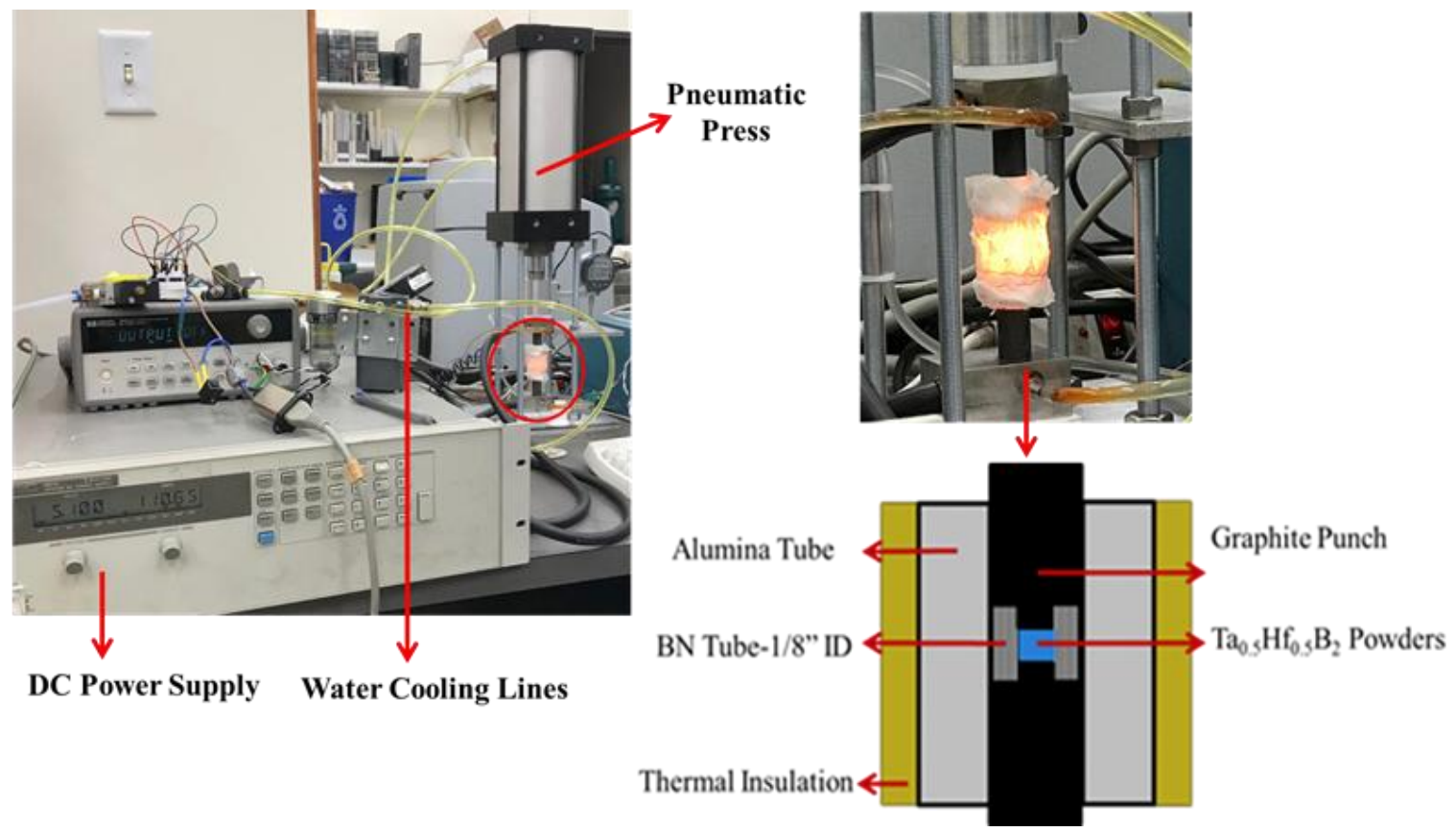

Figure A1: Modified flash sintering set-up used in this study

The $\mathrm{Ta}_{0.5} \mathrm{Hf}_{0.5} \mathrm{~B}_{2}$ solid solution powder synthesized via AMR method from recipe R14 was first poured into a BN tube (inner diameter of $1 / 8 ")$. Then the both ends of the $\mathrm{BN}$ tube were closed by two graphite punches (diameter of $\left.1 / 8^{\prime \prime}\right)$. The $\mathrm{BN}$ tube was then put into a 1/4-inch alumina tube covered with two 1/4-inch graphite punches, which also work as electrodes. Please note that the reason for putting the sample into a smaller tube of $\mathrm{BN}$ was to increase the current density by decreasing the sample area. The alumina tube was wrapped with insulator material to avoid the heat loss during the sintering process. The set-up was placed under a pneumatic press to apply a constant pressure of 10 MPa. This would help keeping the powders in contact during the sintering process. The voltage was then increased slowly (manually) until the maximum current of $90 \mathrm{~A}$ 
could pass through the sample for 5 minutes. Figure A2 shows the change of electric current with voltage. At $\mathrm{V}=4.8 \mathrm{~V}$ the electric current passing through the sample increased suddenly from 8.1 A to 90 A (see Figure A2). The rapid change in electric current can be observed when so-called "flash" occurs. It should be noted that contrary to oxides (e.g., YSZ), no preheating was required here as borides possess high electrical conductivity allowing electric current to flow through them starting from room temperature.

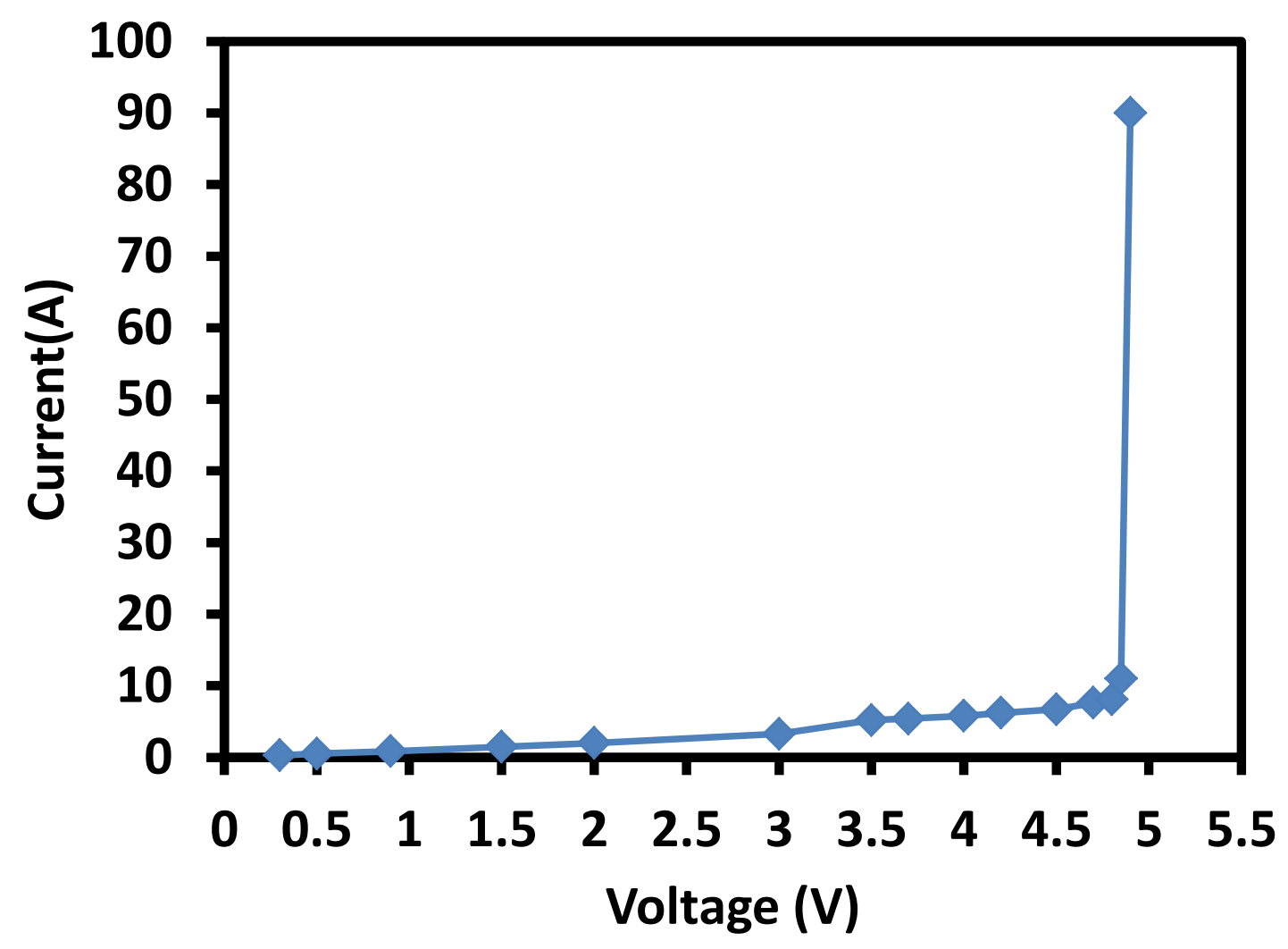

Figure A3: Change of current with voltage for $\mathrm{Ta}_{0.5} \mathrm{Hf}_{0.5} \mathrm{~B}_{2}$ solid solution

Figure A3 shows the SEM image of the sample surface after flash sintering. The micron-sized pores observed in the SEM image suggest that limited sintering or densification had occurred. Helium gas pycnometer (Accupyc 1340, Micromeretics 
Instrument Corporation, Norcross, GA) with help of Dr. Zhang was employed to measure the density of the sample. The average density calculated for this sample was $8.24 \mathrm{~g} / \mathrm{cm}^{3}$, giving a relative density of $\sim 72 \%$. However, since the sample was very small (1/8" pellet) and might have open pores the result obtained from Helium gas pycnometer is not very reliable.

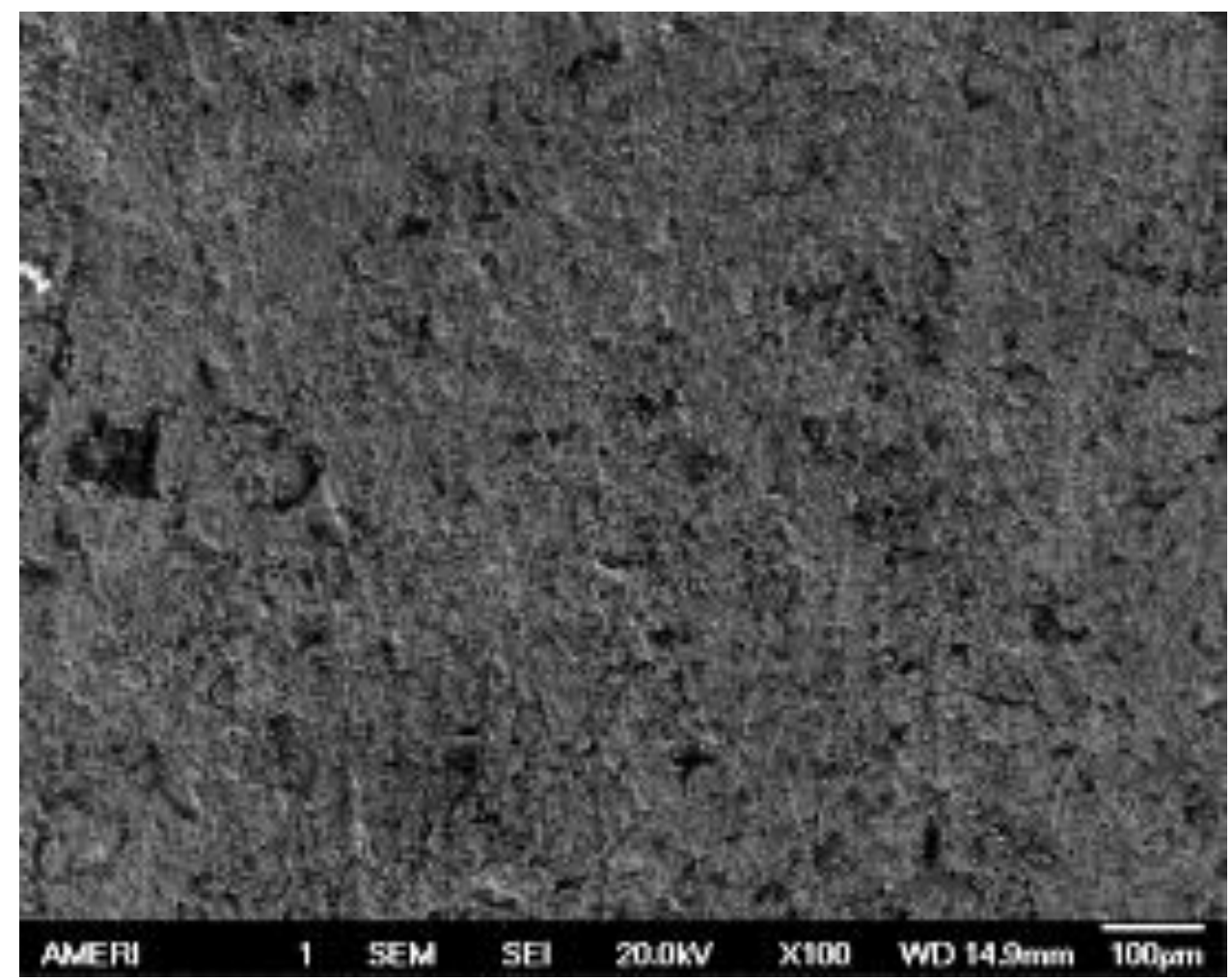

Figure A3: SEM image of the surface of the sample after sintering

Vickers hardness for the sample was measured by a LECO LM810AT microindentation hardness tester (LECO Corporation, St. Joseph, MI) at a load of $200 \mathrm{gf}$ and a dwell time of $10 \mathrm{~s}$. The average hardness for 5 indents was calculated to be $\sim 4.4$ $\mathrm{GPa}$.

These results show that sintering of the $\mathrm{Ta}_{0.5} \mathrm{Hf}_{0.5} \mathrm{~B}_{2}$ solid solution powders occurred, but only to a limited extent. Further studies aimed at understanding the effects 
of current density, time, presintering of the sample and sintering aid on the relative density, microstructure, and mechanical properties of the samples need to be carried out.

\section{References}

[1] Y. Xie, Solution-based Synthesis and Processing of Nanocrystalline $\mathrm{ZrB}_{2}$-based Composites, (2008) 1-160.

[2] M. Cologna, B. Rashkova, R. Raj, Flash sintering of nanograin zirconia in $<5 \mathrm{~s}$ at $850^{\circ}$ C, J. Am. Ceram. Soc. 93 (2010) 3556-3559.

[3] D. Yang, R. Raj, and H. Conrad, Enhanced sintering rate of zirconia (3Y-TZP) through the effect of a weak dc electric field on grain growth, J. Am. Ceram. Soc., vol. (2010), 2935-2937. 


\section{VITA}

\section{PANIZ FOROUGHI}

$2008-2012$

B.Sc., Materials Science and Engineering

Sharif University of Technology

Tehran, Iran

2013-2015

M.Sc., Materials Science and Engineering

Florida International University

Miami, FL, USA

2013-2018

Doctoral Candidate (Ph.D), Materials Science and Engineering Florida International University

Miami, FL, USA

\section{SELECTED JOURNAL PUBLICATIONS AND CONFERENCE PRESENTATIONS}

Paniz Foroughi, Zhe Cheng, "Understanding the morphological variation in the formation of $\mathrm{B}_{4} \mathrm{C}$ via carbothermal reduction reaction" Ceramics International, Volume 42, November 2016.

Paniz Foroughi, Cheng Zhang, Arvind Agarwal and Zhe Cheng, "Controlling Phase Separation of $\left(\mathrm{Ta}_{\mathrm{X}} \mathrm{Hf}_{1-\mathrm{X}} \mathrm{C}\right)$ Solid Solution Nanopowders during Carbothermal Reduction Synthesis" Journal of the American Ceramic Society, Volume 100, July 2017.

Paniz Foroughi, Amin Rabiei Baboukani, Alexander Franco Hernandez, Chunlei Wang and Zhe Cheng "Phase control during the synthesis of nanocrystalline ultrahigh temperature tantalum-hafnium diboride powders" Journal of American Ceramic Society, May 2018.

Paniz Foroughi, Zhe Cheng, "From Micron-Sized Particles to Nanoparticles and Nanobelts: Structural Non-uniformity in the Synthesis of Boron Carbide by Carbothermal Reduction Reaction" Advances in Ceramic Armor XI, Ceramic Engineering and science proceedings, Volume 36, January 2016.

Zhe Cheng, Paniz Foroughi, Andres Behrens, "Synthesis of nanocrystalline TaC powders via single-step high temperature spray pyrolysis from solution precursors", Ceramics International, Volume 43, February 2017.

Mohammad Asadikiya, Paniz Foroughi and $\mathrm{Yu}$ zhong, "Re-Evaluation of the Thermodynamic Equilibria on the Zirconia-Rich Side of the $\mathrm{ZrO}_{2}-\mathrm{YO}_{1.5}$ System" Calphad, March 2018. 
Junheng Xing, Paniz Foroughi, Alexander Franco Hernandez, Andres Behrens and Zhe Cheng "Facile one-step high temperature spray pyrolysis route toward metal carbide nanopowders" Journal of American Ceramic Society, May 2018.

Paniz Foroughi, Mohammadamin Moghaddasi, "Effect Of Heat Treatment On Magnetic Properties of Nanocrystalline Fe-Si-Ni Powders" Advanced Materials Research, vol. 829, pp. 693-697, 2014.

Zhe Cheng, Paniz Foroughi and Andres Behrens. 2018. Synthesis of High Temperature Ceramic Powders. U.S. Patent 9,919,973, issued March 20, 2018.

Paniz Foroughi, Zhe Cheng, "Synthesis, Processing, and Fundamental Reaction Mechanism Study for Nanocrystalline Boron Carbide Powders", 39th International Conference and Expo on advanced ceramics and composites, Daytona Beach, Florida, 2015.

Paniz Foroughi, Zhe Cheng, "Synthesis of Nanocrystalline Ultrahigh Temperature Tantalum Hafnium Carbide Solid Solution $\left(\mathrm{Ta}_{\mathrm{x}} \mathrm{Hf}_{1-\mathrm{x}} \mathrm{C}\right)$ Powders", 40th International Conference and Expo on advanced ceramics and composites, Daytona Beach, Florida, 2016.

Paniz Foroughi, Zhe Cheng, "Understanding the Morphological Variation in the Formation of $\mathrm{B}_{4} \mathrm{C}$ via Carbothermal Reduction Reaction", Materials Science and Technology, Salt Lake City, Utah, 2016

Paniz Foroughi, Cheng Zhang, Arvind Agarwal, Zhe Cheng, "Understanding and Control of Phase Separation in Synthesis of Nanocrystalline $\left(\mathrm{Ta}_{x} \mathrm{Hf}_{1-\mathrm{x}} \mathrm{C}\right)$ Powders", Materials Science and Technology conference in Pittsburgh, Pennsylvania October 2017.

Paniz Foroughi, Zhe Cheng, "Microstructure and Phase Control during Synthesis of Nanocrystalline Ultrahigh Temperature Tantalum Hafnium Diboride Powders $\left(\mathrm{Ta}_{x} \mathrm{Hf}_{1-\mathrm{x}} \mathrm{B}_{2}\right)$ via Carbothermal/Borothermal Reduction Reaction", Materials Science and Technology conference in Pittsburgh, Pennsylvania October 2017.

Zhe Cheng, Junheng Xing, Paniz Foroughi, and Andres Behrens, "Synthesis of Nanocrystalline Ultrahigh Temperature Ceramic Powders via Rapid Single-Step High Temperature Spray Pyrolysis", Materials Science and Technology conference in Pittsburgh, Pennsylvania October 2017.

Archana Loganathan, Pranjal Nautiyal, Paniz Foroughi, Jian Yu, Brandon McWilliams, Zhe Cheng, Benjamin Boesl, Arvind Agarwal,"Synthesis, Consolidation and In-situ Indentation Studies on Bulk Boron Suboxide" Materials Science and Technology conference in Pittsburgh, Pennsylvania October 2017. 